\title{
Timing and Mechanisms of Silicate Differentiation and Basalt Magma Generation on the
}

\section{Howardite-Eucrite-Diogenite Asteroid Parent Body}

\author{
by \\ Jessica Anne Dallas
}

A thesis

submitted to Victoria University of Wellington

in partial fulfilment of the requirements for the degree of

Master of Science with Honours

in Geology.

Victoria University of Wellington

2013 


\begin{abstract}
Meteorites provide the only direct record of the chronology and nature of the processes that occurred in the early solar system. In this study, meteorites were examined in order to gain insight into the timing and nature of magmatism and silicate differentiation on asteroidal bodies in the first few million years of the solar system. These bodies are considered the precursors to terrestrial planets, and as such they provide information about conditions in the solar system at the time of planet formation.

This study focuses on eucrites, which are basaltic meteorites that are believed to represent the crust of the Howardite-Eucrite-Diogenite (HED) parent body. The processes of silicate differentiation and the relationship between eucrites and the diogenitic mafic cumulate of the HED parent body are poorly understood. The major and trace element chemistry of the minerals in the eucrite suite was measured. There is little variability in mineral major element concentrations in eucrites, however considerable variability was observed in mineral trace element concentrations, particularly with respect to incompatible elements in the mineral phases. Magnesium was separated from digested eucrite samples, and the $\mathrm{Mg}$ isotope composition of the eucrites was measured to high precision in order to date the samples using the short-lived ${ }^{26} \mathrm{Al}-{ }^{26} \mathrm{Mg}$ chronometer and examine magmatic evolution on the HED parent body.

Correlations between incompatible elements in pyroxene and ${ }^{26} \mathrm{Mg}$ anomalies, produced by the decay of ${ }^{26} \mathrm{Al}$, indicate that the eucrite suite was formed from a single, evolving magma body. Large trace element and $\mathrm{Mg}$ isotopic differences between eucrites and diogenites indicate that the two meteorite groups did not, as previously suggested, originate from the same magma body. Instead they may have formed from two large
\end{abstract}


magma bodies, which were spatially or temporally separated on the HED parent body. The application of the short-lived ${ }^{26} \mathrm{Al}-{ }^{26} \mathrm{Mg}$ chronometer to this suite of eucrites constrains the onset of eucrite formation to $\sim 3 \mathrm{Myr}$ after the formation of the solar system's first solids, as a result of rapid accretion and melting of planetesimals due to heating from the decay of ${ }^{26} \mathrm{Al}$. 


\section{Acknowledgments}

Firstly, I want to thank my primary supervisor Joel Baker for giving me the opportunity to work on such an interesting and challenging project. I am very grateful for all your valuable insights, constructive feedback and continued support. Martin Schiller, thank you for all your feedback, hard work in the lab, and for staying patient through all the difficulties in the lab. Martin Bizzarro, thank you for your support and for allowing me to spend a few months using your impressive lab facilities in Copenhagen, I am looking forward to working with you again.

The geology department at Victoria has been a great place to complete my Masters, and I'd like to thank all the staff for their support. I'd also like to thank the great group of post-grads in the department, who have made my time here so much fun. To my fantastic office mates over the course of my Masters: Jane, Liz, Loretta and Jenni, thank you for making the past two years so enjoyable, putting up with my messiness and lending an ear when things weren't going so well. I'd also like to thank the staff and students at the Centre for Star and Planet formation in Copenhagen, in particular Mia Olsen for assistance in the lab.

I would like to acknowledge Victoria University for their financial support in the form of the Victoria University Graduate Award and the Victoria University Masters by Thesis scholarship.

John, firstly thank you for your assistance with collecting major and trace element data. I can't thank you enough for all your love and support and putting up with me being a little stressed and grumpy, particularly toward the end of my Masters. Your encouragement and positivity, especially in difficult times made all the difference. Thank you to Sarah 
for always showing an interest in my studies and for being such a great friend over the past decade. Jackson, thanks for brightening my days with your cheerfulness, and for putting up with me working when you wanted to play. I am also grateful for the support of Danny and Wyatt-Danny thank you for the helpful edit of this thesis.

Most importantly, thanks to my amazing family for your support. Mum, I can't thank you enough for all the hard work and sacrifices you have made for me, I definitely would not have been able to do this without you and I hope I have made you proud. Ross thanks for all your support and interest in my studies, and of course all the visits to Wellington. I would also like to thank two of my biggest supporters, my Nana and Grandad, who have always given me so much encouragement, I'm sure if my Nana was still here she would be showing this thesis off to all her golfing friends. 


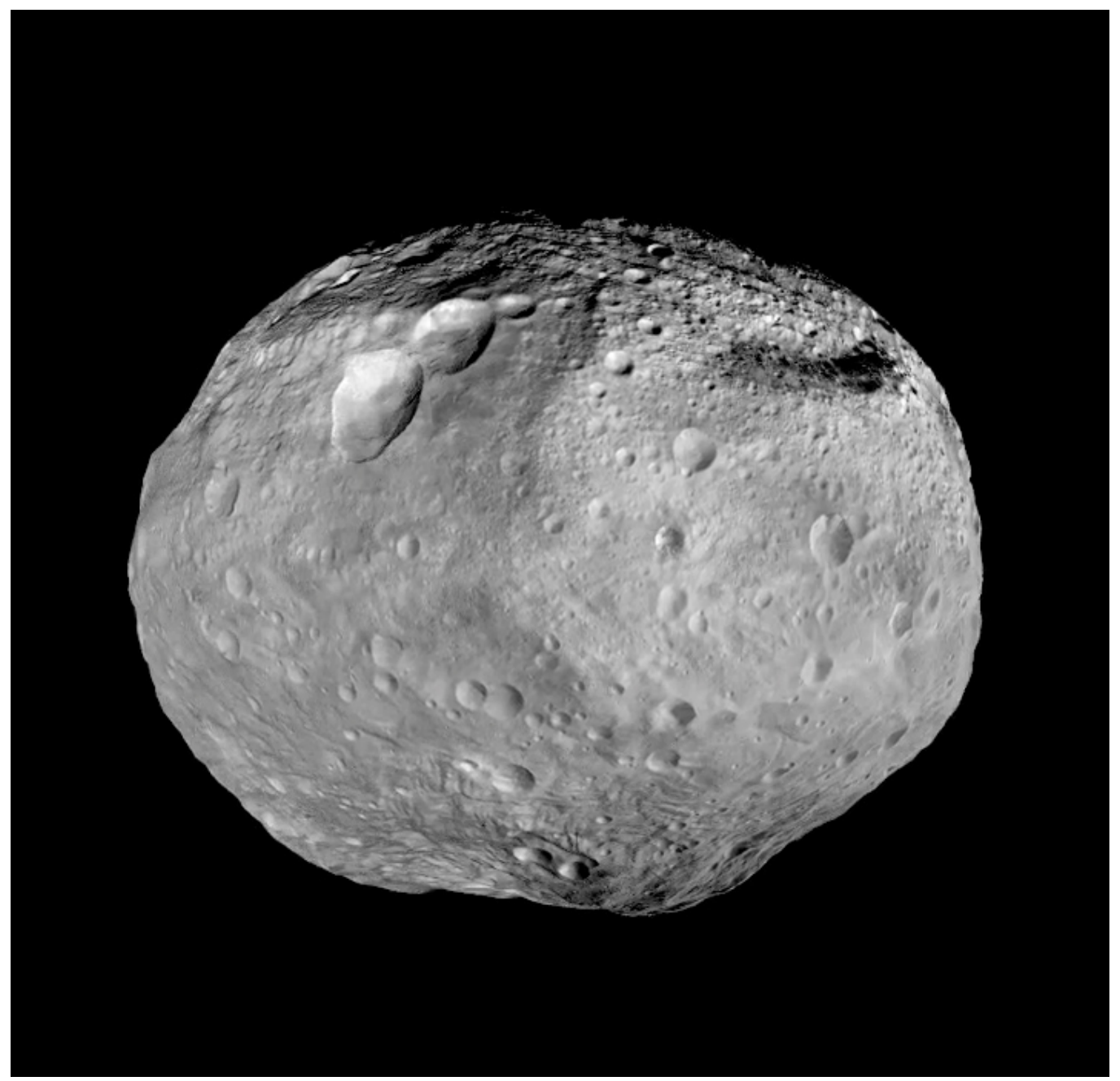

The asteroid Vesta photographed by the Dawn Spacecraft (Image credit: NASA). 


\section{Contents}

1 Introduction 1

1.1 Early solar system evolution and chronology . . . . . . . . . 2

1.1.1 Formation of a central star and proto-planetary disk. 2

1.1 .2 Formation of the first solids . . . . . . . . . . . 3

1.1 .3 Planetary accretion . . . . . . . . . . . . . 3

1.1 .4 Differentiation of planetesimals. . . . . . . . . . . 5

1.2 Early solar system chronometers $\ldots \ldots \ldots$. . . . . . . . 6

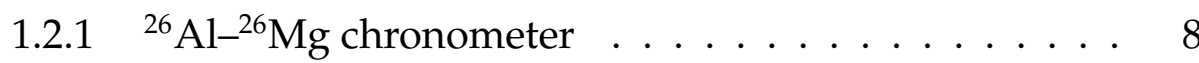

1.3 Classification of meteorites . . . . . . . . . . . . . . . . . 9

1.3 .1 Chondrites . . . . . . . . . . . . . . . . . . . 12

1.3 .2 Non-chondrites . . . . . . . . . . . . . . . . . . . 13

1.4 Howardite-eucrite-diogenite meteorites . . . . . . . . . . 16

$1.4 .1 \quad$ Petrology and geochemistry of HED meteorites . . . 16

1.4 .2 Origins of HED meteorites $\ldots \ldots \ldots \ldots$

1.4 .3 Differentiation of the HED parent body . . . . . . . . 19

1.4 .4 Relationship to the asteroid Vesta. . . . . . . . . . . 22

1.4 .5 Outstanding research questions. . . . . . . . . . . 23

1.5 Structure of this thesis $\ldots \ldots \ldots \ldots \ldots$

2 Methods 25

2.1 Major and trace element measurements . . . . . . . . . 25

$2.1 .1 \quad$ Sample preparation. . . . . . . . . . . . . . . 25

2.1 .2 Major element measurements . . . . . . . . . . . . 25

2.1 .3 Trace element measurements . . . . . . . . . . . 26 
$2.2 \mathrm{Mg}$ isotopes $\ldots \ldots \ldots \ldots \ldots$. . . . . . . . . . . . . 28

2.2 .1 Sample preparation for $\mathrm{Mg}$ isotope measurements . . 28

$2.2 .2 \quad$ Chemical separation of $\mathrm{Mg} \ldots \ldots \ldots$

$2.2 .3 \quad$ Measurement of $\mathrm{Mg}$ isotopes by MC-ICP-MS . . . . . 32

$2.2 .4 \quad$ Measurement of ${ }^{27} \mathrm{Al} /{ }^{24} \mathrm{Mg}$ ratios $\ldots \ldots \ldots . . .33$

3 Petrology and mineral chemistry 35

3.1 Sample petrology . . . . . . . . . . . . . . . . . . 36

3.2 Mineral chemistry . . . . . . . . . . . . . . . . . . 47

4 Trace element data $\quad 62$

4.1 Chondrite-normalized REE plots . . . . . . . . . . . . . 62

4.1 .1 Intra-sample variability $\ldots \ldots \ldots$. . . . . . . . 62

4.1 .2 Inter-sample variability . . . . . . . . . . . . . 68

4.2 Other trace element variations . . . . . . . . . . . . 72

4.2 .1 Trace element plots . . . . . . . . . . . . . 72

4.2 .2 Correlations between plagioclase and pyroxene trace element data . . . . . . . . . . . . . . 81

$5{ }^{26} \mathrm{Al}-{ }^{26} \mathrm{Mg}$ isotope data $\quad 98$

$5.1{ }^{27} \mathrm{Al} /{ }^{24} \mathrm{Mg}$ ratios . . . . . . . . . . . . . . . . . . . . . . . 99

$5.2 \delta^{26} \mathrm{Mg}^{*}$ anomalies $\ldots \ldots \ldots \ldots$

5.3 Stable $\delta^{25} \mathrm{Mg}$ isotope data . . . . . . . . . . . . . . . 102

5.4 Model initial ${ }^{26} \mathrm{Al} /{ }^{27} \mathrm{Al}$ values and model ages . . . . . . . . 102

6 Discussion 106

6.1 Existing models for eucrite and diogenite genesis . . . . . 106

6.2 Effect of weathering on Antarctic meteorites . . . . . . . . 111

6.3 Compositional variations in eucrites . . . . . . . . . . . . . 114

$6.3 .1{ }^{26} \mathrm{Mg}^{*}$ variability in eucrite samples . . . . . . . . 114

6.3.2 $\quad$ Major and trace element and $\mathrm{Mg}$ isotope variations in eucrites . . . . . . . . . . . . . . 116

6.3 .3 Comparison with diogenites . . . . . . . . . . . . . 119

6.4 Models for the genesis of eucrites and diogenites . . . . . . 121 
6.4.1 Timing of silicate differentiation on the HED parent body . . . . . . . . . . . . . . . 129

6.5 Relationship to the asteroid Vesta . . . . . . . . . . . . . . 129

$\begin{array}{|lll|}7 & \text { Conclusions and suggestions for further work } & 131\end{array}$

7.1 Conclusions . . . . . . . . . . . . . . . . . . . . . 131

7.2 Suggestions for further work . . . . . . . . . . . . 132

$\begin{array}{ll}\text { References } & 135\end{array}$

\begin{tabular}{|l|l}
\hline Appendices & 151
\end{tabular}

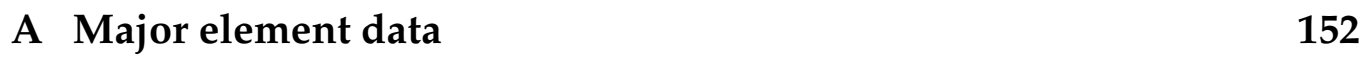

\begin{tabular}{lll}
\hline B Trace element data & 178
\end{tabular}

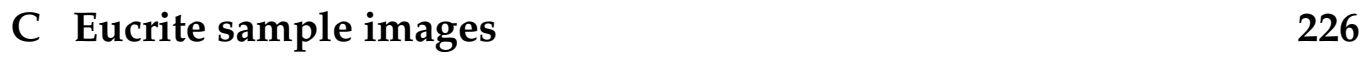




\section{List of Figures}

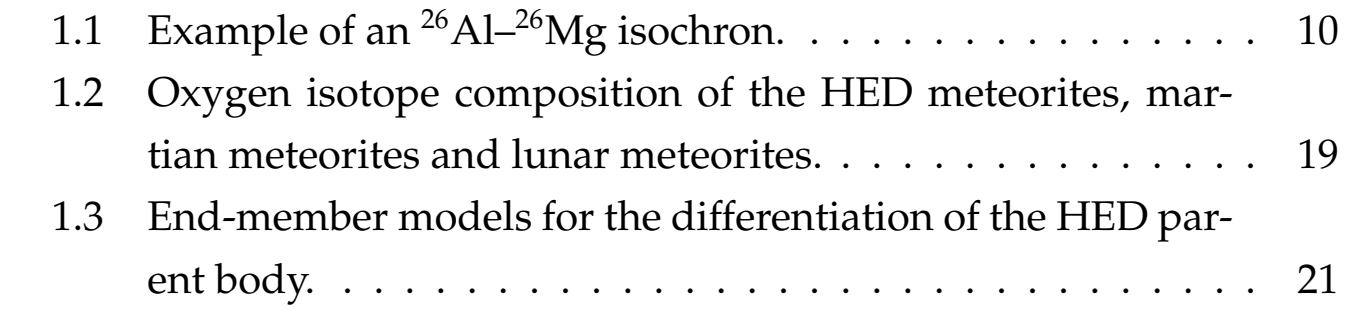

$3.1 \quad$ Back-scattered electron images of the studied eucrite samples 41

3.2 Ternary diagrams of eucrite pyroxene and plagioclase com-

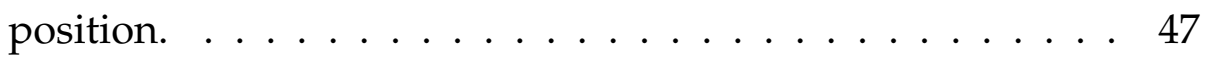

$3.3 \quad$ Major element mineral compositions of the eucrite groups. . 48

$4.1 \quad$ CI-chondrite normalized REE plots showing individual analyses for selected eucrites. . . . . . . . . . . . . 63

4.2 Average CI-chondrite normalized REE plots for plagioclase and pyroxene phases from each sample. . . . . . . . . . . . 69

$4.3 \quad$ Plots of trace element variations in plagioclase in the eucrite samples. . . . . . . . . . . . . . . . . . 77

4.4 Plots of trace element variations in low-Ca pyroxene in the eucrite samples. . . . . . . . . . . . . . . . . . . 84

$4.5 \quad$ Plots of trace element variations in high-Ca pyroxene from eucrite samples. . . . . . . . . . . . . . . . 99 90

4.6 Plots of trace element variations in pyroxene from eucrites with a single pyroxene phase. . . . . . . . . . . . . . 95

4.7 Variation in trace elements in plagioclase and pyroxene from eucrites. . . . . . . . . . . . . . . . . . . 97 


\section{List of Tables}

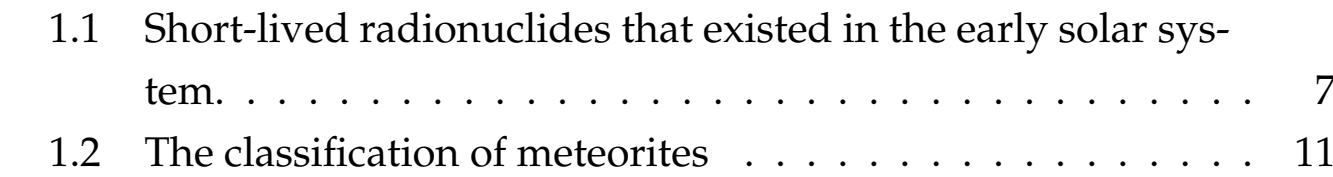

2.1 Major element compositions measured in the secondary standards and reference values for the standards. . . . . . . 27

2.2 Trace element compositions of secondary standards and reference values forthe standards. . . . . . . . . . . . . . . . 29

$2.3 \mathrm{Mg}$ isotope compositions of the secondary standard BHVO-2. 33

$2.4 \quad{ }^{27} \mathrm{Al} /{ }^{24} \mathrm{Mg}$ ratios measured in secondary standards and reference values for these standards. . . . . . . . . . . . . . . . 34

3.1 Petrographic descriptions of eucrite samples . . . . . . . . 37

3.2 Plagioclase major element concentrations in $\mathrm{wt} \%$. . . . . . 49

3.3 Low-Ca pyroxene major element concentrations in $\mathrm{wt} \%$. . . 52

3.4 High-Ca pyroxene major element concentrations in $\mathrm{wt} \%$. . . 55

4.1 Average CI-chondrite normalized REE concentrations in plagioclase in eucrite samples. . . . . . . . . . . . 70

4.2 Average CI-chondrite normalized REE concentrations in

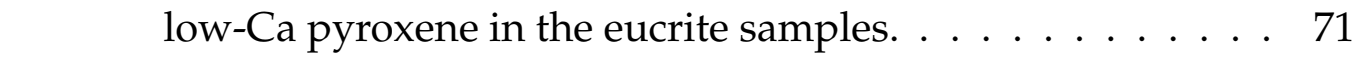

4.3 Average CI-chondrite normalized REE concentrations in high-Ca pyroxene in the eucrite samples. . . . . . . . . . 73

4.4 Average CI-chondrite normalized REE concentrations in pyroxene from eucrite samples with a single pyroxene phase. 73 
4.5 Trace element concentrations in plagioclase from eucrite samples. . . . . . . . . . . . . . . 75

4.6 Correlation matrix for trace elements in plagioclase. . . . . . 79

4.7 Trace element concentrations in low-Ca pyroxene from eucrite samples. . . . . . . . . . . . . . 82

4.8 Correlation matrix for trace elements in low-Ca pyroxene . . 86

4.9 Trace element concentrations in high-Ca pyroxene from eucrite samples. . . . . . . . . . . . . . . . . . . 88

4.10 Correlation matrix for trace elements in high-Ca pyroxene . 92

4.11 Trace element concentrations in pyroxene from eucrites with a single pyroxene phase. . . . . . . . . . . . . 94

$5.1 \mathrm{Al} / \mathrm{Mg}$ ratios, $\mathrm{Mg}$ isotope data, model ${ }^{26} \mathrm{Al} /{ }^{27} \mathrm{Al}_{0}$ and model ages relative to CAIs of the studied eucrites . . . . . 100

6.1 The mixture of diogenite and eucrite compositions required to obtain concentrations equal to twice that of chondrites. . . 126 


\section{Chapter 1}

\section{Introduction}

Astronomical observations and astrophysical models can provide important insights into the formation of the stars and their planetary systems. However, meteorites provide the only samples that directly record the chronology and processes of solar system formation. In this study, the petrographic, chemical and ${ }^{26} \mathrm{Al}-{ }^{26} \mathrm{Mg}$ isotopic properties of a suite of differentiated and genetically related meteorites (eucrites) thought to originate from the solar system's third largest asteroid (Vesta) were examined (Drake, 1979). These data were acquired in order to gain insights into the timing and nature of magmatism and silicate differentiation on asteroidal bodies that is known to have occurred in the first few million years of the 4567 Myr history of our Solar System (Mittlefehldt, 2007; McKeegan and Davis, 2007). As these bodies are considered to be the precursors to terrestrial planets, they provide important insights into conditions in the early solar system and the nature of planet formation (e.g., Greenberg et al. 1978; Fernández and Ip, 1984).

The howardite-eucrite-diogenite (HED) group of meteorites provide an important record of magmatic evolution in the early solar system, with meteorites sampling both the mantle and crust of the HED parent body, which is thought to be the asteroid Vesta (Drake, 1979). This study focuses on eucrites, which are basaltic meteorites representing the crustal material of the HED parent body. 
Constraining the timing of silicate differentiation on asteroids requires the application of an appropriate chronometer. In this thesis study, the short-lived ${ }^{26} \mathrm{Al}-{ }^{26} \mathrm{Mg}$ chronometer was chosen as $\mathrm{Al}$ and $\mathrm{Mg}$ are fractionated by igneous processes making this chronometer ideal for dating silicate differentiation. Moreover, the short half-life of the chronometer $(0.73$ Myr; Walker et al. 1989) means it can provide very precise relative ages $( \pm 0.1 \mathrm{Myr})$ of processes that occurred in the first few million years of the solar system.

\subsection{Early solar system evolution and chronology}

\subsubsection{Formation of a central star and proto-planetary disk}

It is generally accepted that the creation of stars occurs exclusively within molecular clouds, which form from the diffuse interstellar medium over relatively short lifetimes of 10-20 Myr (McKeegan and Davis, 2007). Initially, turbulent motion and gas pressure within the molecular cloud support the dense core, preventing gravitational collapse of the core. Eventually the turbulent motion diminishes, and magnetic fields support the cloud against its own gravity. However, over timescales of a few million years the magnetic field is no longer sufficient to support the dense cloud core, leading to the rapid collapse of the core and formation of low mass stars. It is likely that this process was responsible for the formation of the proto-sun and the solar nebula from which the solar system originated (Boss et al. 2008). After collapse of the molecular cloud, the sun was an embedded young solar object surrounded by gas and dust (proto-planetary disk) that was eventually distributed into an envelope from which an accretion disk evolved (McKeegan and Davis, 2007). The timescales of this process are poorly constrained. By summing the amount of rocky and icy material comprising the planets, as well as enough hydrogen and helium to produce a nebula with the same composition as the sun, Weidenschilling (1977) determined that this accretion disk contained a minimum of $1 \%$ of the mass of the sun. 


\subsubsection{Formation of the first solids}

The components of chondrite meteorites are regarded as the solar system's earliest solids (Scott and Krot, 2007) and, as such, provide records of the conditions in the early solar system. Chondrules are a major component of almost all primitive meteorites, and comprise mostly crystalline silicate material with some glass. Chondrule textures suggest that they were almost heated to their melting point and then rapidly cooled. The short cooling times indicate that chondrules were heated in events that only affected a small area of the solar nebula (Desch and Connolly, 2002). This idea is supported by the fact that pre-solar grains have not experienced significant heating events (Mendybaev et al., 2002).

In addition to chondrules, many primitive chondritic meteorites contain small amounts of refractory inclusions, such as calcium-aluminiumrich inclusions (CAIs) and amoeboid olivine aggregates (AOAs). Refractory inclusions contain minerals that have been heated for longer than chondrules, and their refractory nature (i.e., $\mathrm{Ca}-\mathrm{Al}-\mathrm{Ti}$-rich) suggests that they may have formed closer to the sun than chondrules (Alexander et al. 2008). Age dating of CAIs has shown they are the oldest solids in the solar system (e.g., Amelin et al., 2002) having formed as condensates from a cooling gas phase during the early stages of the proto-planetary disk (Ireland and Fegley, 2000; Wood, 2004). AOAs are found in carbonaceous chondrites and have similar textures, mineralogies and oxygen isotope compositions as accretionary rims on some CAIs, which indicates that AOAs formed in the CAI-forming region as aggregates of condensates from the solar nebula (Krot et al. 2004). Dating of refractory inclusions requires that they survived in the solar nebula for several million years before being incorporated into larger planetary bodies (Chambers, 2007).

\subsubsection{Planetary accretion}

After formation of the proto-sun, bipolar winds from the young sun efficiently expelled gas from the nebula, allowing the dust particles that had been supported in the gas to settle into the mid-plane of the neb- 
ula over a timescale of $10^{3}-10^{4} \mathrm{yr}$ (Weidenschilling, 1980). Gravitational instability cannot account for the initial stages of planetesimal formation, as gravity is only important once bodies become kilometre-sized (Weidenschilling, 2000). The most likely process responsible for the initial coagulation of dust is "dust grain sticking", which occurs due to low velocity collisions between dust grains. Laboratory studies and theoretical models have shown that surface forces make it possible for small grains to stick together when they collide at the velocities expected in the solar nebula (Weidenschilling, 2000). The process of "dust grain sticking" results in the formation of centimetre-sized dust aggregates. However, little is understood about the growth of these macroscopic aggregates into kilometresized bodies. Once bodies are kilometre-sized, gravitational interactions between them become significant and influence their velocities and orbital trajectories and the likelihood of collision and accretion of larger bodies (Chambers, 2007).

There are three stages of planetary accretion that followed the formation of planetesimals: runaway growth, oligarchic growth and late stage accretion and giant impacts. Initially runaway growth occurred when larger bodies with relatively slow velocities grew rapidly by colliding with and incorporating smaller, faster bodies. This resulted in the formation of planetary embryos up to 1000 times the size of the planetesimals from which they formed. During oligarchic growth, the planetary embryos were so large they gravitationally disturbed the area surrounding them, resulting in fewer collisions with smaller bodies, and slowed growth. Oligarchic growth produced Moon- to Mars-sized bodies in a process thought to take approximately $1 \mathrm{Myr}$ at $1 \mathrm{AU}$ (Weidenschilling, 2000). The final stage of accretion is the giant impact stage, which began when the planetesimals no longer had a significant gravitational effect on the much larger embryos. This resulted in sizable collisions between embryos, eventually forming the larger terrestrial planets (Chambers, 2007). This entire process of planetary accretion is considered to have taken approximately $100 \mathrm{Myr}$, with some planets experiencing several impacts in the final stages of their formation. While not every impact results in accre- 
tion, some were energetic enough to cause extensive melting and possibly resulted in the formation of large-scale magma oceans.

\subsubsection{Differentiation of planetesimals}

In various meteoritic materials there is evidence for the former presence of at least 14 short-lived radionuclides with half-lives of $\leq 100 \mathrm{Myr}$ (Table 1.1. Although these radionuclides are now extinct, their existence can be inferred from excesses in their decay or daughter products found in some meteorites. In addition to their use as chronometers, short-lived radionuclides are thought to have played an integral role in the differentiation of planetesimals. Early studies considered that planetesimal melting was the result of heating due to the radioactive decay of $\mathrm{K}, \mathrm{U}$ and $\mathrm{Th}$ (Kuiper. 1954). However, as these are long-lived nuclides with half-lives of billions of years, the time required to produce sufficient heat to melt early formed planetesimals is too long. Urey (1955) suggested that the heat produced by the radioactive decay of short-lived ${ }^{26} \mathrm{Al}$ may have been responsible for the melting and, in turn, differentiation of planetesimals. Although several other heat sources have been proposed for the early melting and differentiation of planetesimals, such as impact energy and electromagnetic induction, the radioactive decay of short-lived nuclides remains the most widely accepted and plausible hypothesis. The decay of both ${ }^{60} \mathrm{Fe}$ and ${ }^{26} \mathrm{Al}$ were thus considered to be the most important heat sources for planetesimal melting (e.g., Shukolyukov and Lugmair, 1993). However the recent revision of the half-life of ${ }^{60} \mathrm{Fe}$ to a longer value (Rugel et al., 2009) suggests that it was not a significant source of heat, implying that ${ }^{26} \mathrm{Al}$ was the most important source of heat in the early solar system (Hevey and Sanders, 2006). This is supported by evidence of excesses of the daughter product of ${ }^{26} \mathrm{Al}\left({ }^{26} \mathrm{Mg}\right)$ in many CAIs and meteorite groups, indicating that at least in a general sense it was widely distributed in the solar nebula (Baker et al., 2005: Bizzarro et al., 2005b; Wadhwa et al., 2009; Schiller et al. 2010, 2011).

Relative age differences between CAIs and achondritic meteorites can 
provide constraints on the timing of planetesimal differentiation and, combined with thermal modelling, can be used to estimate the timing of planetesimal accretion. Application of ${ }^{26} \mathrm{Al}-{ }^{26} \mathrm{Mg}$ chronometry to basaltic meteorites suggests that silicate melting and differentiation of planetesimals occurred within the first 3-4 Myr of solar system formation, which implies that accretion took place in the first $1 \mathrm{Myr}$ of the solar system (Baker et al. 2005: Bizzarro et al., 2005b; Wadhwa et al., 2009; Schiller et al., 2010, 2011).

\subsection{Early solar system chronometers}

Application of various chronometers to meteorites and their constituent solids and minerals provides unique constraints on the timing and rates of processes in the early solar system. A variety of chronometers can be used to date meteorites. $\mathrm{Pb}-\mathrm{Pb}$ dating is based on the long-lived decay chains of ${ }^{235} \mathrm{U}$ and ${ }^{238} \mathrm{U}$ and is the only absolute chronometer with sufficient precision to resolve time differences in the first few million years of the solar system. In addition, a number of short-lived or relative chronometers also allow relative ages of early solar system processes to be determined with high temporal resolution (Table 1.1).

The short-lived chronometers most widely used to study early solar system processes are the ${ }^{182} \mathrm{Hf}-{ }^{182} \mathrm{~W},{ }^{53} \mathrm{Mn}-{ }^{53} \mathrm{Cr}$ and ${ }^{26} \mathrm{Al}-{ }^{26} \mathrm{Mg}$ systems, which are briefly reviewed below.

$\mathrm{Hf}$ is a lithophile element (has a strong affinity to be in silicate reservoirs) whereas $\mathrm{W}$ is a siderophile element (has a strong affinity to be in metallic iron, e.g., metallic cores of differentiated bodies) and, as such, the ${ }^{182} \mathrm{Hf}_{-}{ }^{182} \mathrm{~W}$ chronometer is ideally suited to dating metal-silicate differentiation (i.e., core formation) of planetesimals. Superchondritic $\mathrm{Hf} / \mathrm{W}$ ratios in the silicate portion of planets results in ${ }^{182} \mathrm{~W}$ excesses, and complementary deficits in the metal core, provided core formation occurred during the lifetime of ${ }^{182} \mathrm{Hf}\left(\mathrm{t}_{1 / 2}=8.9 \mathrm{Myr}\right.$; Vockenhuber et al. 2004). The ${ }^{53} \mathrm{Mn}-{ }^{53} \mathrm{Cr}$ short-lived chronometer is suitable for dating processes that occurred in the first ca. 20 Myr of the solar system $\left(t_{1 / 2}=3.7\right.$ Myr; Honda and 
Table 1.1: Short-lived radionuclides that existed in the early solar system. Table from McKeegan and Davis (2007). Half-lives are taken from National Nuclear Data Centre. References: (1) Chaussidon et al. (2006); (2) Srinivasan et al. (1994); (3) Lin et al. (2005) and Hsu et al. (2006); (4) Bizzarro et al. (2005a), Bizzarro et al. (2005b) and McKeegan and Davis (2007); (5) Chaussidon et al. (2006) and McKeegan and Davis (2007); (6) Mostefaoui et al. (2005) and Tachibana et al. (2006); (7) Dauphas et al. (2005); (8) Chen and Wasserburg (1990); (9) Kleine et al. (2005); (10) Jeffery and Reynolds (1961); (11) Nielsen et al. (2006); (12) Schönbächler et al. (2002); (13) Hudson et al. (1988).

\begin{tabular}{lcccc}
\hline Parent nuclide & Half-life & Daughter nuclide & Estimated initial solar system abundance & References \\
\hline${ }^{7} \mathrm{Be}$ & $53.1 \mathrm{days}$ & ${ }^{7} \mathrm{Li}$ & ${ }^{7} \mathrm{Be} /{ }^{9} \mathrm{Be}=1 \times 10^{-3}$ & $(1)$ \\
${ }^{41} \mathrm{Ca}$ & $102 \mathrm{kyr}$ & ${ }^{41} \mathrm{~K}$ & ${ }^{41} \mathrm{Ca} /{ }^{40} \mathrm{Ca}=1 \times 10^{-8}$ & $(2)$ \\
${ }^{36} \mathrm{Cl}$ & $301 \mathrm{kyr}$ & ${ }^{36} \mathrm{~S},{ }^{36} \mathrm{Ar}$ & ${ }^{36} \mathrm{Cl} /{ }^{35} \mathrm{Cl}=\sim 4 \times 10^{-6}$ & $(3)$ \\
${ }^{26} \mathrm{Al}$ & $717 \mathrm{kyr}$ & ${ }^{26} \mathrm{Mg}$ & ${ }^{26} \mathrm{Al} /{ }^{27} \mathrm{Al}=\sim 5-6 \times 10^{-5}$ & $(4)$ \\
${ }^{60} \mathrm{Fe}$ & $1.5 \mathrm{Myr}$ & ${ }^{60} \mathrm{Ni}$ & ${ }^{60} \mathrm{Fe} /{ }^{56} \mathrm{Fe}=\sim 5-10 \times 10^{-7}$ & $(5)$ \\
${ }^{10} \mathrm{Be}$ & $1.51 \mathrm{Myr}$ & ${ }^{10} \mathrm{~B}$ & ${ }^{10} \mathrm{Be} /{ }^{9} \mathrm{Be}=\sim 1 \times 10^{-3}$ & $(6)$ \\
${ }^{53} \mathrm{Mn}$ & $3.74 \mathrm{Myr}$ & ${ }^{53} \mathrm{Cr}$ & ${ }^{53} \mathrm{Mn} /{ }^{55} \mathrm{Mn}=1 \times 10^{-5}$ & $(7)$ \\
${ }^{107} \mathrm{Pd}$ & $6.5 \mathrm{Myr}$ & ${ }^{107} \mathrm{Ag}$ & ${ }^{107} \mathrm{Pd} /{ }^{108} \mathrm{Pd}=\sim 5 \times 10^{-5}$ & $(8)$ \\
${ }^{182} \mathrm{Hf}$ & $8.90 \mathrm{Myr}$ & ${ }^{182} \mathrm{~W}$ & ${ }^{182} \mathrm{Hf} /{ }^{180} \mathrm{Hf}=1.07 \times 10^{-4}$ & $(9)$ \\
${ }^{129} \mathrm{I}$ & $15.7 \mathrm{Myr}$ & ${ }^{129} \mathrm{Xe}$ & ${ }^{129} /{ }^{127} \mathrm{I}=1 \times 10^{-4}$ & $(10)$ \\
${ }^{205} \mathrm{~Pb}$ & $17.3 \mathrm{Myr}$ & ${ }^{205} \mathrm{Tl}$ & ${ }^{205} \mathrm{~Pb} /{ }^{204} \mathrm{~Pb}=\sim 1-2 \times 10^{-4}$ & $(11)$ \\
${ }^{92} \mathrm{Nb}$ & $34.7 \mathrm{Myr}$ & ${ }^{92} \mathrm{Zr}$ & ${ }^{92} \mathrm{Nb} /{ }^{93} \mathrm{Nb}=1 \times 10^{-4}$ & $(12)$ \\
${ }^{244} \mathrm{Pu}$ & $80.0 \mathrm{Myr}$ & $\mathrm{Fission} \mathrm{Xe}$ & ${ }^{244} \mathrm{Pu} /{ }^{238} \mathrm{U}=7 \times 10^{-3}$ & $(13)$ \\
${ }^{146} \mathrm{Sm}$ & $103 \mathrm{Myr}$ & ${ }^{142} \mathrm{Nd}$ & ${ }^{146} \mathrm{Sm} /{ }^{147} \mathrm{Sm}=9 \times 10^{-4}$ & $(14)$ \\
\hline
\end{tabular}

Imamura, 1971). Mn and Cr undergo relative fractionation during evaporation/condensation and magmatic processes, making the chronometer suitable for investigating the time between accretion and differentiation of planetesimals (McKeegan and Davis, 2007). Short-lived chronometers only allow for relative dating between samples of two different ages, as the initial abundance of the parent nuclide is unknown. However, these relative ages can be anchored onto an absolute timescale by dating the same material with the $\mathrm{Pb}-\mathrm{Pb}$ chronometer. 


\subsection{1 ${ }^{26} \mathrm{Al}-{ }^{26} \mathrm{Mg}$ chronometer}

There are three stable isotopes of magnesium $\left({ }^{24} \mathrm{Mg},{ }^{25} \mathrm{Mg}\right.$ and $\left.{ }^{26} \mathrm{Mg}\right)$ that are produced in stellar environments. ${ }^{24} \mathrm{Mg}$ is produced through hydrogen burning, whereas neon burning during the $\alpha$ process, carbon burning and explosive nucleosynthesis are responsible for the production of ${ }^{25} \mathrm{Mg}$ and ${ }^{26} \mathrm{Mg}$ (Burbidge et al., 1957). In addition, ${ }^{26} \mathrm{Mg}$ is produced by the decay of the short-lived radionuclide ${ }^{26} \mathrm{Al}$, with a half-life of $0.73 \mathrm{Myr}$ through positron emission/electron capture to ${ }^{26} \mathrm{Mg}$ (Lee et al., 1977).

The ${ }^{26} \mathrm{Al}-{ }^{26} \mathrm{Mg}$ chronometer has been widely applied to obtain precise relative ages of silicate melting and crystallization in the early solar system (e.g., Srinivasan et al., 1999; Baker et al., 2005; Bizzarro et al., 2005b: Spivak-Birndorf et al., 2009, Wadhwa et al., 2009, Schiller et al., 2010, 2011) as $\mathrm{Al}$ and $\mathrm{Mg}$ are fractionated by partial melting and the formation of basaltic magmas as well as the crystallization of different mineral phases (McKeegan and Davis, 2007).

The validity of short-lived radionuclides as chronometers relies on an understanding of their distribution within the solar nebula, which also requires some knowledge of how and where the short-lived nuclide originated from. The origin of short-lived nuclides is a subject of controversy, with a number of models having been proposed to account for their existence, such as formation by energetic particle irradiation in the protomolecular cloud, or in the solar nebula by the early sun (Sahijpal et al. 1998) . The most widely accepted model for the formation of most shortlived radionuclides is, however, by nucleosynthetic processes of a stellar origin (Sahijpal et al., 1998).

A homogeneous distribution of ${ }^{26} \mathrm{Al}$ in the solar system has been inferred from the agreement between ${ }^{26} \mathrm{Al}-{ }^{26} \mathrm{Mg}$ and ${ }^{206} \mathrm{~Pb}-{ }^{207} \mathrm{~Pb}$ ages of refractory inclusions and chondrules from primitive meteorites (Amelin, 2002) and $\mathrm{Mg}$ isotope measurements of these components (Villeneuve et al. 2009). However, high-precision $\mathrm{Mg}$ isotope measurements of solids from the inner solar system indicate that there is widespread heterogeneity in the abundance of ${ }^{26} \mathrm{Mg}$, reflecting early heterogeneity in the distribu- 
tion of ${ }^{26} \mathrm{Al}$ throughout the proto-planetary disk (Larsen et al., 2011). This means that rather than applying a solar system wide initial ${ }^{26} \mathrm{Al} /{ }^{27} \mathrm{Al}$ ratio (the canonical ratio based on measurements of CAIs), variations in initial ${ }^{26} \mathrm{Al}$ abundances need to be considered when applying the ${ }^{26} \mathrm{Al}-{ }^{26} \mathrm{Mg}$ chronometer to material from different source regions.

The decay equation for the ${ }^{26} \mathrm{Al}-{ }^{26} \mathrm{Mg}$ chronometer can be written as:

$$
\left(\frac{{ }^{26} M g}{{ }^{24} M g}\right)_{\Delta t}=\left(\frac{{ }^{26} M g}{{ }^{24} M g}\right)_{0}+\left(\frac{{ }^{26} A l}{{ }^{24} M g}\right)_{0} \times e^{-\lambda t}
$$

where $\left({ }^{26} \mathrm{Mg} /{ }^{24} \mathrm{Mg}\right)_{\Delta \mathrm{t}}$ is the $\mathrm{Mg}$ isotopic composition after an interval of time, and $\left({ }^{26} \mathrm{Mg} /{ }^{24} \mathrm{Mg}\right)_{0}$ is the $\mathrm{Mg}$ isotopic composition at $\mathrm{t}=0$, which is usually the time of solar system formation. $\left({ }^{26} \mathrm{Al} /{ }^{24} \mathrm{Mg}\right)_{0}$ is the initial abundance (i.e., $\mathrm{t}=0$ ) of ${ }^{26} \mathrm{Al}$ relative to ${ }^{24} \mathrm{Mg}$, and $\lambda$ is the decay constant of ${ }^{26} \mathrm{Al}$. ${ }^{26} \mathrm{Al}$ is now extinct, so the initial abundance $\left({ }^{26} \mathrm{Al} /{ }^{24} \mathrm{Mg}\right)_{0}$ cannot be measured, however $\left({ }^{26} \mathrm{Al} /{ }^{24} \mathrm{Mg}\right)_{0}$ can be replaced in the equation by $\left[\left({ }^{26} \mathrm{Al} /{ }^{27} \mathrm{Al} l_{0}\right) \times\left({ }^{27} \mathrm{Al} /{ }^{24} \mathrm{Mg}\right)\right]$ where $\left({ }^{26} \mathrm{Al} /{ }^{27} \mathrm{Al} l_{0}\right)$ is given by slope of the correlation line (isochron) on a plot of ${ }^{26} \mathrm{Mg} /{ }^{24} \mathrm{Mg}$ versus ${ }^{27} \mathrm{Al} /{ }^{24} \mathrm{Mg}$ (e.g., Fig. 1.1), and ${ }^{27} \mathrm{Al} /{ }^{24} \mathrm{Mg}$ is the measured $\mathrm{Al} / \mathrm{Mg}$ ratio of the sample. With knowledge of the initial ${ }^{26} \mathrm{Al} /{ }^{27} \mathrm{Al}$ ratio, based on this ratio in CAIs, an age relative to CAIs can be calculated using the equation:

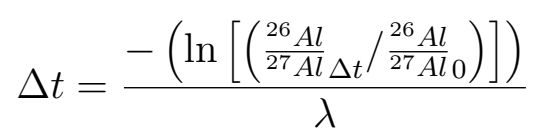

Based on the assumption that CAIs are the solar system's first solids, a time calculated relative to CAIs can be interpreted as the time that has elapsed since the beginning of the solar system.

\subsection{Classification of meteorites}

Meteorites are divided into two general groups (chondrites and nonchondrites) on the basis of their bulk compositions and textures, with non- 


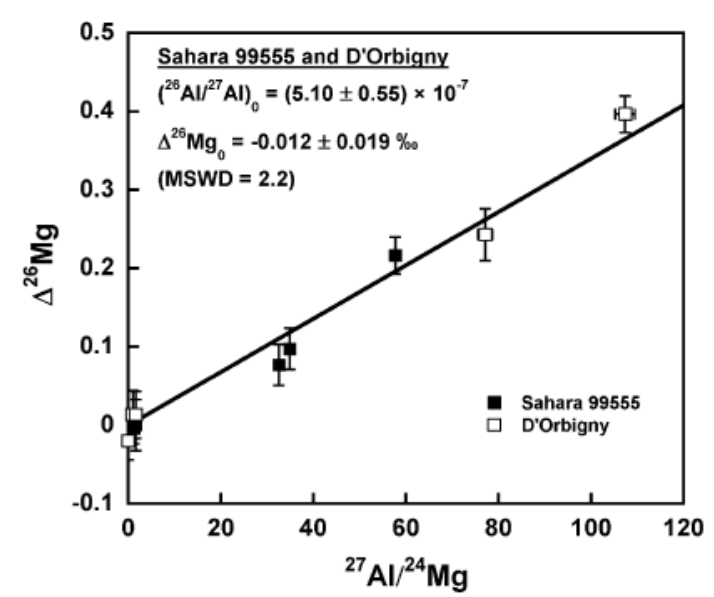

Figure 1.1: Example of an ${ }^{26} \mathrm{Al}-{ }^{26} \mathrm{Mg}$ isochron from Spivak-Birndorf et al. (2009).

chondrites further sub-divided into achondrites, irons and stony-irons (Table 1.2 .

Chondrites are generally considered to be the most primitive meteorites, originating from parent bodies that did not melt and differentiate, unlike the parent bodies of non-chondrites that have experienced varying degrees of melting and differentiation. Some non-chondritic meteorites have characteristics of both chondrites and achondrites, and are referred to as primitive achondrites. With a greater metal and siderophile element content than most achondrites, primitive achondrites are thought to have come from parent bodies that underwent a lesser degree of melting, and thus did not fully differentiate into a mantle and core (Krot et al., 2003). The most evolved achondrites are considered to be products of silicate differentiation, and share some similar characteristics to terrestrial basalts. Iron meteorites are believed to represent core material of differentiated planetesimals that have metal-rich cores (Krot et al., 2003). Stony-iron meteorites comprise approximately equal amounts of silicate and metal, which suggests that they may originate from the core-mantle boundary of small, differentiated planetesimals (Krot et al., 2003). 


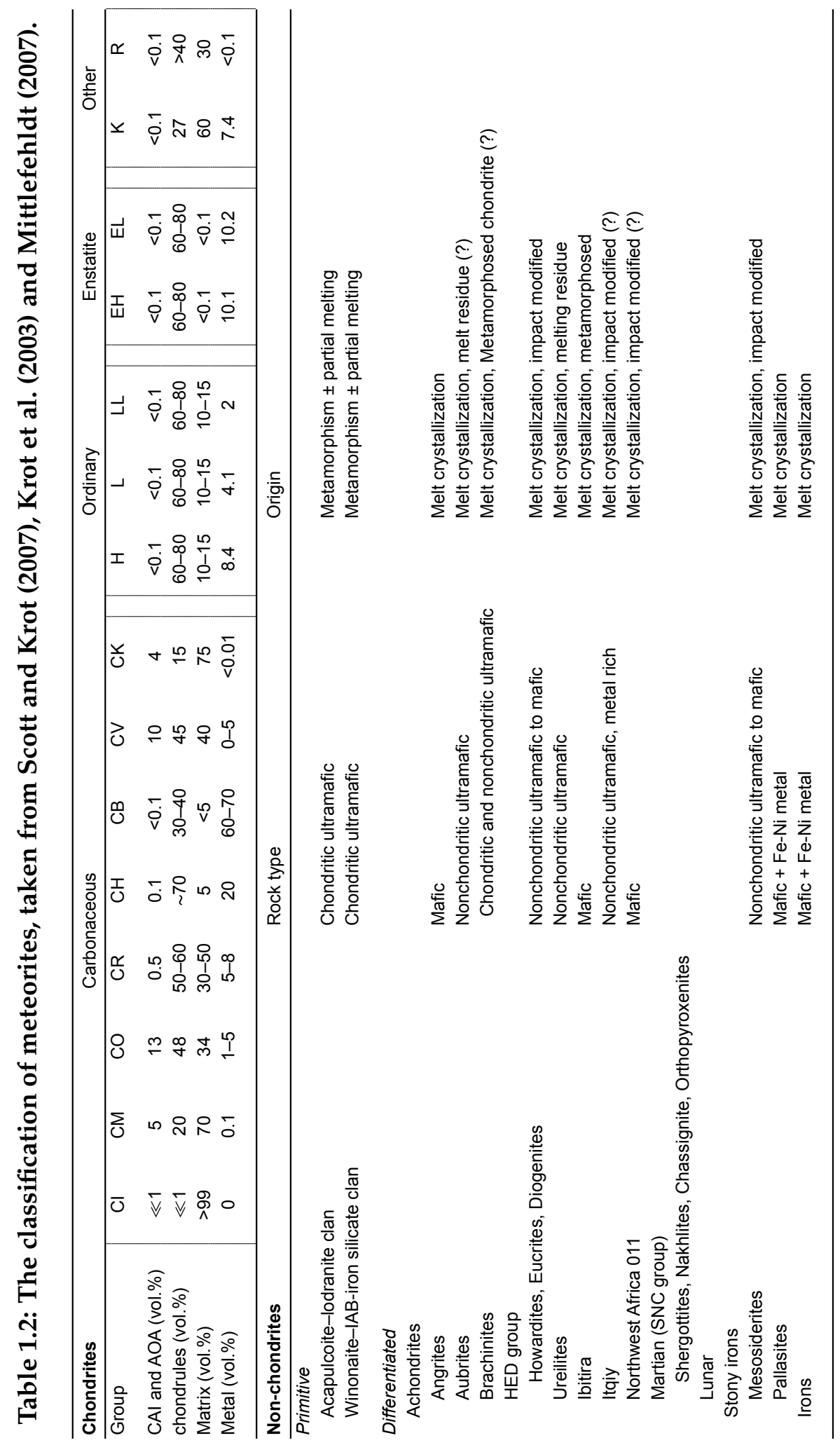




\subsubsection{Chondrites}

Whole-rock elemental and oxygen isotope compositions provide the basis for categorizing chondrites into 14 groups. A chondrite group is defined where there are at least five unpaired chondrites with similar mineralogy, petrography, oxygen isotopic properties and bulk chemical compositions (Krot et al. 2003). There are also several chondrites with unique properties that are ungrouped. From these 14 chondrite groups, 13 of them comprise three major classes of chondrites i.e., carbonaceous $(\mathrm{C})$, ordinary $(\mathrm{O})$ and enstatite $(\mathrm{E})$.

\section{Carbonaceous chondrites}

Carbonaceous chondrites are divided into eight groups: $\mathrm{CI}, \mathrm{CM}, \mathrm{CR}, \mathrm{CH}$, $\mathrm{CB}, \mathrm{CV}, \mathrm{CK}$ and $\mathrm{CO}$. The second letter of theses acronyms refers to the type meteorite of that class (e.g., the CV group takes its name from the Vigarano meteorite). Carbonaceous chondrites contain variable amounts of refractory material, including calcium-aluminium-rich inclusions (CAIs), which are thought to be the first solids that condensed from the cooling proto-planetary disk.

\section{Ordinary chondrites}

Ordinary chondrites are divided on the basis of their Fe content into three groups i.e., $\mathrm{H}$ (highest total iron but lower iron oxide), L (relatively lower total iron but higher iron oxide than H group) and LL chondrites (lowest total iron but the highest iron oxide content) (Krot et al. 2003). The oxygen isotope composition of chondrules from chondrites of all three groups define a common fractionation line, which suggests that all the ordinary chondrites originate from a common source (Wasson, 1972).

\section{Enstatite chondrites}

Enstatite chondrites are grouped based on Fe-content, mineralogy and bulk chemistry into EH (high enstatite) and EL (low enstatite) chondrites. 
The oxygen isotope composition of enstatite chondrites is indistinguishable from the terrestrial fractionation line, suggesting a potential genetic relationship between enstatite chondrites, Earth and the Moon (Clayton et al. 1984).

\subsubsection{Non-chondrites}

Non-chondrites are considered to be derived from chondritic material that has melted and fractionated, the degree of which determines how much their bulk composition deviates from that of chondrites. Two major categories of non-chondrites are defined based on their degree of melting i.e., primitive and differentiated. Primitive non-chondrites have bulk compositions that are very similar to those of chondrites, but have igneous or metamorphic textures consistent with them representing either metamorphosed chondrites or residues from a small degree of partial melting (Krot et al., 2003). Differentiated non-chondrites originate from parent planetesimals that are thought to have undergone large-scale melting and differentiation.

\section{Differentiated achondrites}

The following summarizes the most common groups of achondrites. More detailed descriptions of the achondrite meteorite groups can be found in Krot et al. (2003) and references therein.

\section{Howardite-Eucrite-Diogenite group}

The howardite-eucrite-diogenite (HED) achondrites originated from a differentiated parent body that experienced extensive processing, producing mafic and ultramafic igneous rocks that, in some respects, closely resemble terrestrial igneous rocks. The oxygen isotope compositions of HED meteorites indicate that these meteorites originate from a single parent body (Clayton and Mayeda, 1996), which is believed to be the asteroid 
Vesta (Drake, 1979). Howardites are regolith breccias of eucrite and diogenite material, representing lithified impact ejecta. Eucrites are basalts composed of orthopyroxene, pigeonite, Ca-rich clinopyroxene and plagioclase with minor amounts of chromite, ilmenite, troilite and Fe-Ni metal (Mittlefehldt, 2007) that likely originated from the crust of the HED parent body. Diogenites are primarily monomict orthopyroxenites containing lesser amounts of plagioclase and olivine, which are thought to have originated from relatively deeper levels than eucrites within the HED parent body (Mittlefehldt, 2007).

As the HED meteorites are the subject of this thesis research, a separate, detailed description of their characteristics follows in Section 1.4.

\section{Angrites}

Angrites are basaltic in composition, consisting of $\mathrm{Ca}-\mathrm{Al}-\mathrm{Ti}$ - rich pyroxene, anorthitic plagioclase and Ca-rich olivine. Based on experimental partial melting of chondrite meteorites, angrites are believed to have formed from partial melting of primitive material under oxidizing conditions (Jurewicz et al., 1993). Unlike the HED suite of meteorites, most angrites show no signs of thermal or shock metamorphism, suggesting that either the parent body was smaller, or that the parent body formed in an area of the solar system that was less affected by the late heavy bombardment associated with the shock metamorphism of eucrites (Mittlefehldt et al. 2002). Angrites can be precisely dated with the $\mathrm{Pb}-\mathrm{Pb}$ chronometer owing to their extreme volatile depletion and very low ${ }^{204} \mathrm{~Pb} /{ }^{238} \mathrm{U}$ of their parent body (Amelin, 2008). As such absolute and relative ages for angrites provide a useful time anchor for short-lived chronometers applied to other meteorite suites.

\section{Aubrites}

Aubrites are primarily composed of enstatite, with lesser amounts of olivine, iron-nickel metal and troilite, which indicates formation under extremely reducing conditions. Aubrites lack a basaltic component, and 
the process by which they formed is enigmatic. However, aubrites are thought to be cumulate material from a magma ocean on what was an extremely reduced planetesimal (Mittlefehldt, 2007).

\section{Ureilites}

Ureilites are ultramafic rocks composed of olivine, pyroxene and carbonrich interstitial material. Ureilites display a wide range of oxygen isotope compositions that plot along a mass-independent line with the same 1:1 slope as that of the carbonaceous chondrites anhydrous mineral line (Goodrich, 1992). The origin of ureilites is poorly understood as they exhibit some properties that suggest that they are primitive rocks, while other features indicate that they have a high-temperature origin, perhaps reflecting partial melting of a differentiated planetesimal that did not experience complete melting (Goodrich et al., 2004).

\section{Brachinites}

Brachinites are predominantly comprised of olivine and pyroxene, and have variable bulk chemistry. The origins of brachinites are uncertain, and they may be primitive rocks, partial melt residues or igneous cumulates (Krot et al. 2003). The petrological and geochemical variations between different brachinites suggests that they may have formed by a range of these processes.

\section{Stony-irons}

\section{Mesosiderites}

Mesosiderites are stony-iron meteorites consisting of silicate material and iron-nickel metal. The silicate material in mesosiderites is a polymict breccia of crustal rocks, similar to that of the HED meteorites, leading to speculation that mesosiderites originated from the HED parent body. However, differences in mineralogy and composition imply that mesosiderites 
come from a separate parent body, possibly with a similar thermal history to the HED parent body (Mittlefehldt, 2007). The metal component of mesosiderites is presumed to be from the core of a planetesimal, which was mixed with silicate material due to an impact. However, there is debate as to whether the silicate and metal components originated from the same parent body.

\section{Pallasites}

Pallasites are stony-iron meteorites composed predominantly of olivine, iron-nickel metal and troilite. On the basis of their mineralogy and composition, pallasites are separated into three groups, possibly originating from three separate parent bodies. Pallasites are believed to originate from the core-mantle boundary of asteroids, despite some apparent difficulties of this model in explaining all the features of pallasites, such as mixing of olivine and metal (Krot et al. 2003)

\section{Irons}

Iron meteorites are classified into 13 groups based on chemistry, and are assumed to originate from the metal-rich cores of differentiated bodies (Krot et al., 2003).

\subsection{Howardite-eucrite-diogenite meteorites}

\subsubsection{Petrology and geochemistry of HED meteorites}

Howardites are regolith breccias predominantly comprising eucritic and diogenitic material, along with abundant melt clasts. Howardites also occasionally contain xenoliths of carbonaceous chondritic material that is thought to have been introduced by impactors (Metzler et al. 1995). The high noble gas content of howardites was likely introduced by solar winds, confirming their origin as surface material from the HED parent body (Suess et al., 1964). 
Eucrites are basalts composed predominantly of high- and low-Ca pyroxene and plagioclase, with minor amounts of chromite, ilmenite, troilite and Fe-Ni metal. There are three sub-classes of eucrites: non-cumulate eucrites, cumulate eucrites and polymict eucrites. Polymict eucrites are breccias consisting of at least $90 \%$ eucritic material, and a variety of clasts of diogenitic material, pyroxene cumulates, feldspar cumulates and other minerals. The variety of lithologies that comprise the polymict eucrites suggests that they are the result of serial magmatism, which has produced a diverse crust on the HED parent body (Delaney et al., 1984). Noncumulate eucrites are the most common group of eucrites, most of which belong to one of three sub-groups; main group eucrites and the Stannern and Nuevo Laredo trend eucrites. These sub-groups are defined on the basis of $\mathrm{Mg} \#$ (whole rock molar $\mathrm{Mg} /\left(\mathrm{Mg}+\mathrm{Fe}^{2+}\right)$ ) and incompatible trace element concentrations (Basaltic Volcanism Study Project, 1981). Noncumulate eucrites typically have relatively flat chondrite-normalized rare earth element (REE) patterns, in some cases characterized by a negative Eu anomaly (Hsu and Crozaz, 1996). Non-cumulate eucrites are thought to have formed as surface lava flows that cooled rapidly (Mittlefehldt, 2007).

Almost all eucrites have experienced some degree of metamorphism resulting in mineral re-equilibration and recrystallization, with the majority of eucrites being metamorphosed at temperatures between $700^{\circ} \mathrm{C}$ and $1000^{\circ} \mathrm{C}$ (Takeda and Graham, 1991; Yamaguchi et al., 1996). It has been proposed that the crust of the HED parent body formed from a series of stacked lava flows, resulting in thermal metamorphism where earlier erupted eucrites were buried and heated by subsequent flows (Yamaguchi et al. 1996). However, a study by Metzler et al. (1995) contends that thermal metamorphism resulted from the intrusion of dykes and hot melt sheets created by impacts. Multiple impacts have resulted in considerable reworking of the crust of the HED parent body, as evidenced by significant brecciation of howardites and many eucrites, recrystallization of minerals and melt inclusions of impact origin (Yamaguchi et al., 2009). These impact events occurred before, during and after thermal metamorphism and, therefore, many eucrites show evidence of both shock and thermal meta- 
morphism (Metzler et al., 1995; Yamaguchi et al., 2009).

Cumulate eucrites are gabbros with plutonic textures. They are distinct from non-cumulate eucrites not only in terms of their texture, but also chemistry. The Mg\# of high-Ca pyroxene is usually higher in cumulate eucrites than non-cumulate eucrites. Similarly, REE abundances in cumulate eucrites are lower than non-cumulate eucrites. The cumulate eucrites also exhibit positive Eu anomalies (Consolmagno and Drake, 1977).

Diogenites are coarse-grained cumulates from the HED parent body. These cumulates are predominantly comprised of orthopyroxene, with minor amounts of olivine, plagioclase and clinopyroxene. There is also evidence of dunite meteorites that are linked to diogenites that may originate from the HED parent body (Mittlefehldt, 2007; Beck et al., 2011).

\subsubsection{Origins of HED meteorites}

Oxygen isotope variations in differentiated planetesimals such as the HED parent body are mass-dependent, with fractionation lines that have a slope of $\sim 0.52$ in three oxygen isotope space (Clayton, 2003) (Fig. 1.2). Although different bodies have parallel trends, their $\Delta^{17} \mathrm{O}\left(\Delta^{17} \mathrm{O}=\delta^{17} \mathrm{O}-0.52 \delta^{18} \mathrm{O}\right)$ values differ, reflecting the unique oxygen isotope composition of their parent body (Fig: 1.2). Extensive melting of differentiated bodies resulted in isotopic homogenization to varying degrees, and allows genetic relationships between different meteorites to be established. The HED meteorites were determined to have originated from the same parent body based on a uniform $\Delta^{17} \mathrm{O}$ of $-0.25 \%$ for howardites, eucrites and diogenites (Clayton and Mayeda, 1996). This finding is consistent with a number of early petrological and chemical studies that identified the HED meteorites as originating from a common parent body (e.g., Duke and Silver 1967; Bunch, 1975; Fukuoka et al., 1977). Similarities in the Fe/Mn ratios of pyroxenes from eucrites, diogenites and howardites also provides further evidence that these meteorites originate from a common parent body (Papike, 1998), as does the existence of rocks containing pyroxene and plagioclase with compositions intermediate to those found in diogenites and 


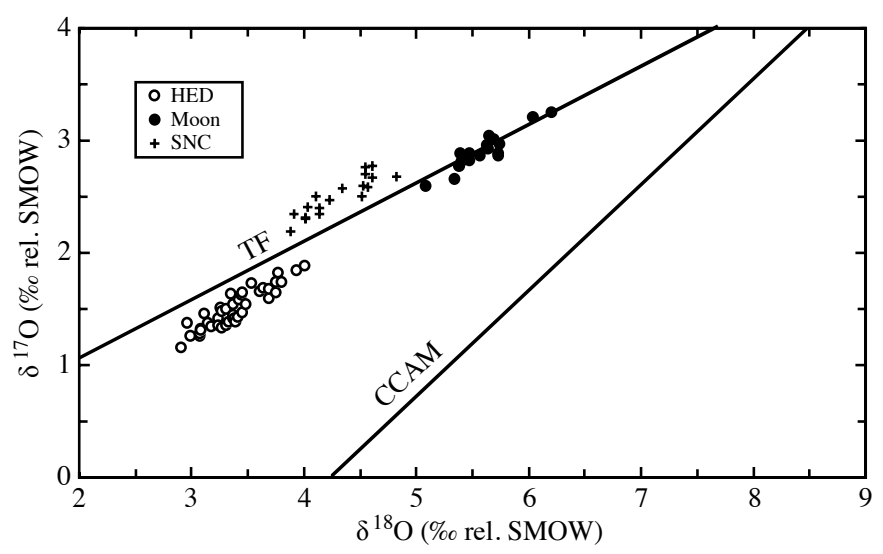

Figure 1.2: Oxygen isotope composition of the HED meteorites, martian meteorites and lunar meteorites. The terrestrial fractionation line (TF) represents the oxygen isotope composition on Earth. Figure taken from Clayton (2003).

cumulate eucrites (Takeda and Mori, 1985).

A high precision study of oxygen isotopes in the HED meteorites revealed some subtle oxygen isotope heterogeneity (Wiechert et al., 2004). In general, HED meteorites have consistent $\Delta^{17} \mathrm{O}$. However, howardites generally have a slight enrichment in ${ }^{16} \mathrm{O}$, whilst some eucrites display slight depletions in ${ }^{16} \mathrm{O}$. This suggests that there may have been incomplete mixing and isotopic equilibration on the HED parent body, resulting in some primary oxygen isotope heterogeneity (Wiechert et al., 2004). This could reflect formation of eucrites from localized partial melts (Stolper. 1977), or partial melting of the mantle with near surface layers experiencing much lower temperatures and undergoing little or no melting (Ghosh and McSween, 1998), and thus preserving some of this initial primary oxygen isotope heterogeneity.

\subsubsection{Differentiation of the HED parent body}

The relationships between cumulate eucrites, non-cumulate eucrites and diogenites is poorly understood, and is the subject of a long-standing debate. There are two distinct models that have been proposed in order to explain the formation of eucrites and diogenites and the differentiation of 
the HED parent body.

An early study of eucrites by Stolper (1977) utilizing low pressure melting experiments suggested that eucrites formed from increasing degrees of partial melting of primitive, undifferentiated material. In this model, cumulate eucrites are the products of liquids resulting from fractionation of partial melts, and diogenites formed from melting of a source region that had undergone earlier melting to form eucrites, and were thus depleted in basaltic components (Fig. 1.3A). Since the work of Stolper (1977), a number of other studies of HED meteorites have proposed variations on the partial melting model (e.g., Consolmagno and Drake, 1977; Jones, 1984 Mittlefehldt and Lindstrom, 2003). If eucrites and diogenites were indeed formed by partial melting, there is still uncertainty as to whether or not they are cogenetic, with some studies suggesting that diogenites and eucrites formed as part of the same crystallization sequence, with diogenites crystallizing first and eucrites forming from residual liquids (Fig. 1.3 A). Conversely, it is possible that eucrites and diogenites are not cogenetic and that they crystallized from different parental magmas, with the difference between the two reflecting compositionally distinct magma sources, resulting from heterogeneities on the parent body (Jurewicz et al., 1995) or differing degrees of partial melting (Shearer et al., 1997) (Fig. 1.3B). Both variations on the partial melting model require relatively low to moderate temperatures, which are inconsistent with the amount of heat required for the metal-silicate differentiation that took place during core formation on the HED parent body (Newsom and Drake, 1983). Another difficulty with the partial melting model is that there is no evidence for unmelted primitive material on the HED parent body (other than small amounts in howardites thought to originate from impactors), which would likely comprise a reasonably large proportion of a body that was not entirely melted. A common argument against the partial melting model on the HED parent body is that the oxygen isotope homogeneity of the HED meteorites could only be achieved with (near-) complete melting of the parent body, even though a high precision study of oxygen isotopes in the HED meteorites did reveal some subtle oxygen isotope heterogeneity (Wiechert et al. 

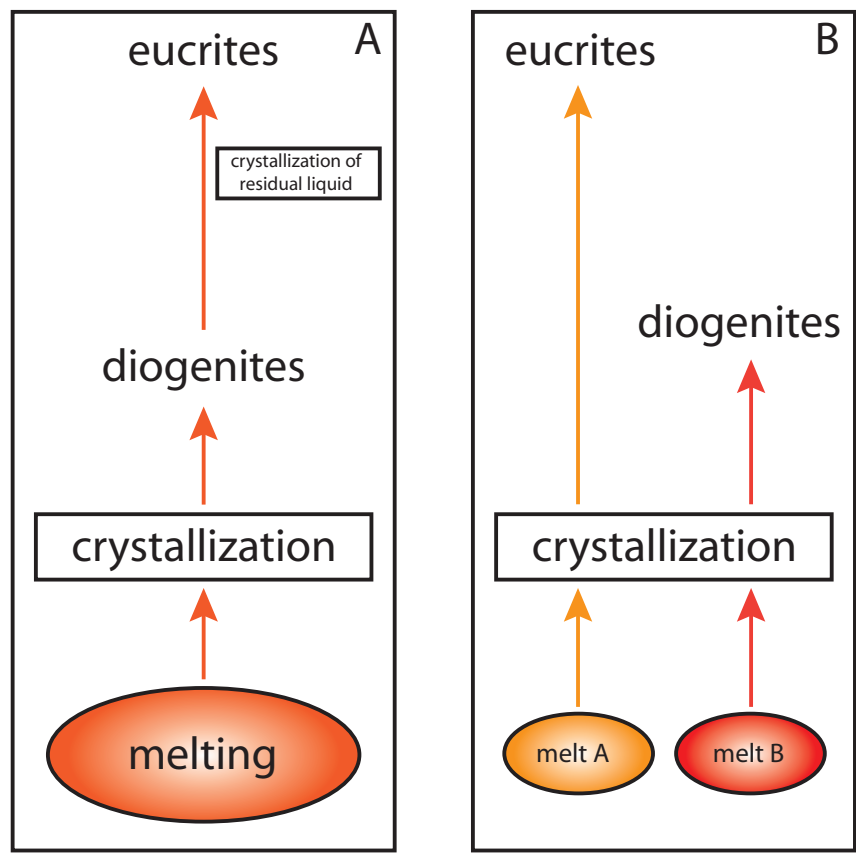

Partial Melting

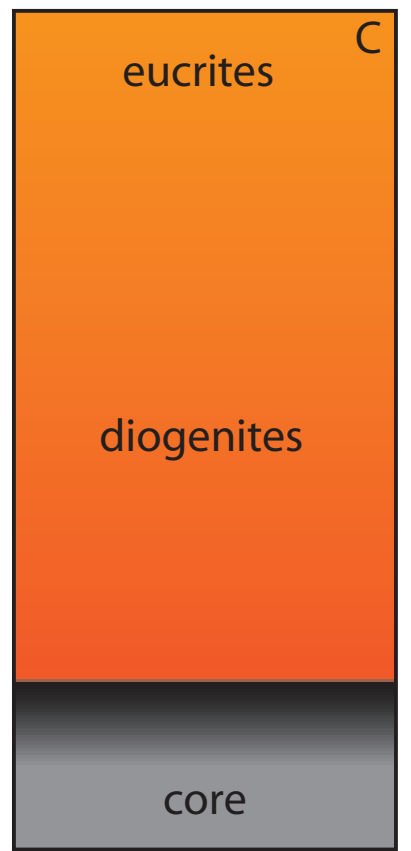

Large scale melting

Figure 1.3: End-member models for the differentiation of the HED parent body. Figure adapted from Shearer et al. (1997). Models A and B require relatively small degrees of partial melting, while model $\mathrm{C}$ requires near complete melting of the HED parent body. In models $A$ and $C$ eucrites and diogenites are part of the same crystallization continuum, whereas in model $B$ the eucrites and diogenites crystallize independently from separate magma sources.

2004).

As an alternative to the partial melting models, it was proposed that eucrites and diogenites are the products of extensive fractional crystallization of an asteroidal magma ocean resulting from large scale melting that existed on the HED parent body (Ikeda and Takeda, 1985). Diogenites and cumulate eucrites would have formed as the magma ocean crystallized, with non-cumulate eucrites forming from residual magmas (Fig. 1.3 C). A number of studies have favoured this model (Righter and Drake, 1997; Wiechert et al., 2004; Greenwood et al., 2005: Schiller et al., 2010, 2011), as it explains the absence of unmelted, primitive material on the HED parent body and is also consistent with core segregation. However, the extreme trace element variability in HED meteorites (e.g., Fowler et al., 1995) is dif- 
ficult to reconcile with eucrites and diogenites forming from continuous crystallization of the same magma body.

Barrat et al. (2000) suggested that the HED parent body differentiated as a result of in situ crystallization, which is a concept originally proposed by Langmuir (1989) to explain geochemical variations in terrestrial magmas. Without this crystallization model, the decoupling of major and trace elements in non-cumulate eucrites is difficult to reconcile with fractional crystallization of a magma ocean (Barrat et al., 2000). The in situ crystallization model still invokes the presence of a global magma ocean, but cumulate eucrites are envisaged to have crystallized in solidification zones at the margins of magma bodies where heat was being lost. Residual melts were trapped in the solidification zone and extruded as non-cumulate eucrites, with Nuevo Laredo and Stannern trend eucrites resulting from heterogeneities brought about by the in situ crystallization regime within the magma ocean (Barrat et al., 2000).

\subsubsection{Relationship to the asteroid Vesta}

The HED meteorites are unusual amongst meteorites found on Earth, in that their parent body has potentially been identified. Similarities between the mineralogy of the HED meteorites and the surface mineralogy of the asteroid Vesta, as determined by spectral reflectance measurements (McCord et al. 1970), suggest that the HED meteorites may have originated from Vesta (Drake, 1979). Vesta is the second most massive object in the asteroid belt and has a diameter of $525 \mathrm{~km}$. It is dynamically linked to a group of smaller asteroids called the Vestoids that originated from a large impact on Vesta that may have produced the HED meteorites (Drake. 2001). Images captured by NASA's Dawn spacecraft show evidence of giant impacts and the youngest impact basin (Rheasilvia) is a $\sim 500 \mathrm{~km}$ wide and $\sim 19 \mathrm{~km}$ deep feature (Schenk et al., 2012). These large impacts excavated a substantial volume of material, sufficient to have created the Vestoids and the HED meteorites (Schenk et al., 2012). 


\subsubsection{Outstanding research questions}

The HED meteorites have been studied extensively. However, there are many research questions that remain unanswered, and in particular, two important questions relating to the origin of these meteorites:

1. There is still uncertainty as to the timing and nature of silicate differentiation on the HED parent body and, as such, the relationship between the eucrites and diogenites remains unclear. It is possible that the eucrites and diogenites crystallized from separate partial melts, or that they are part of the same crystallization sequence either resulting from fractional crystallization of partial melts or a large-scale magma ocean. This research question is the main focus of this study.

2. The asteroid Vesta has similar surface mineralogy to the HED meteorites, suggesting that it may be the HED parent body. However there are a number of unexplored basaltic planetesimals in the asteroid belt that are also potential parent bodies. NASA has recently sent a space probe to the asteroid Vesta as part of the Dawn mission, which should provide important information about Vesta making it possible to confirm if it is the HED parent body (Russell et al., 2007).

\subsection{Structure of this thesis}

This thesis is structured into seven chapters:

1. An introduction that provides the background information for this study.

2. A chapter that presents the methods used in order to determine the major element, trace element and $\mathrm{Mg}$ isotopic compositions of the eucrite meteorites analysed in this study.

3. A description of the suite of samples, including the petrographic features and the major element composition of each sample.

4. The trace element chemistry of each sample.

5. Mg isotope data and model ages of the studied eucrites.

6. A discussion chapter where the major element, trace element and 
$\mathrm{Mg}$ isotopic compositions are used to constrain the timing and nature of processes occurring on the HED parent body in the early solar system.

7. A brief conclusion that summarizes the main findings of this study and provides suggestions for future work. 


\section{Chapter 2}

\section{Methods}

Twenty-three eucrite meteorites were used in this study, the majority of which were obtained on request from NASA's Antarctic meteorite collection.

\subsection{Major and trace element measurements}

\subsubsection{Sample preparation}

Fragments of each meteorite sample weighing 100-200 mg were mounted in blocks of epoxy resin and polished. Prior to major element analysis by electron probe microanalysis (EPMA), sample mounts were coated with a thin (25 nm) film of carbon (Reed, 2005). Following major element analysis, the carbon coatings were removed using methanol, and mounts were then cut in half for analysis by laser ablation inductively coupled plasma mass spectrometry (LA-ICP-MS).

\subsubsection{Major element measurements}

Major element compositions of pyroxene and plagioclase were determined by EPMA using a JEOL JXA-8230 Superprobe. Analyses were performed using an accelerating voltage of $15 \mathrm{kV}$, a beam current of $12 \mathrm{nA}$ and a focused beam (spot size $<0.5 \mu \mathrm{m}$ ). 
Measured X-ray intensities in pyroxene analyses were calibrated against elemental concentrations by analysis of the standards Natural Bridge diopside (NMNH 117733) ( $\mathrm{Ca}, \mathrm{Mg}, \mathrm{Si})$, Johnstown hypersthene (USNM 746) (Al, Fe), Kakanui augite (NMNH 122142) (Ti, Na) and pure synthetic oxides ( $\mathrm{Cr}, \mathrm{Mn})$. Johnstown hypersthene and Natural Bridge diopside were also used as secondary standards and measured repeatedly throughout the analytical sessions (Table 2.1).

Elemental concentrations in plagioclase were calibrated by analysis of Plagioclase (Labradorite) Lake County, OR (NMNH 115900) (Na, Si, Al, $\mathrm{Ca})$, Orthoclase Or-1a (K), and pure synthetic oxides (Ti, Mg, Fe, Mn). The plagioclase standard was also analysed throughout the session as a secondary standard (Table 2.1). Measurements of secondary standards are within error of the reference values for most elements, particularly the high concentration elements for which more robust measurements can be made (Table 2.1).

\subsubsection{Trace element measurements}

Trace elements measurements were performed using an Agilent 7500cs ICP-MS coupled to a New Wave deep UV laser that operates at a wavelength of $193 \mathrm{~nm}$. Pyroxene and plagioclase were each analysed 10-15 times per sample, as close as possible to EPMA analytical sites. Each analysis comprised $90 \mathrm{~s}$ of background measurement followed by $60 \mathrm{~s}$ of sample ablation. For pyroxene analyses, the BCR-2G glass standard (GeoRem, 2010) was used as a bracketing standard and measured before and after every five sample analyses. Analyses of the BHVO-2G glass standard were used as a secondary standard (Table 2.2). Plagioclase analyses were bracketed with measurements of the NIST612 glass standard (GeoRem, 2010) before and after every five sample measurements, and the ATHO-G glass standard (GeoRem, 2010) was used as a secondary standard (Table 2.2).

Trace element data reduction was carried out with the software iolite using the "trace element IS" data reduction scheme (Paton et al., 2011). Any laser ablation or instrumentally induced trace element fractionation 
Table 2.1: Major element compositions measured in the secondary standards: Plagioclase (Labradorite) Lake County, OR; Natural Bridge diopside and Johnstown hypersthene, and reference values for these standards. Reference values taken from Jarosewich et al. (1980).

\begin{tabular}{lcccc}
\hline & \multicolumn{3}{c}{$\begin{array}{c}\text { Plagioclase (Labradorite) Lake County, OR } \\
(\mathrm{n}=22)\end{array}$} \\
\cline { 2 - 5 } & $\begin{array}{c}\text { average } \\
\text { (wt \%) }\end{array}$ & 2 s.d. & $\begin{array}{c}\text { ref. values } \\
\text { (wt \%) }\end{array}$ & $\begin{array}{c}\text { difference } \\
\%\end{array}$ \\
\hline $\mathrm{SiO}_{2}$ & 50.79 & 1.93 & 51.25 & -0.9 \\
$\mathrm{TiO}_{2}$ & 0.05 & 0.05 & 0.05 & 3.1 \\
$\mathrm{Al}_{2} \mathrm{O}_{3}$ & 30.56 & 1.36 & 30.91 & -1.1 \\
$\mathrm{FeO}$ & 0.45 & 0.05 & 0.46 & -0.7 \\
$\mathrm{MnO}$ & 0.01 & 0.02 & 0.01 & -1.2 \\
$\mathrm{MgO}$ & 0.15 & 0.04 & 0.14 & 3.7 \\
$\mathrm{CaO}$ & 13.62 & 0.16 & 13.64 & -0.2 \\
$\mathrm{Na} \mathrm{O}_{2} \mathrm{O}$ & 3.42 & 0.17 & 3.45 & -0.8 \\
$\mathrm{~K}_{2} \mathrm{O}$ & 0.19 & 0.05 & 0.18 & 4.7 \\
$\mathrm{Total}$ & 99.24 & 3.34 & 100.09 & -0.8 \\
\hline \hline
\end{tabular}

Natural Bridge diopside $(n=39)$

\begin{tabular}{lcccc}
\cline { 2 - 5 } & $\begin{array}{c}\text { average } \\
\text { (wt \%) }\end{array}$ & 2 s.d. & $\begin{array}{c}\text { ref. values } \\
\text { (wt \%) }\end{array}$ & $\begin{array}{c}\text { difference } \\
\%\end{array}$ \\
\hline $\mathrm{SiO}_{2}$ & 54.76 & 0.85 & 54.87 & -0.2 \\
$\mathrm{TiO}_{2}$ & 0.01 & 0.02 & & \\
$\mathrm{Al}_{2} \mathrm{O}_{3}$ & 0.24 & 0.20 & 0.11 & 121.0 \\
$\mathrm{Cr}_{2} \mathrm{O}_{3}$ & 0.00 & 0.02 & & \\
$\mathrm{FeO}$ & 0.23 & 0.08 & 0.24 & -4.6 \\
$\mathrm{MnO}$ & 0.03 & 0.03 & 0.04 & -32.4 \\
$\mathrm{MgO}$ & 18.58 & 0.33 & 18.30 & 1.5 \\
$\mathrm{Na} \mathrm{O}_{2} \mathrm{O}$ & 0.19 & 0.03 & 0.34 & -45.6 \\
$\mathrm{CaO}$ & 25.52 & 0.33 & 25.63 & -0.4 \\
Total & 99.56 & 1.21 & 99.29 & 0.3 \\
\hline \hline
\end{tabular}

Johnstown hypersthene $(n=23)$

\begin{tabular}{lcccc}
\cline { 2 - 5 } & $\begin{array}{c}\text { average } \\
\text { (wt \%) }\end{array}$ & 2 s.d. & $\begin{array}{c}\text { ref. values } \\
\text { (wt \%) }\end{array}$ & $\begin{array}{c}\text { difference } \\
\%\end{array}$ \\
\hline $\mathrm{SiO}_{2}$ & 53.76 & 0.60 & 54.09 & -0.6 \\
$\mathrm{TiO}_{2}$ & 0.06 & 0.02 & 0.16 & -59.9 \\
$\mathrm{Al}_{2} \mathrm{O}_{3}$ & 0.89 & 0.92 & 1.23 & -27.4 \\
$\mathrm{Cr}_{2} \mathrm{O}_{3}$ & 0.72 & 0.05 & 0.75 & -4.6 \\
$\mathrm{FeO}$ & 14.89 & 0.27 & 15.22 & -2.2 \\
$\mathrm{MnO}$ & 0.49 & 0.04 & 0.49 & 0.3 \\
$\mathrm{MgO}$ & 27.25 & 0.60 & 26.79 & 1.7 \\
$\mathrm{Na} \mathrm{O}_{2} \mathrm{O}$ & 0.02 & 0.02 & $<0.05$ & 0.0 \\
$\mathrm{CaO}$ & 1.28 & 0.05 & 1.52 & -15.6 \\
$\mathrm{Total}$ & 99.36 & 0.87 & 100.25 & -0.9 \\
\hline \hline
\end{tabular}


was corrected using the bracketed standard measurements of the respective glass standards (BCR-2G and NIST612). Bracketed standards were interpolated with the 'spline smooth auto' function, and a two standard deviation outlier rejection was used for all baselines and integrations. Background-corrected data were converted to absolute element concentrations using internal corrections based on mean $\mathrm{Si}$ concentrations for each sample and mineral phase previously measured by EPMA. Measurements of secondary standards are within error or close to the reference values for most of the measured elements (Table 2.2).

\section{2 $\mathrm{Mg}$ isotopes}

\subsubsection{Sample preparation for $\mathrm{Mg}$ isotope measurements}

All sample preparation, including digestion and ion exchange chromatography, was carried out in a class 10 laminar flow hood in a class 100 clean laboratory. Ultrapure Optima acids and $>18.2 \mathrm{M} \Omega$ water were used for cleaning, acid dilutions and sample digestions. Savillex Teflon beakers were used throughout the laboratory work.

Beakers were cleaned by fluxing in $6 \mathrm{M} \mathrm{HCl}$ for $24 \mathrm{~h}$, followed by fluxing in $7 \mathrm{M} \mathrm{HNO}_{3}$ for $24 \mathrm{~h}$, before being rinsed three times with ultrapure water. Following this, $1 \mathrm{~mL}$ of a concentrated $\mathrm{HF}-\mathrm{HNO}_{3}$ solution was fluxed in each beaker for $24 \mathrm{~h}$, after which each beaker was rinsed three times with ultrapure water. Then, $2 \mathrm{~mL}$ of $6 \mathrm{M} \mathrm{HCl}$ was fluxed in each beaker for $24 \mathrm{~h}$, before being rinsed three times with ultrapure water, and dried ready for use.

Any obviously altered surfaces were removed from meteorite samples using an agate mortar and pestle, in order to ensure that the digested samples were unaltered. A 100-200 mg piece of each meteorite was then selected for digestion. Given that the maximum grain size in the samples is $2000 \mu \mathrm{m}$, chips of this size are likely to be broadly representative of each sample. The sample chips were rinsed in ethanol and placed in $10 \mathrm{~mL}$ of $0.05 \mathrm{M} \mathrm{HNO}_{3}$ in an ultrasonic bath for $5 \mathrm{~min}$ for cleaning prior to digestion. 
Table 2.2: Trace element compositions of secondary standards BHVO-2G and ATHO-G measured in this study, and reference values for the same standards. Reference values taken from GeoRem (2010).

\begin{tabular}{|c|c|c|c|c|c|c|c|c|c|}
\hline & \multicolumn{4}{|c|}{ BHVO-2G $(n=15)$} & & \multicolumn{4}{|c|}{ ATHO-G $(n=15)$} \\
\hline & $\begin{array}{c}\text { average } \\
(\mathrm{ppm})\end{array}$ & 2 s.d. & $\begin{array}{l}\text { ref. values } \\
(\mathrm{ppm})\end{array}$ & $\begin{array}{c}\text { difference } \\
\% \\
\end{array}$ & & $\begin{array}{c}\text { average } \\
(\mathrm{ppm})\end{array}$ & 2 s.d. & $\begin{array}{l}\text { ref. values } \\
(\mathrm{ppm})\end{array}$ & $\begin{array}{c}\text { difference } \\
\%\end{array}$ \\
\hline $\mathrm{Li}$ & 4.38 & 0.32 & 4.40 & -0.4 & $\mathrm{Li}$ & 36.16 & 1.29 & 28.60 & -20.9 \\
\hline $\mathrm{Na}$ & 16718 & 482 & 17805 & -6.1 & $\mathrm{Na}$ & 38003 & 1296 & 27820 & -26.8 \\
\hline $\mathrm{Mg}$ & 38818 & 876 & 42996 & -9.7 & $\mathrm{Mg}$ & 798.8 & 22.6 & 621.1 & -22.2 \\
\hline Al & 64128 & 674 & 71978 & -10.9 & $\mathrm{Al}$ & 82442 & 2875 & 64569 & -21.7 \\
\hline Sc & 27.56 & 0.96 & 33.00 & -16.5 & $\mathrm{Ti}$ & 1893.8 & 49.7 & 1021.7 & -46.1 \\
\hline $\mathrm{Ti}$ & 15571 & 246 & 11178 & 39.3 & $\mathrm{Mn}$ & 887.1 & 40.0 & 820.9 & -7.5 \\
\hline v & 316.2 & 4.81 & 308.0 & 2.7 & $\mathrm{Rb}$ & 72.46 & 2.89 & 65.30 & -9.9 \\
\hline $\mathrm{Cr}$ & 307.9 & 13.26 & 293.0 & 5.1 & $\mathrm{Sr}$ & 96.89 & 3.89 & 94.10 & -2.9 \\
\hline $\mathrm{Mn}$ & 1282 & 26 & 1317 & -2.7 & $\mathrm{Ba}$ & 580.0 & 28.43 & 547.0 & -5.7 \\
\hline Co & 44.3 & 1.93 & 44.0 & 0.6 & La & 57.91 & 2.76 & 55.60 & -4.0 \\
\hline $\mathrm{Ni}$ & 121.8 & 9.77 & 116.0 & 5.0 & $\mathrm{Ce}$ & 133.8 & 5.75 & 121.0 & -9.5 \\
\hline $\mathrm{Cu}$ & 158.1 & 31.57 & 127.0 & 24.5 & $\operatorname{Pr}$ & 14.95 & 0.74 & 14.60 & -2.3 \\
\hline $\mathrm{Zn}$ & 93.4 & 2.43 & 102.0 & -8.5 & $\mathrm{Nd}$ & 65.33 & 2.94 & 60.90 & -6.8 \\
\hline $\mathrm{Rb}$ & 8.95 & 0.47 & 9.20 & -2.8 & $\mathrm{Sm}$ & 15.45 & 0.75 & 14.20 & -8.1 \\
\hline $\mathrm{Sr}$ & 369.9 & 7.93 & 396.0 & -6.6 & $\mathrm{Eu}$ & 2.79 & 0.18 & 2.76 & -1.0 \\
\hline $\mathrm{Zr}$ & 143.1 & 4.19 & 170.0 & -15.8 & $\mathrm{Gd}$ & 15.73 & 1.32 & 15.30 & -2.8 \\
\hline $\mathrm{Ba}$ & 125.2 & 1.92 & 131.0 & -4.4 & & & & & \\
\hline La & 13.55 & 0.36 & 15.20 & -10.9 & & & & & \\
\hline $\mathrm{Ce}$ & 36.35 & 1.22 & 37.60 & -3.3 & & & & & \\
\hline $\operatorname{Pr}$ & 4.83 & 0.20 & 5.35 & -9.6 & & & & & \\
\hline $\mathrm{Nd}$ & 22.0 & 0.90 & 24.5 & -10.3 & & & & & \\
\hline $\mathrm{Sm}$ & 5.52 & 0.55 & 6.10 & -9.6 & & & & & \\
\hline $\mathrm{Eu}$ & 1.88 & 0.21 & 2.07 & -9.4 & & & & & \\
\hline Gd & 5.53 & 0.51 & 6.16 & -10.3 & & & & & \\
\hline $\mathrm{Tb}$ & 0.76 & 0.07 & 0.92 & -17.4 & & & & & \\
\hline Dy & 4.51 & 0.35 & 5.28 & -14.6 & & & & & \\
\hline Ho & 0.82 & 0.11 & 0.98 & -16.8 & & & & & \\
\hline $\mathrm{Er}$ & 2.13 & 0.23 & 2.56 & -16.8 & & & & & \\
\hline $\mathrm{Tm}$ & 0.26 & 0.05 & 0.34 & -22.4 & & & & & \\
\hline $\mathrm{Yb}$ & 1.78 & 0.16 & 2.01 & -11.4 & & & & & \\
\hline Lu & 0.23 & 0.03 & 0.28 & -19.3 & & & & & \\
\hline $\mathrm{Hf}$ & 3.57 & 0.42 & 4.32 & -17.3 & & & & & \\
\hline$w$ & 0.21 & 0.10 & 0.23 & -10.7 & & & & & \\
\hline
\end{tabular}


The samples were digested, along with two USGS basaltic rock standards (BHVO-2 and BCR-2) in concentrated $\mathrm{HF}-\mathrm{HNO}_{3}(3: 1)$ at a temperature of $120^{\circ} \mathrm{C}$. Following this, samples were refluxed repeatedly in concentrated $\mathrm{HNO}_{3}$ and $\mathrm{HCl}$ acids, before a final reflux in aqua regia, in order to ensure that the samples were completely dissolved. All samples were visually inspected during these latter digestion steps to ensure that no material remained undigested. Two procedural blanks also went through the digestion process and the subsequent $\mathrm{Mg}$ separation process.

\subsubsection{Chemical separation of $\mathrm{Mg}$}

The procedures for chemical separation of $\mathrm{Mg}$ from eucrites samples were carried out using a modified version of the method reported by Bizzarro et al. (2011) as described below. Mg was separated from elements that may result in isobaric interferences during isotope measurements, such as ${ }^{48} \mathrm{Ca}$, ${ }^{48} \mathrm{Ti},{ }^{50} \mathrm{Ti},{ }^{50} \mathrm{~V},{ }^{50} \mathrm{Cr}$ and ${ }^{52} \mathrm{Cr}$, and elements such as $\mathrm{Al}, \mathrm{Fe}, \mathrm{Na}, \mathrm{Ni}$ and $\mathrm{Ca}$, which may affect instrumental mass bias (Bizzarro et al., 2011). Following digestion, an aliquot of each of the digested samples was evaporated to dryness and redissolved in $6 \mathrm{M} \mathrm{HCl}$. A volume of this solution equivalent to $2.5-5.0 \mathrm{mg}$ of digested sample was sequentially loaded onto several ion exchange or extraction chromatographic columns for $\mathrm{Mg}$ separation as listed below.

\section{Step 1: Removal of Fe}

The sample was passed through a $1.25 \mathrm{~mL}$ pipette tip column loaded with $0.5 \mathrm{~mL}$ of AG1-X8 100-200 mesh anion exchange resin that had been cleaned with dilute $\mathrm{HCl}$ and pre-conditioned with $2 \mathrm{~mL}$ of $6 \mathrm{M} \mathrm{HCl}$. The sample matrix, including $\mathrm{Mg}$, was eluted from the column with $2 \mathrm{~mL}$ of $6 \mathrm{M} \mathrm{HCL}$, while Fe was retained on the column.

\section{Step 2: Removal of $\mathrm{Cr}, \mathrm{Na}, \mathrm{Al}$ and $\mathrm{Ti}$}

After drying down the $\mathrm{Mg}$ cut from step 1, this was dissolved in 100 $\mu \mathrm{L}$ of $6 \mathrm{M} \mathrm{HCl}$ and refluxed over night. Immediately prior to adding the sample to the columns, $1.9 \mathrm{~mL}$ of refrigerated ultrapure water was added to the $\mathrm{Mg}$ cut, diluting it to $2 \mathrm{~mL}$ of $0.5 \mathrm{M} \mathrm{HCl}$. The solution was then 
passed through a $10 \mathrm{~mL}$ Biorad cation exchange column loaded with $1 \mathrm{~mL}$ of Biorad AG50W-X8 200-400 mesh resin, that had been cleaned with alternating volumes of $6 \mathrm{M} \mathrm{HCl}$ and ultrapure water and conditioned with $4 \mathrm{~mL}$ of $0.5 \mathrm{M} \mathrm{HCl}$. Na and $\mathrm{Cr}$ were eluted with $3 \mathrm{~mL}$ of $0.5 \mathrm{M} \mathrm{HCl}$, followed by $4 \mathrm{~mL}$ of $1 \mathrm{M} \mathrm{HNO}_{3}$. Following this, $1 \mathrm{~mL}$ of ultrapure water was passed through the column, and $\mathrm{Al}$ and Ti were eluted with $2 \mathrm{~mL}$ of $1 \mathrm{M}$ HF. Finally, Mg was eluted and collected in $10 \mathrm{~mL}$ of $6 \mathrm{M} \mathrm{HCl}$.

Step 3: Removal of $\mathrm{Ca}$

After drying down the $\mathrm{Mg}$ cut from step 2, this was converted from chloride to nitrate form, and then dissolved in $1 \mathrm{~mL}$ of $3 \mathrm{M} \mathrm{HNO}_{3}$. This solution was passed through a $10 \mathrm{~mL}$ Biorad cation exchange column loaded with $1 \mathrm{~mL}$ of diglycolamide resin, which was cleaned with dilute $\mathrm{HCl}$ and conditioned with $4 \mathrm{~mL}$ of $3 \mathrm{M} \mathrm{HNO}_{3}$. After the $\mathrm{Mg}$ cut was loaded onto the columns a further $4 \mathrm{~mL}$ of $3 \mathrm{M} \mathrm{HNO}_{3}$ was used to elute $\mathrm{Mg}$, with $\mathrm{Ca}$ retained on the resin.

Step 4: Removal of $\mathrm{Ni}$

Columns loaded with $1 \mathrm{~mL}$ of Eichrom Ni-spec resin were cleaned with three column volumes of ultrapure water and conditioned with $4 \mathrm{~mL}$ of $0.2 \mathrm{M} \mathrm{NH}_{4}+0.1 \mathrm{M} \mathrm{HCl}$. The $\mathrm{Mg}$ cuts from the previous step were dissolved in $0.5 \mathrm{~mL}$ of $0.1 \mathrm{M} \mathrm{HCl}$, and $1.25 \mathrm{~mL}$ of ultrapure water and $0.25 \mathrm{~mL}$ of $1 \mathrm{M}$ $\mathrm{NH}_{4}$ were added to the solution, resulting in a solution with a $\mathrm{pH}$ of 9-10. This solution was loaded onto the columns, with Mg eluted in $4 \mathrm{~mL}$ of $0.2 \mathrm{M} \mathrm{NH}_{4}+0.1 \mathrm{M} \mathrm{HCl}$. A small amount of $6 \mathrm{M} \mathrm{HCl}$ was added to the $\mathrm{Mg}$ cuts before they were dried down. Once dried down, the $\mathrm{Mg}$ cuts were fluxed in $1 \mathrm{~mL}$ of aqua regia for at least $12 \mathrm{~h}$ before being evaporated again.

\section{Step 5: Removal of $M n$}

The evaporated $\mathrm{Mg}$ cut from step 4 was converted to chloride form and dissolved in $2 \mathrm{~mL}$ of $0.5 \mathrm{M} \mathrm{HCl}-95 \%$ acetone. This solution was passed through a column containing $1 \mathrm{~mL}$ of Biorad AG50W-X8 200-400 mesh resin, which had been pre-cleaned with alternate volumes of $6 \mathrm{M} \mathrm{HCl}$ and ultrapure water and conditioned with $4 \mathrm{~mL}$ of $0.5 \mathrm{M} \mathrm{HCl}-95 \%$ acetone. $\mathrm{Mn}$ was eluted with $4 \mathrm{~mL}$ of $0.5 \mathrm{M} \mathrm{HCl}-95 \%$ acetone and $\mathrm{Mg}$ was collected in 
$10 \mathrm{~mL}$ of $6 \mathrm{M} \mathrm{HCl}$.

Step 6: A repeat of step 2

Finally, step 2 was repeated on the $\mathrm{Mg}$ cuts to ensure complete $\mathrm{Al}$ removal, as well as removal of any $\mathrm{Na}$ that may have been introduced as blank during the previous steps. After this final separation step, the $\mathrm{Mg}$ cuts were converted to nitrate form in preparation for analysis.

This chemical separation process ensures $99.9 \%$ recovery of $\mathrm{Mg}$ of a high a degree of purity. The full procedural blanks were $<15 \mathrm{ng}$, which is negligible compared to the amount of $\mathrm{Mg}$ processed and recovered ( $>200$ $\mu \mathrm{g})$. The ratios of $\mathrm{Fe} / \mathrm{Mg}, \mathrm{Na} / \mathrm{Mg}, \mathrm{Ti} / \mathrm{Mg}, \mathrm{Cr} / \mathrm{Mg}, \mathrm{V} / \mathrm{Mg}$ and $\mathrm{Al} / \mathrm{Mg}$ observed in the separated $\mathrm{Mg}$ cuts were typically $<0.0001$ and therefore do not affect the quality of the obtained $\mathrm{Mg}$ isotope data.

\subsubsection{Measurement of Mg isotopes by MC-ICP-MS}

High precision $\mathrm{Mg}$ isotope measurements were made using a ThermoFisher Neptune multiple-collector inductively coupled plasma mass spectrometer (MC-ICP-MS) at the Centre for Star and Planet Formation, Natural History Museum of Denmark, University of Copenhagen, using a modified version of the method outlined in Bizzarro et al. (2011). In preparation for measurement, the chemically separated $\mathrm{Mg}$ cuts were dissolved in $2 \% \mathrm{HNO}_{3}$, before being introduced into the plasma source with an Apex IR desolvating nebulizer combined with an ACM unit for additional membrane desolvation. Measurements were made in medium resolution mode, allowing for the resolution of molecular interferences on the high mass side of $\mathrm{Mg}$. The low-3, axial and high-3 Faraday collectors were used to measure ${ }^{26} \mathrm{Mg}$, ${ }^{25} \mathrm{Mg}$ and ${ }^{24} \mathrm{Mg}$, respectively, with the $\mathrm{Mg}$ isotope data acquired in static mode. A $10^{10} \Omega$ resistor was used on the low- 3 collector, while the axial and high-3 collectors were both equipped with $10^{11}$ $\Omega$ resistors.

Samples and standards were all analysed at a signal intensity of at least $100 \mathrm{~V}$ on mass ${ }^{24} \mathrm{Mg}$. Each analysis comprised a total of $630 \mathrm{~s}$ of baseline measurements, followed by 1667 s of data acquisition (100 scans integrated 
Table 2.3: Mg isotope compositions (in \%o) of the secondary standard BHVO-2 as measured in this study and by Schiller et al. (2010) and Bizzarro et al. (2011).

\begin{tabular}{lcccccc}
\hline BHVO-2 & $\delta^{25} \mathrm{Mg}$ & 2 s.e. & $\delta^{26} \mathrm{Mg}$ & 2 s.e. & $\delta^{26} \mathrm{Mg}^{*}$ & 2 s.e. \\
\hline This study & -0.133 & 0.020 & -0.252 & 0.038 & -0.0015 & 0.0010 \\
Bizzarro et al. (2011) & -0.101 & 0.009 & -0.189 & 0.023 & -0.0004 & 0.0012 \\
Schiller et al. (2010) & -0.153 & 0.049 & -0.300 & 0.095 & -0.0017 & 0.0044 \\
\hline
\end{tabular}

over $16.67 \mathrm{~s}$. An 8 min rinse was carried out between all analyses. Sample analyses were bracketed with analyses of the DTS-2 standard to monitor instrumental mass fractionation, and each sample was analyzed 10 times, resulting in the consumption of $10-20 \mu \mathrm{g}$ of $\mathrm{Mg}$ per sample. Mg separated from the BHVO-2 standard was measured and compared to measurements made by Schiller et al. (2010) and Bizzarro et al. (2011), to verify the quality of the $\mathrm{Mg}$ isotope analyses (Table 2.3). The measurements of BHVO-2 are within error of those made by Schiller et al. (2010) and Bizzarro et al. (2011) (Table 2.3). Mg isotope ratios are expressed as the per mil (\%) deviations from the mean $\mathrm{Mg}$ isotopic composition measured on the bracketing standards (DTS-2 standard):

$$
\delta^{x} M g=\left[\frac{\left(\frac{x M g}{24 M g}\right)_{\text {sample }}}{\left(\frac{x M g}{24 M g}\right)_{\text {standard }}}-1\right] \times 10^{3}
$$

\subsubsection{Measurement of ${ }^{27} \mathrm{Al} /{ }^{24} \mathrm{Mg}$ ratios}

${ }^{27} \mathrm{Al} /{ }^{24} \mathrm{Mg}$ ratios were measured using a Thermo X-series 2 ICP-MS at the Centre for Star and Planet Formation, Natural History Museum of Denmark, University of Copenhagen. Aliquots of digested samples were diluted in $2 \% \mathrm{HNO}_{3}$ to a $\mathrm{Mg}$ concentration of approximately $250 \mathrm{ppb}$ for analysis. A gravimetrically prepared solution with an ${ }^{27} \mathrm{Al} /{ }^{24} \mathrm{Mg}$ ratio of 1.0 was prepared from Aristar single element ICP-MS solutions and used as the bracketing standard. This standard solution was measured before and after every five sample analyses. ${ }^{27} \mathrm{Al} /{ }^{24} \mathrm{Mg}$ ratios in BHVO-2 and BCR-2 were also measured, and were within estimated uncertainties of 
Table 2.4: ${ }^{27} \mathrm{Al} /{ }^{24} \mathrm{Mg}$ ratios measured in the secondary standards BCR-2 and BHVO-2 and reference values for these standards. Reference values taken from GeoRem (2010).

\begin{tabular}{lcccc}
\hline & $\begin{array}{c}\text { measured } \\
{ }^{27} \mathrm{Al} /{ }^{24} \mathrm{Mg}\end{array}$ & 2 s.e. & $\begin{array}{c}\text { reference } \\
{ }^{27} \mathrm{Al} /{ }^{24} \mathrm{Mg}\end{array}$ & $\begin{array}{c}\text { difference } \\
\%\end{array}$ \\
\hline BCR-2 & 3.82 & 0.009 & 3.76 & 1.65 \\
BHVO-2 & 1.78 & 0.004 & 1.87 & -4.96 \\
\hline
\end{tabular}

reference values for these standards (Table 2.4). 


\section{Chapter 3}

\section{Petrology and mineral chemistry}

In order to investigate the evolution of the crust of the HED parent body, it is important that the eucrites chosen for this study encompassed a range of geochemical compositions that reflect varying degrees of magmatic evolution. To this end, a range of samples were selected for this study on the basis of their pyroxene ferrosilite (Fs) content, which ranges from $12-65 \%$ (the least and most evolved compositions, respectively). Weathering grades of $\mathrm{A}, \mathrm{B}$ and $\mathrm{C}$ are assigned to Antarctic meteorites by the Meteorite Working group at the Johnson Space Centre to denote the degree of terrestrial alteration of each meteorite, with the official definitions being as follows:

A: Minor rustiness $=$ rust haloes on metal particles and rust stains along fractures are minor.

B: Moderate rustiness $=$ large rust haloes occur on metal particles and rust stains on internal fractures are extensive.

C: Severe rustiness $=$ metal particles have been mostly stained by rust throughout.

e: Evaporite minerals visible to the naked eye (added to the above grades). 


\subsection{Sample petrology}

Twenty-three eucrites were selected for study. Nineteen of these were requested from the NASA Antarctic meteorite collection and the other four samples are well characterised and widely available eucrites (Dhofar 007, Camel Donga, Juvinas and Millbillillie). With the exception of Dhofar 007, all of the studied eucrites are non-cumulates, and the majority are brecciated. The key characteristics of each studied eucrite are outlined in Table 3.1. and backscattered electron images of each sample are shown in Fig. 3.1 .

\section{Polymict eucrites}

EET 83227 is the only eucrite that is classified as being polymict, meaning that it contains some diogenitic material ( $<10$ vol.\%). This sample has a weathering grade of $\mathrm{A}$, and is relatively fine grained with a maximum grain size of $200 \mu \mathrm{m}$. EET 83227 has a heavily brecciated texture with larger pyroxene and plagioclase clasts set in a comminuted matrix of the same material. The pyroxene in this sample exhibits simple zoning and exsolution lamallae that are $<10 \mu \mathrm{m}$ in width.

\section{Mg-rich eucrites}

There are two Mg-rich eucrites in the sample suite (EET 87548 and LEW 87002), which have weathering grades of $\mathrm{B} / \mathrm{C}$ and $\mathrm{A}$, respectively. EET 87548 contains pyroxene with exsolution lamallae that have a maximum width of $50 \mu \mathrm{m}$, whilst LEW 87002 shows no pyroxene exsolution. LEW87002 has a high proportion of pyroxene to plagioclase (5:1) and a maximum grain size of $1800 \mu \mathrm{m}$. EET 87548 contains approximately twice as much pyroxene as plagioclase, and has a maximum grain size of 1500 $\mu \mathrm{m}$. 


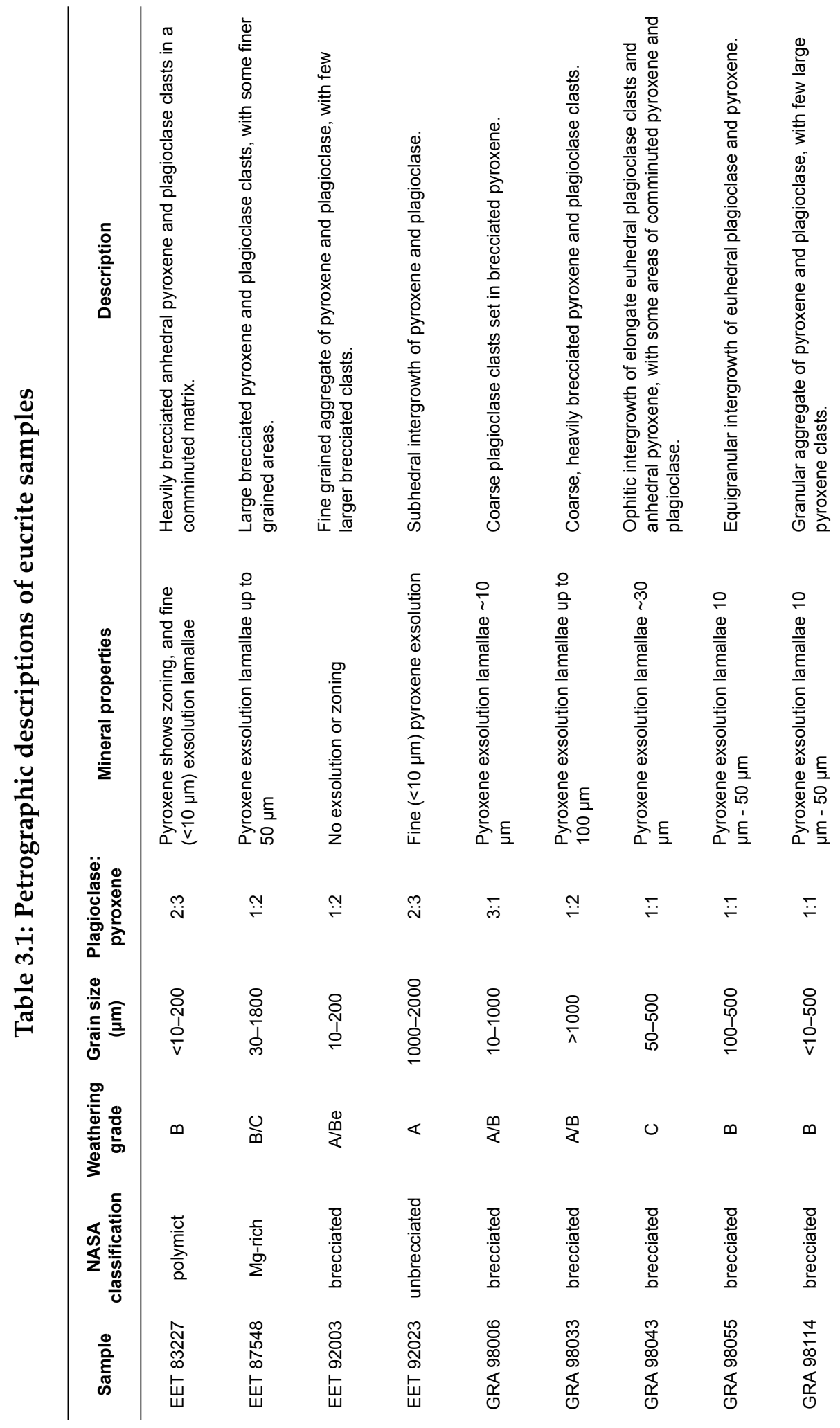




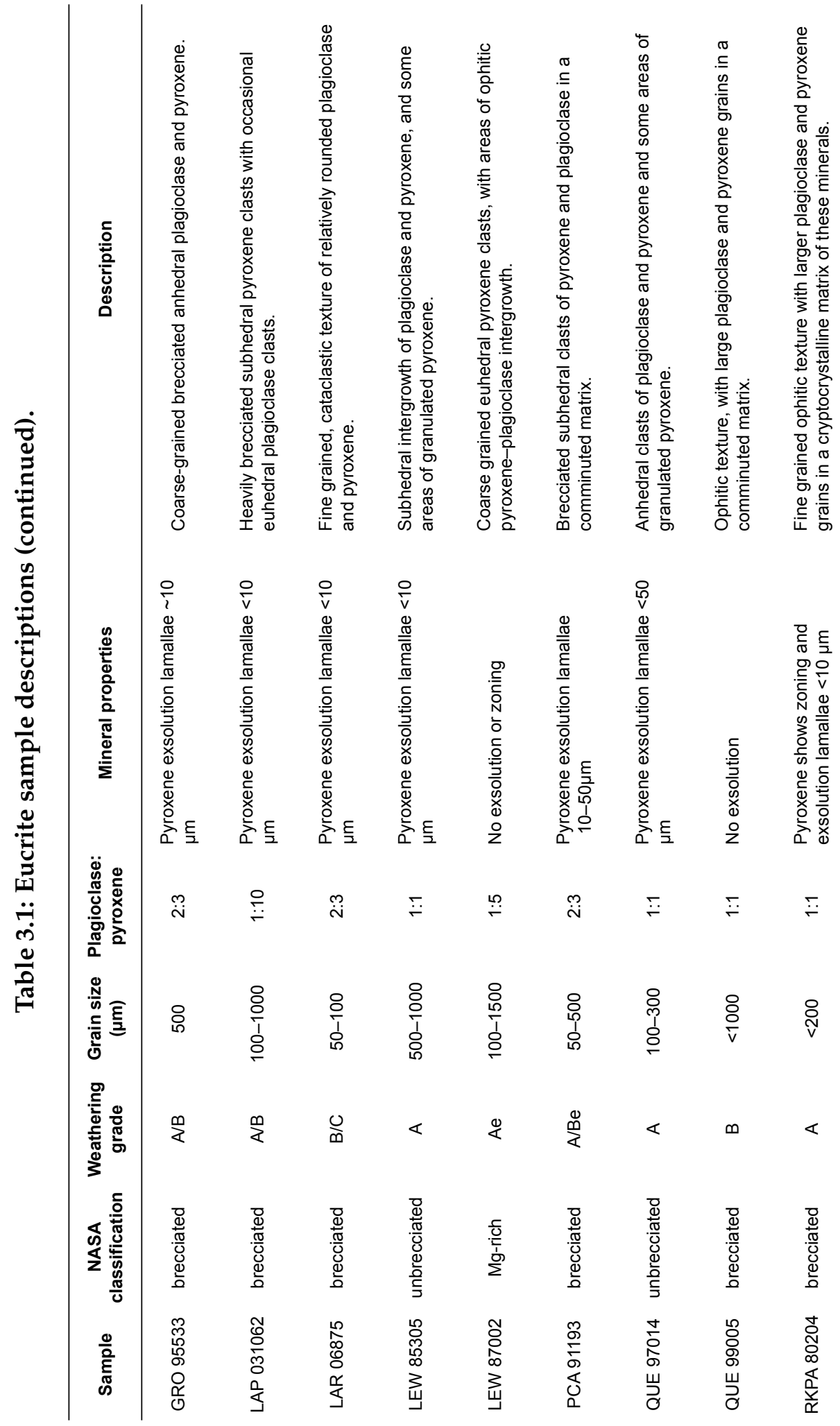




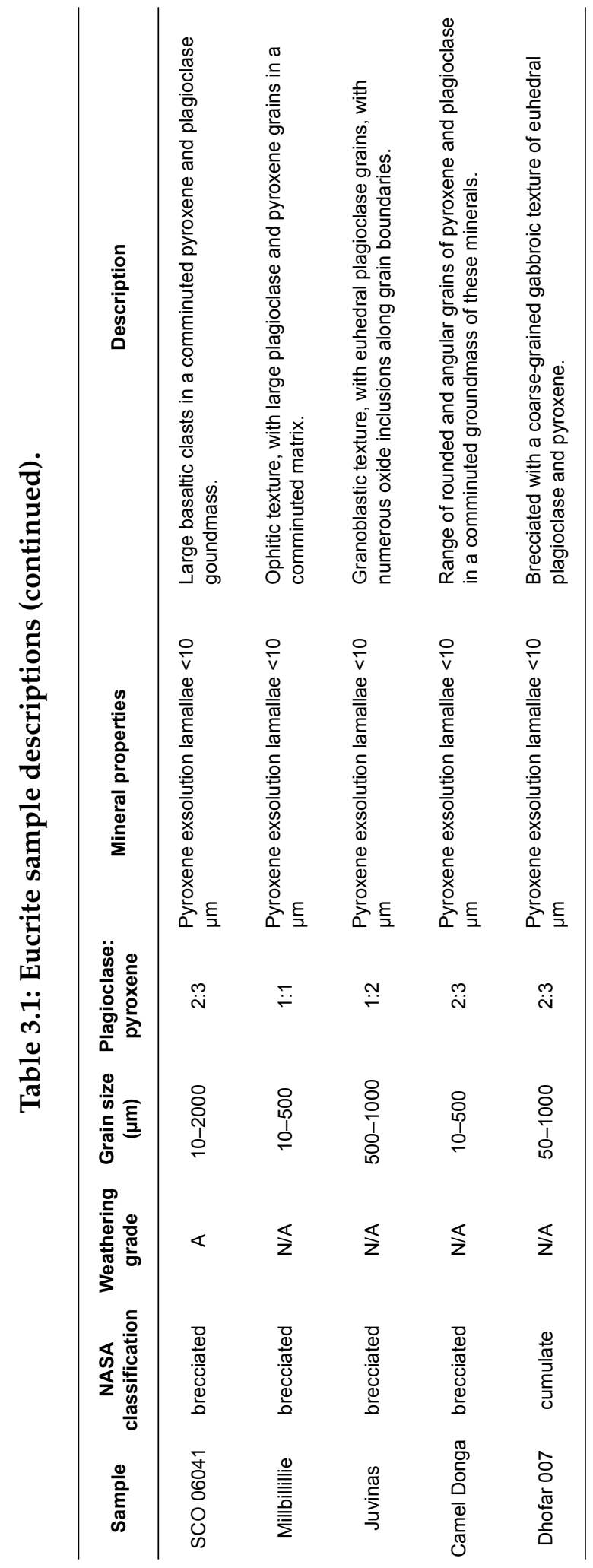




\section{Brecciated eucrites}

Brecciated eucrites comprise the majority of the sample suite, with weathering grades ranging from $\mathrm{A}-\mathrm{C}$. The maximum grain size of samples in this group ranges from $100 \mu \mathrm{m}$ (LAR 06875) through to $2000 \mu \mathrm{m}$ (SCO 06041), although most of the samples have a maximum grain size of 500-1000 $\mu \mathrm{m}$. Apart from two samples (EET 92003 and QUE 99005), the brecciated eucrites exhibit pyroxene exsolution lamallae, which range in maximum width from 10-100 $\mu \mathrm{m}$. The degree of brecciation and textural nature is variable amongst this group of eucrites. Most of the brecciated eucrites have equal or sub-equal proportions of pyroxene and plagioclase, with the exception of LAP 031062, which is almost exclusively comprised of pyroxene.

\section{Unbrecciated eucrites}

There are three unbrecciated eucrites in the sample suite, which all have a weathering grade of $\mathrm{A}$. All the unbrecciated eucrites exhibit pyroxene exsolution lamallae, with maximum widths ranging from 10-50 $\mu \mathrm{m}$. EET 92023 has the largest grain size of all the eucrite samples, and QUE 97014 is relatively fine grained, with a maximum grain size of $300 \mu \mathrm{m}$. LEW 85305 and EET 92023 have very similar textures comprising subhedral intergrowths of pyroxene and plagioclase crystals, whereas QUE97014 does not show this distinctive intergrown texture and contains some individual brecciated clasts.

\section{Cumulate eucrites}

Dhofar 007 is the only cumulate eucrite in the eucrite suite. Like most cumulate eucrites, Dhofar 007 has a coarse-grained gabbroic texture, with a maximum grain size of $1000 \mu \mathrm{m}$, and slightly more modal pyroxene than plagioclase (3:2). Pyroxene exsolution lamallae are all $<10 \mu \mathrm{m}$ in width. 


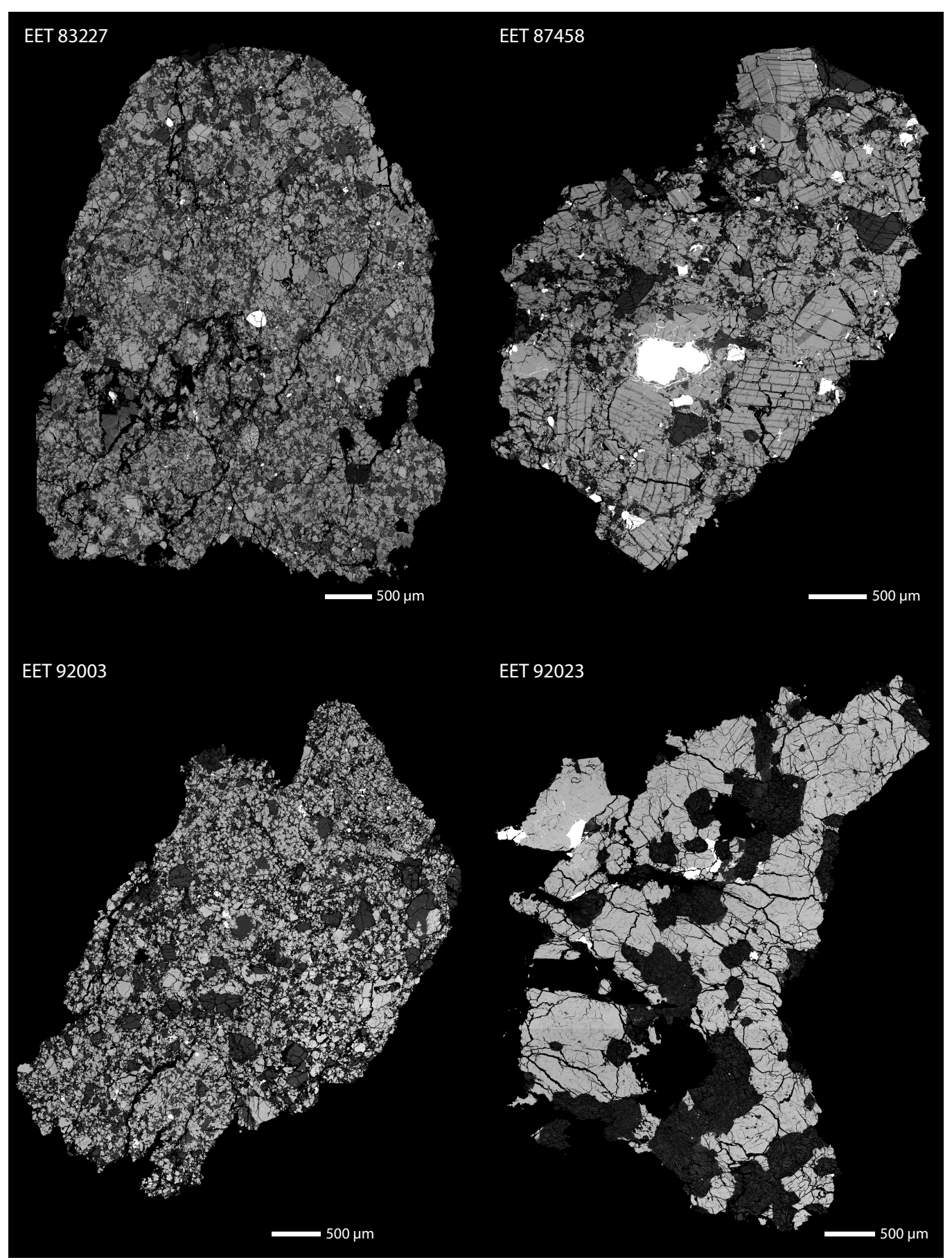

Figure 3.1: Back-scattered electron images of the studied eucrite samples 


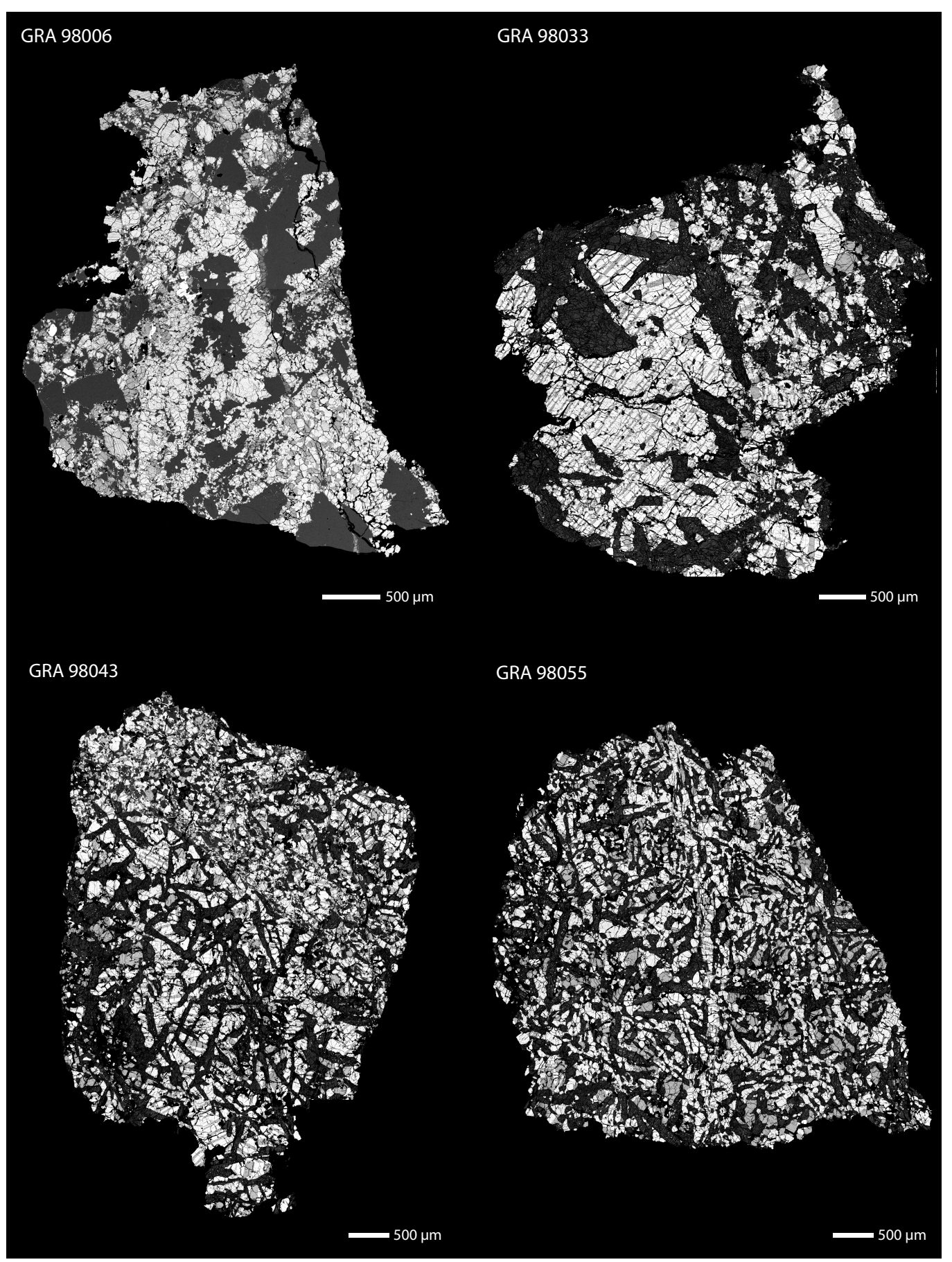

Figure 3.1: Back-scattered electron images of the studied eucrite samples (continued). 


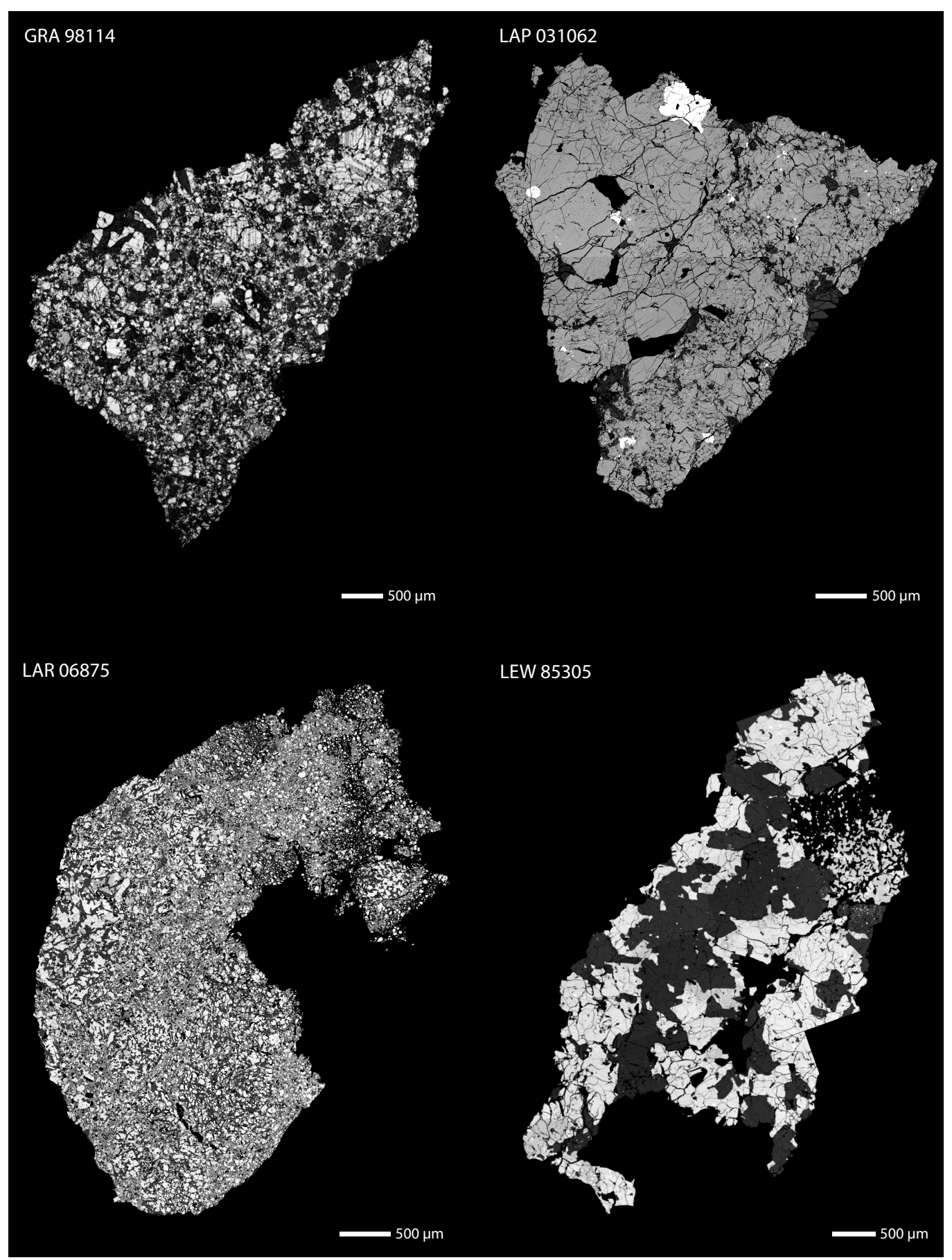

Figure 3.1: Back-scattered electron images of the studied eucrite samples (continued). 


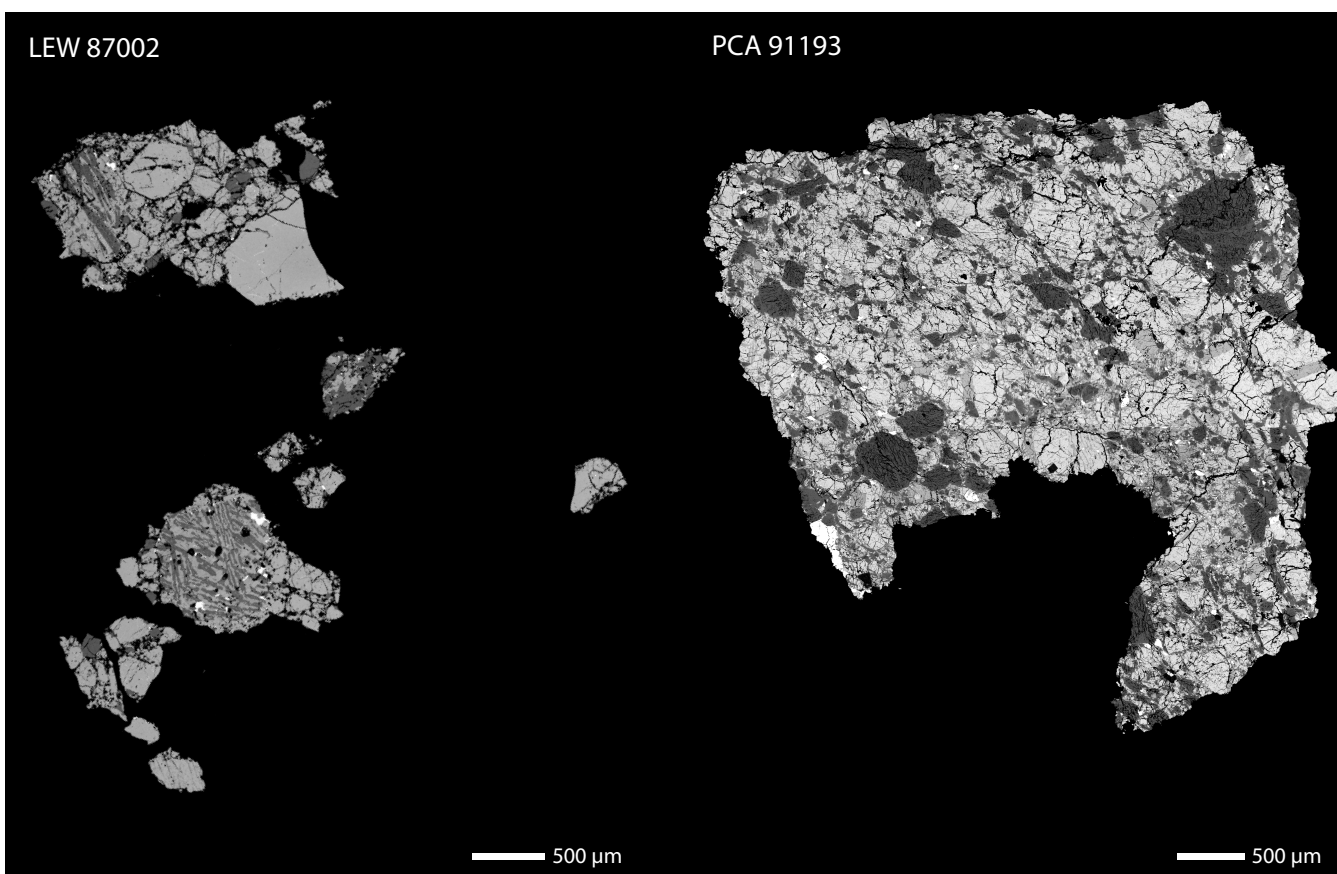

QUE 97014

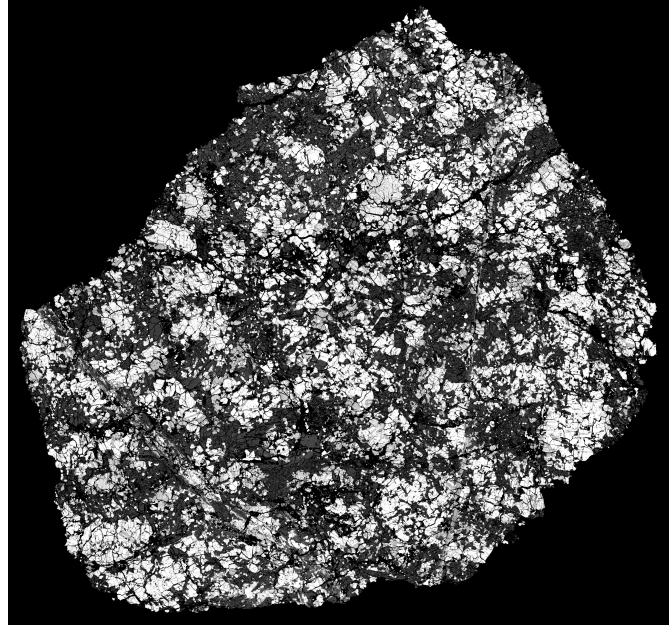

Figure 3.1: Back-scattered electron images of the studied eucrite samples (continued). 


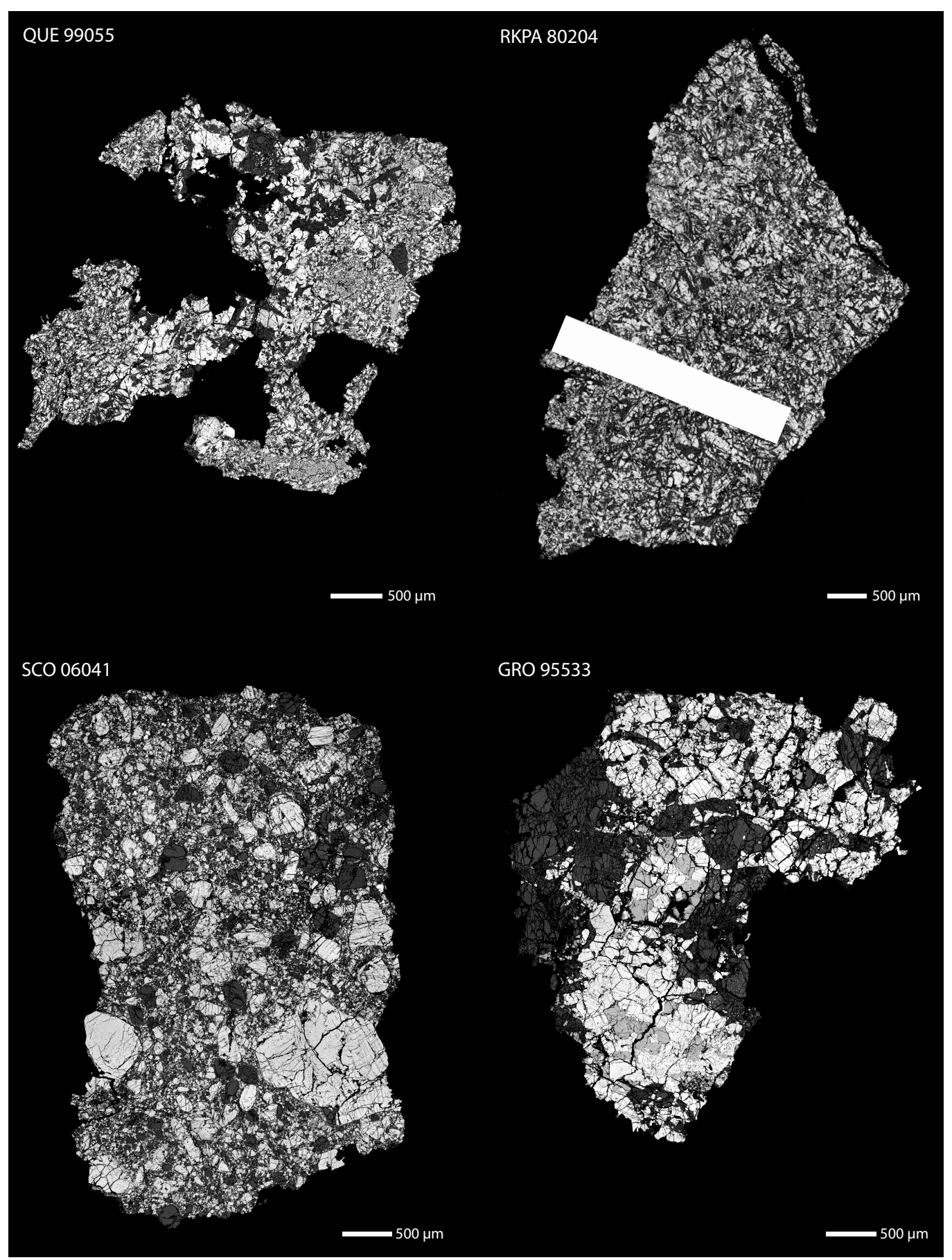

Figure 3.1: Back-scattered electron images of the studied eucrite samples (continued). 


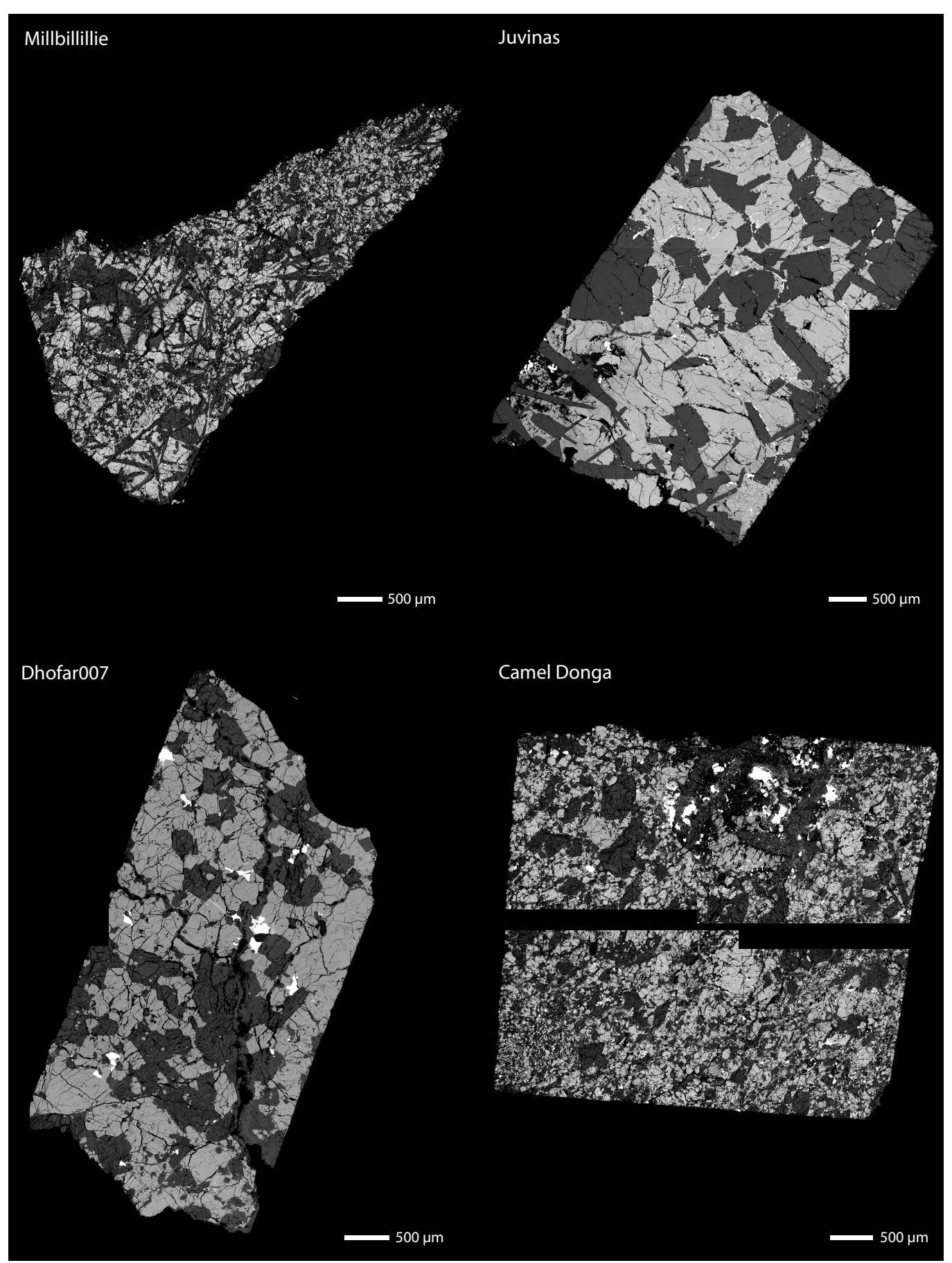

Figure 3.1: Back-scattered electron images of the studied eucrite samples (continued). 

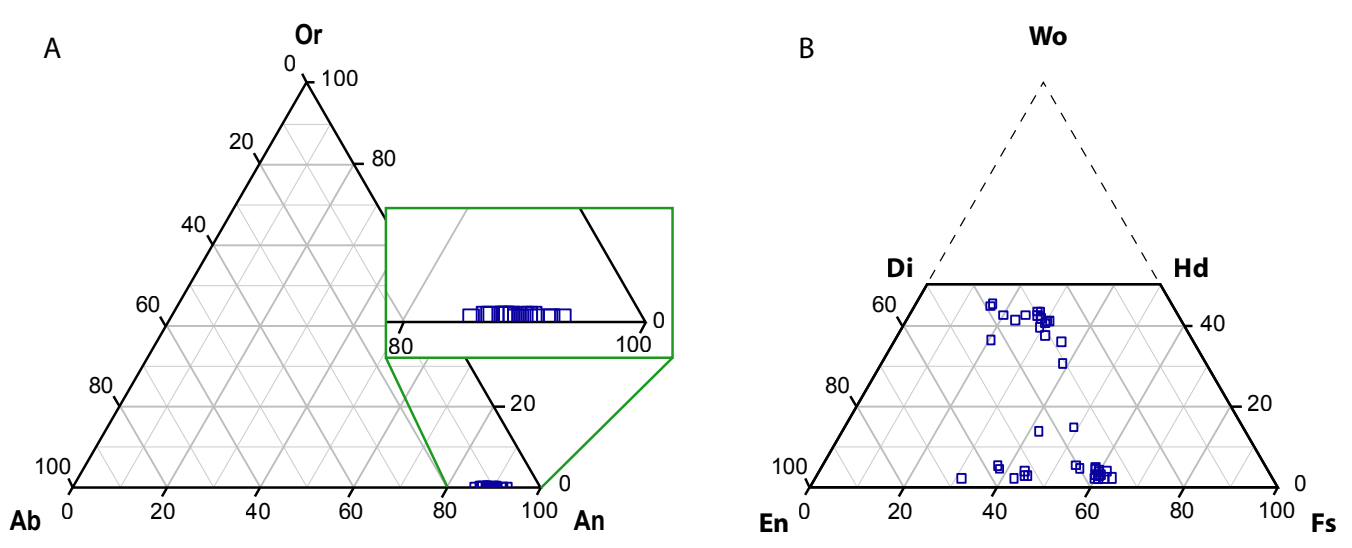

Figure 3.2: Ternary diagrams showing (A) plagioclase and (B) pyroxene mineral compositions in the studied eucrite samples.

\subsection{Mineral chemistry}

This chapter presents summarized major element data, the full data set can be found in Appendix A. The eucrite samples predominantly comprise plagioclase and high- and low-Ca pyroxene ( $>90$ vol. $\%$ ), with lesser amounts of chromite, ilmenite, troilite and Fe-Ni metal. As such, this study focused on the mineral chemistry of plagioclase and both types of pyroxene. However, samples EET 92003, EET 92023, LEW 87002, Dhofar 007 and Juvinas only contain a low-Ca pyroxene phase. The major element composition of plagioclase in the eucrites is summarised in Table 3.2 . and the major element chemistry of low- and high-Ca pyroxene are given in Tables 3.3 and 3.4, respectively. The plagioclase is anorthite (An) rich $(>86 \%$ ) (Fig. 3.3A) with a negligible orthoclase component $(\leq 0.5 \%)$ (Fig. 3.2A). Low-Ca pyroxene falls into two groups on the basis of ferrosilite (Fs) contents (Fig. 3.2B, Fig. 3.3E). One group has Fs of 50-62\%, and the other group is more enstatite (En)-rich with Fs of $31-50 \%$. The average Wo content of the low-Ca pyroxene phase ranges from $2-15 \%$ (Fig. $3.2 \mathrm{~B}$ and 3.3D). The high-Ca pyroxene phases are relatively wollastonite (Wo)-rich, with a range in average Wo contents of $30-45 \%$ (Fig. $3.2 \mathrm{~B}$ and $3.3 \mathrm{~B}$ ). The Fs content of the high-Ca pyroxene is variable, with average Fs contents ranging from $17-39 \%$ (Fig. $3.2 \mathrm{~B}$ and $3.3 \mathrm{C}$ ). 


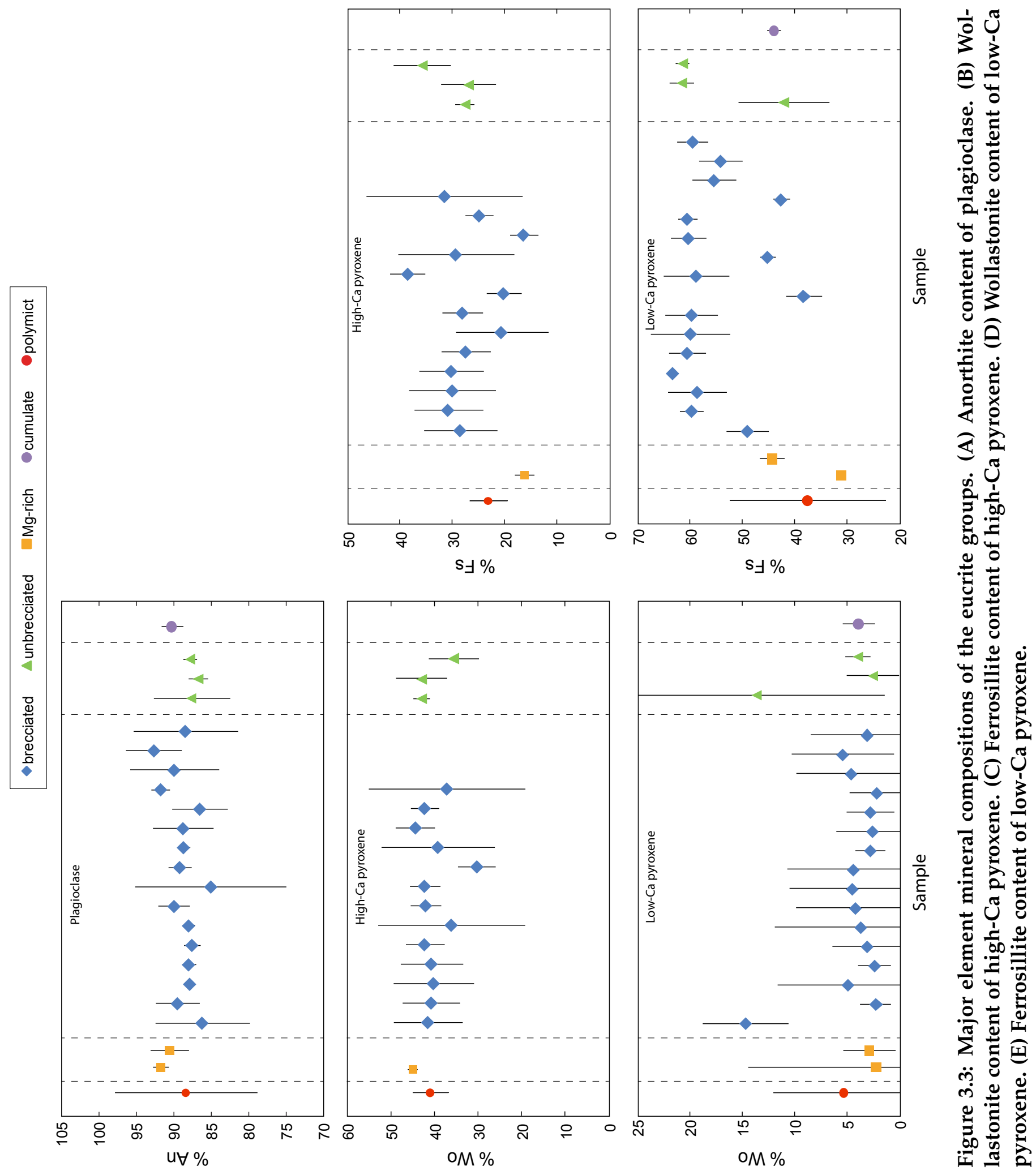




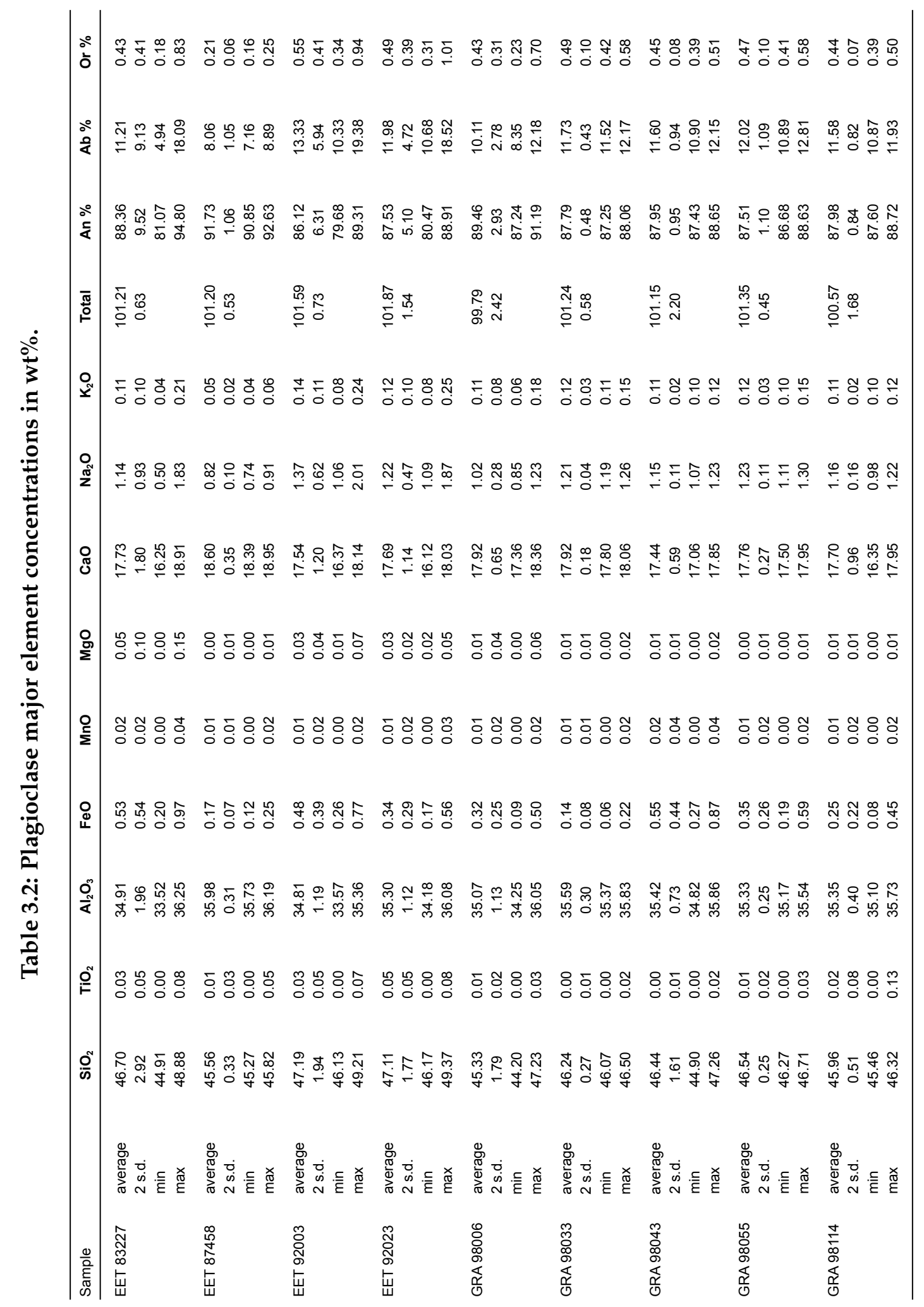




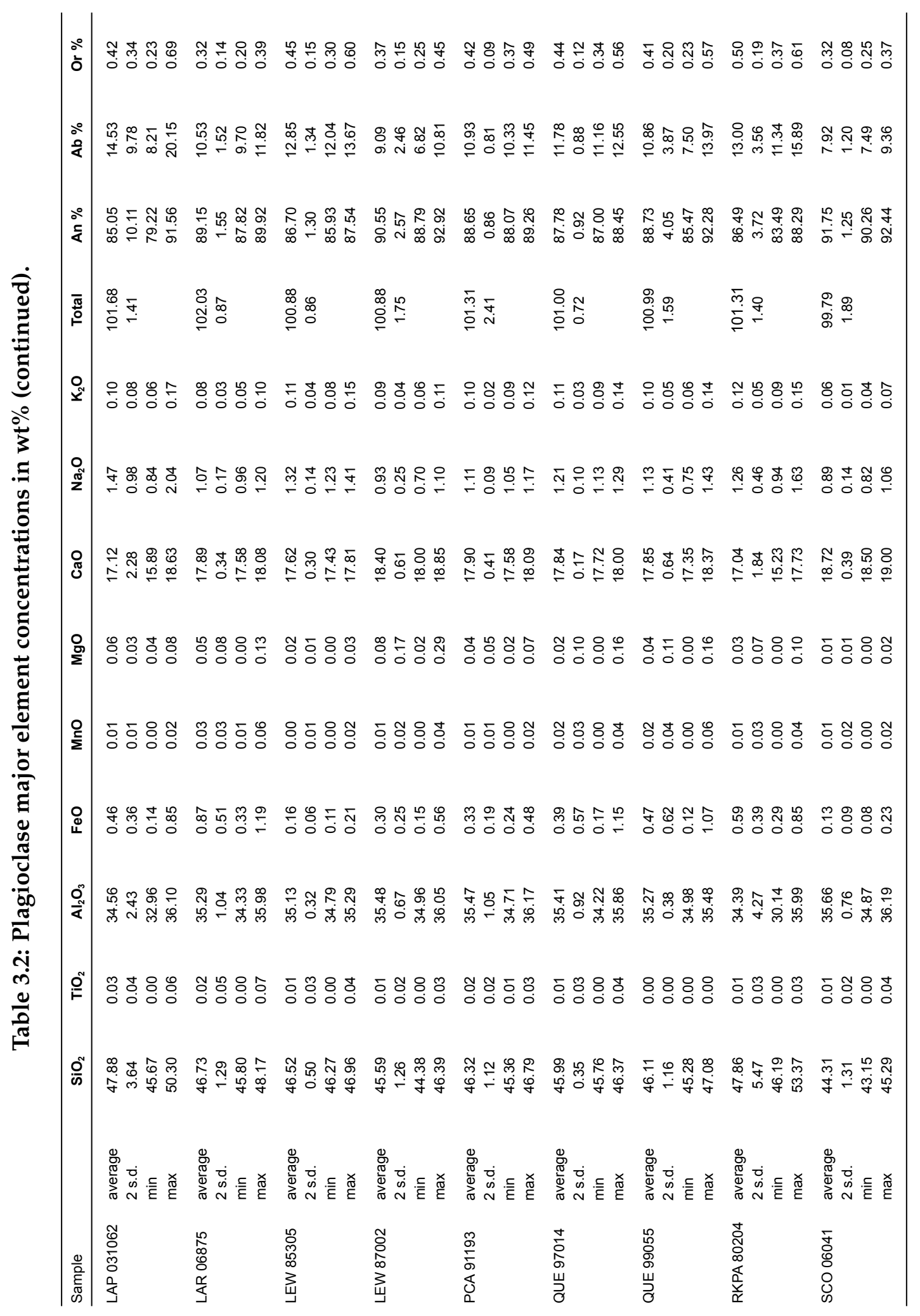




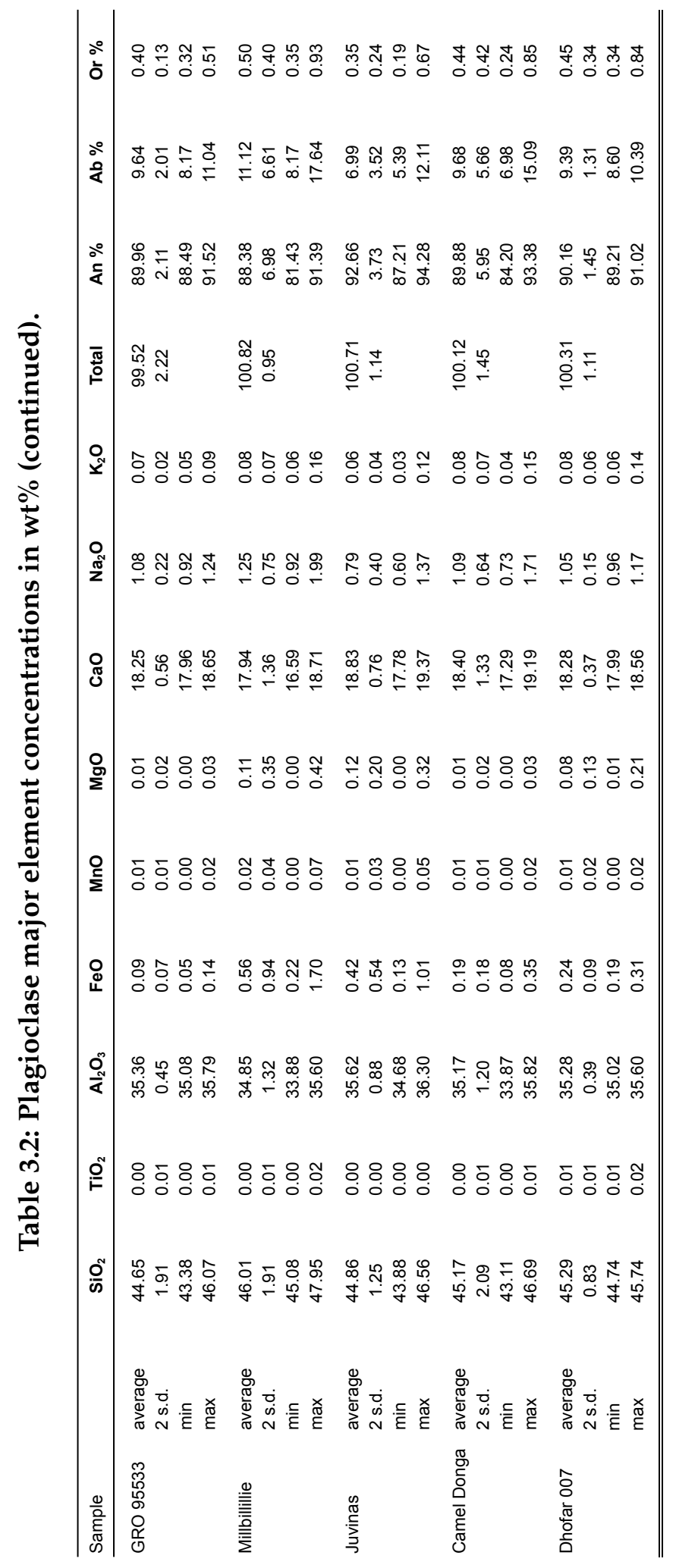




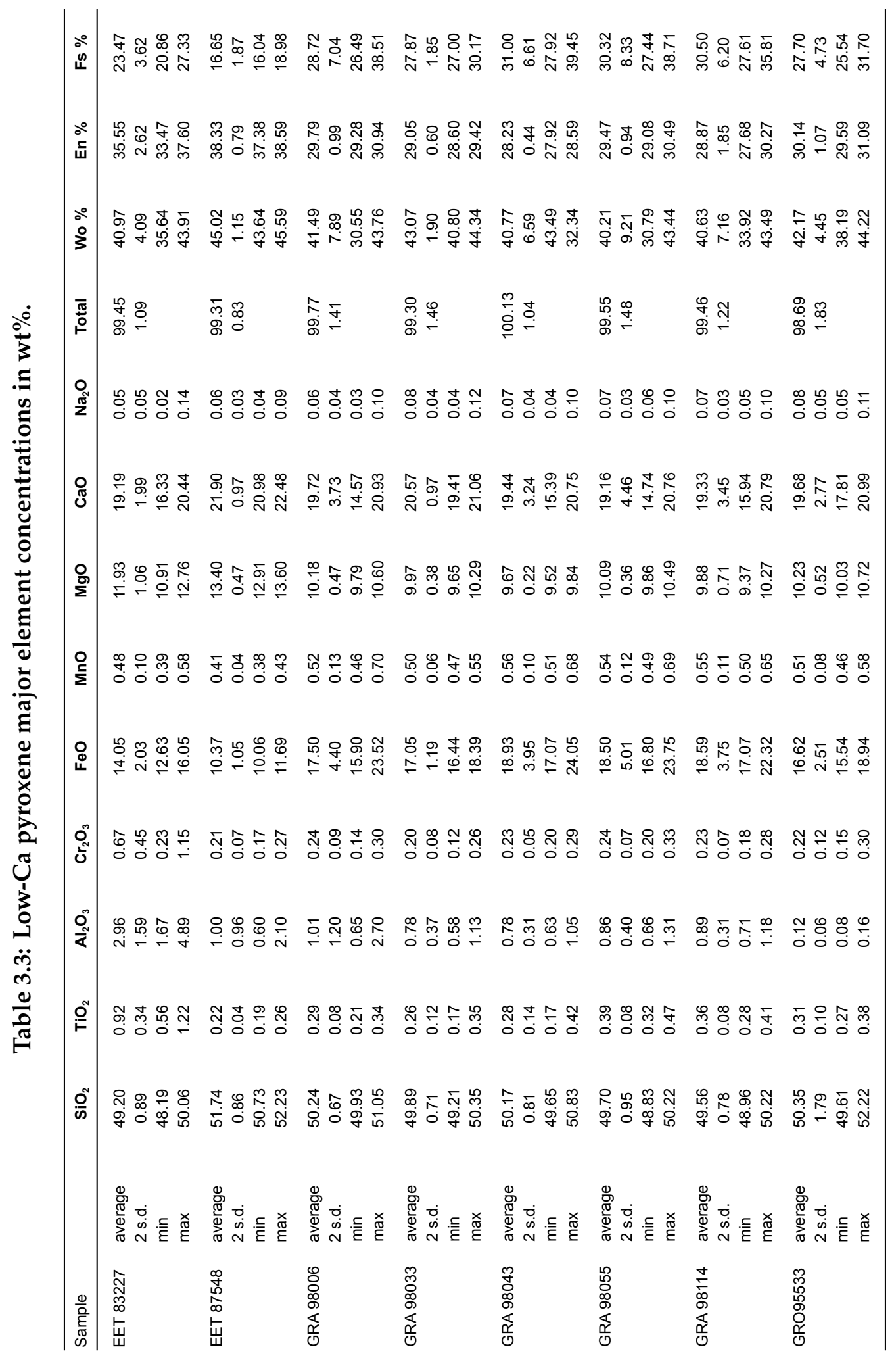




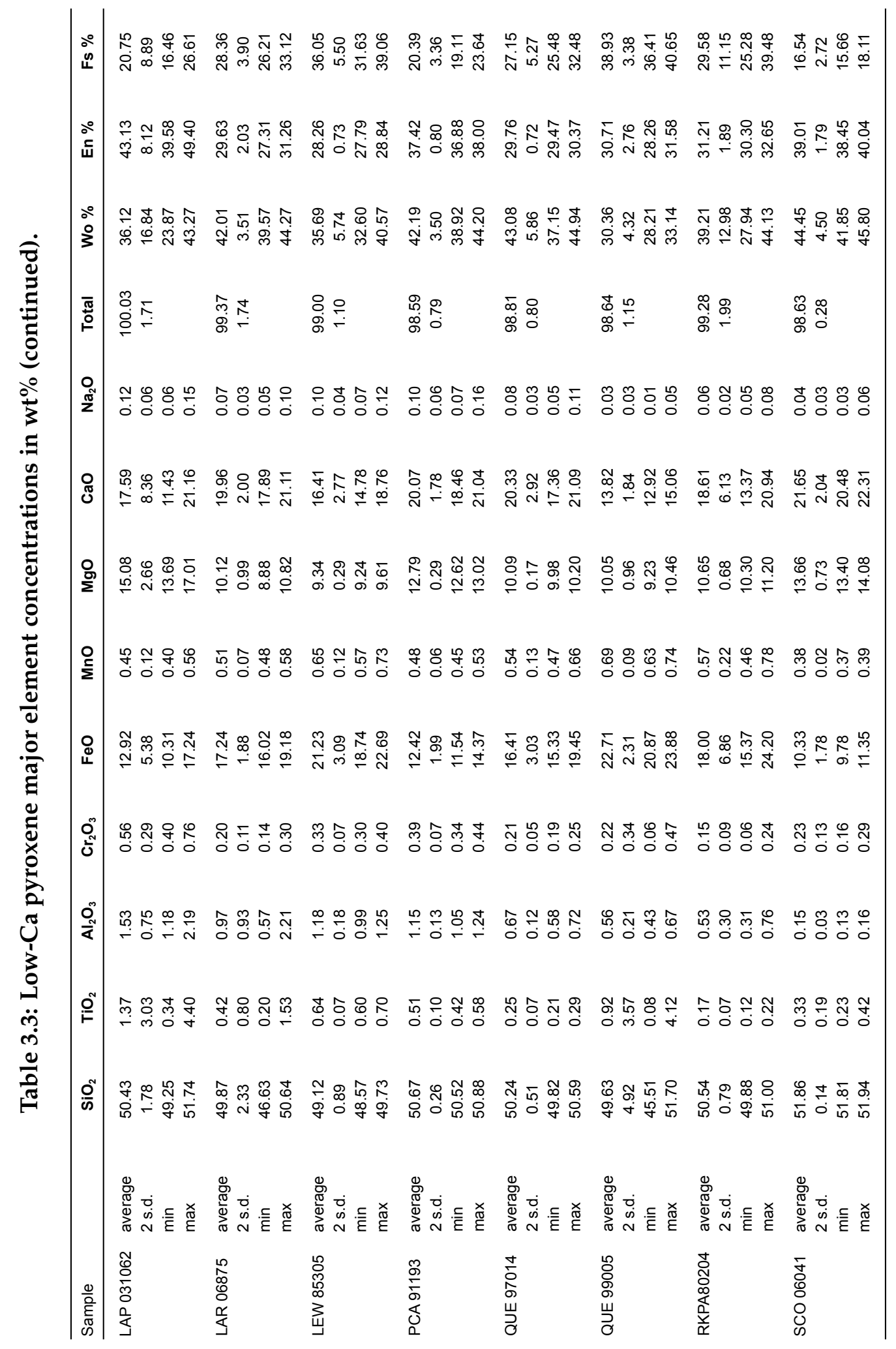




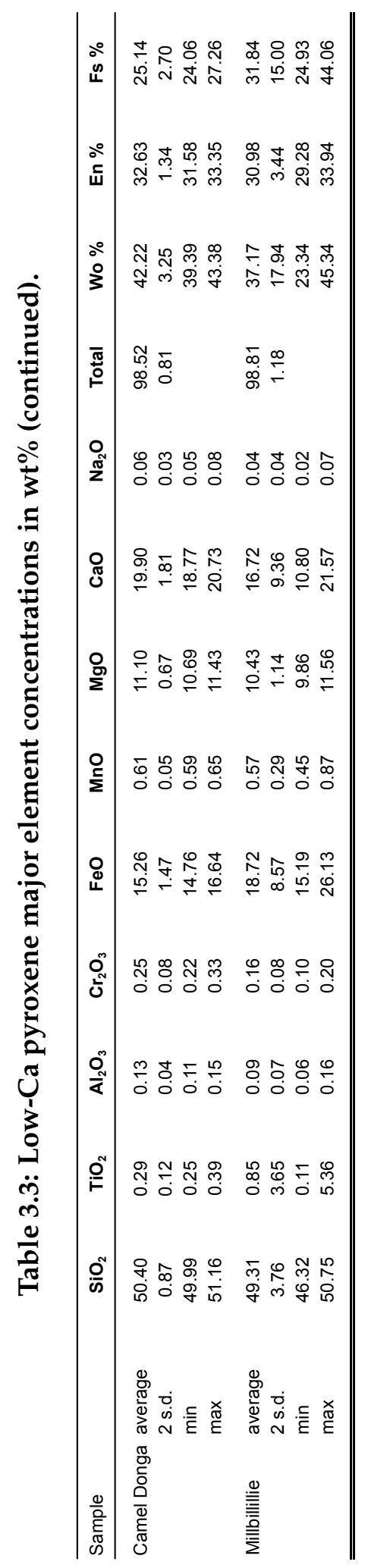




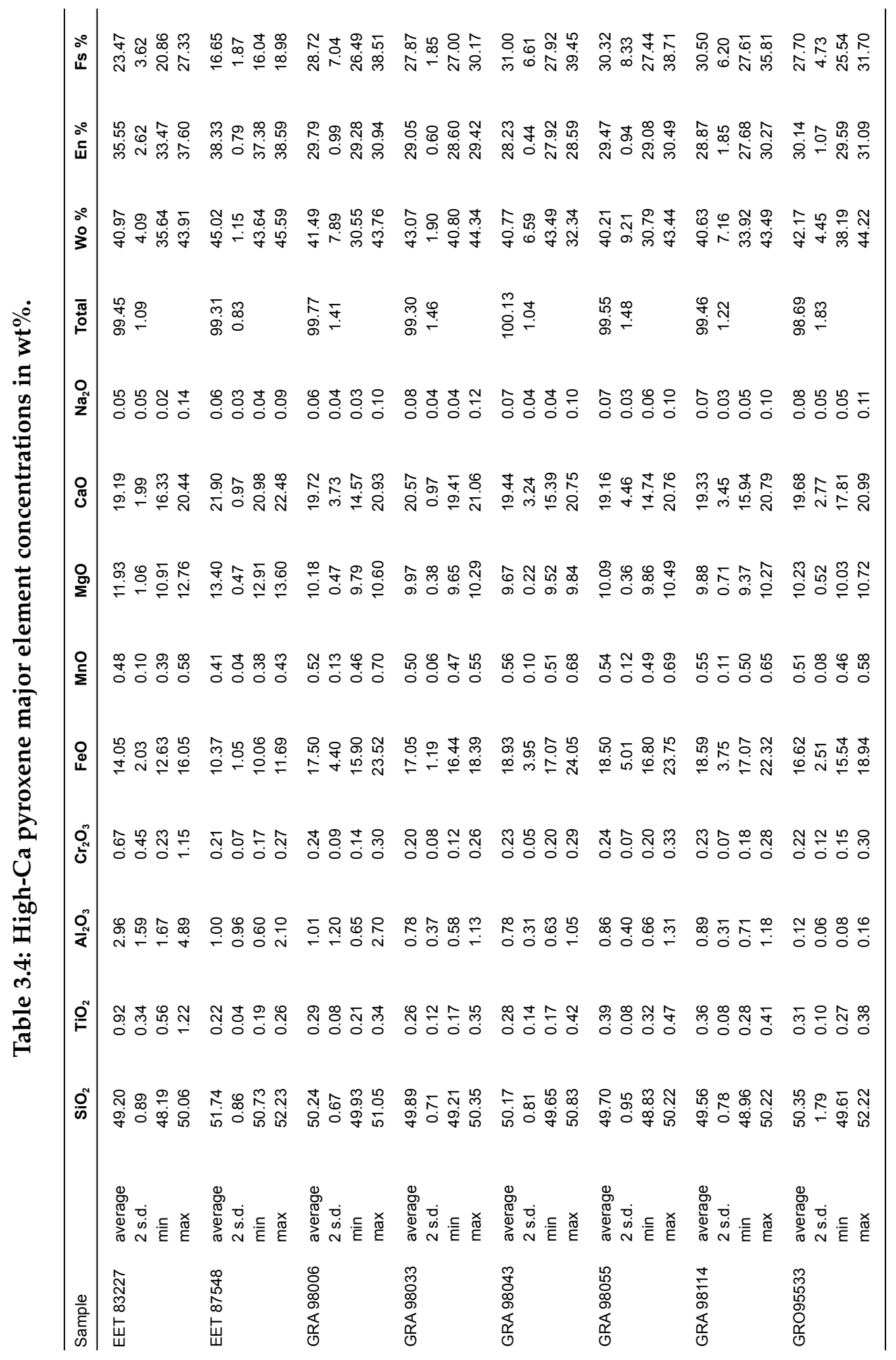




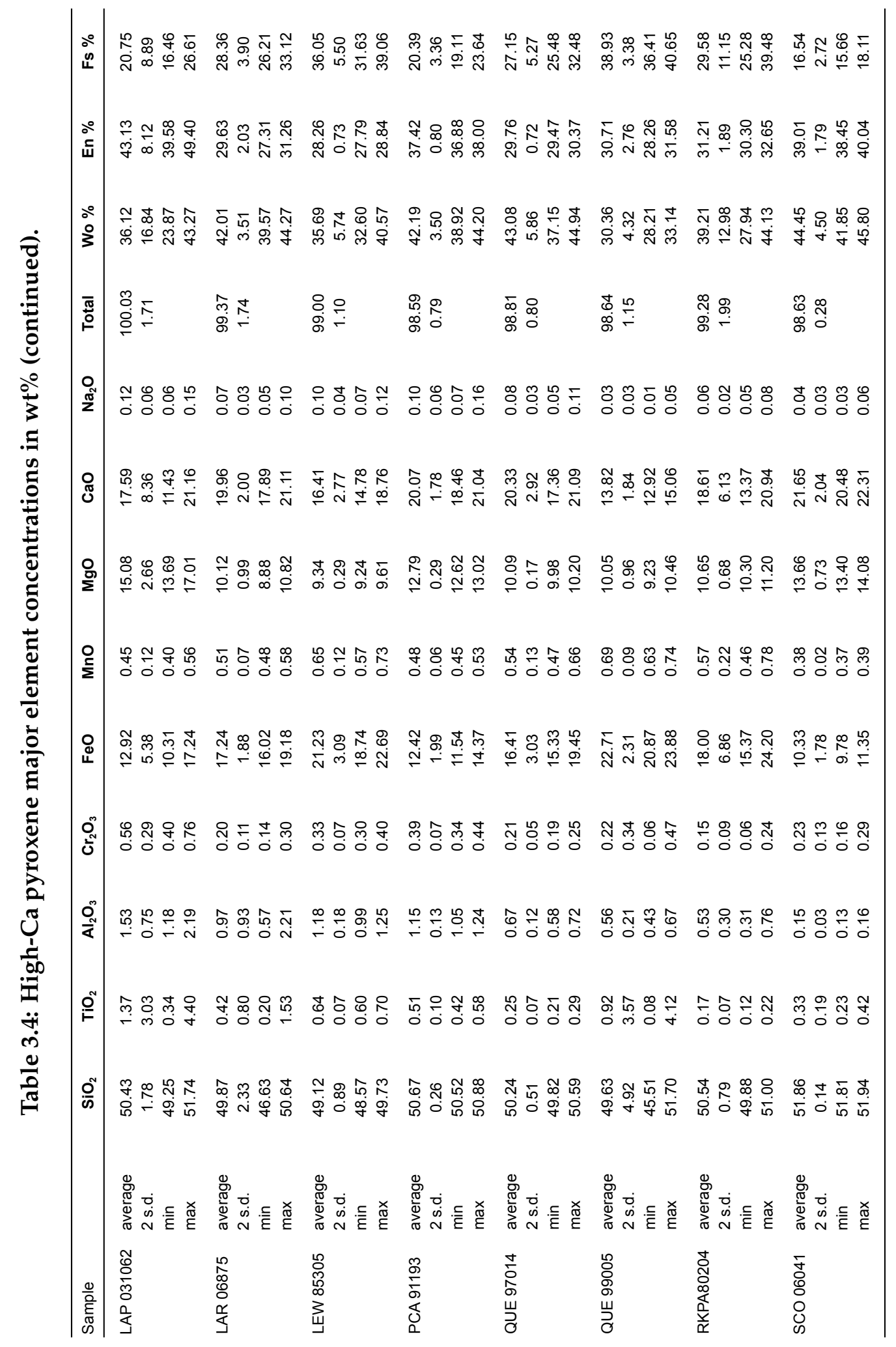




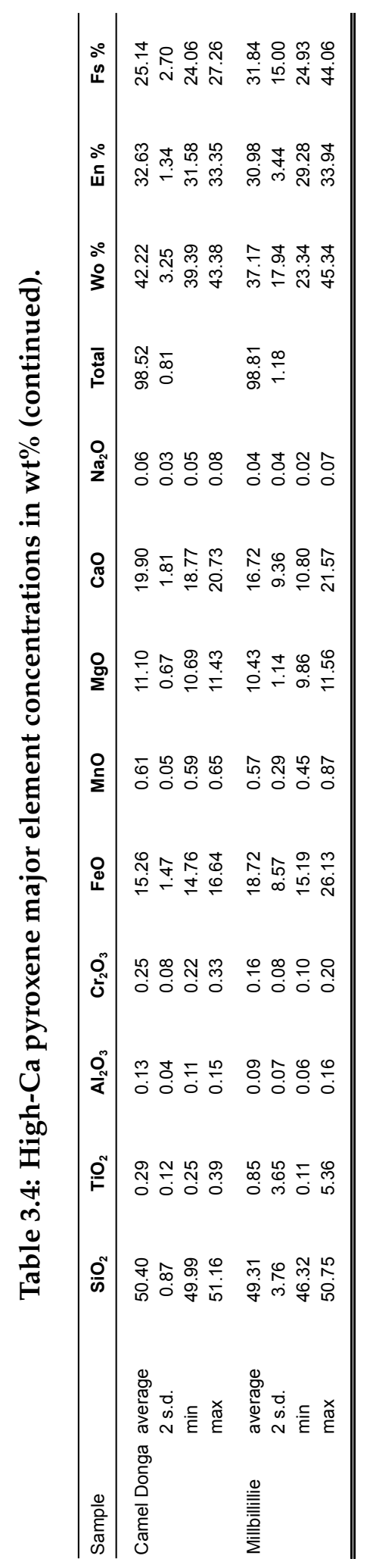




\section{Polymict eucrites}

\section{Low-Ca pyroxene}

EET 83227 is the only polymict eucrite in the sample suite, and there is a large range in the major element composition of the low-Ca pyroxene in this sample. The Wo content ranges from 1.4-15.0\% (average $=5.3 \%$ ) and the Fs content is also variable ranging from 30.0-51.6\% (average $=37.6 \%$ ) (Table 3.3).

\section{High-Ca pyroxene}

The major element chemistry of high-Ca pyroxene in EET 83227 is similar to the brecciated and unbrecciated eucrites, and is less variable than the major element chemistry of the low-Ca pyroxene in this sample. The Wo content ranges from $35.6-43.9 \%$ (average $=40.1 \%$ ) and the Fs content ranges from 20.9-27.3\% (average $=23.5 \%$ ) (Table 3.4).

\section{Plagioclase}

The major element chemistry of plagioclase in EET 83227 is similar to the majority of the other eucrites. However, there is considerable variation in plagioclase chemistry within this sample. The An content ranges from $81.1-94.8 \%$ (average $=88.4 \%$ ) (Table 3.2).

\section{Mg-rich eucrites}

\section{Low-Ca pyroxene}

Low-Ca pyroxene in the two Mg-rich eucrites (EET 87548 and LEW 87002) have average Wo contents of $3.0 \%$ and $2.3 \%$, respectively, and average Fs contents of $44.4 \%$ and $31.3 \%$, respectively. EET 87458 has a much greater range in Wo contents of $1.7-8.5 \%$, as compared with a range of $1.5-3.2 \%$ for LEW 87002 (Table 3.3). 


\section{High-Ca pyroxene}

EET 87458 is the only Mg-rich eucrite to contain a high-Ca pyroxene phase. This pyroxene has a Wo content of $45.0 \%$. Compared with other eucrites in the sample suite, high-Ca pyroxene in EET 87458 also has a relatively low average Fs content of $16.7 \%$ (Table 3.4).

\section{Plagioclase}

Plagioclase compositions of the two Mg-rich eucrites are similar, with average An contents of $91.7 \%$ and $90.6 \%$, respectively (Table 3.2).

\section{Brecciated eucrites}

\section{Low-Ca pyroxene}

Low-Ca pyroxene in the brecciated eucrites has an average Wo content of $<6 \%$. However, low-Ca pyroxene in EET 92003 has an average Wo content of $14.7 \%$. The majority of the brecciated samples contain low-Ca pyroxene with an average Fs content of 49.1-53.5\%. However, some of the brecciated eucrites contain less ferroan low-Ca pyroxene (e.g., LAP 031062 (average $\mathrm{Fs}=38.4 \%$ ), PCA 91193 (average $\mathrm{Fs}=45.2 \%$ ) and SCO 06041 (average Fs = $42.6 \%)$ ) (Table 3.3.

\section{High-Ca pyroxene}

The high-Ca pyroxene in the brecciated eucrites has a range in average Wo content from 36.1-44.6\%. However, high-Ca pyroxene in QUE 99005 has a considerably lower average Wo content of $30.4 \%$. The average Fs content ranges from $25.1-31.8 \%$, with the exception of three samples with lower average Fs content (LAP 031062 (average Fs = 20.8\%), PCA 91193 (average Fs $=20.4 \%$ ) and SCO 06041 (average Fs = 16.5\%). QUE 99005 has the highest average Fs content (38.9\%) of high-Ca pyroxene in any of the samples (Table 3.4). 


\section{Plagioclase}

Plagioclase in the brecciated eucrites has a range in average An contents of 85.1-89.9\%. However, SCO 06041 and Juvinas contain plagioclase with higher average An contents of $91.8 \%$ and $92.7 \%$, respectively. Most of the brecciated eucrites exhibit little variability in plagioclase composition within a sample. However, EET 92003, LAP 031062, Millbillillie and Camel Donga all have intra-sample variations in An contents of 9-12.5\% (Table 3.2.).

\section{Unbrecciated eucrites}

\section{Low-Ca pyroxene}

Low-Ca pyroxene from two of the unbrecciated eucrites (QUE 97014 and LEW 85305) has similar major element compositions with average Wo contents of $2.6 \%$ and $4.0 \%$ and average Fs of $61.7 \%$ and $61.6 \%$, respectively. Low-Ca pyroxene in EET 92023 is different to the aforementioned unbrecciated eucrites and is higher in Wo (average $=13.7 \%$ ) and more magnesian (average Fs $=42.2 \%$ ) (Table 3.3).

\section{High-Ca pyroxene}

EET 92023 and QUE 97014 both have average Wo contents of 43.1\%, and similar average Fs contents of $27.9 \%$ and $27.2 \%$, respectively. LEW 85305 has a considerably lower Wo content (average $=35.7 \%$ ) and a higher average Fs content of $36.1 \%$ (Table 3.4).

\section{Plagioclase}

There is little difference in the average major element composition of plagioclase in the three unbrecciated eucrites. EET 92023, LEW 85305 and QUE 97014 have average An contents of $87.6 \%, 86.7 \%$ and $87.8 \%$, respectively. However, EET 92023 has a considerably larger variation in An content within the sample, with An content varying $>7 \%$, as compared with 
the $<2 \%$ variation observed in the other two samples (Table 3.2).

\section{Cumulate eucrites}

\section{Low-Ca pyroxene}

Low-Ca pyroxene in Dhofar 007 is relatively magnesian, with a low average Fs content of $44.1 \%$ as compared with an average of Fs content of $53.0 \%$ for the non-cumulate eucrites. The average Wo content is 3.9\%, which is similar to the majority of the non-cumulate eucrites (Table 3.3).

\section{Plagioclase}

Plagioclase in Dhofar 007 is compositionally similar to that in the noncumulate eucrites. Dhofar 007 has an average An content of $90.2 \%$ and exhibits little variability within the sample (Table 3.2). 


\section{Chapter 4}

\section{Trace element data}

Trace element data is summarized in this chapter, the full data set can be found in Appendix B.

\subsection{Chondrite-normalized REE plots}

\subsubsection{Intra-sample variability}

The low concentration of heavy rare earth elements (REE) in plagioclase meant that only light and medium REE concentrations were measured in plagioclase. While pyroxene is relatively depleted in light REE, these were in measurable concentrations in the pyroxene analysed in this study.

The intra-sample variability of REE concentrations in plagioclase and pyroxene was examined to determine if an average REE pattern for each sample would be representative of the entire sample. Chondritenormalized REE plots for a selection of samples from all the eucrite groups are discussed below (Fig. 4.1).

\section{Plagioclase}

Chondrite-normalized REE data for plagioclase have flat to light REE enriched patterns across the suite of samples, with all samples exhibiting marked positive Eu anomalies. Samples such as GRA 98033 and QUE 

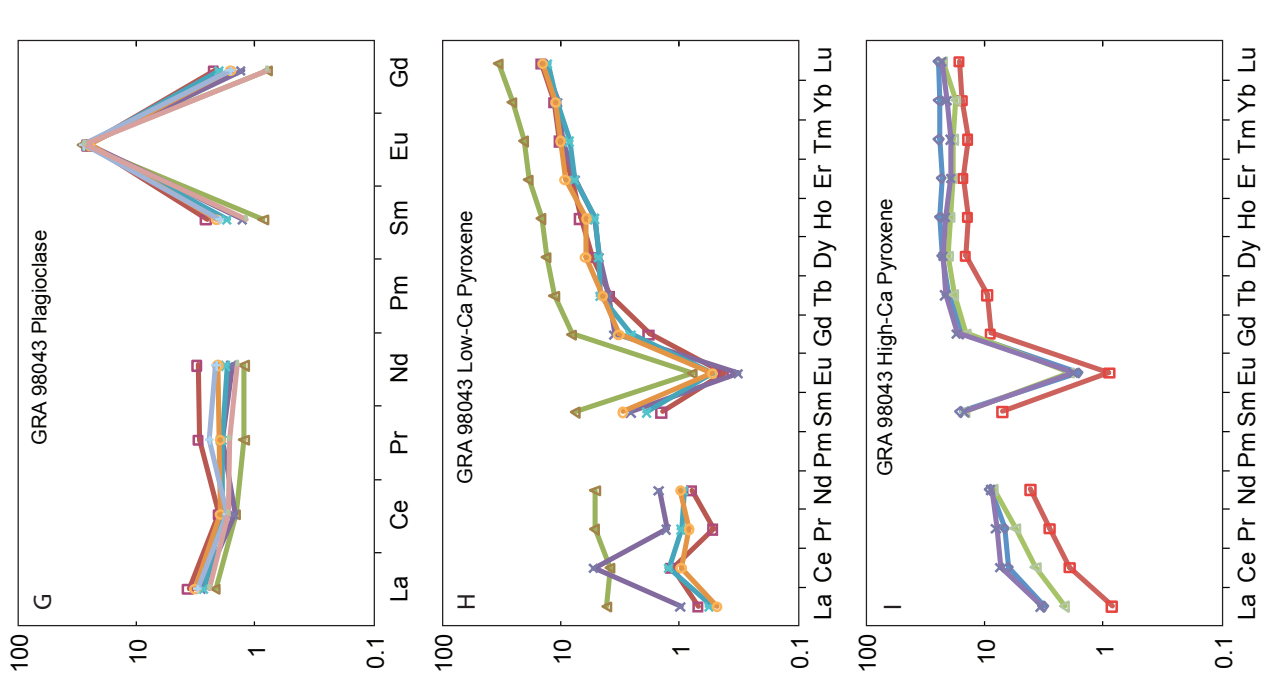

Dे
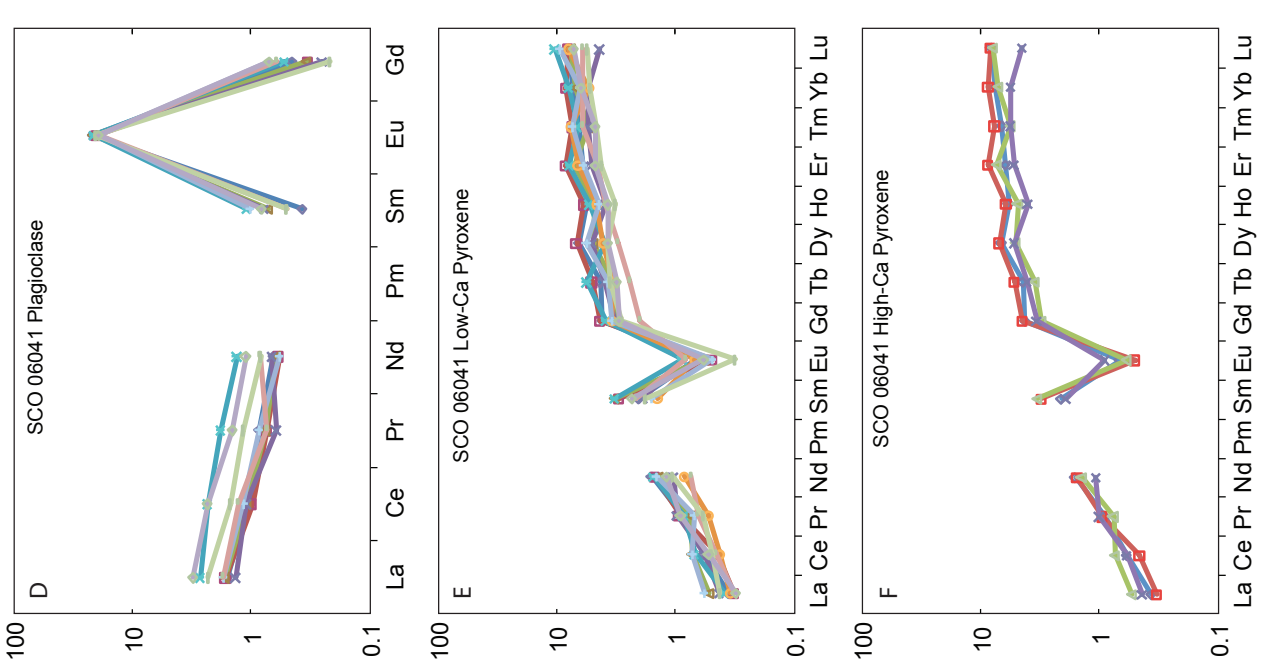

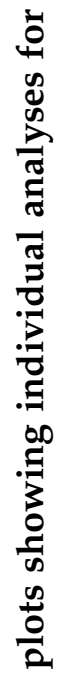
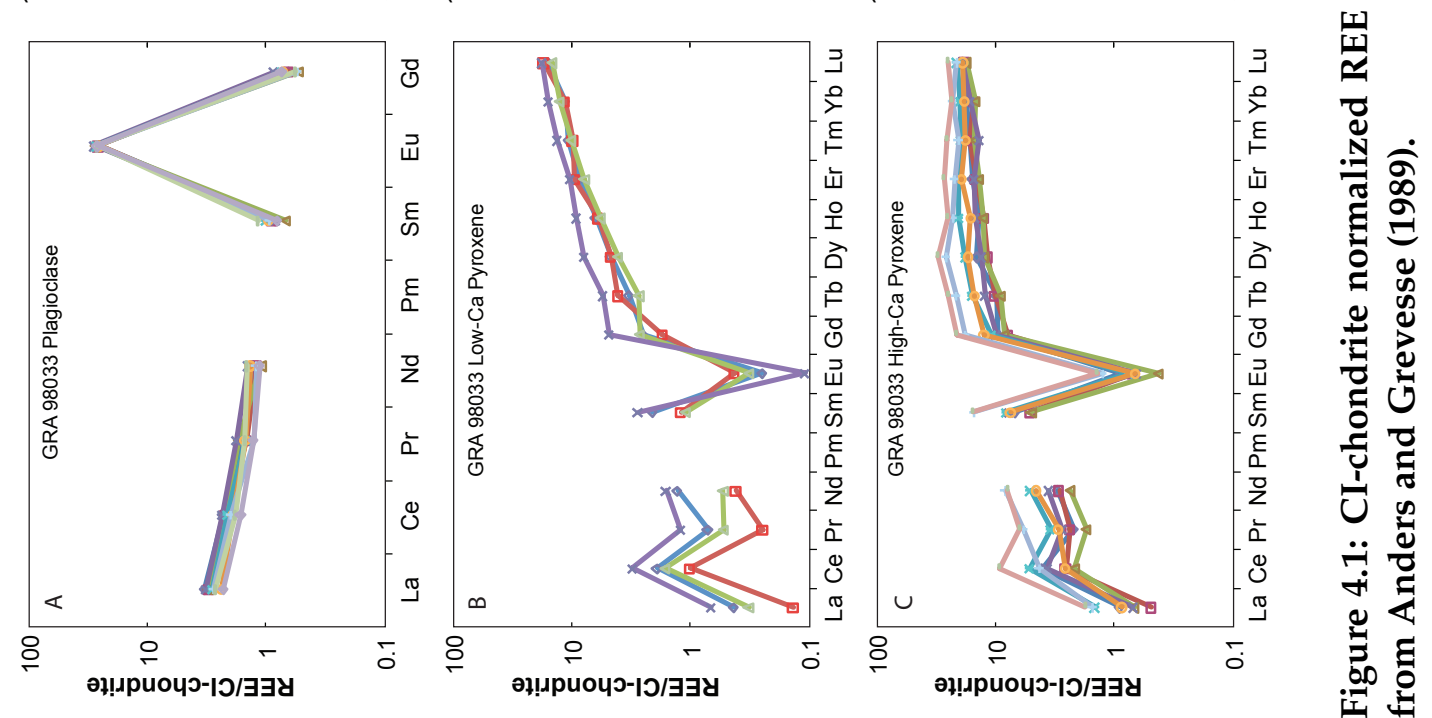

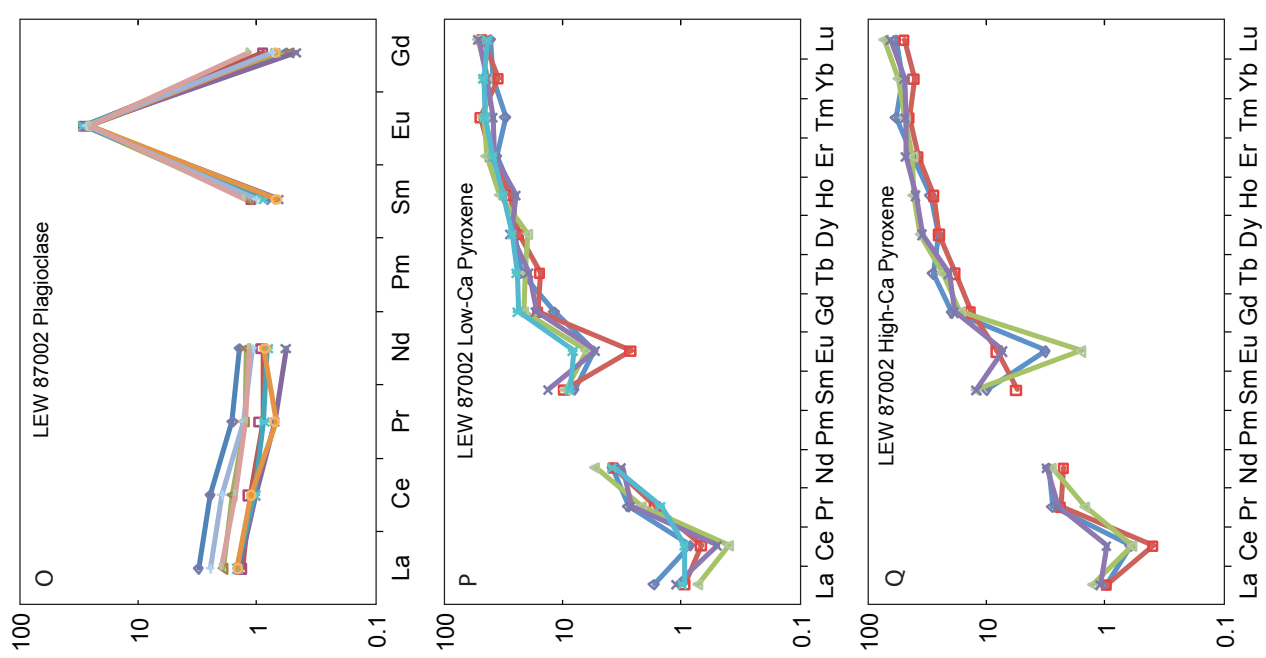

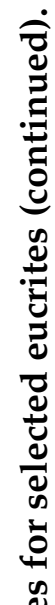
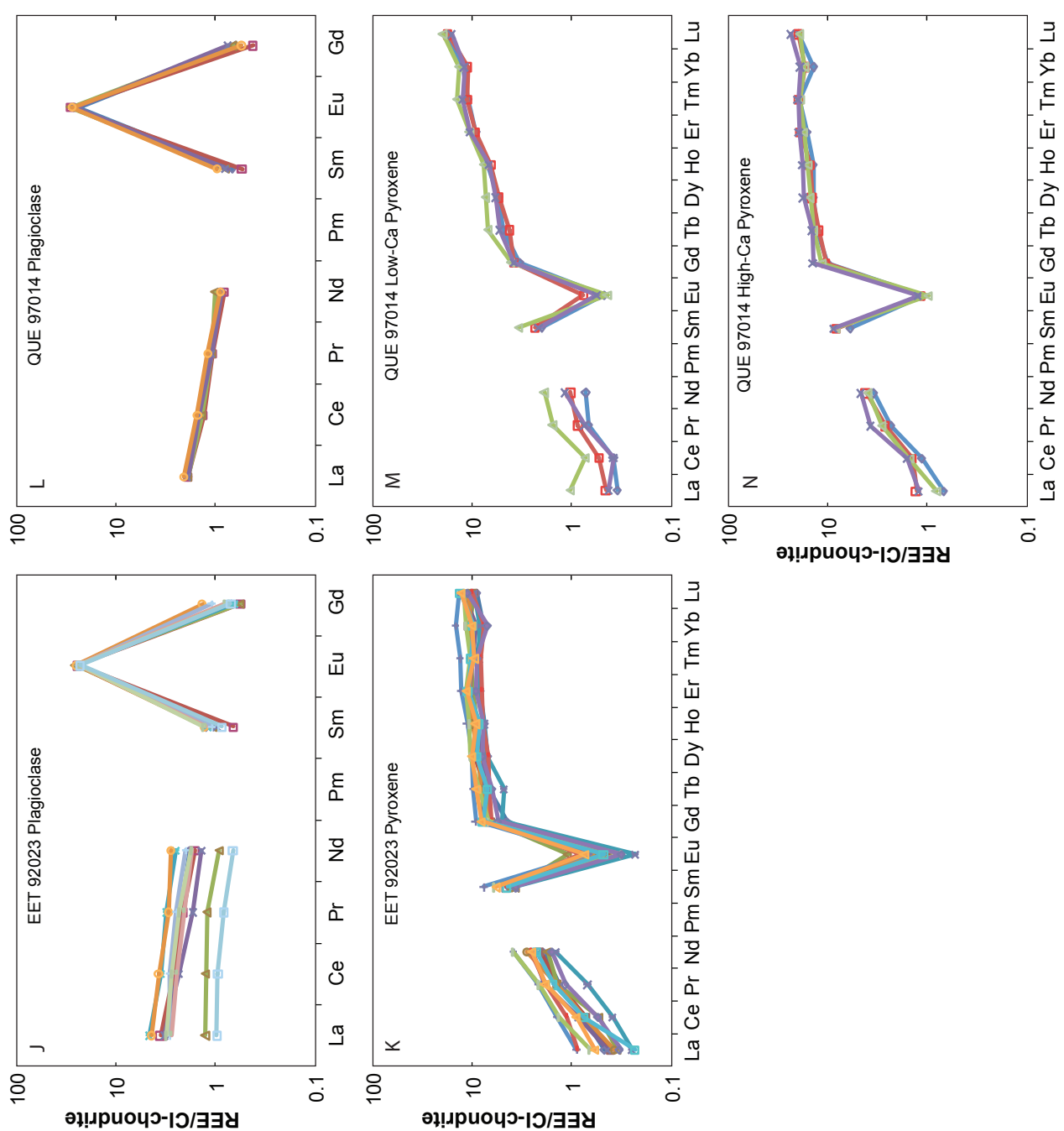


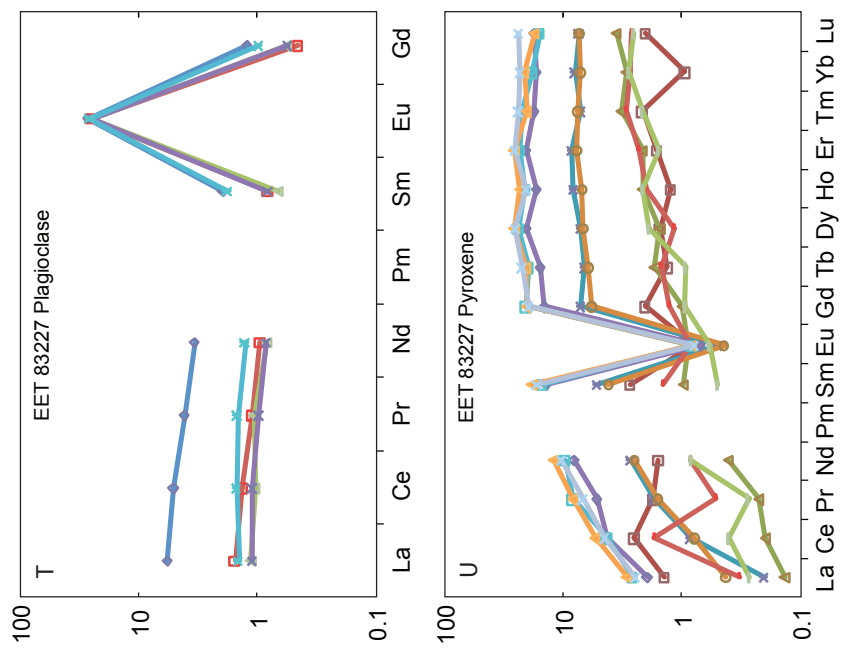

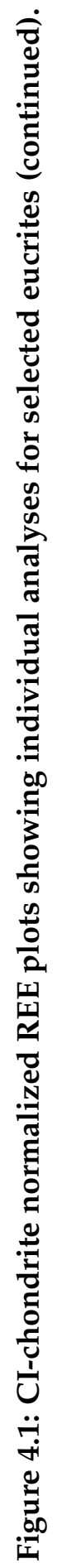

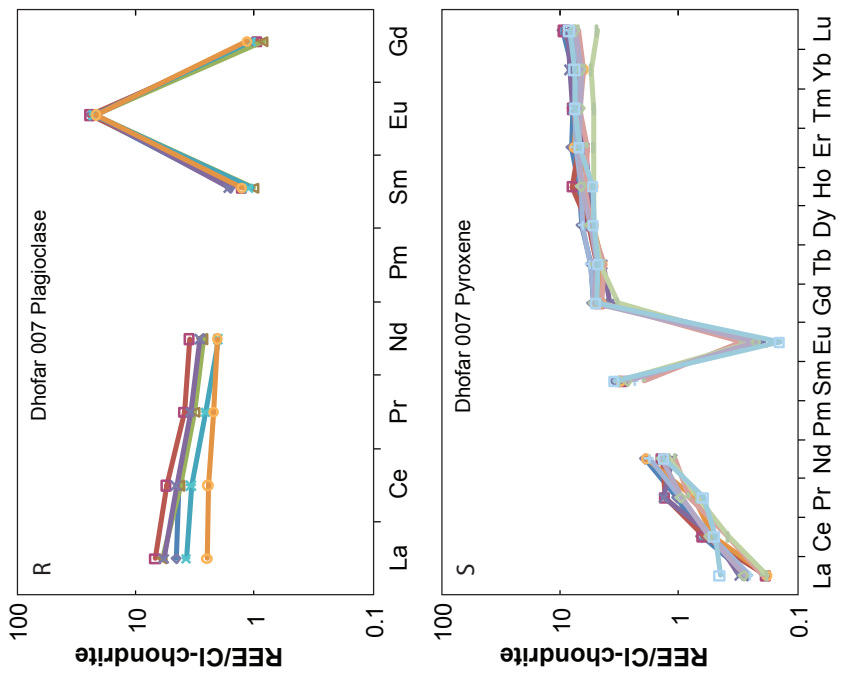


97014 show very limited REE variability that is comparable to the estimated analytical uncertainty (Fig. 4.1 A and L), whereas analyses of plagioclase in some other samples (e.g., EET 92023) have REE concentrations that may vary by up to a factor of three (Fig. 4.1 J). Eu in all samples shows little intra-sample variability and, as such, Eu anomalies (Eu/Eu*) generally become smaller (i.e., less positive) with increasing plagioclase REE contents. The polymict eucrite EET 83227 has more variation between REE analyses of plagioclase than most other samples, with one analysis in particular having considerably higher REE concentrations (Fig. 4.1T). The majority of the plagioclase REE analyses of GRA 98043 have a negative Ce anomaly $\left(\mathrm{Ce} / \mathrm{Ce}^{*}\right)$ (Fig. 4.1 G), whereas the other samples do not exhibit Ce anomalies in plagioclase.

\section{Low-Ca pyroxene}

Chondrite-normalized REE patterns for low-Ca pyroxene in the eucrite samples are more variable than those for plagioclase. Low-Ca pyroxene in all samples is LREE depleted and HREE enriched, and all analyses have marked negative Eu anomalies. Some low-Ca pyroxene analyses exhibit positive Ce anomalies (e.g., Fig. 4.1B), whereas others have negative $\mathrm{Ce}$ anomalies (e.g., Fig. 4.1 $\mathrm{M}$ and P) or no Ce anomaly. In general, there is limited variation in REE analyses of low-Ca pyroxene within most samples, particularly with respect to Eu anomalies. However, there is some intra-sample variability in Ce anomalies for low-Ca pyroxene. For example, both positive and negative Ce anomalies are evident in analyses of GRA 98043 (Fig. 4.1 H).

\section{High-Ca pyroxene}

High-Ca pyroxene in all samples is LREE depleted and HREE enriched, and all the samples have negative Eu anomalies. Like the low-Ca pyroxene phase there is variability in the $\mathrm{Ce}$ anomalies of high-Ca pyroxene within individual samples. The heavy REE patterns of the high-Ca pyroxene generally have flatter chondrite-normalized REE profiles than low-Ca 
pyroxene for the same samples, but have very similar $\mathrm{Yb}$ and $\mathrm{Lu}$ concentrations. However, chondrite-normalized REE patterns for high-Ca pyroxene in some samples are almost identical to those of low-Ca pyroxene in the same samples, such as SCO 06041 and LEW 87002 (Fig. 4.1F and Q respectively). This may be because the two-pyroxene phases in these samples are more compositionally similar to each other than for other samples. There is limited intra-sample REE variability in high-Ca pyroxene in some samples and REE analyses are within analytical error of each other in the majority of samples. However, REE analyses of some samples such as GRA 98033 have larger variations (Fig. 4.1 C), although the overall shape of the chondrite-normalized REE patterns are similar for all analyses in samples such as this example.

\section{Single-phase pyroxene}

In samples with only a single pyroxene phase, chondrite-normalized REE patterns of pyroxene show LREE depletion and HREE enrichment, and marked negative Eu anomalies. REE analyses of pyroxene in Dhofar 007 are all within analytical error of each other (Fig. 4.1 S), whereas those of EET 92023 are more variable, but still have consistent chondritenormalized REE profiles (Fig. 4.1 K). These samples both have relatively flat HREE profiles, which are similar to the high-Ca pyroxene phase of some other samples. There is a very large amount of variability between individual REE analyses of pyroxene in the polymict sample EET 83227 (Fig. 4.1 U). With the exception of $\mathrm{Ce}$ and Eu the REE concentration data in the polymict sample vary by about an order of magnitude. Some analyses exhibit positive Ce anomalies (up to 4.12), whereas other analyses have no Ce anomaly. Eu anomalies are almost absent in the most REE-depleted analyses and become increasingly negative (as low as 0.04) with increasing REE concentrations. 


\subsubsection{Inter-sample variability}

The trace element abundances in the eucrites analysed in this study show considerable variability as illustrated by the CI-chondrite normalized REE patterns in plagioclase and pyroxene (Fig. 4.2). The general REE patterns of plagioclase and pyroxene are as expected, with plagioclase exhibiting a relative enrichment in the light REE and a positive Eu anomaly, while pyroxene has negative Eu anomalies, and is enriched in heavy REE.

The intra-sample mineral variations in REE concentrations of the polymict eucrite EET 83227 were so large that calculating an average value for this sample was not undertaken as it is clearly heterolithic. The average CI-chondrite normalized REE patterns for the other samples are discussed below.

\section{Plagioclase}

REE abundances in plagioclase (Fig. 4.2 A; Table 4.1) are less variable between samples than pyroxene ( Fig. 4.2 B, C and D). However, there is still approximately an order of magnitude range in light REE abundances in plagioclase. $\mathrm{Eu}$ anomalies in plagioclase are positive and exhibit a large range from 5.9 in LAR 06875 to 57.3 in Juvinas. In addition to its relatively low Eu anomaly, LAR 06875 has considerably higher abundances of both heavy and light REE compared with the rest of the samples, and a generally much flatter REE profile (Fig. 4.2A).

\section{Low-Ca Pyroxene}

There is considerable variation in the abundance of REE in low-Ca pyroxene between the eucrite samples, particularly light REE abundances (Fig. 4.2 B; Table 4.2), which exhibit more than an order of magnitude variability. Eu anomalies in low-Ca pyroxene are negative, and range from 0.02 in Camel Donga (which has a distinctly lower Eu abundance than other samples) to 0.45 in the Mg-rich eucrite EET 87458. The samples also exhibit a wide range of $\mathrm{Ce}$ anomalies ranging from the most positive anomaly of 


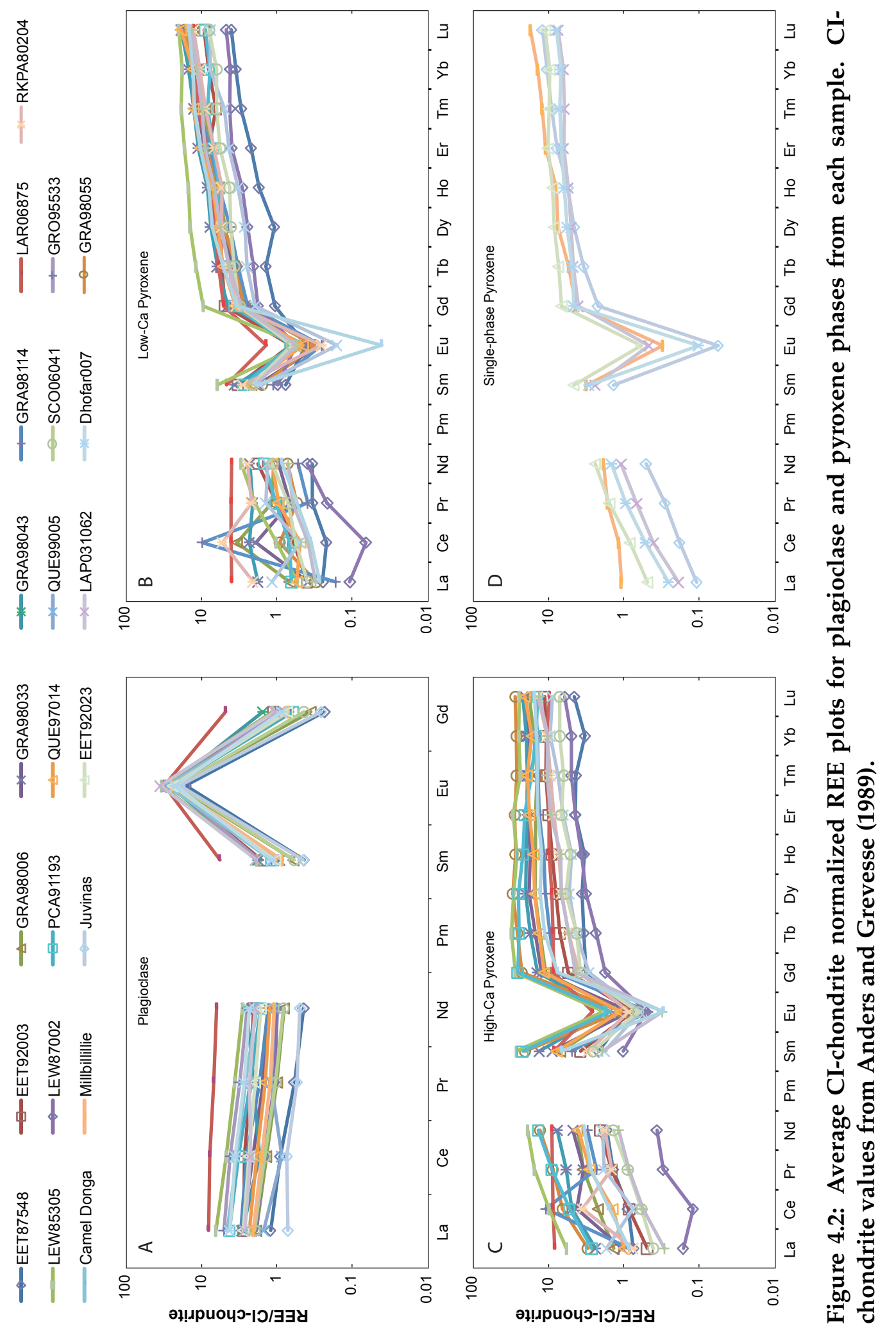


Table 4.1: Average CI-chondrite normalized REE concentrations in plagioclase in eucrite samples. CI-chondrite values from Anders and Grevesse (1989).

\begin{tabular}{lccccccccc}
\hline Sample & $\mathrm{La}$ & $\mathrm{Ce}$ & $\mathrm{Pr}$ & $\mathrm{Nd}$ & $\mathrm{Sm}$ & $\mathrm{Eu}$ & $\mathrm{Gd}$ & $\mathrm{Ce} / \mathrm{Ce}^{*}$ & $\mathrm{Eu}^{\mathrm{E}} \mathrm{Eu}^{*}$ \\
\hline EET 83227 & 2.60 & 2.32 & 1.95 & 1.69 & 1.36 & 25.6 & 0.86 & 1.03 & 23.7 \\
EET 87548 & 1.23 & 0.90 & 0.59 & 0.44 & 0.44 & 16.4 & 0.23 & 1.06 & 50.8 \\
EET92003 & 2.77 & 2.72 & 2.26 & 2.05 & 1.63 & 25.5 & 1.12 & 1.09 & 18.9 \\
EET 92023 & 2.81 & 2.35 & 1.96 & 1.64 & 1.06 & 24.1 & 0.73 & 1.00 & 27.4 \\
GRA 98006 & 1.88 & 1.39 & 1.01 & 0.82 & 0.60 & 22.1 & 0.36 & 1.01 & 47.6 \\
GRA 98033 & 2.90 & 2.09 & 1.53 & 1.31 & 0.92 & 27.2 & 0.68 & 0.99 & 34.4 \\
GRA 98043 & 2.86 & 1.72 & 2.05 & 2.54 & 1.78 & 26.9 & 1.54 & 0.71 & 16.2 \\
GRA 98114 & 3.00 & 2.52 & 1.69 & 1.32 & 1.19 & 24.6 & 1.05 & 1.12 & 22.0 \\
LAP 031062 & 2.68 & 2.25 & 2.36 & 1.97 & 1.91 & 35.4 & 1.07 & 0.89 & 24.8 \\
LAR 06875 & 8.14 & 7.81 & 6.95 & 6.31 & 5.78 & 31.3 & 4.82 & 1.04 & 5.9 \\
LEW 85305 & 6.49 & 4.71 & 3.64 & 2.84 & 1.84 & 34.0 & 1.15 & 0.97 & 23.4 \\
LEW 87002 & 1.91 & 1.50 & 1.09 & 1.01 & 0.96 & 27.4 & 0.73 & 1.04 & 32.8 \\
PCA 91193 & 4.27 & 3.22 & 2.24 & 1.66 & 1.18 & 24.6 & 0.62 & 1.04 & 28.7 \\
QUE 97014 & 2.37 & 1.86 & 1.46 & 1.27 & 1.02 & 27.5 & 0.88 & 1.00 & 28.9 \\
QUE 99005 & 1.50 & 0.86 & 1.21 & 1.08 & 1.13 & 29.1 & 0.79 & 0.64 & 30.8 \\
SCO 06041 & 1.98 & 1.46 & 1.05 & 0.82 & 0.59 & 20.6 & 0.44 & 1.01 & 40.4 \\
GRO 95533 & 5.04 & 4.18 & 3.15 & 2.50 & 1.73 & 25.4 & 0.96 & 1.05 & 19.7 \\
Millbillillie & 2.07 & 1.60 & 1.22 & 1.09 & 0.85 & 24.9 & 0.71 & 1.00 & 31.9 \\
Juvinas & 0.72 & 0.74 & 0.55 & 0.50 & 0.45 & 19.5 & 0.26 & 1.18 & 57.3 \\
Dhofar 007 & 4.27 & 3.60 & 2.77 & 2.35 & 1.18 & 22.3 & 0.87 & 1.05 & 22.1 \\
Camel Donga & 4.63 & 3.42 & 2.64 & 1.87 & 1.21 & 28.0 & 0.71 & 0.98 & 30.0 \\
\hline
\end{tabular}

37.8 measured in GRA 98114, to an anomaly of 0.39 in QUE 99005 (Table 4.2. As was the case for REE abundances in plagioclase in LAR 06875, the low-Ca pyroxene in this sample has a much flatter REE pattern than other samples, and higher abundances of the middle and light REE (Fig. 4.2 B). The two Mg-rich eucrites EET 87548 and LEW 87002 have the lowest REE abundances in low-Ca pyroxene. LEW 85305 has the highest heavy REE abundance, and has a flatter heavy REE profile as compared with the other samples.

\section{High-Ca Pyroxene}

Like plagioclase and low-Ca pyroxene, high-Ca pyroxene REE abundances show considerable variability between samples, as evidenced by CI-chondrite normalized REE plots (Fig. 4.2 C; Table 4.3). In general, the 


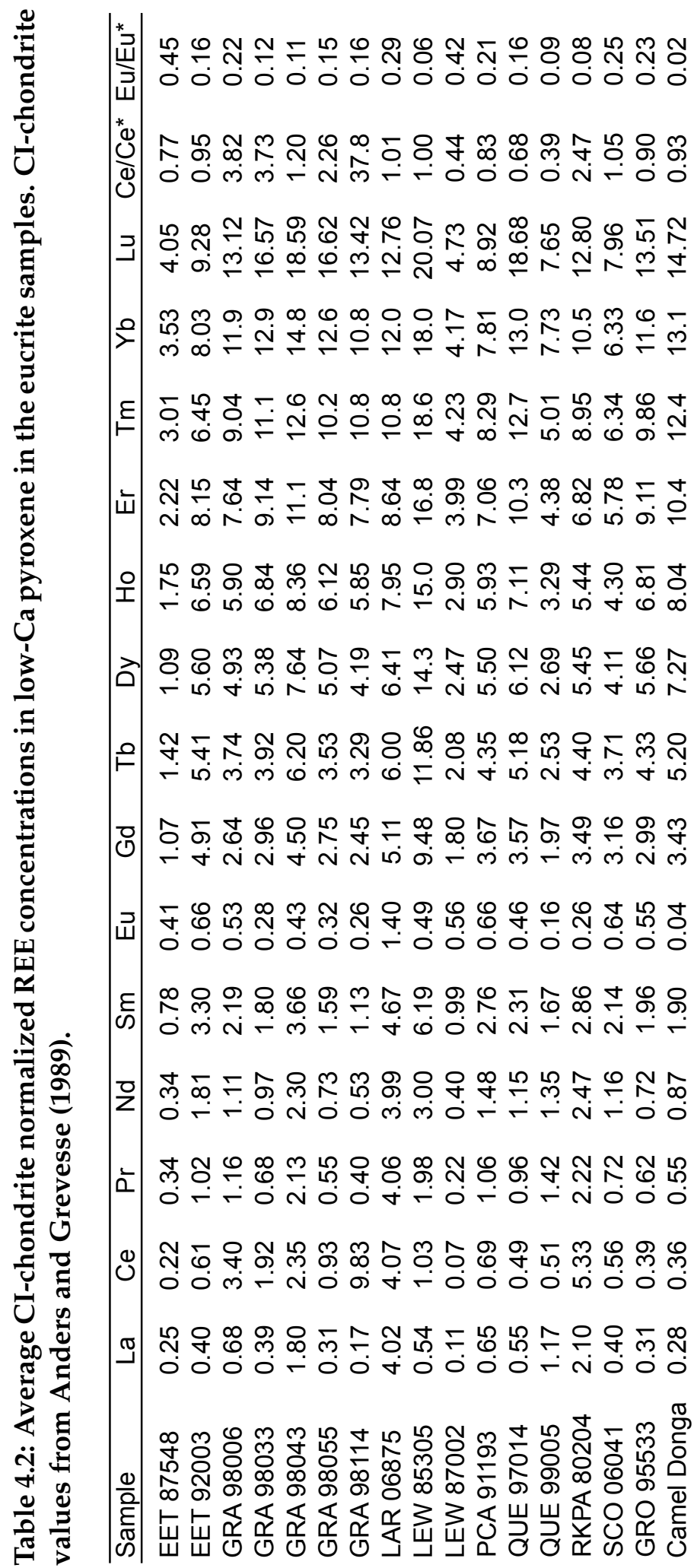


heavy REE profile of high-Ca pyroxene is much flatter than that of lowCa pyroxene. As in low-Ca pyroxene, Camel Donga has the largest negative Eu anomaly of 0.04, while LEW 87002, an Mg-rich eucrite, has the smallest negative Eu anomaly of 0.38 (Table 4.3 ). Ce anomalies range from 0.43 in QUE 99005 to 7.8 in GRA 98114, which are also the samples with the smallest and largest respective Ce anomalies in low-Ca pyroxene. The Mg-rich eucrites LEW 87002 and EET 87458 have the lowest abundances of the heavy REE, and LEW 87002 also has the lowest light REE abundance. LAR 06875 exhibits the same flat REE pattern as in plagioclase and low-Ca pyroxene.

\section{Single-phase pyroxene}

There are five samples with only one discernible pyroxene phase, and with the exception of Millbillillie, the CI-chondrite normalized REE patterns of these samples are similar to those of high-Ca pyroxene in that they have relatively flat heavy REE profiles (Fig. 4.2 D). There is less variability in REE abundances in these samples (Table 4.4). However, there are only five samples in this group. Juvinas and Dhofar 007 have the most negative Eu anomalies of 0.03 , while LAP 031062 has smallest negative anomaly of 0.15 , Ce anomalies range from $0.26-1.16$.

\subsection{Other trace element variations}

\subsubsection{Trace element plots}

\section{Plagioclase}

Trace element concentrations in plagioclase are presented in 4.5 , with selected elements plotted in 4.3 . There is considerable overlap in the concentrations of trace elements in plagioclase amongst samples from all the different groups of eucrites in the sample suite and, as such, they are all considered together here, rather than in separate groups. Plagioclase has a range of La concentrations from $0.17-1.91$ ppm, which correlates pos- 

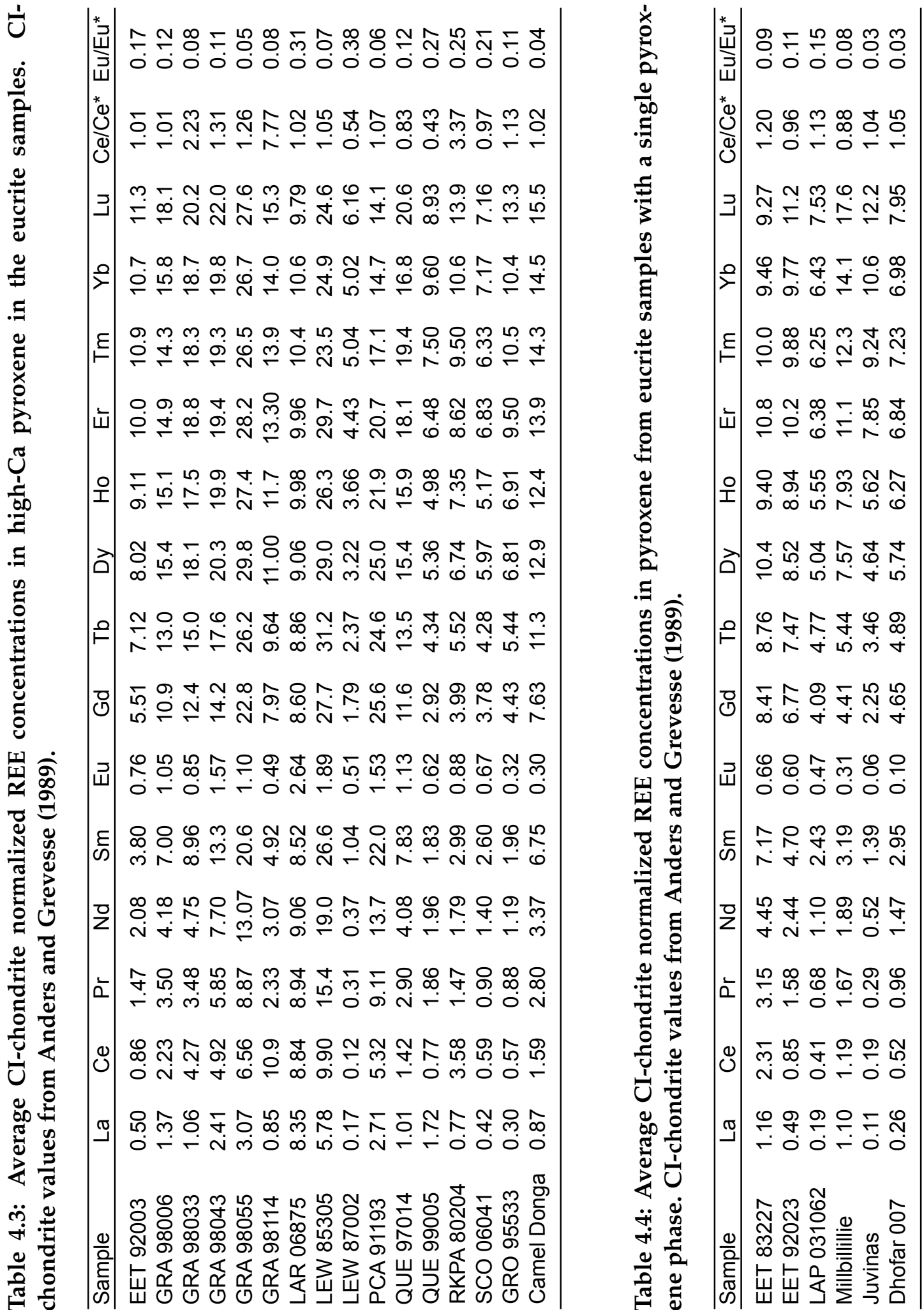
itively with $\mathrm{Sr}$ concentrations (4.3). However, $\mathrm{Li}$ and $\mathrm{Ba}$ concentrations do not correlate with La concentrations in plagioclase. No correlations exist between the concentrations of $\mathrm{Sr}, \mathrm{Li}, \mathrm{Ba}$ and $\mathrm{La}$ and $\mathrm{Ce}$ anomalies. $\mathrm{Eu}$ anomalies in plagioclase range from 5.9-57.3 across the sample suite and correlate negatively with $\mathrm{Sr}$ concentration (4.6), and positively with La concentration. Although increasing La is correlated with increasingly smaller positive Eu anomalies, no obvious correlations exists between the concentrations of $\mathrm{Li}$ and $\mathrm{Ba}$, and $\mathrm{Eu}$ anomalies. The CI-chondrite normalized La/Sm ratio in plagioclase ranges from 1.3-3.8 across the sample suite, which does not correlate with $\mathrm{Li}$, $\mathrm{Sr}$ and Ba concentrations, but does correlate with light and middle REE concentrations.

\section{Low-Ca Pyroxene}

As is the case for plagioclase there is overlap in the concentrations of trace elements in low-Ca pyroxene amongst samples from all the different groups of eucrites in the sample suite, so they are not considered here in individual groups (Table 4.7. Fig. 4.4). However, the Mg-rich samples do exhibit systematic differences from the other samples, particularly in terms of $\mathrm{Yb}$ concentrations, $\mathrm{Eu}$ anomalies and $\mathrm{Ce}$ anomalies (Fig. 4.4. There is a strong positive correlation in low-Ca pyroxene across the entire suite of samples between most of the HREE (Fig. 4.8). Pr, Nd and Sm also correlate well across the entire sample suite, as do Sm, Gd and Tb (Table 4.8). There is a negative correlation between the concentrations of Sc and $\mathrm{Yb}$ and $\mathrm{Eu}$ anomalies in low-Ca pyroxene (Fig. 4.4 E, H and P) . Sc positively correlates with $\mathrm{Yb}$, whereas $\mathrm{V}$ and $\mathrm{Yb}$ exhibit a general negative correlation (Fig. 4.4 R). Al and Eu appear to exhibit a subtle positive correlation (Fig. 4.4 U), as do Ti and Hf (Fig. 4.4 T), and Hf and Zr (Fig. 4.4 $\mathrm{V})$. La concentrations do not correlate with the concentrations of $\mathrm{Li}, \mathrm{Sc}, \mathrm{V}$ and $\mathrm{Yb}$ in low-Ca pyroxene. There is no correlation between $\mathrm{Yb}$ concentrations and Li concentrations, or between $\mathrm{Ce}$ anomalies and concentrations of $\mathrm{Li}, \mathrm{Sc}, \mathrm{Yb}$ and $\mathrm{La}$ (Fig. 4.4). The concentrations of $\mathrm{Li}$ and $\mathrm{La}$ do not 


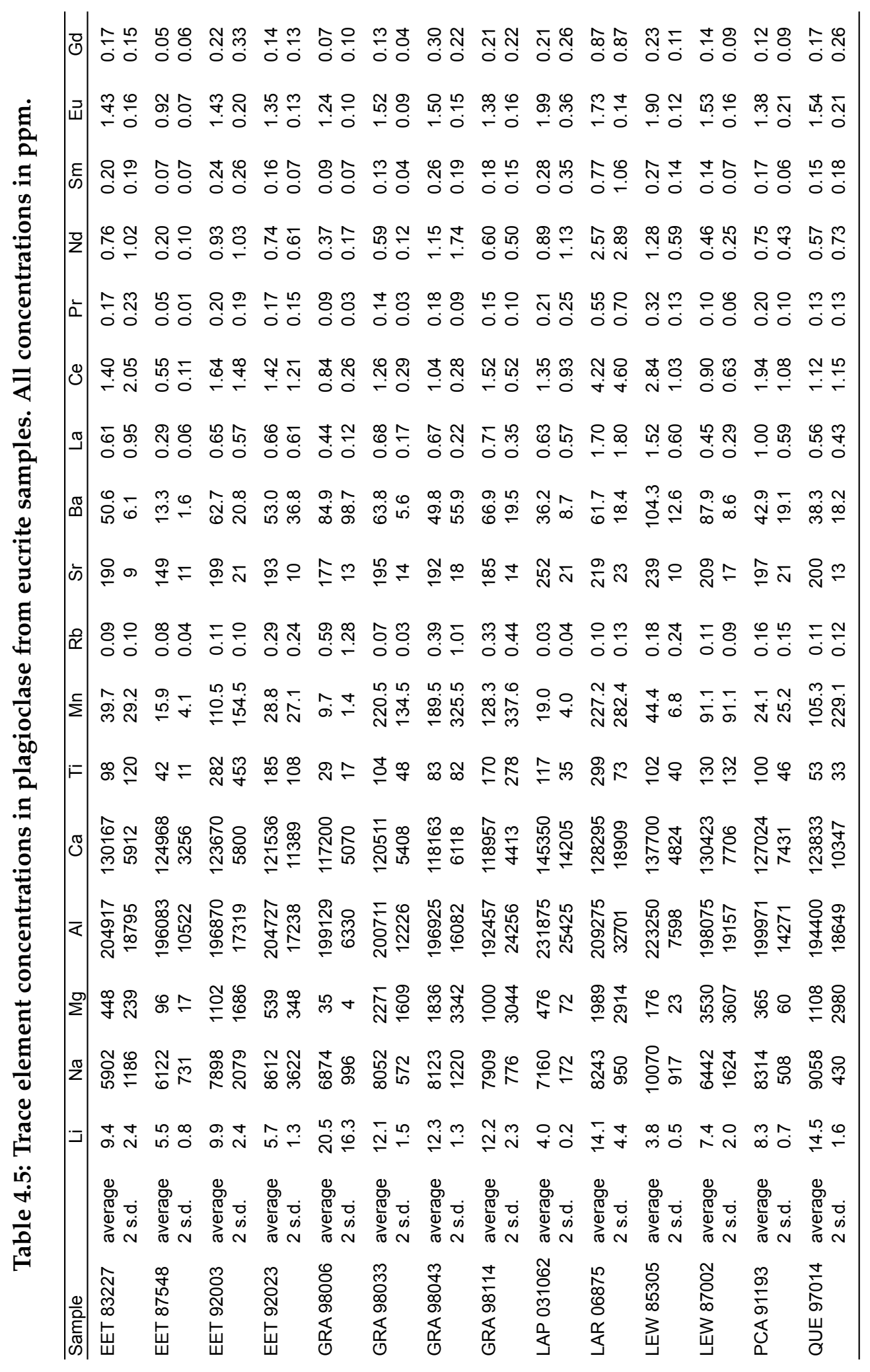




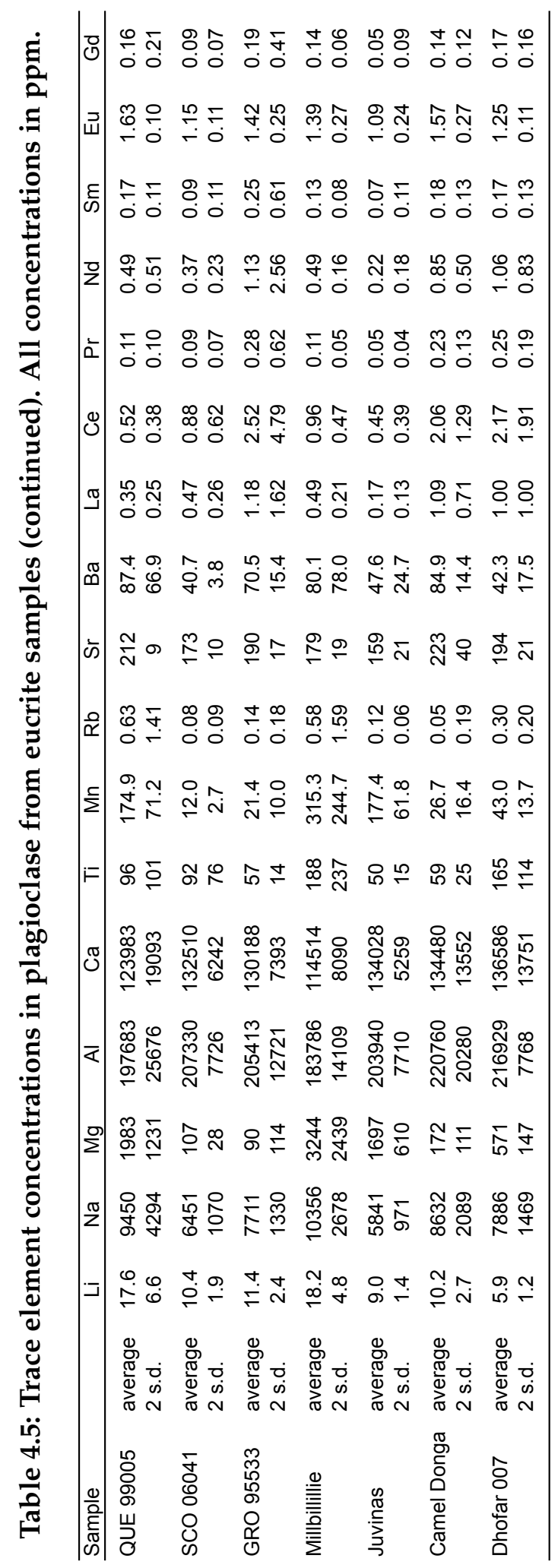



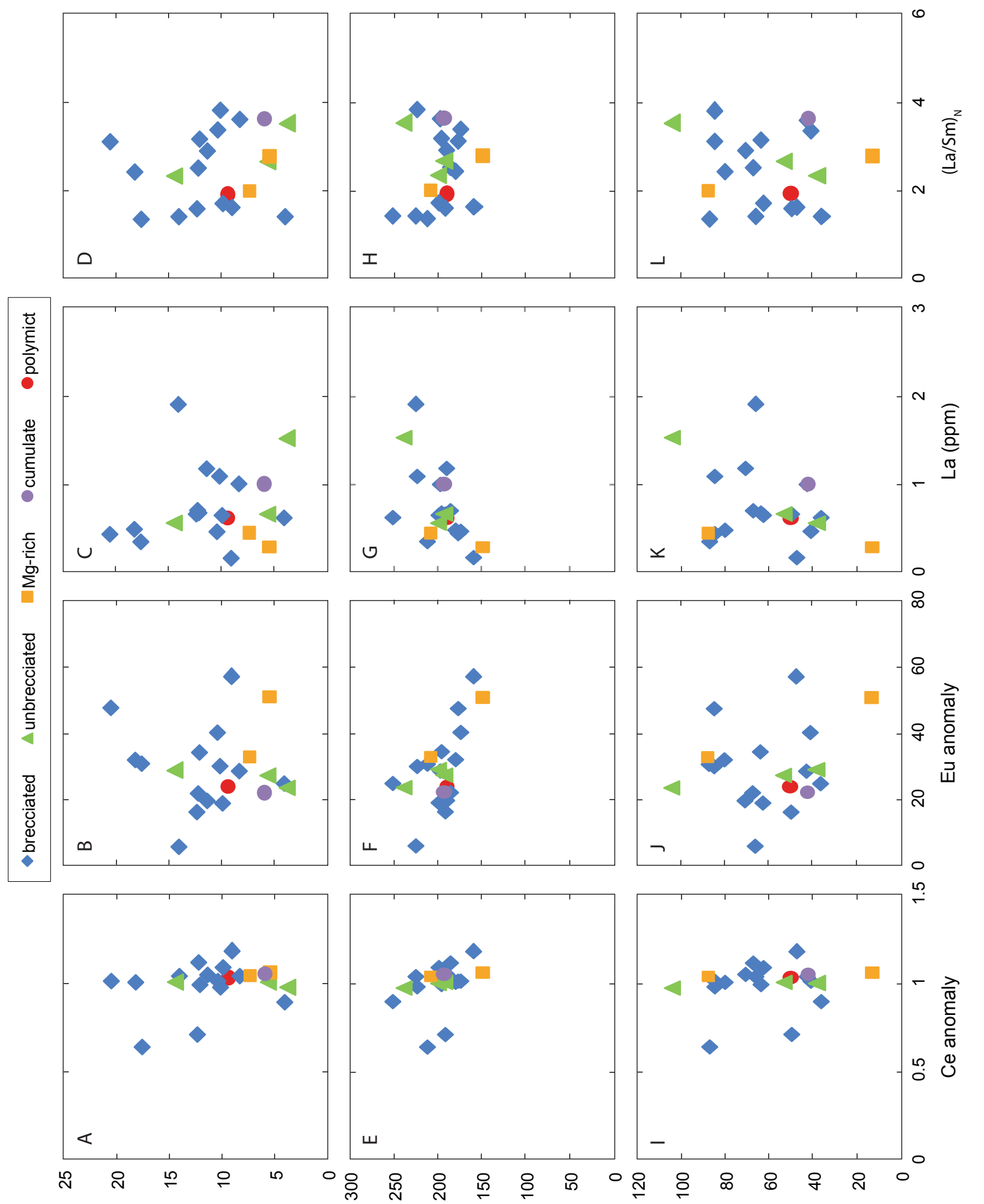

(udd) !7
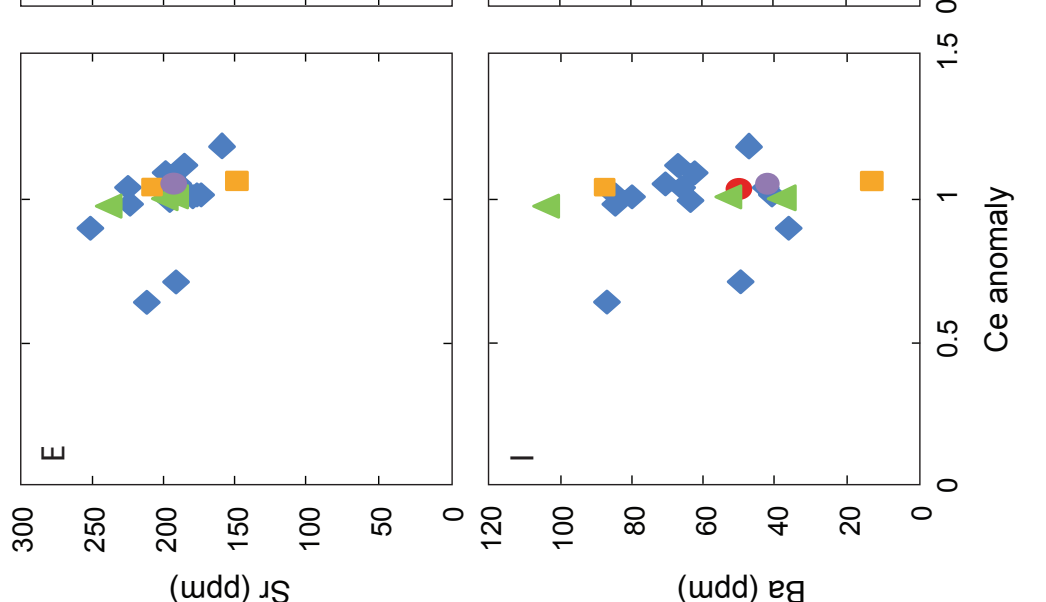

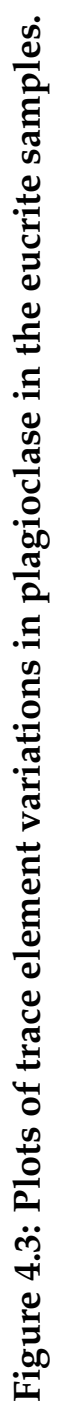
(udd) eg 

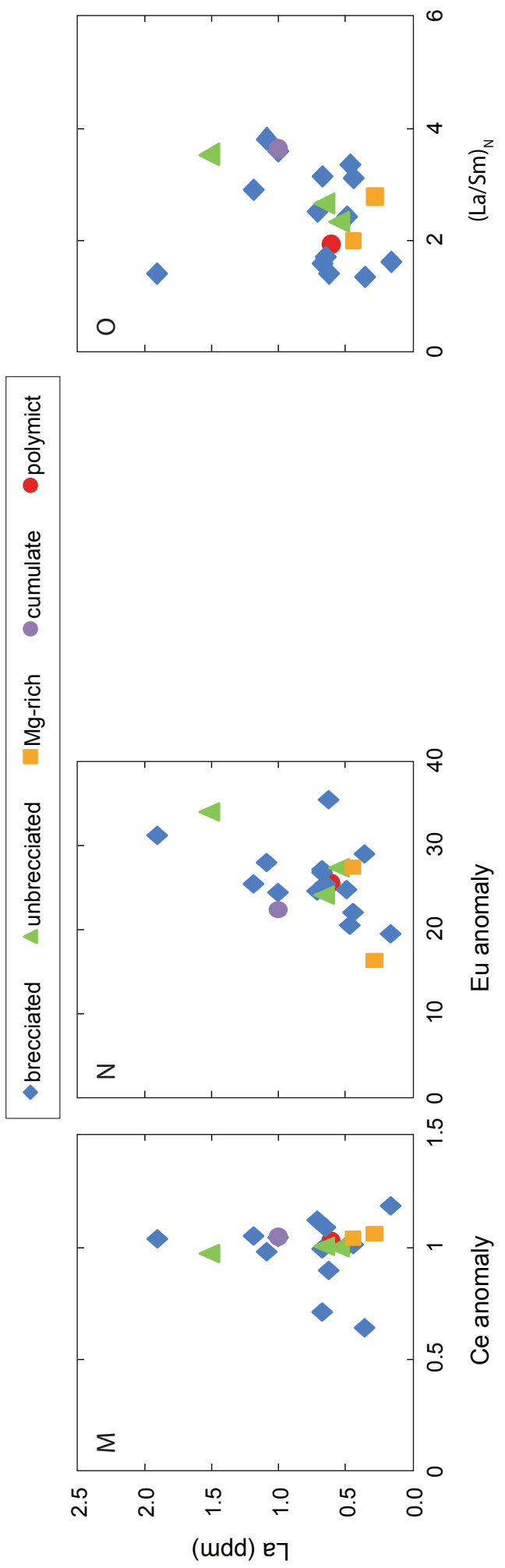


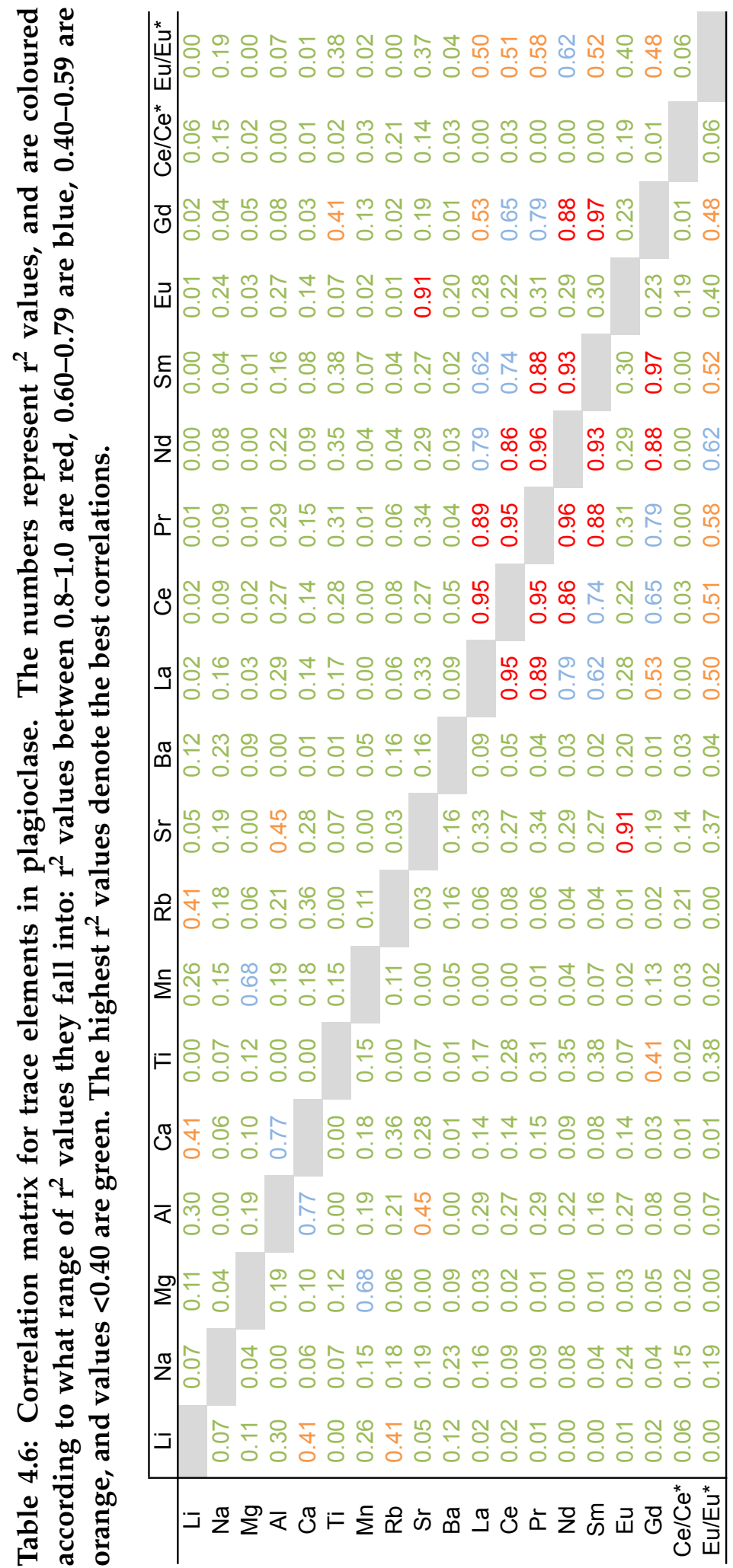


correlate with $\mathrm{Eu}$ anomalies. Chondrite normalized $\mathrm{La} / \mathrm{Sm}$ ratios range from 0.1-0.9 and correlate with La concentration (Fig. 4.4 J) but not with concentrations of $\mathrm{Li}, \mathrm{Sc}$ or $\mathrm{Yb}$.

\section{High-Ca Pyroxene}

Like the other mineral phases, trace element concentrations in high-Ca pyroxene amongst samples from the different groups of eucrites in the sample suite overlap, and so they are considered together here (Fig. 4.5; Table 4.9). There is a strong positive correlation in high-Ca pyroxene across the entire suite of samples between the different heavy REE (Table 4.10). Light REE also correlate positively with each other, and Sm is correlated with most heavy REE across the entire sample suite (Table. 4.10) . There are positive trace element correlations amongst the entire group of samples, including Mg-rich samples, between La and Eu (Fig. 4.5 W), Sc and Eu (Fig. 4.5 E), Sc and La (Fig. 4.5 O), $\mathrm{Na}$ and $\mathrm{Nd}, \mathrm{Na}$ and Pr (Table 4.10), Pr and $\mathrm{Nd}$, and $\mathrm{Zr}$ and $\mathrm{Hf}$ in the high-Ca pyroxene phase (Table 4.10). However, there are also a number of other trace element correlations for the brecciated and, possibly, unbrecciated eucrites, which the Mg-rich eucrites are not part of, largely due to their distinct middle to heavy REE concentrations (Table 4.9). As is the case for low-Ca pyroxene, the high-Ca pyroxene phases in the $\mathrm{Mg}$-rich samples have distinct $\mathrm{Eu}$ anomalies compared to the other samples (Fig. 4.5 B-K). Trace element analyses of the high-Ca pyroxene exhibit general positive correlations between $\mathrm{Yb}$ and $\mathrm{La}$ (Fig. 4.5 S), V and La (Fig. 4.5Q), Sc and La (Fig. 4.5 O) and, possibly, Li and La concentrations in the brecciated eucrites (Fig. 4.5 M). Li, Sc and V concentrations appear to positively correlate with $\mathrm{Yb}$ concentrations (Fig. $4.5 \mathrm{~N}, \mathrm{P}$ and R). However, there is no clear correlation between Sc and V. $\mathrm{Eu}$ concentrations correlate with concentrations of both $\mathrm{Sc}$ and $\mathrm{Yb}$ (Fig. 4.5 $\mathrm{E}$ and $\mathrm{H}$ ), and Sc concentration also correlates positively with middle and heavy REE concentrations (Table 4.10). Na correlates positively with concentrations of some light REE (e.g., Pr, Table 4.10) and geochemically similar $\mathrm{Zr}$ and Hf are also positively correlated (Table 4.10). Ce anomalies 
and CI-chondrite normalized $\mathrm{La} / \mathrm{Sm}$ ratios do not correlate with $\mathrm{Li}$, Sc or $\mathrm{Yb}$ concentrations (Fig. 4.5 A, D and J), although there is a correlation between La/Sm ratios and La concentrations (Fig. 4.5J).

\section{Single-phase pyroxene}

Five samples only contain one pyroxene phase on the basis of trace element chemistry. The trace element concentrations are detailed in Table 4.11. however with relatively few samples it is difficult to identify meaningful trace element correlations. However, there does appear to be a negative correlation between the concentrations of $\mathrm{Sc}$ and $\mathrm{Yb}$ and Ce anomalies (Fig. 4.6 F and I). There also appears to be positive correlations between the concentration of both $\mathrm{V}$ and $\mathrm{Sc}$ and the $\mathrm{Yb}$ concentration (Fig. $4.5 \mathrm{R}$ and $\mathrm{P})$.

\subsubsection{Correlations between plagioclase and pyroxene trace element data}

There is no correlation between concentrations of $\mathrm{La}, \mathrm{Li}, \mathrm{Sr}$ and $\mathrm{Eu}$ and Ce anomalies in plagioclase and pyroxene (Fig $4.7 \mathrm{~A}, \mathrm{~B}, \mathrm{C})$. There is a general positive correlation between $\mathrm{Yb}$ in pyroxene and $\mathrm{La}$ in plagioclase (Fig. 4.5 E), with $\mathrm{Yb}$ concentrations in pyroxene increasing from 0.6-4.0 ppm across the entire eucrite suite, and La concentration in plagioclase increasing from $0.2-1.5 \mathrm{ppm}$ (excluding one sample). In addition, Eu concentrations in plagioclase positively correlate with $\mathrm{Yb}$ concentrations in pyroxene (Fig. 4.5F). 


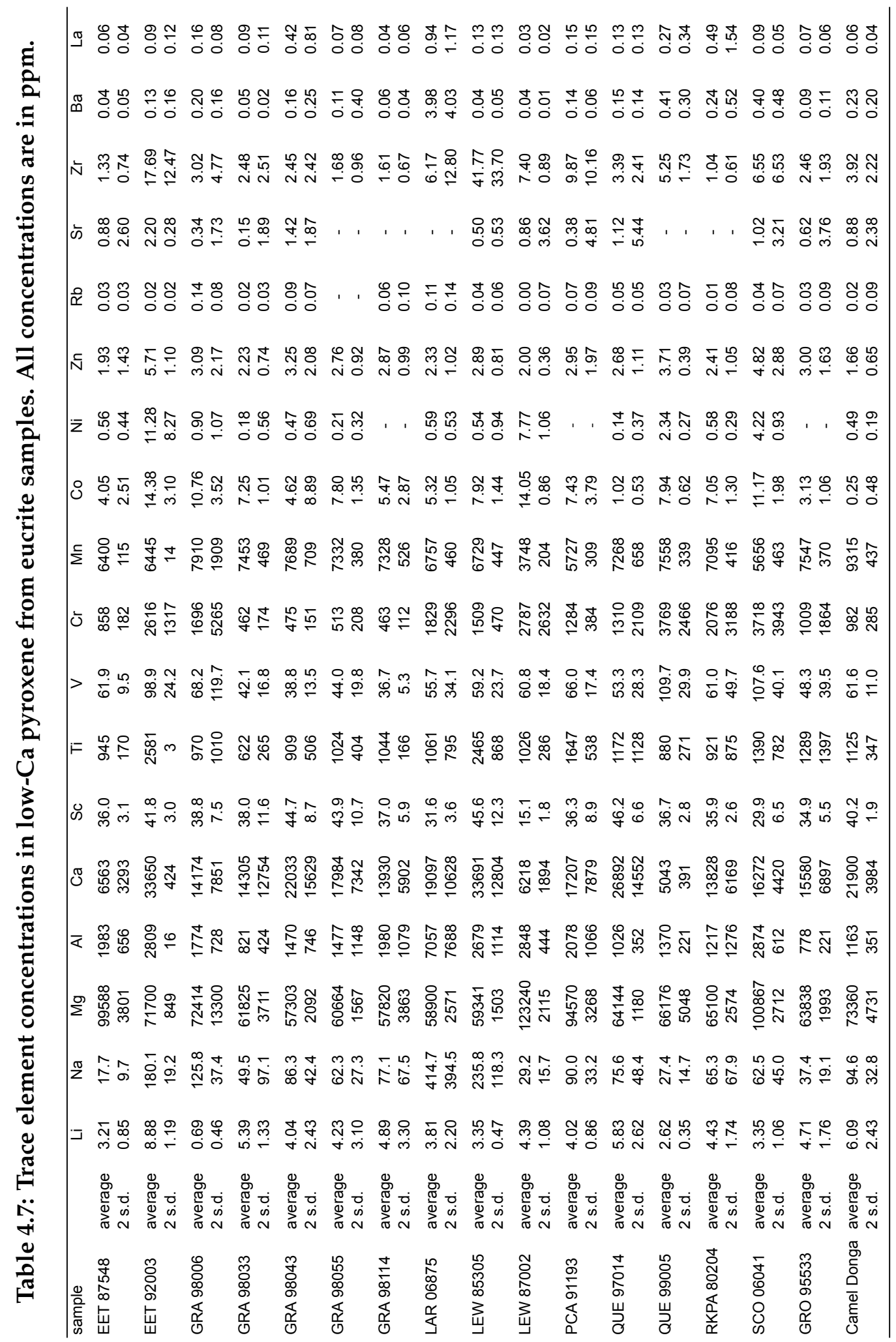




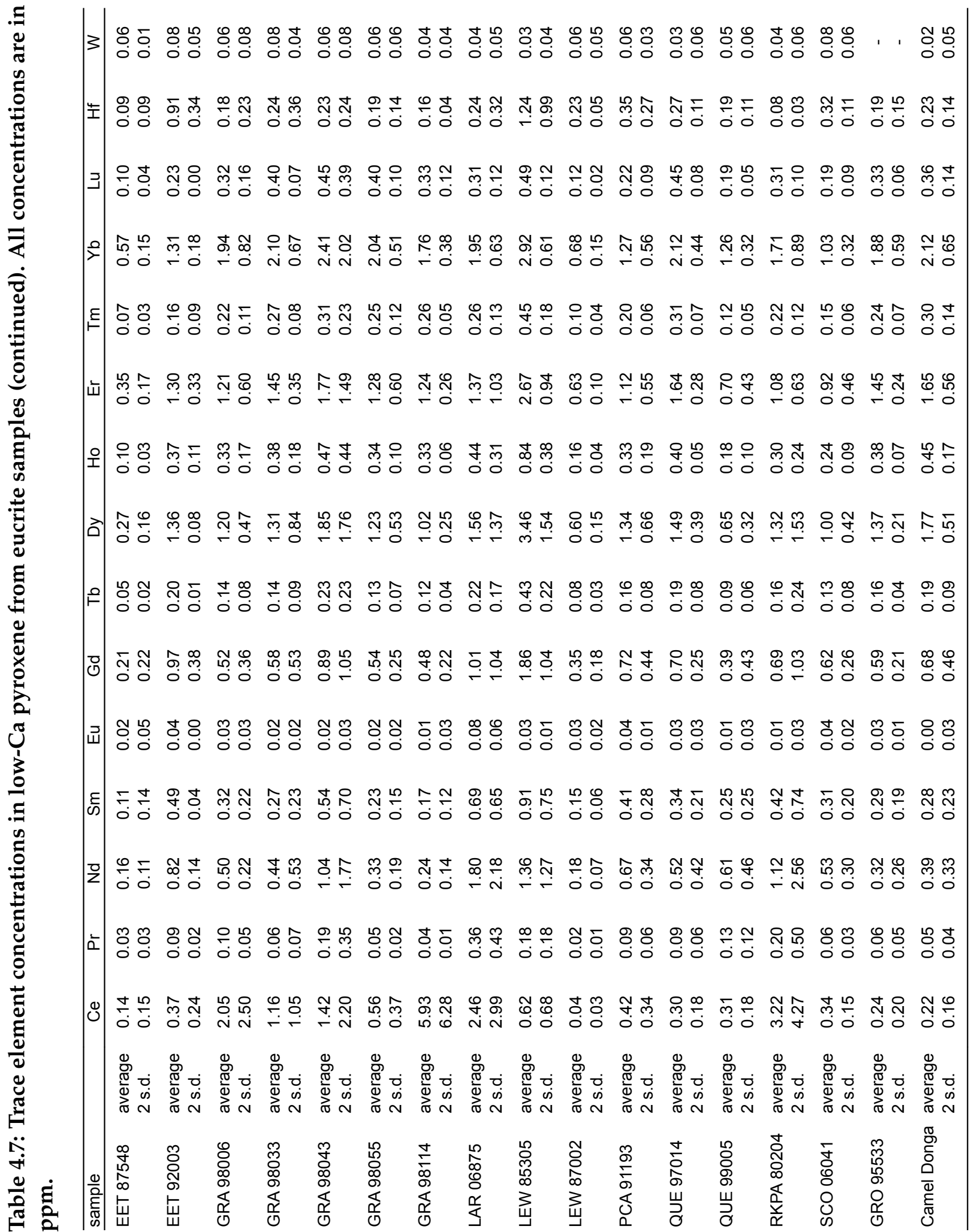




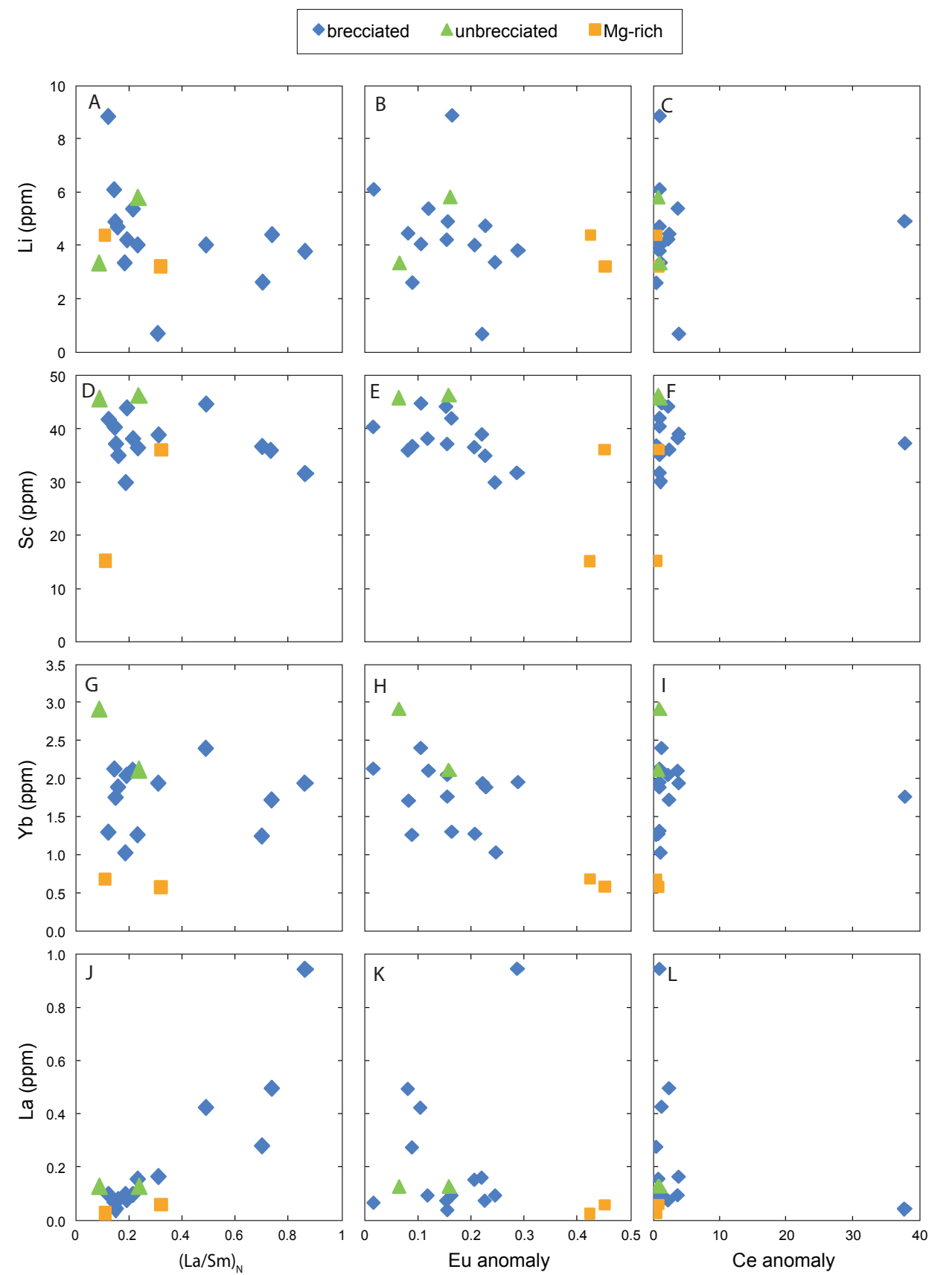

Figure 4.4: Plots of trace element variations in low-Ca pyroxene in the eucrite samples. 


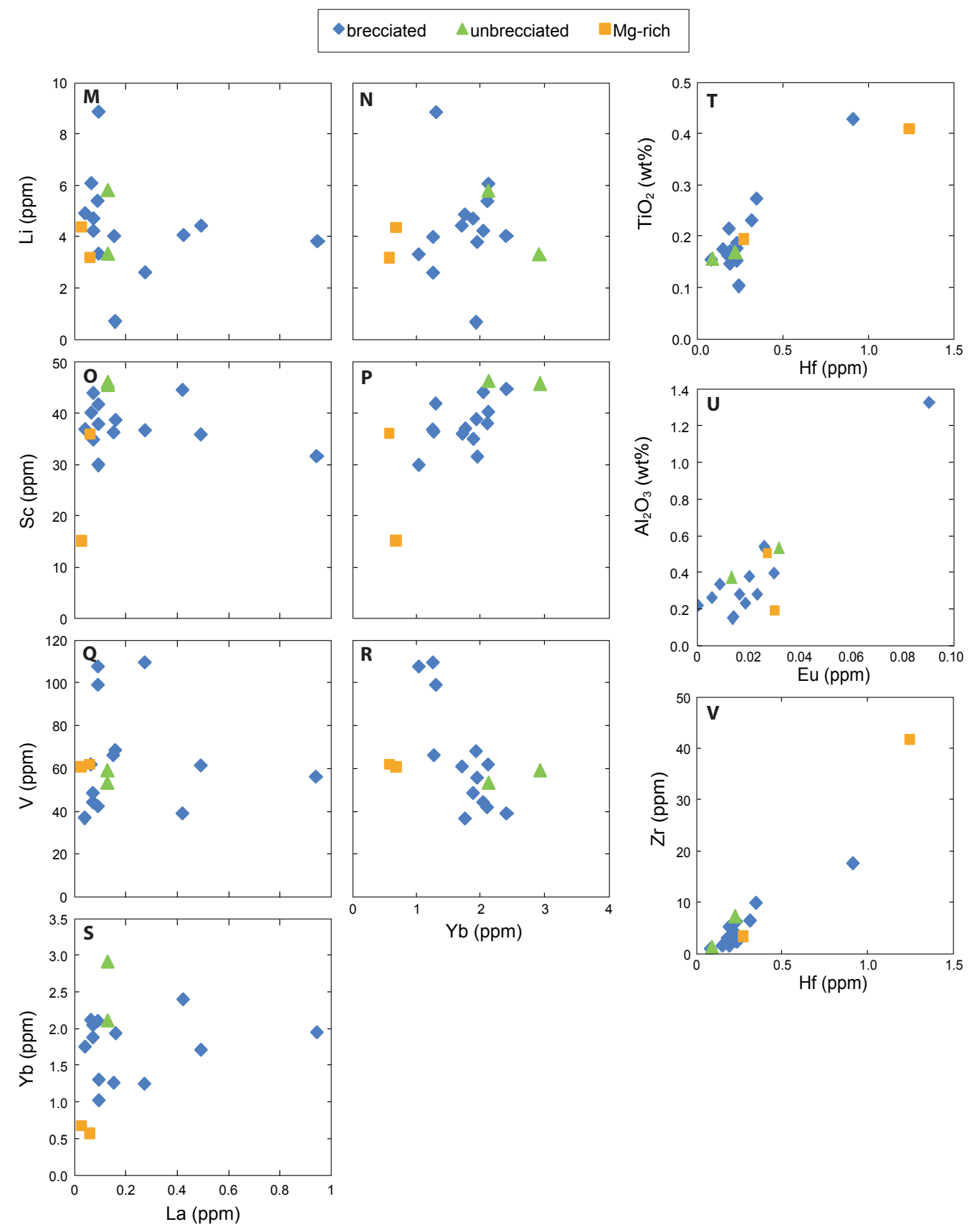

Figure 4.4: Trace element concentrations in low-Ca pyroxene from eucrite samples (continued). All concentrations are in ppm. 


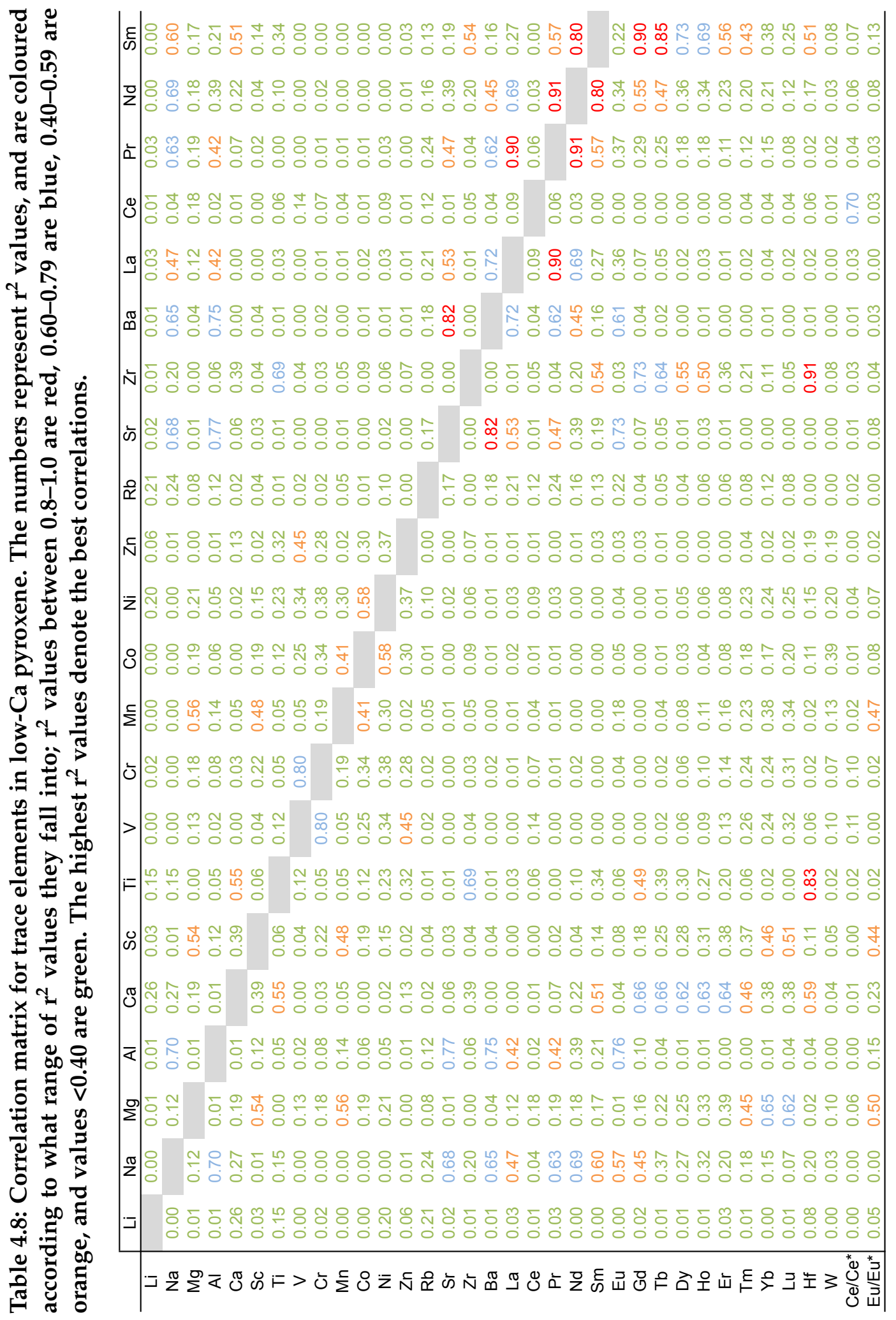




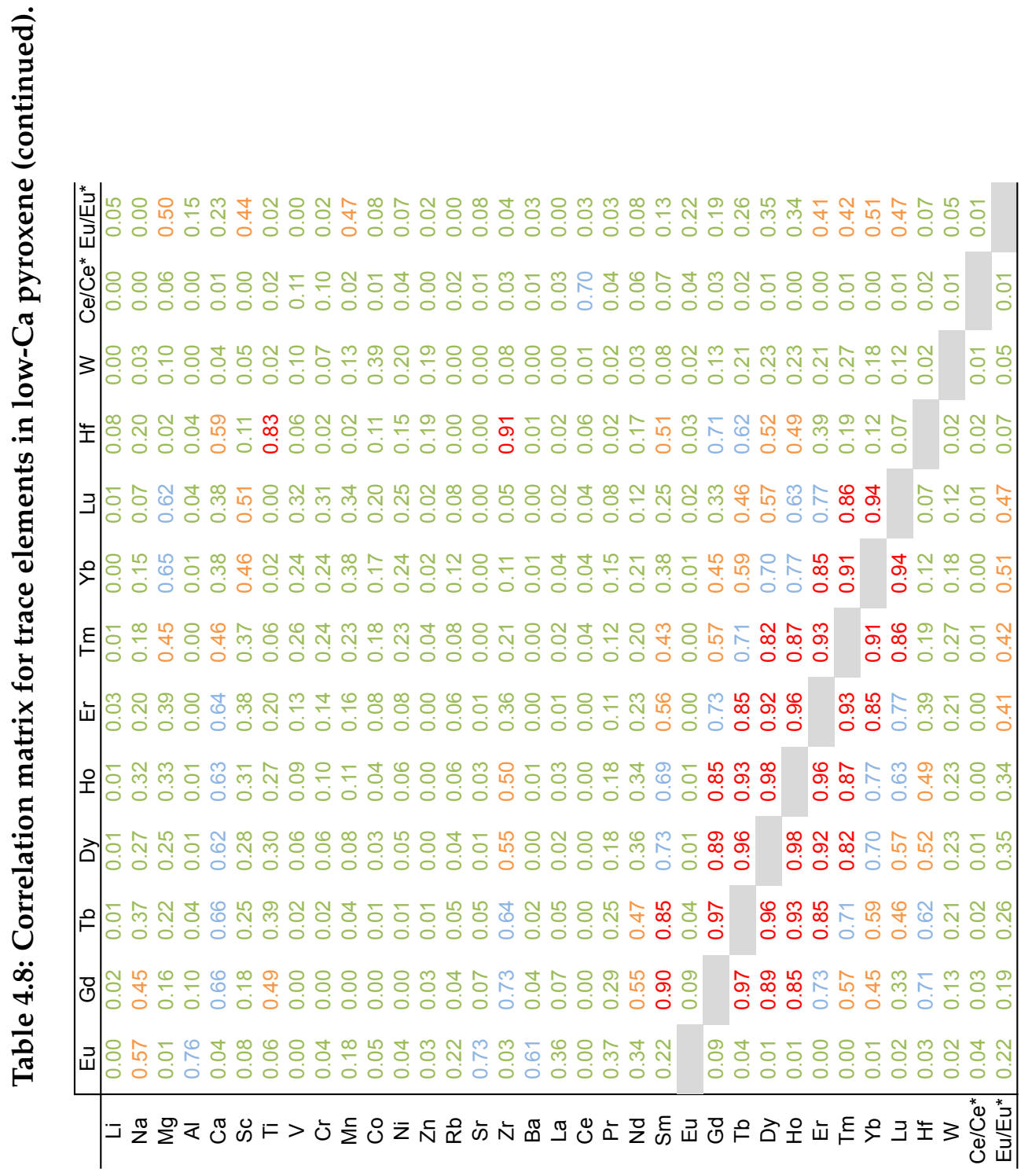




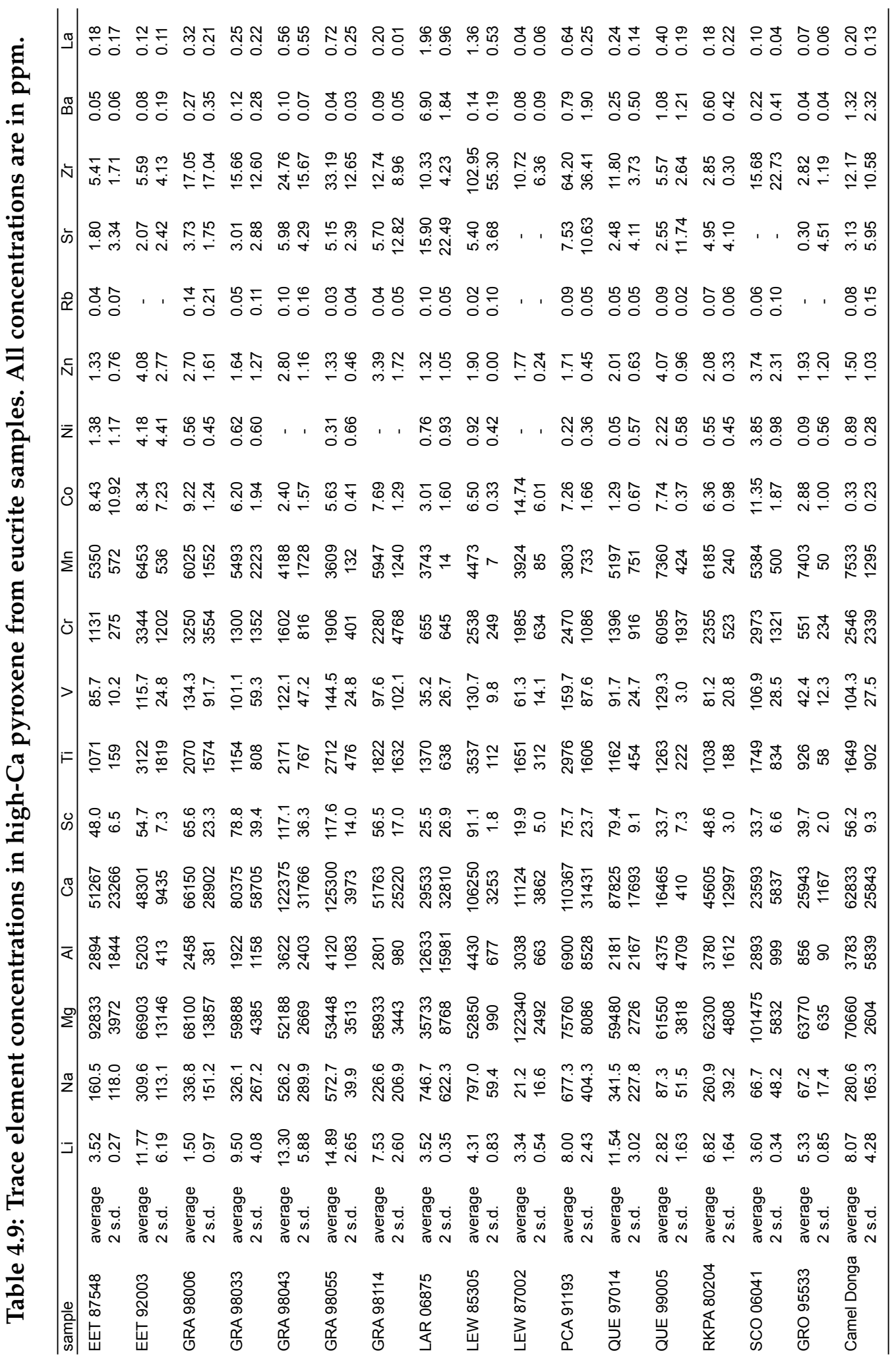




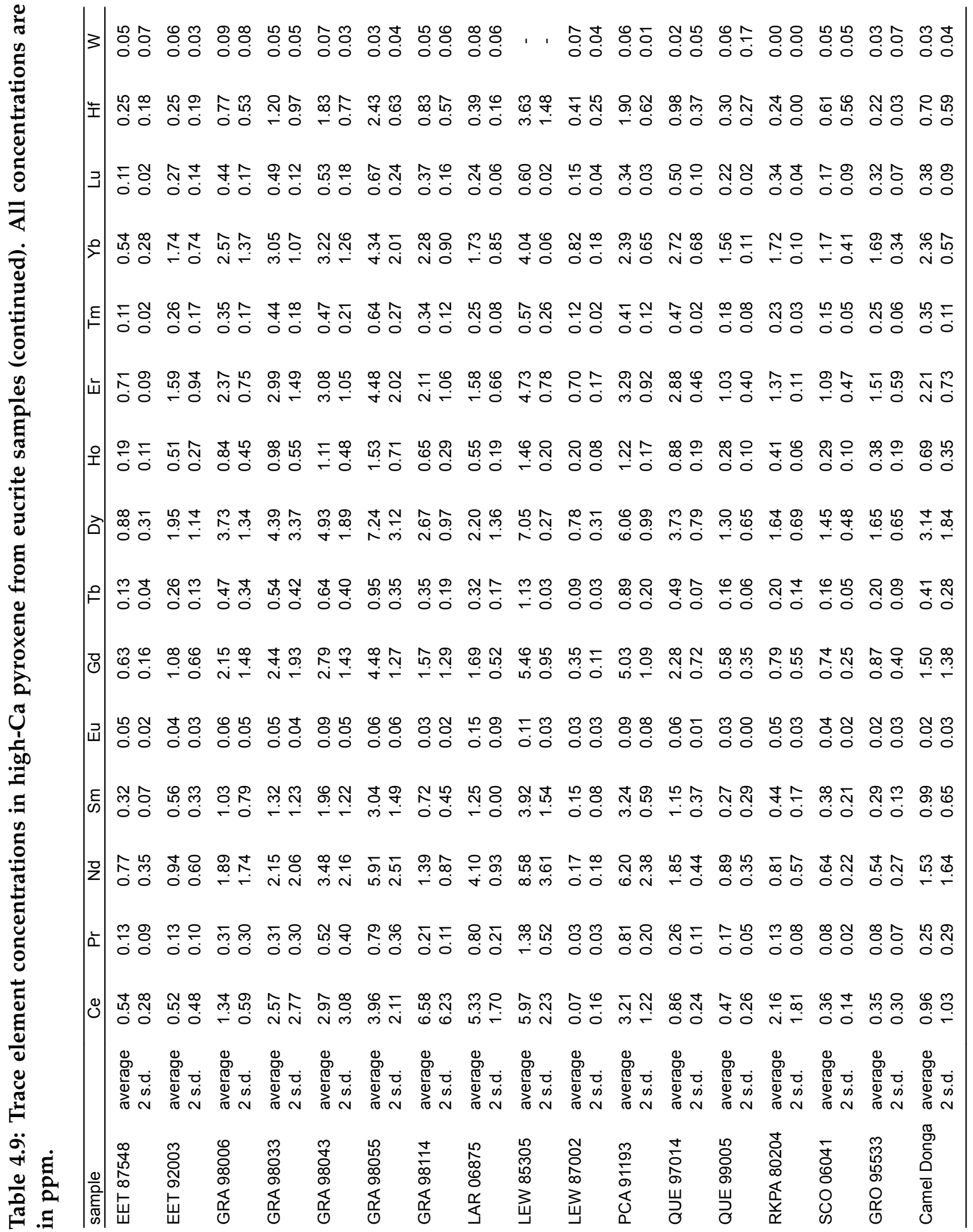




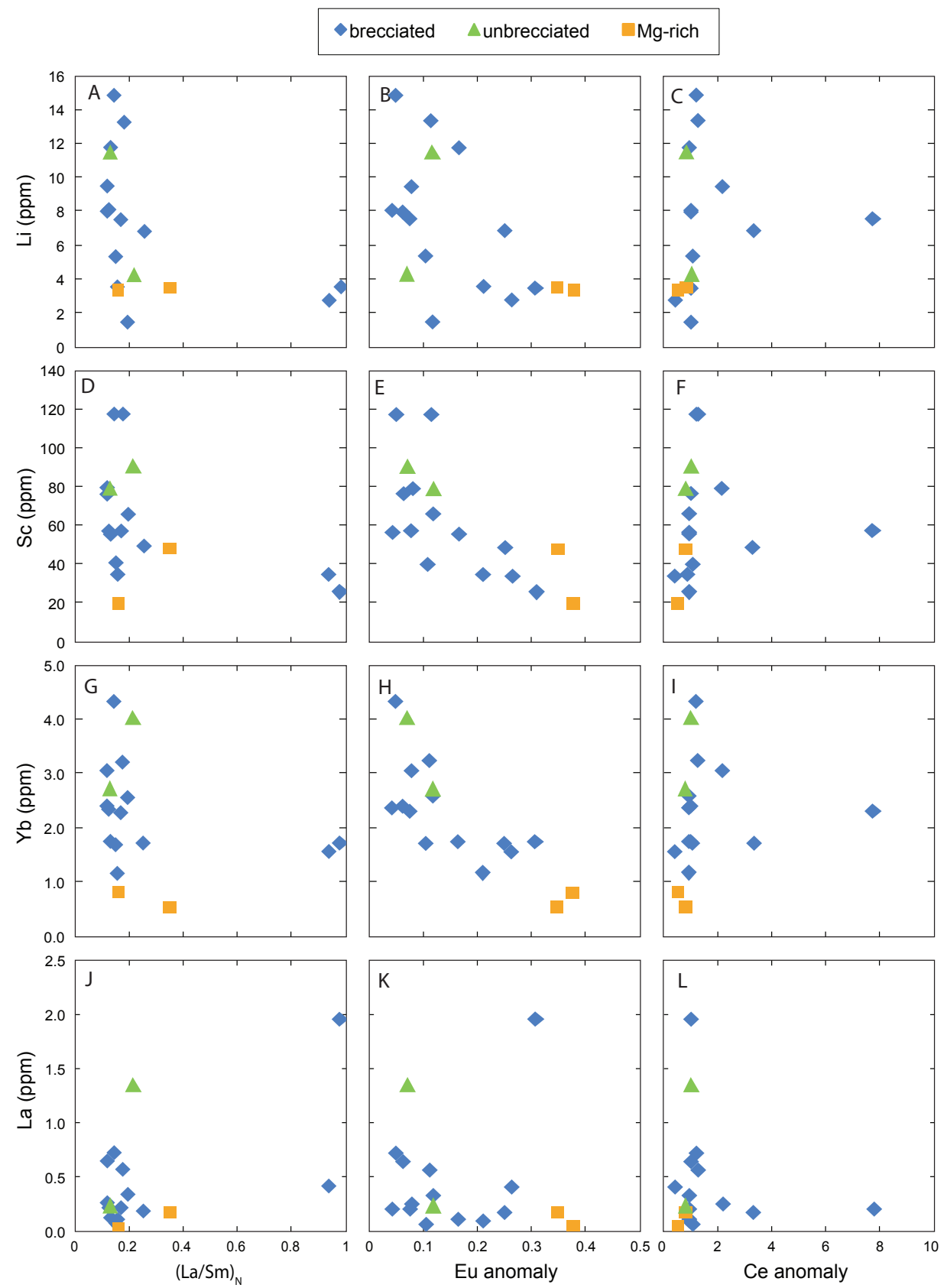

Figure 4.5: Plots of trace element variations in high-Ca pyroxene from eucrite samples. 


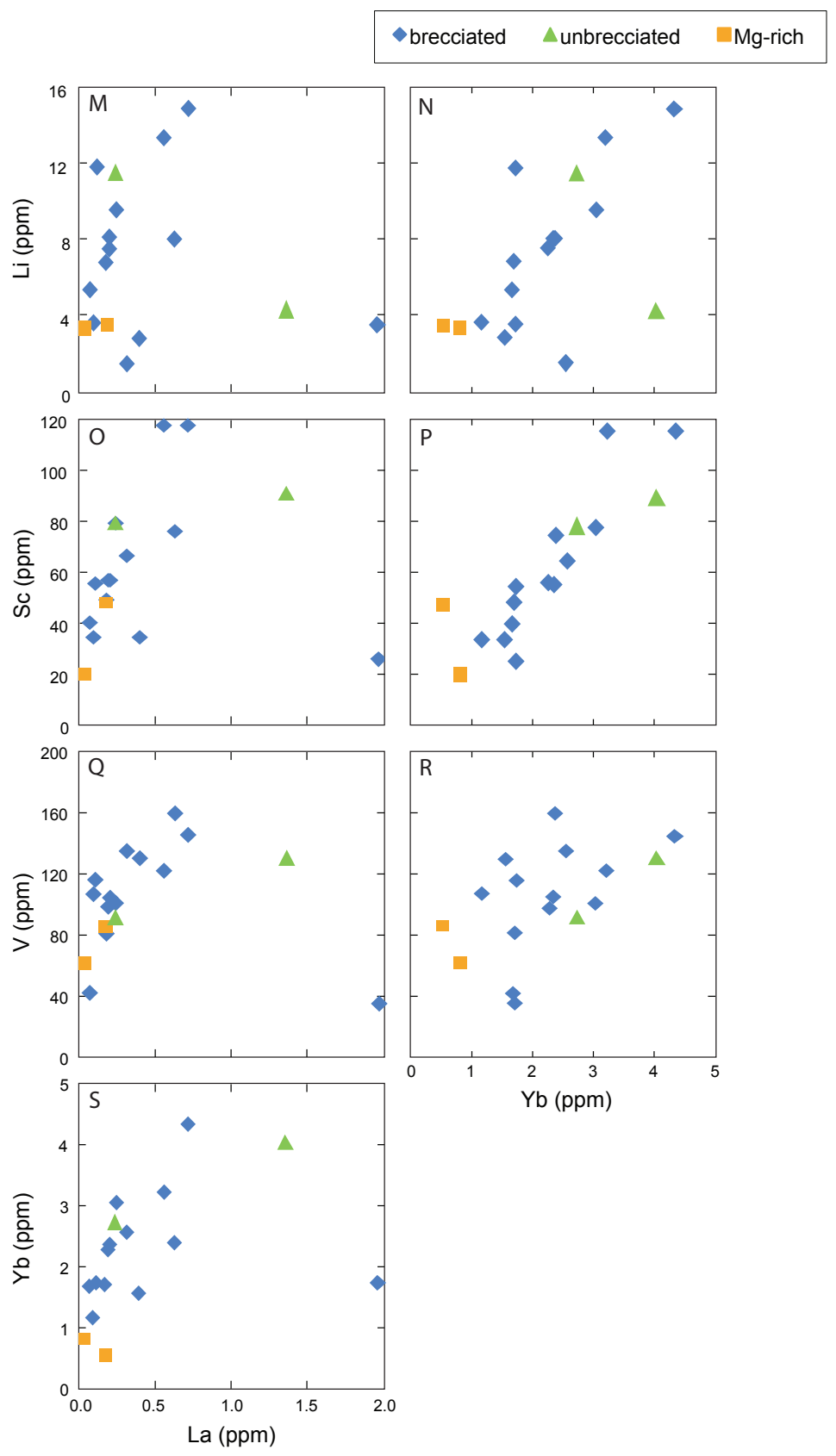

Figure 4.5: Plots of trace element variations in high-Ca pyroxene from eucrite samples (continued). 


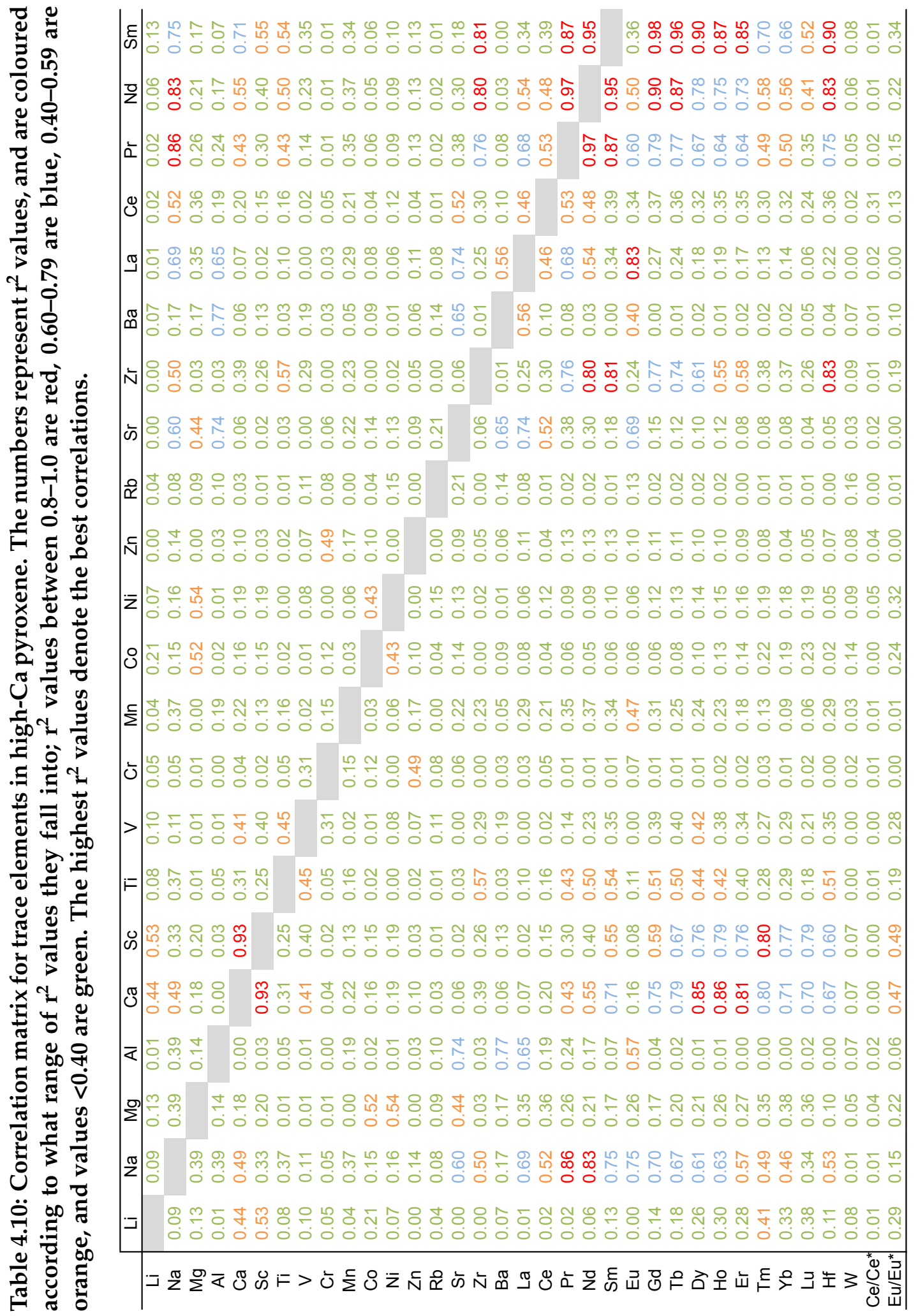




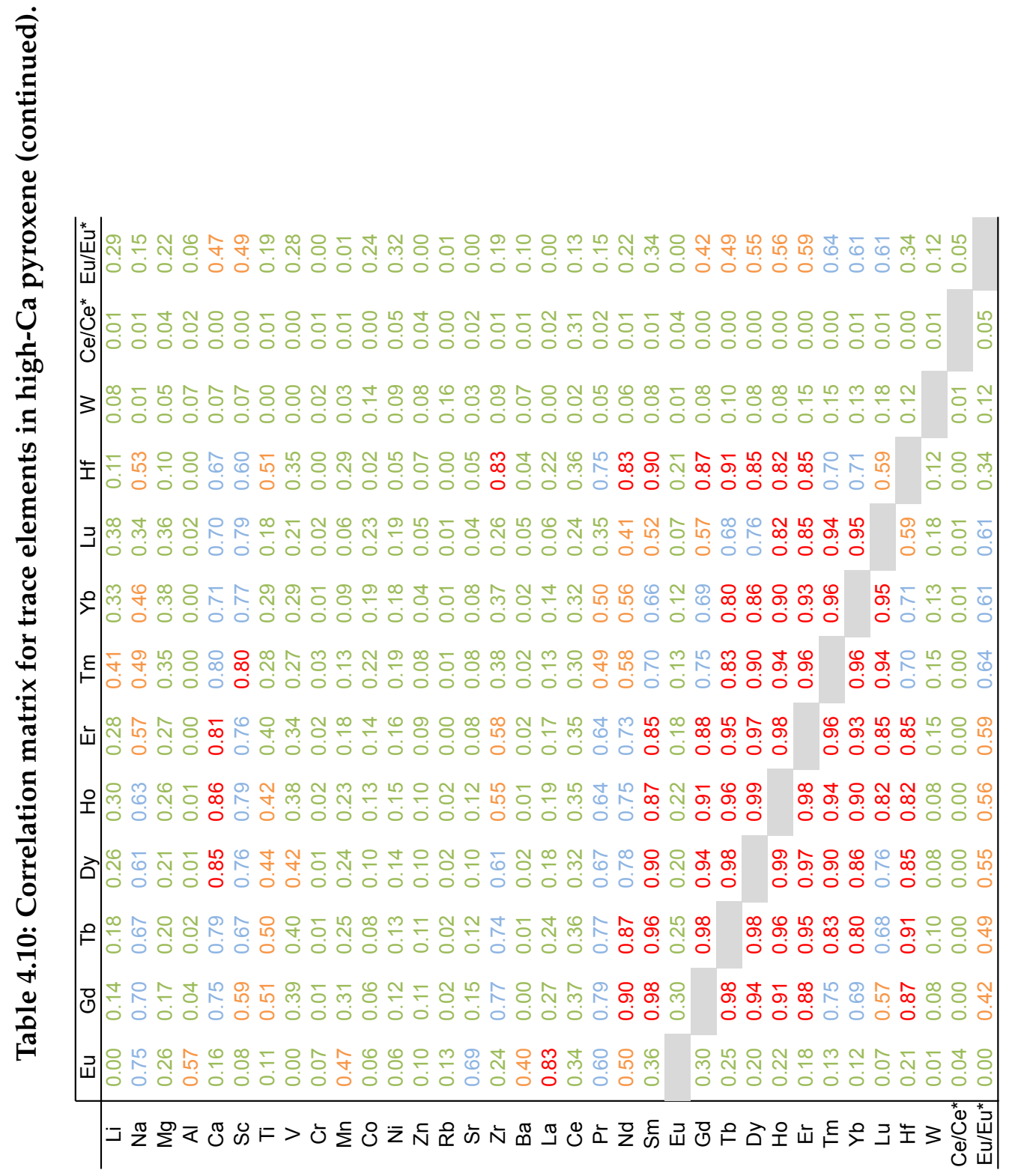




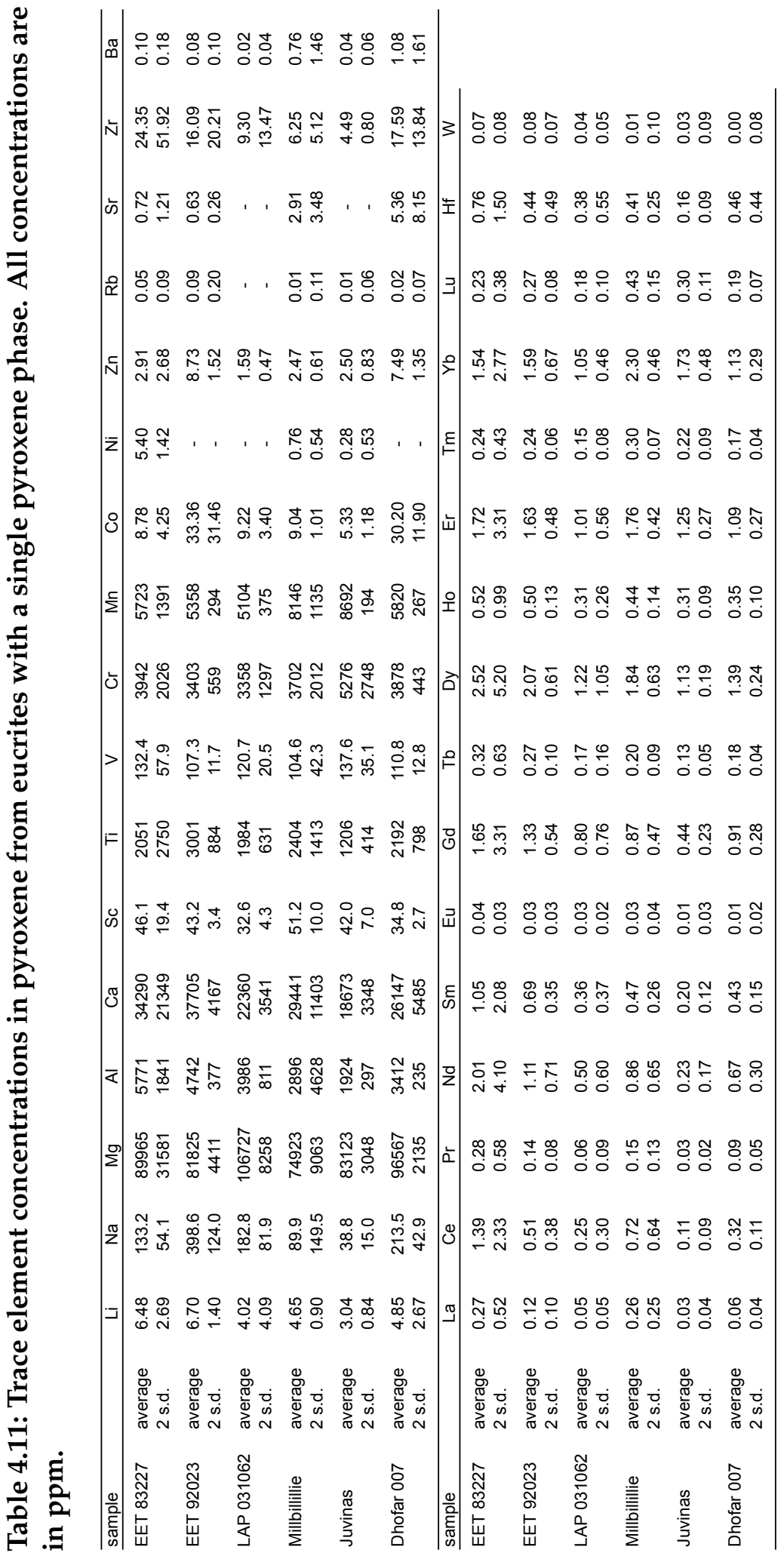




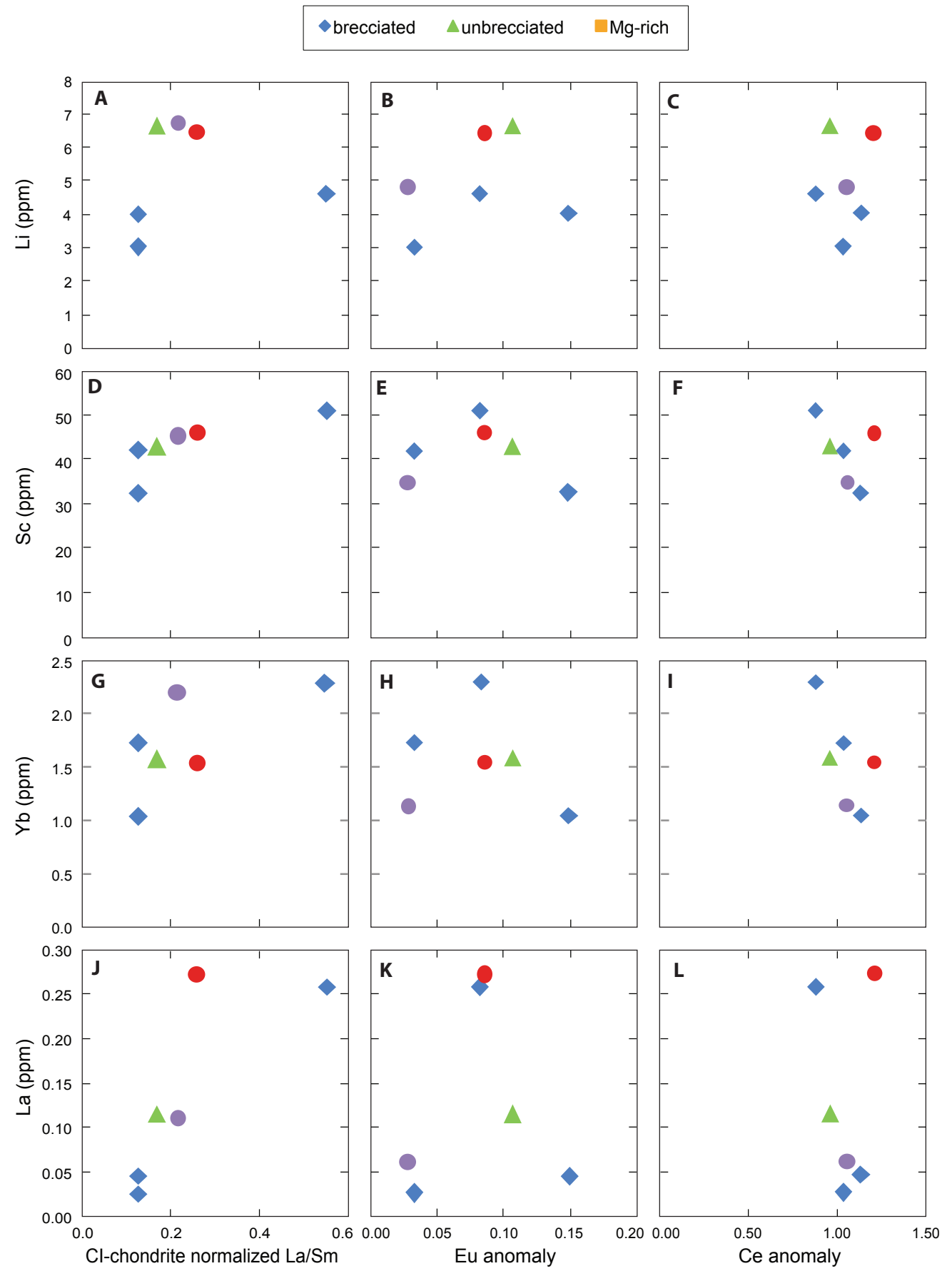

Figure 4.6: Plots of trace element variations in pyroxene from eucrites with a single pyroxene phase. 

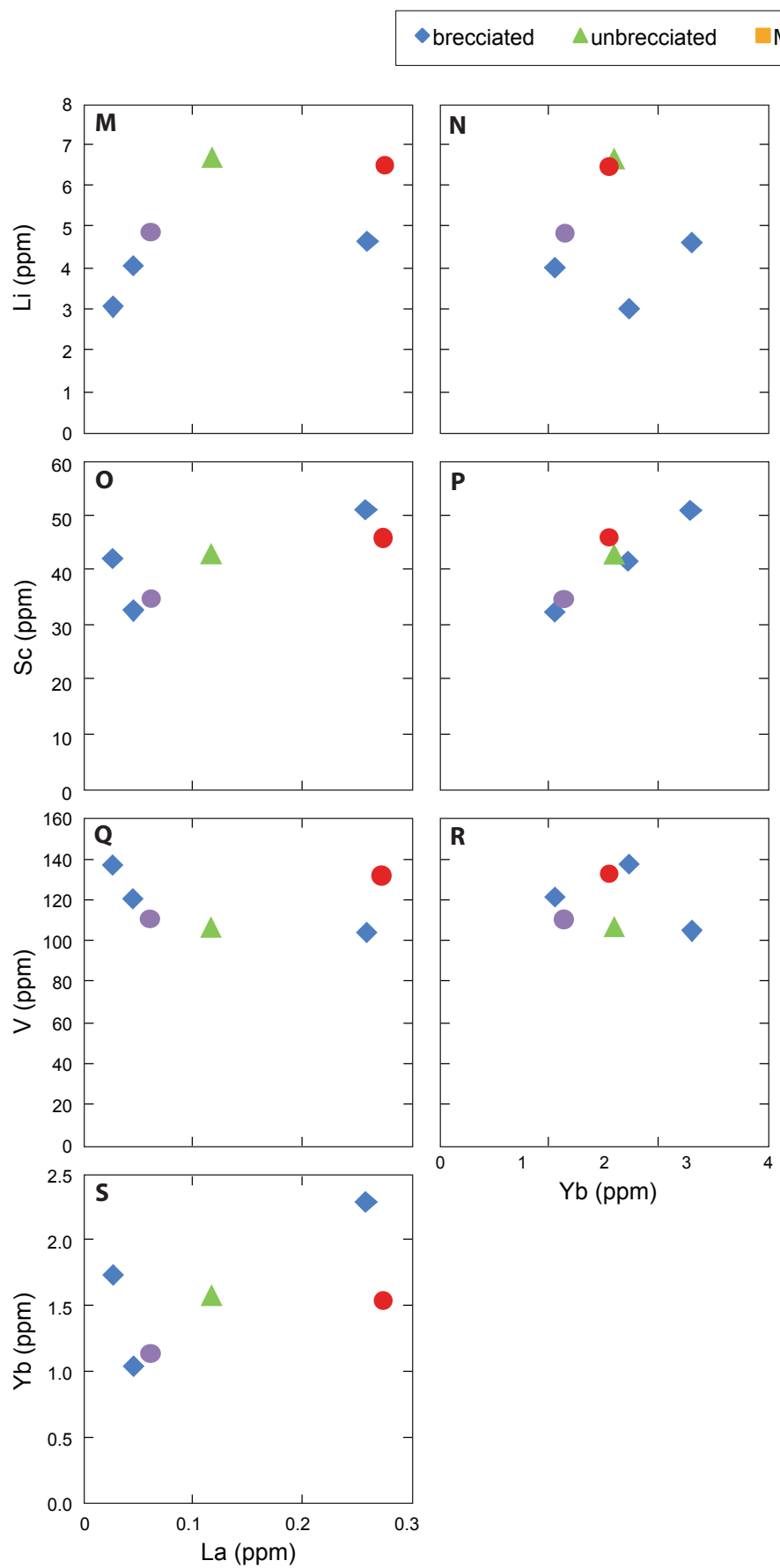

Figure 4.6: Plots of trace element variations in pyroxene from eucrites with a single pyroxene phase (continued). 

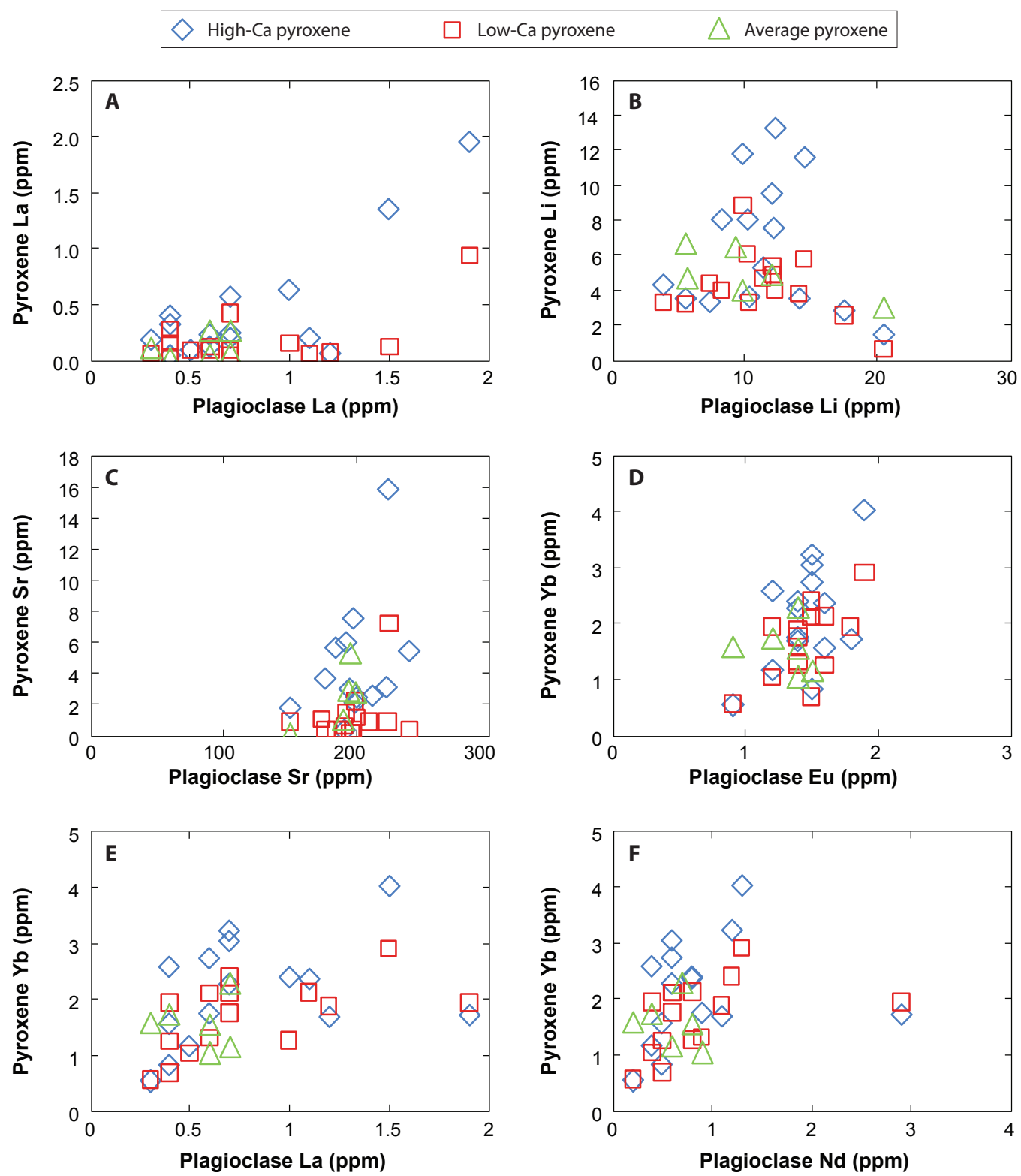

Figure 4.7: Variation in trace elements in plagioclase and pyroxene from eucrites. 


\section{Chapter 5}

\section{${ }^{26} \mathrm{Al}-{ }^{26} \mathrm{Mg}$ isotope data}

${ }^{26} \mathrm{Al}-{ }^{26} \mathrm{Mg}$ isotope data were collected for all of the eucrites in the samples suite, with the exception of Dhofar 007 (Table 5.1). This chapter briefly discusses this data in four sections: ${ }^{27} \mathrm{Al} /{ }^{24} \mathrm{Mg}$ ratios, ${ }^{26} \mathrm{Mg}$ isotope anomalies $\left(\delta^{26} \mathrm{Mg}^{*}\right)$, stable $\delta^{25} \mathrm{Mg}$ isotope data, and model initial ${ }^{26} \mathrm{Al} /{ }^{27} \mathrm{Al}$ values and ages. Standard-sample bracketing was used to conduct the isotopic measurements presented in this chapter. Mg separated from the dunite standard DTS was used as the bracketing standard. Mg isotope ratios are expressed as the per mil (\%o) deviations from the mean $\mathrm{Mg}$ isotopic composition measured on the bracketing standards:

$$
\delta^{x} M g=\left[\frac{\left(\frac{x M g}{24 M g}\right)_{\text {sample }}}{\left(\frac{x_{M g}}{24 M g}\right)_{\text {standard }}}-1\right] \times 10^{3}
$$

where ${ }^{\times} \mathrm{Mg}$ is either ${ }^{25} \mathrm{Mg}$ or ${ }^{26} \mathrm{Mg}$. To calculate the mass-independent ${ }^{26} \mathrm{Mg}$ anomalies $\left(\delta^{26} \mathrm{Mg}^{*}\right)$ after correction for instrumental mass bias, the measured ${ }^{26} \mathrm{Mg} /{ }^{24} \mathrm{Mg}$ ratios were normalized to a ${ }^{25} \mathrm{Mg} /{ }^{24} \mathrm{Mg}$ ratio of 0.12663 (Catanzaro et al., 1966) using the exponential fractionation law (where $\beta=$ 0.511). $\delta^{25} \mathrm{Mg}$ and $\delta^{26} \mathrm{Mg}$ values were also recalculated relative to the $\mathrm{Mg}$ standard DSM- 3 using the $\delta^{25} \mathrm{Mg}$ and $\delta^{26} \mathrm{Mg}$ values reported for DTS- 2 by Bizzarro et al. (2011), in order to compare the stable isotope data to previously published data. A model initial ${ }^{26} \mathrm{Al} /{ }^{27} \mathrm{Al}\left({ }^{26} \mathrm{Al} /{ }^{27} \mathrm{Al} l_{0}\right)$ value was calculated for each sample from the slope of a line (isochron) on a plot of 
$\delta^{26} \mathrm{Mg}^{*}$ versus ${ }^{27} \mathrm{Al} /{ }^{24} \mathrm{Mg}$. The model isochrons are based on the assumption that the precursor material of each sample initially had a chondritic ${ }^{27} \mathrm{Al} /{ }^{24} \mathrm{Mg}$ ratio of $0.1 .{ }^{26} \mathrm{Al}-{ }^{26} \mathrm{Mg}$ model ages were then calculated relative to CAIs, assuming a canonical ${ }^{26} \mathrm{Al} /{ }^{27} \mathrm{Al}$ value of $5.23 \pm 0.13 \times 10^{-5}$ in CAIs (Jacobsen et al., 2008) using the equation below:

$$
\Delta T=-\frac{\left(\ln \left[\frac{\left({ }^{26} A l /^{27} A l\right)}{\left({ }^{26} A l /{ }^{27} A l\right)_{0}}\right]\right)}{\lambda}
$$

\section{$5.1 \quad{ }^{27} \mathrm{Al} /{ }^{24} \mathrm{Mg}$ ratios}

The majority of the eucrites have ${ }^{27} \mathrm{Al} /{ }^{24} \mathrm{Mg}$ ratios in the range $1.00-2.25$, with the exception of three samples (EET 87458, LAP 031062 and LEW 87002) that all have ratios $<1$ (Table 5.1). LEW 87002 is a Mg-rich sample that has a particularly low $\mathrm{Al} / \mathrm{Mg}$ ratio of 0.19 , although this ratio is still considerably higher than $\mathrm{Al} / \mathrm{Mg}$ ratios measured in diogenites (0.0080.091) by Schiller et al. (2011).

\section{$5.2 \quad \delta^{26} \mathrm{Mg}^{*}$ anomalies}

There is a relatively large range in $\delta^{26} \mathrm{Mg}^{*}$ values across the sample suite, ranging from +0.0038 to +0.0402 (Fig. 5.1. Table 5.1) with the exception of LEW 87002 which has a $\delta^{26} \mathrm{Mg}^{*}$ value of -0.0005 , which is considerably lower than all the other samples and not resolvable with respect to the terrestrial standard. The $\delta^{26} \mathrm{Mg}^{*}$ values of Juvinas, Camel Donga and Millbillillie from this study are within error of $\delta^{26} \mathrm{Mg}^{*}$ values from the same samples determined by Bizzarro et al. (2005b) and Schiller et al. (2010). There is a general positive correlation between ${ }^{27} \mathrm{Al} /{ }^{24} \mathrm{Mg}$ ratios and $\delta^{26} \mathrm{Mg}^{*}$ (Fig. $\left.5.3 \mathrm{~A}\right)$. 
Table 5.1: $\mathrm{Al} / \mathrm{Mg}$ ratios, $\mathrm{Mg}$ isotope data, model ${ }^{26} \mathrm{Al} /{ }^{27} \mathrm{Al}_{0}$ and model ages relative to CAIs of the studied eucrites

\begin{tabular}{|c|c|c|c|c|c|c|c|c|c|}
\hline $\begin{array}{l}\text { Eucrite } \\
\text { sample }\end{array}$ & Eucrite type & $\begin{array}{c}\delta^{25} \mathrm{Mg} \\
\text { vs. DTS-2 }\end{array}$ & $\begin{array}{c}\delta^{25} \mathrm{Mg} \\
\text { vs. } D S M-3\end{array}$ & $\pm 2 \mathrm{se}$ & $\begin{array}{c}\delta^{26} \mathrm{Mg} \\
\text { vs. DTS-2 }\end{array}$ & $\begin{array}{c}\delta^{26} \mathrm{Mg} \\
\text { vs. } D S M-3\end{array}$ & \pm 2 se & $\begin{array}{c}\delta^{26} \mathrm{Mg}^{*} \\
\text { vs. DTS-2 }\end{array}$ & \pm 2 se \\
\hline EET 83227 & polymict & 0.0168 & -0.1052 & 0.0056 & 0.0497 & -0.1803 & 0.0096 & 0.0201 & 0.0022 \\
\hline EET 87548 & Mg-rich & 0.0180 & -0.1040 & 0.0250 & 0.0380 & -0.1920 & 0.0470 & 0.0043 & 0.0010 \\
\hline EET 92003 & brecciated & 0.0810 & -0.0410 & 0.0120 & 0.1780 & -0.0520 & 0.0240 & 0.0191 & 0.0023 \\
\hline EET 92023 & unbrecciated & 0.0263 & -0.0957 & 0.0049 & 0.0740 & -0.1560 & 0.0110 & 0.0252 & 0.0025 \\
\hline GRA 98006 & brecciated & 0.0552 & -0.0668 & 0.0099 & 0.1420 & -0.0880 & 0.0180 & 0.0365 & 0.0033 \\
\hline GRA 98033 & brecciated & 0.0390 & -0.0830 & 0.0130 & 0.1060 & -0.1240 & 0.0250 & 0.0286 & 0.0025 \\
\hline GRA 98043 & brecciated & 0.0590 & -0.0630 & 0.0140 & 0.1410 & -0.0890 & 0.0270 & 0.0257 & 0.0024 \\
\hline GRA 98055 & brecciated & 0.0520 & -0.0700 & 0.0250 & 0.1410 & -0.0890 & 0.0490 & 0.0375 & 0.0024 \\
\hline GRA 98114 & brecciated & 0.0390 & -0.0830 & 0.0180 & 0.1190 & -0.1110 & 0.0360 & 0.0402 & 0.0025 \\
\hline LAP 031062 & brecciated & 0.0620 & -0.0600 & 0.0120 & 0.1340 & -0.0960 & 0.0240 & 0.0117 & 0.0013 \\
\hline LAR 06875 & brecciated & 0.0880 & -0.0340 & 0.0170 & 0.2040 & -0.0260 & 0.0320 & 0.0340 & 0.0014 \\
\hline LEW 85035 & unbrecciated & 0.0570 & -0.0650 & 0.0170 & 0.1390 & -0.0910 & 0.0330 & 0.0291 & 0.0012 \\
\hline LEW 87002 & Mg-rich & 0.0850 & -0.0370 & 0.0140 & 0.1650 & -0.0650 & 0.0300 & -0.0005 & 0.0023 \\
\hline PCA 91193 & brecciated & 0.0560 & -0.0660 & 0.0180 & 0.1210 & -0.1090 & 0.0350 & 0.0082 & 0.0015 \\
\hline QUE 97014 & unbrecciated & 0.0670 & -0.0550 & 0.0140 & 0.1560 & -0.0740 & 0.0280 & 0.0270 & 0.0010 \\
\hline QUE 99005 & brecciated & 0.0600 & -0.0620 & 0.0110 & 0.1490 & -0.0810 & 0.0210 & 0.0297 & 0.0010 \\
\hline RKPA 80204 & brecciated & 0.0565 & -0.0655 & 0.0089 & 0.1370 & -0.0930 & 0.0170 & 0.0300 & 0.0024 \\
\hline SCO 06041 & brecciated & 0.1010 & -0.0210 & 0.0110 & 0.2010 & -0.0290 & 0.0200 & 0.0038 & 0.0018 \\
\hline GRO 95533 & brecciated & 0.0680 & -0.0540 & 0.0130 & 0.1690 & -0.0610 & 0.0250 & 0.0359 & 0.0014 \\
\hline Millibillilie & brecciated & 0.0620 & -0.0600 & 0.0280 & 0.1540 & -0.0760 & 0.0650 & 0.0259 & 0.0027 \\
\hline Juvinas & brecciated & 0.0158 & -0.1062 & 0.0041 & 0.0559 & -0.1741 & 0.0071 & 0.0227 & 0.0016 \\
\hline Camel Donga & brecciated & 0.1550 & 0.0330 & 0.0210 & 0.3410 & 0.1110 & 0.0430 & 0.0354 & 0.0019 \\
\hline $\begin{array}{l}\text { Eucrite } \\
\text { sample }\end{array}$ & ${ }^{27} \mathrm{Al} /{ }^{24} \mathrm{Mg}$ & $\begin{array}{c}\text { Model } \\
{ }^{26} \mathrm{Al}^{27} \mathrm{Al}_{0} \\
\left(\times 10^{-6}\right)\end{array}$ & \pm 2 se & $\begin{array}{c}\Delta \mathrm{T} \text { after } \\
\text { CAls (Myr) }\end{array}$ & $\begin{array}{l}+2 \mathrm{se} \\
\text { (Myr) }\end{array}$ & $\begin{array}{l}-2 \text { se } \\
\text { (Myr) }\end{array}$ & $\mathrm{n}$ & & \\
\hline EET 83227 & 1.20 & 2.54 & 0.28 & 3.18 & 0.11 & 0.12 & 10 & & \\
\hline EET 87548 & 0.66 & 1.08 & 0.25 & 4.08 & 0.22 & 0.28 & 10 & & \\
\hline EET 92003 & 1.48 & 1.93 & 0.23 & 3.47 & 0.12 & 0.14 & 10 & & \\
\hline EET 92023 & 1.13 & 3.42 & 0.34 & 2.87 & 0.10 & 0.11 & 10 & & \\
\hline GRA 98006 & 1.75 & 3.09 & 0.28 & 2.97 & 0.09 & 0.10 & 10 & & \\
\hline GRA 98033 & 2.14 & 1.95 & 0.17 & 3.46 & 0.09 & 0.10 & 10 & & \\
\hline GRA 98043 & 2.01 & 1.88 & 0.18 & 3.50 & 0.09 & 0.10 & 10 & & \\
\hline GRA 98055 & 1.72 & 3.23 & 0.21 & 2.93 & 0.07 & 0.07 & 10 & & \\
\hline GRA 98114 & 2.09 & 2.82 & 0.18 & 3.07 & 0.06 & 0.07 & 10 & & \\
\hline LAP 031062 & 0.25 & & & & & & 10 & & \\
\hline LAR 06875 & 1.99 & 2.51 & 0.10 & 3.19 & 0.04 & 0.04 & 10 & & \\
\hline LEW 85035 & 1.23 & 3.60 & 0.15 & 2.82 & 0.04 & 0.04 & 10 & & \\
\hline LEW 87002 & 0.19 & & & & & & 10 & & \\
\hline PCA 91193 & 1.26 & 0.98 & 0.18 & 4.18 & 0.18 & 0.21 & 10 & & \\
\hline QUE 97014 & 2.25 & 1.76 & 0.06 & 3.57 & 0.04 & 0.04 & 10 & & \\
\hline QUE 99005 & 1.86 & 2.36 & 0.08 & 3.26 & 0.03 & 0.04 & 10 & & \\
\hline RKPA 80204 & 2.01 & 2.19 & 0.18 & 3.34 & 0.08 & 0.09 & 10 & & \\
\hline SCO 06041 & 1.04 & 0.56 & 0.27 & 4.77 & 0.41 & 0.68 & 10 & & \\
\hline GRO 95533 & 1.94 & 2.72 & 0.11 & 3.11 & 0.04 & 0.04 & 10 & & \\
\hline Millibillilie & 1.87 & 2.04 & 0.21 & 3.41 & 0.10 & 0.12 & 10 & & \\
\hline Juvinas & 1.86 & 1.79 & 0.13 & 3.55 & 0.07 & 0.08 & 10 & & \\
\hline Camel Donga & 1.96 & 2.66 & 0.14 & 3.13 & 0.06 & 0.06 & 10 & & \\
\hline
\end{tabular}




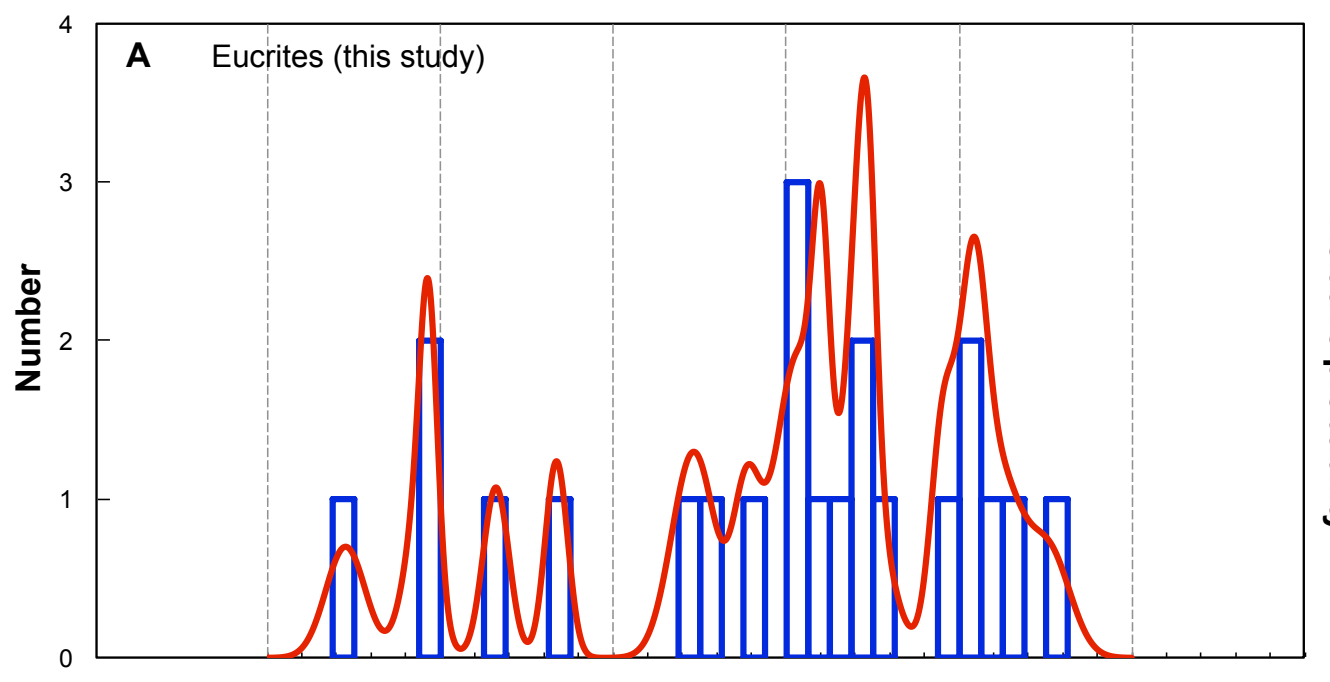

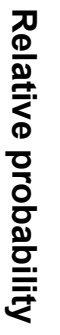

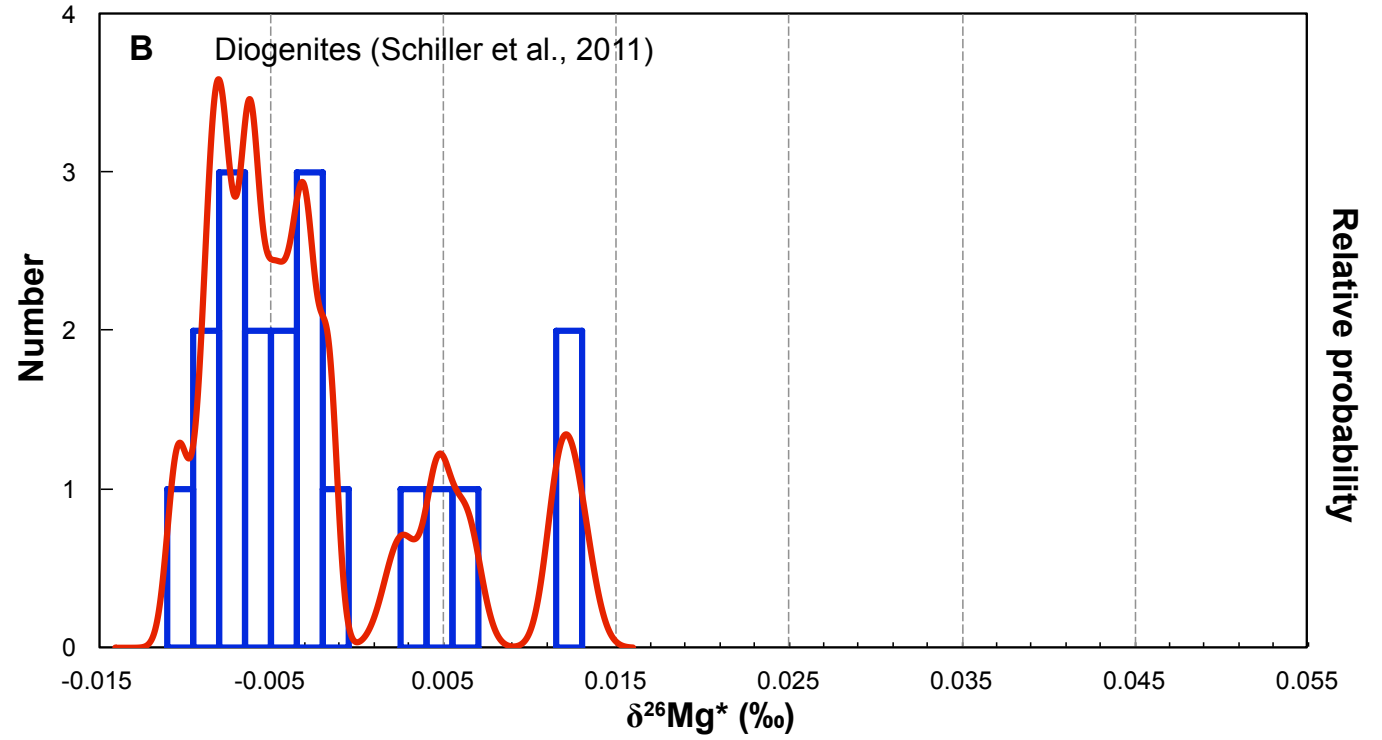

Figure 5.1: Histogram of $\delta^{26} \mathrm{Mg}^{*}$ values in eucrite samples and diogenite samples (Schiller et al., 2011), with superimposed probability curve. 


\subsection{Stable $\delta^{25} \mathrm{Mg}$ isotope data}

The eucrite samples have $\delta^{25} \mathrm{Mg}_{\mathrm{DSM}-3}$ values in the range -0.1062 to -0.0210 , with the exception of Camel Donga, which has a considerably higher value of 0.0330 (Table 5.1, Fig. 5.2 A ). Terrestrial basalts have very similar $\delta^{25} \mathrm{Mg}_{\mathrm{DSM}-3}$ values to terrestrial mantle olivines, while most of the eucrites have slightly heavier $\delta^{25} \mathrm{Mg}_{\mathrm{DSM}-3}$ values (Fig. 5.2).

The $\delta^{25} \mathrm{Mg}_{\mathrm{DSM}-3}$ values measured in eucrites in this study are also heavier than $\delta^{25} \mathrm{Mg}$ values measured in the diogenites studied by Schiller et al. (2011), which range from -0.0496 to -0.1621 . The $\delta^{25} \mathrm{Mg}$ value for Camel Donga reported by Bizzarro et al. (2005b) is -0.087 , which is considerably less than the value measured in this study. The $\delta^{25} \mathrm{Mg}$ value of Juvinas measured in this study is within error of the $\delta^{25} \mathrm{Mg}$ value measured in the same sample by Bizzarro et al. (2005b) and Schiller et al. (2010). The $\delta^{25} \mathrm{Mg}$ value of Millbillillie determined in this study is also within error of the $\delta^{25} \mathrm{Mg}$ value for this sample measured by Schiller et al. (2010), however, the Millbillillie $\delta^{25} \mathrm{Mg}$ value $(-0.131 \pm 0.025)$ determined by Bizzarro et al. (2005b) is not within error of this study.

\subsection{Model initial ${ }^{26} \mathrm{Al} /{ }^{27} \mathrm{Al}$ values and model ages}

Model ${ }^{26} \mathrm{Al} /{ }^{27} \mathrm{Al}_{0}$ values range from $0.56 \times 10^{-6}$ to $3.42 \times 10^{-7}$, with the exception of two samples. LAP 031062 has a higher model ${ }^{26} \mathrm{Al} /{ }^{27} \mathrm{Al}_{0}$ value of $1.06 \times 10^{-5}$ and LEW 87002 has an implausible value of $-7.50 \times 10^{-7}$. Both of these samples have very low ${ }^{27} \mathrm{Al} /{ }^{24} \mathrm{Mg}$ ratios for eucritic meteorites $(0.25$ and 0.19$)$ and $\delta^{26} \mathrm{Mg}^{*}$ values within uncertainty of the terrestrial standard, which means that calculations of model ${ }^{26} \mathrm{Al} /{ }^{27} \mathrm{Al}_{0}$ values are not meaningful. The model ${ }^{26} \mathrm{Al} /{ }^{27} \mathrm{Al}_{0}$ values correspond to a range in single-stage model ages of 2.82-4.77 Myr after the formation of CAIs. The ages of Millbillillie, Juvinas and Camel Donga obtained in this study are within error of those determined for the same samples by Bizzarro et al. 
CHAPTER 5. ${ }^{26} \mathrm{AL}-{ }^{26} \mathrm{MG}$ ISOTOPE DATA

(2005b) and Schiller et al. (2010). 

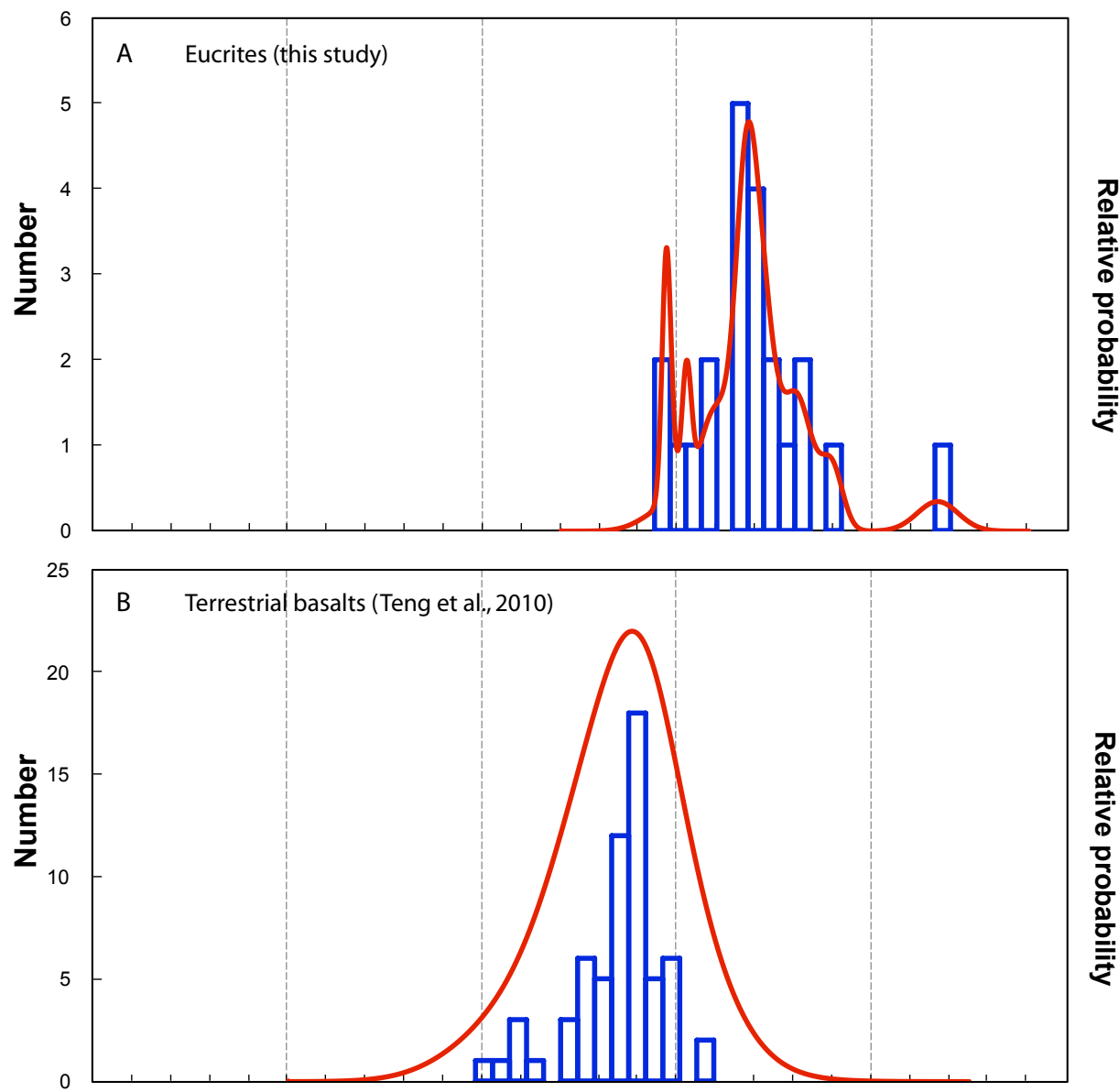

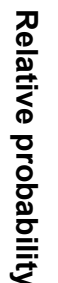

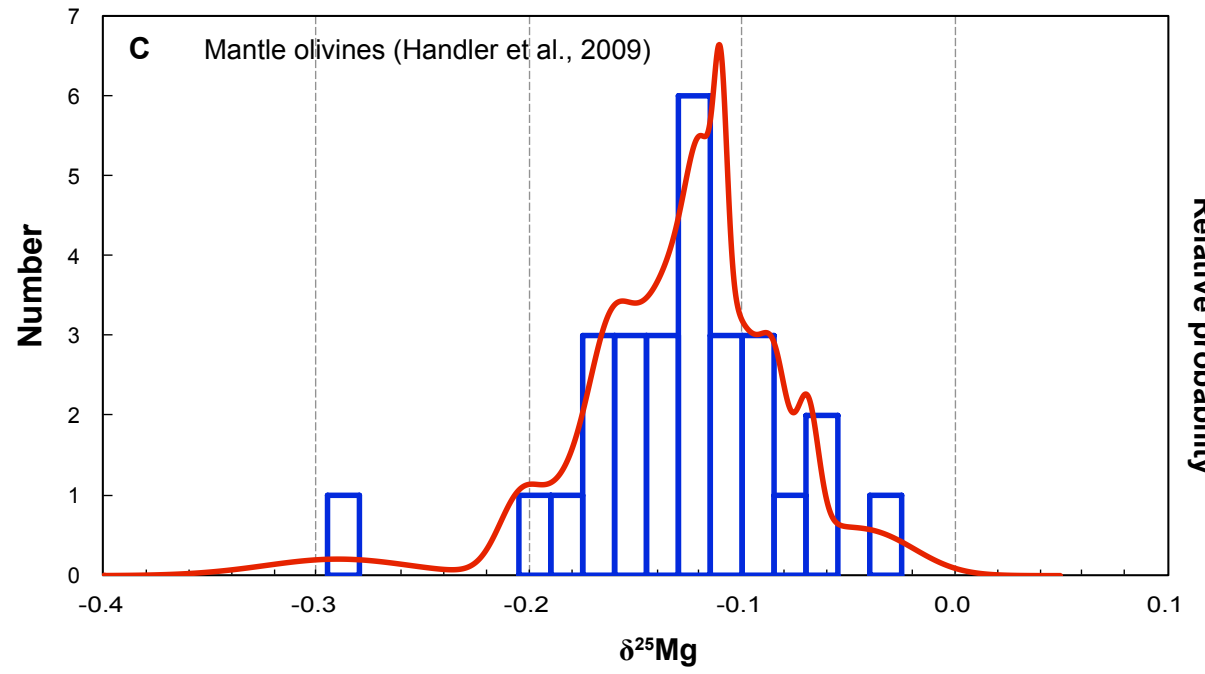

Figure 5.2: Histogram of $\delta^{25} \mathrm{Mg}$ values in eucrite samples, with superimposed probability (A). Histograms of $\delta^{25} \mathrm{Mg}$ values in terrestrial basalt from Teng et al. (2010) (B) and mantle olivine from Handler et al. (2009) (C), with super imposed probabilities. 

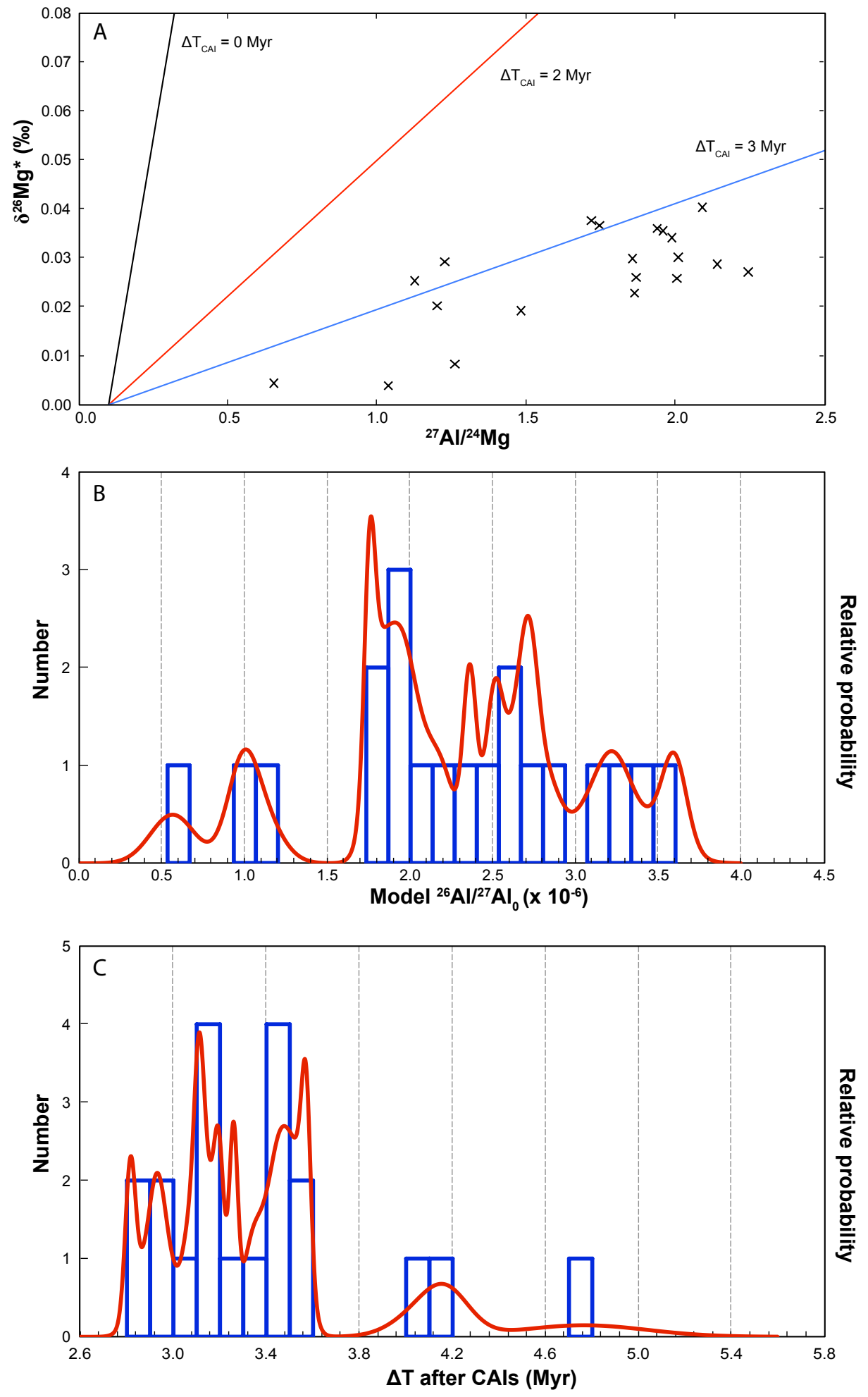

Figure 5.3: A- ${ }^{26} \mathrm{Al}-{ }^{26} \mathrm{Mg}$ isochron diagram, with eucrite data from this study, and reference isochrons. B- Histogram of model ${ }^{26} \mathrm{Al} /{ }^{27} \mathrm{Al}_{0}$ values of eucrite samples with superimposed probability curve. C- Histogram of model ages of eucrites relative to CAIs with superimposed probability curve. 


\section{Chapter 6}

\section{Discussion}

This chapter begins with a discussion of previously proposed models for the genesis of eucrites and diogenites. The majority of eucrites analysed in this study are from the NASA Antarctic meteorite collection and may have been affected by weathering. As such, the effect of weathering on the samples from this study is evaluated.

Major and trace element and $\mathrm{Mg}$ isotope data for the eucrites presented in the previous three chapters are integrated in this chapter. The data from this study are also compared to data from other studies on eucrites and diogenites. Based on correlations in eucrite and diogenite data, four models for the genesis of the eucrites and diogenites are proposed and evaluated. Age data for eucrites obtained in this study with the Al-Mg chronometer are compared to ages from other studies of eucrites and diogenites. The relationship between the eucrites and the asteroid Vesta is also considered.

\subsection{Existing models for eucrite and diogenite genesis}

Non-cumulate eucrites can be divided into three groups based on their whole-rock major and trace element compositions: main group eucrites, Stannern trend eucrites and Nuevo Laredo trend eucrites. The main group 


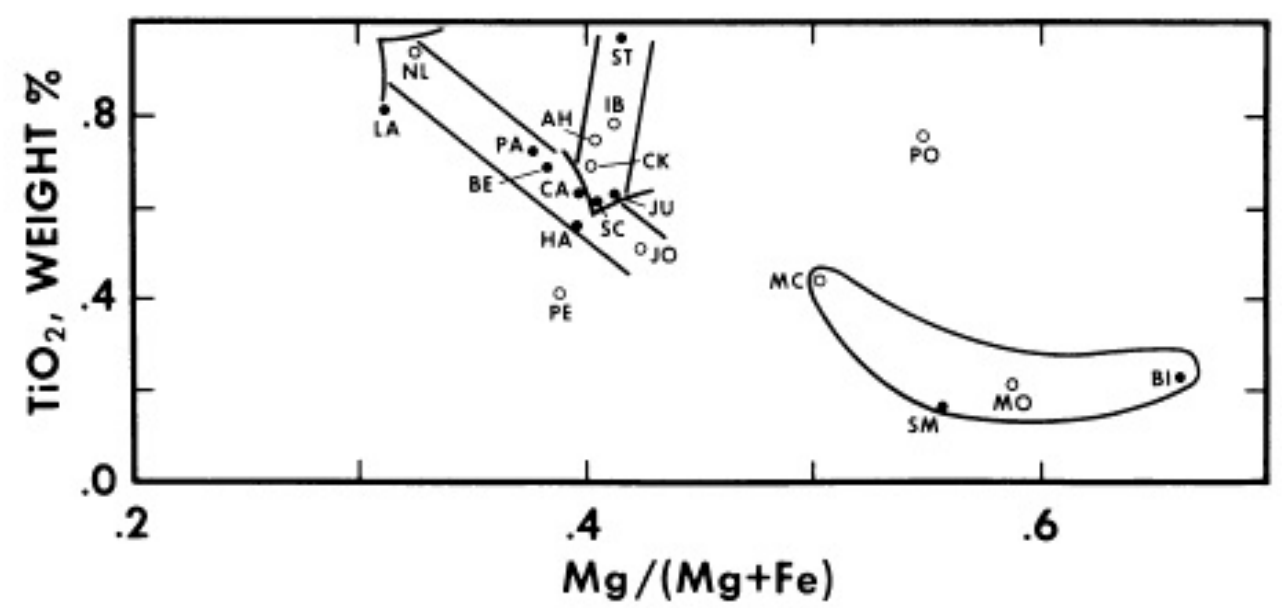

Figure 6.1: Plot of whole-rock $\mathrm{TiO}_{2}$ versus $\mathrm{Mg} \#$ in eucrites showing the classification of eucrites into Stannern trend, Nuevo Laredo trend, main group and cumulate eucrites. Nuevo Laredo trend eucrites plot within the left trending arrow, Stannern trend eucrites plot within the right, downward trending arrow, and main group eucrites plot in the cluster of samples between both arrows. Cumulate eucrites plot in the lower right corner of the diagram at higher Mg\#. Figure taken from Basaltic Volcanism Study Project (1981).

eucrites are the most common and cluster on a plot of $\mathrm{TiO}_{2}$ versus $\mathrm{Mg \#}$ $(\mathrm{Mg} /(\mathrm{Mg}+\mathrm{Fe}))$. The Stannern trend eucrites are characterized by a signifi-

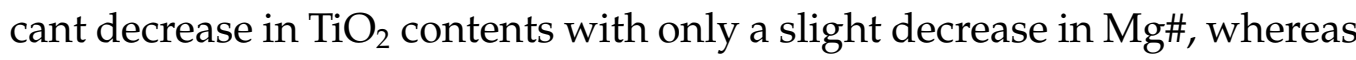
the Nuevo Laredo trend eucrites exhibit increasing $\mathrm{TiO}_{2}$ contents and a marked decrease in Mg\# (Basaltic Volcanism Study Project, 1981) (Fig. 6.1). Cumulate eucrites have high Mg\# numbers and low $\mathrm{TiO}_{2}$ contents as compared with non-cumulate eucrites. Some eucrites do not fit into any of these geochemical groupings and are referred to as being anomalous.

Any model for the silicate differentiation of the HED parent body must account for these variations observed amongst the suite of eucrite meteorites. In addition, the formation of diogenites and their relationship to eucrites also needs to be explained. Understanding the formation of diogenites is complicated by the fact that they exhibit a large range in incompatible element concentrations (e.g., $\mathrm{Yb}$ varies by a factor of 16 across the diogenite suite) over a relatively small range in Mg\# (Fowler et al., 1995). 
There are three general processes which could be responsible for the compositional variation observed amongst the eucrites: (i) different degrees of partial melting of a single homogeneous source material possibly combined with: (ii) fractional crystallization (or equilibrium or in situ crystallization) of a relatively homogeneous source magma (e.g., a magma ocean) or; (iii) partial melting of heterogeneous sources to produce different magma batches (Basaltic Volcanism Study Project, 1981).

In an early study of eucrites, Stolper (1977) argued that main group and Stannern trend eucrites resulted from different degrees of partial melting of primitive chondritic material. Following partial melting, fractional crystallization of these melts produced the main group and Stannern trend eucrites, and the Nuevo Laredo trend eucrites formed from residual liquid (Stolper, 1977). However, the primary criticism of this model is that it does not account for the large range of incompatible element concentrations in diogenites (Righter and Drake, 1997). Modelling performed by Consolmagno and Drake (1977) determined that the REE compositions of main group eucrites are consistent with 10-15\% partial melting of a chondritic source, with the Stannern trend eucrites resulting from small degrees $(\sim 4 \%)$ of partial melting of the same source. However, this model does not account for the formation of diogenites, which are more primitive than the eucrites. In addition, melting experiments have shown it is implausible for eucrites and diogenites to both be derived from primary melts of the same source material (Jurewicz et al., 1995).

Others studies have suggested that diogenites crystallized as cumulates from primary magmas produced by partial melting, followed by the fractional crystallization of eucrites from the residual magma (e.g., Warren and Jerde, 1987), rather than the eucrites being primary magmas. This model implies that eucrites and diogenites are related to each other, and represent a crystallization continuum of partial melts. However, it is again difficult to relate all the diogenites with this model, as it requires very high levels of crystallization of a single magma source to produce the large range in incompatible trace element concentrations in the diogenite suite (Fowler et al., 1995). The limitations of these two partial melting models 
might be overcome if eucrites and diogenites are both the products of crystallization of primary melts, but formed from two heterogeneous magma batches.

There are several drawbacks to these partial melting models, which are all based on $15-20 \%$ partial melting of the HED parent body. For example, there is no evidence of primitive, unmelted material from the HED parent body in the meteorite suite, which would be expected if the parent body had only undergone partial melting (Shearer et al., 1997). The partial melting model is also difficult to reconcile with mechanisms for core formation and metal-silicate differentiation, which would require a minimum of 50\% silicate melting (Taylor, 1992). Similarly, in order to achieve oxygen isotope homogeneity as observed in the HED meteorites on the parent body, a minimum of $50 \%$ melting has been suggested as being required (Greenwood et al., 2005).

An alternative to partial melting models is the magma ocean hypothesis, which requires near complete melting of the HED parent body. (Righter and Drake, 1997). This model suggests that eucrites formed progressively as residual liquids of magma ocean crystallization that were extruded from the magma ocean onto or close to the surface of the HED parent body, whereas diogenites are cumulates from the same magma body (Righter and Drake, 1997). This model can account for some of the limitations of the partial melting models, as it is consistent with conditions required for core formation and consequently the very low concentrations of siderophile elements in the HED meteorites (Righter and Drake, 1997), as well as the three-oxygen isotope homogeneity of the HED meteorite suite. In this model eucrites and diogenites form as part of the same crystallization sequence. However, it would require extraordinarily high amounts of crystallization in order to produce the compositional trace element range exhibited by the diogenites and eucrites (Fowler et al., 1995).

To explain this extreme trace element heterogeneity, Barrat et al. (2000) proposed that in situ crystallization of a magma ocean could generate the observed trace element characteristics of eucrites i.e., decoupling of major and trace elements. Diogenites would form as cumulates in this magma 
ocean. However, it is still not clear how this model can account for the large range in incompatible element concentrations in diogenites.

Thus, it does not appear that a single, simple model like those outlined above can explain the formation of eucrites and diogenites and silicate differentiation of the HED parent body. This has prompted the proposal of more complex models in order to account for all the compositional features of the HED meteorites. For example, Shearer et al. (1997) argued that it is possible to produce diogenites and eucrites by fractional melting of a source that was originally homogeneous (thus explaining the homogeneity in three-oxygen isotope compositions), but was subsequently disturbed by varying degrees of partial melting and melt extraction. Remelting of this material could produce batches of magmas from which eucrites and diogenites with realistic compositions formed if there was substantial changes to the orthopyroxene/melt distribution coefficients during melting or crystallization (Shearer et al., 1997). However, this model offers no explanation as to the cause of the two melting episodes, as it is widely believed that there was only a single, early, melting episode resulting from the heat produced by the decay of ${ }^{26} \mathrm{Al}$ (Hevey and Sanders, 2006). It is also not clear how the required changes in distribution coefficients were brought about. Shearer et al. (1997) also proposed a "serialmagmatism" model to explain the genesis of eucrites and diogenites. In this model, there are varying degrees of partial melting, and the magmas from which diogenites form transfer heat to the outer portions of the HED parent body, resulting in melting that generates eucritic magmas. This is consistent with models that suggest that the eucrites are primary melts, with compositional differences resulting from varying degrees of partial melting (e.g., Stolper, 1977). However, this model requires high degrees of melting in the production of diogenites (possibly facilitating core formation), which is, yet again, not consistent with the range of incompatible trace element contents (Shearer et al., 1997). 


\subsection{Effect of weathering on Antarctic meteorites}

Weathering of meteorites found in Antarctica has the potential to alter the original chemical composition of these meteorites (Mittlefehldt and Lindstrom, 1991; Floss and Crozaz, 1991; Crozaz et al., 2003). A weathering classification for Antarctic meteorites was introduced (Antarctic Meteorite Newsletter, vol. 1, no. 3, Nov 1978) due to the potential problems that may arise from weathering of Antarctic meteorites. This weathering classification scheme was outlined in Chapter 3. Based on this scheme, samples in this study were selected with weathering grades of B or better wherever possible. However, Crozaz et al. (2003) noted that these weathering grades are not well suited to eucrites, as rust is used as the primary indicator of the weathering degree, and eucrites are poor in metal and sulfide, thus making them less likely to show large amounts of rust even after high degrees of weathering.

A number of studies (e.g., Mittlefehldt and Lindstrom, 1991; Floss and Crozaz, 1991; Crozaz et al., 2003) have documented evidence of unusual REE compositions in some Antarctic eucrites, most likely as a result of REE mobilization caused by weathering on the Antarctic ice. REE mobilization may be due to interaction with weakly acidic melt water (Mittlefehldt and Lindstrom, 1991) infiltrating the meteorite through shockinduced fractures (Floss and Crozaz, 1991). Ca-phosphates are most susceptible to dissolution and, as such, are most likely to be the first mineral altered, although other minerals can also be potentially altered. Due to density differences, pyroxene is more likely than plagioclase to have extensive micro-fracturing, making it more susceptible than plagioclase to leaching and redistribution of REE (Floss and Crozaz, 1991).

Mittlefehldt and Lindstrom (1991) found that samples taken from the exterior of meteorite samples had REE concentrations that exhibited greater variability than interior samples. In this study, only small pieces of each meteorite were used, and the external surfaces were removed from all the samples to minimize the affects of alteration on the measured compositions of these samples. 
The presence of either negative or positive Ce anomalies is considered an indicator of weathering in Antarctic meteorites (Mittlefehldt and Lindstrom, 1991; Floss and Crozaz, 1991), as mineral-melt partition coefficients mean it is difficult to explain $\mathrm{Ce}$ anomalies as representing magmatic processes on the HED parent body. Ce is particularly affected by weathering because oxidation partially converts $\mathrm{Ce}^{3+}$ to $\mathrm{Ce}^{4+}$, and $\mathrm{Ce}^{4+}$ is less soluble than trivalent REE, resulting in some Ce being separated from other REE due to the difference in solubility of $\mathrm{Ce}^{3+}$ and $\mathrm{Ce}^{4+}$ (Mittlefehldt and Lindstrom, 1991; Floss and Crozaz, 1991). Both negative and positive Ce anomalies characterise pyroxene from some samples in this study, which is most likely the result of weathering.

In addition to the presence of Ce anomalies, Mittlefehldt and Lindstrom (1991) noted that the whole rock REE patterns of altered eucrites are also generally characterized by positive Eu anomalies, as opposed to the negative Eu anomalies observed in most unaltered eucrites. Pyroxene and plagioclase from samples in this study have Eu anomalies consistent with what would be expected from unaltered eucrites i.e., plagioclase would be expected to exhibit positive Eu anomalies, whereas pyroxene should have negative $\mathrm{Eu}$ anomalies. For this reason, it does not appear that $\mathrm{Eu}$ anomalies in pyroxene and plagioclase in samples in this study have been affected by weathering. Mittlefehldt and Lindstrom (1991) also noted that the whole rock REE compositions of altered eucrites are relatively low. The Antarctic samples in this study have REE abundances in both plagioclase and pyroxene that are consistent with the REE abundances in the four non-Antarctic samples, which is an indication that, apart from $\mathrm{Ce}$, the REE concentrations have not been significantly affected by weathering. In addition, the REE chemistry of both low- and high-Ca pyroxene in samples from this study is consistent with the REE compositions of both whole rock and pyroxene from non-Antarctic eucrites published in other studies (Fig. 6.2).

The Antarctic samples from this study do not appear to have the low REE abundances relative to non-Antarctic eucrites that characterize altered eucrites. Floss and Crozaz (1991) found that pyroxene in altered 


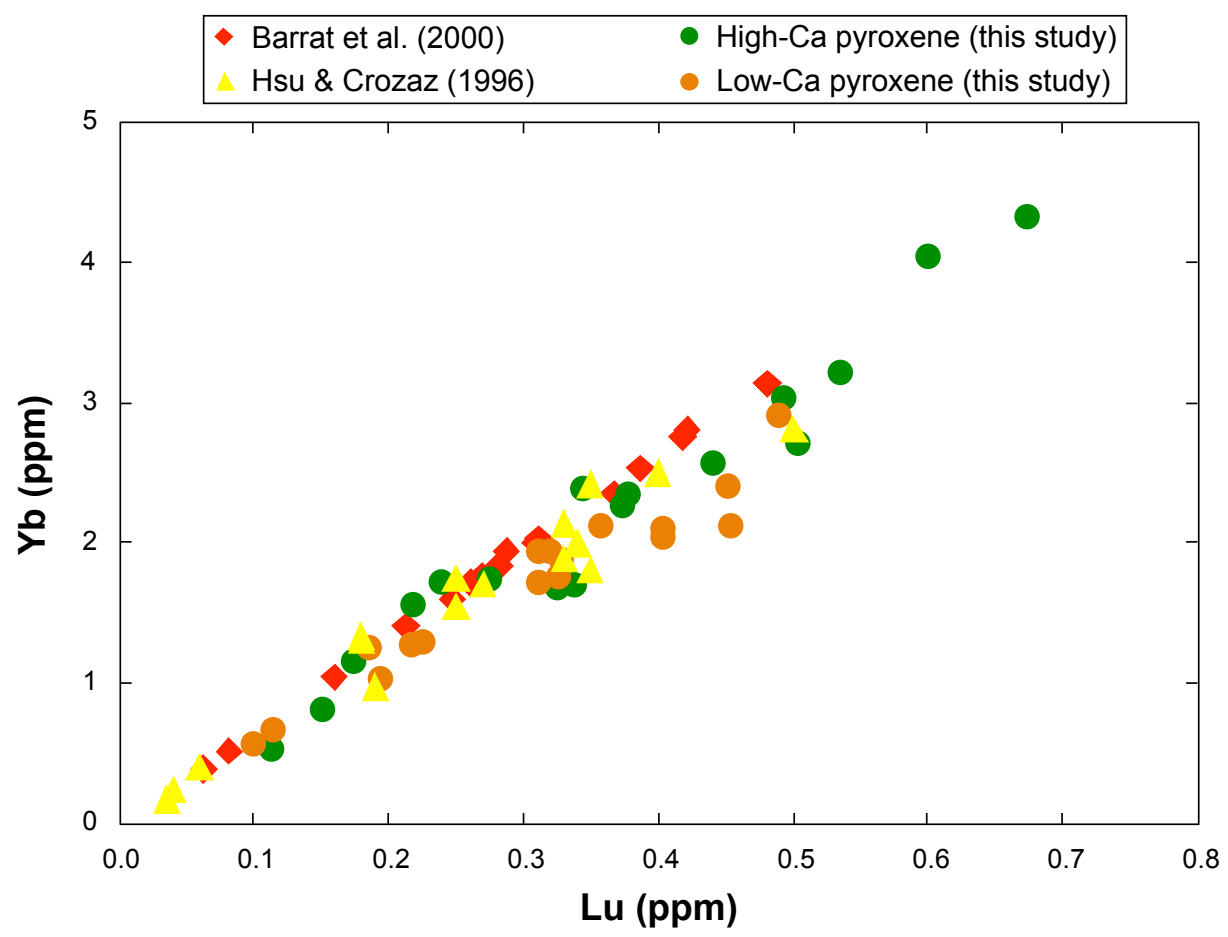

Figure 6.2: Concentrations of $\mathrm{Lu}$ and $\mathrm{Yb}$ in low- and high-Ca pyroxene in eucrites from this study, pyroxene from non-Antarctic eucrites from $\mathrm{Hsu}$ and Crozaz (1996), and whole-rock non-Antarctic eucrites from Barrat et al. (2000).

Antarctic eucrites may display a negative correlation between Nd concentration and Ce anomalies. However, no correlation between $\mathrm{Nd}$ concentration and Ce anomalies was observed in this study either within a single sample, or amongst the mean compositions for each eucrite (Fig. 6.3).

If significant mobilization of elements were taking place within a sample, Ce anomalies would be expected to correlate with elements that are also easily mobilized. Floss and Crozaz (1991) observed this phenomenon in pyroxene from an altered Antarctic eucrite, where $\mathrm{Na}, \mathrm{Ba}, \mathrm{Sr}$ and $\mathrm{P}$ all correlate negatively with Ce anomaly. These correlations are not observed in samples from this study, indicating that there may not have been significant mobilization of elements in these samples (Fig. 6.4). Based on comparisons between non-Antarctic and Antarctic eucrites, major elements do not appear to be effected by weathering in Antarctic eucrites (Mittlefehldt and Lindstrom, 2003). This is consistent with major element concentra- 


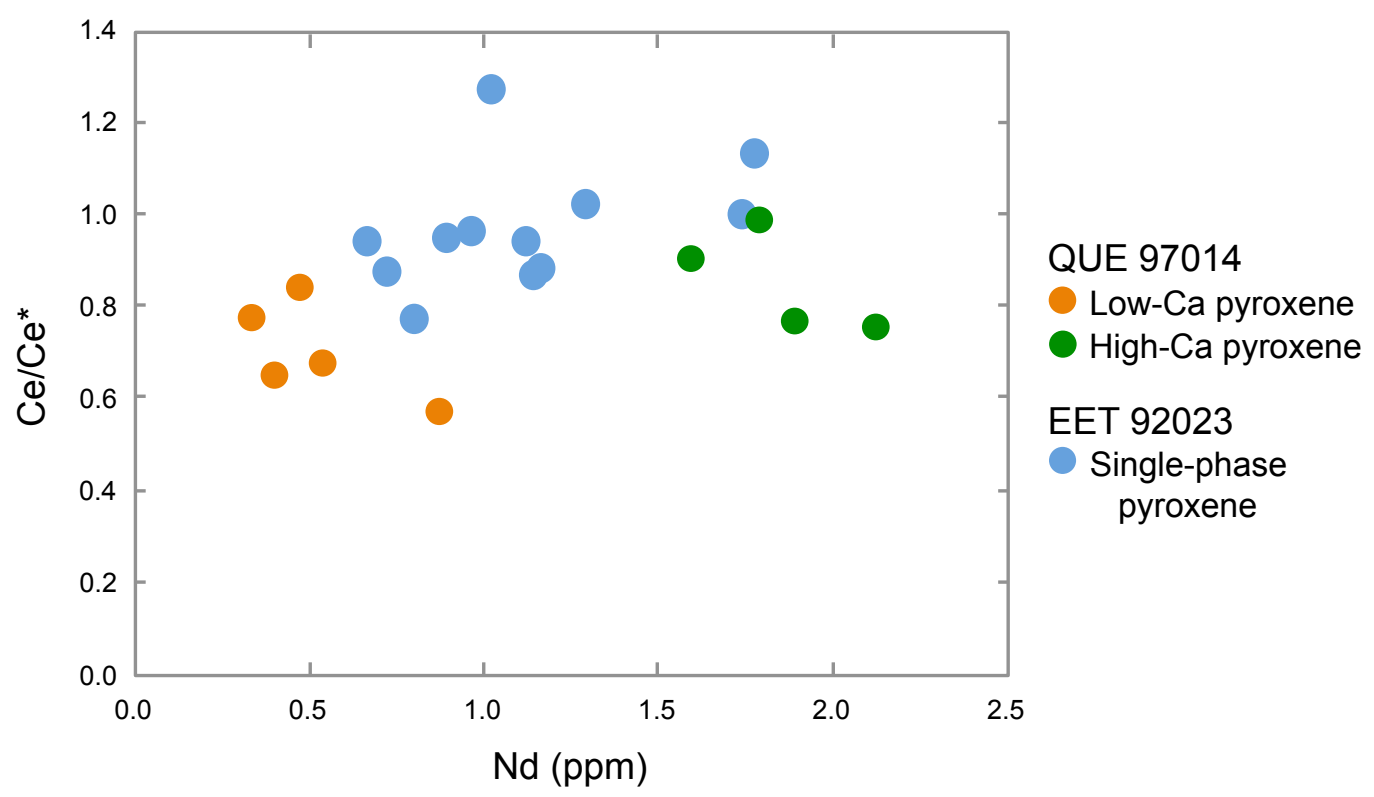

Figure 6.3: Plot of $\mathrm{Nd}$ concentration versus $\mathrm{Ce}$ anomaly for individual analyses of pyroxene in QUE 97014 and EET 92023.

tions in eucrites in this study, which are in the same range as major element mineral concentrations in non-Antarctic eucrites measured by $\mathrm{Hsu}$ and Crozaz (1996). In summary, while there is evidence for weathering induced Ce anomalies in pyroxene and to a lesser extent plagioclase in the Antarctic samples in this study, weathering does not appear to have had a noticeable effect on the other REE concentrations. Major element concentrations and, therefore, $\mathrm{Mg}$ isotopes are also unlikely to have been affected by weathering.

\subsection{Compositional variations in eucrites}

\subsection{1 $\delta{ }^{26} \mathrm{Mg}^{*}$ variability in eucrite samples}

The variations in $\delta^{26} \mathrm{Mg}^{*}$ in eucrite samples do not correlate with the stable $\mathrm{Mg}$ isotope compositions of the same samples and, therefore, are not the result of an erroneous instrumental mass bias correction (Bizzarro et al. 2011: Schiller et al., 2011). While there are no cosmic ray exposure ages 

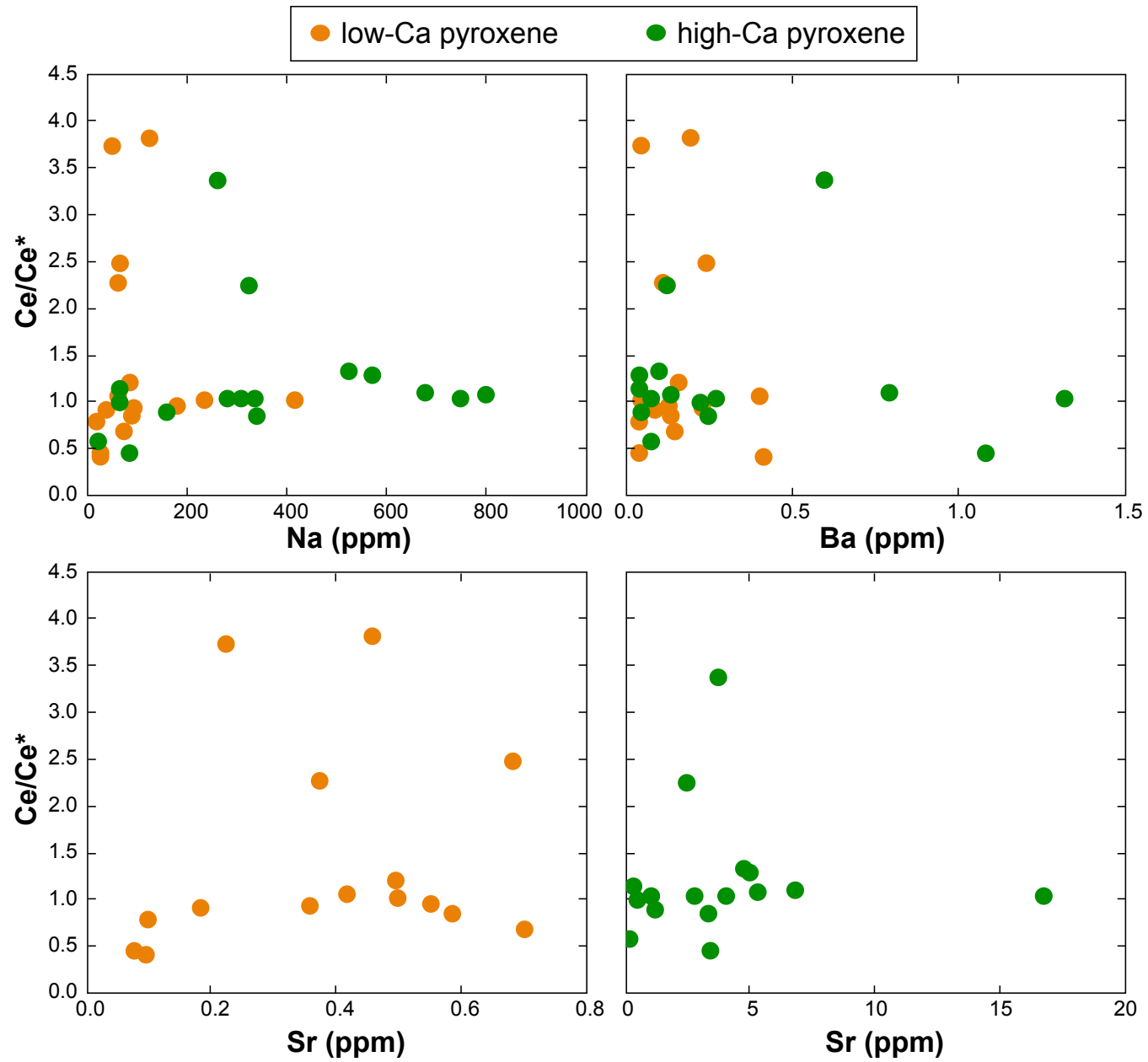

Figure 6.4: Average Ce anomalies in pyroxene from Antarctic eucrites plotted versus concentrations of $\mathrm{Na}, \mathrm{Ba}$ and $\mathrm{Sr}$ in the same samples.

for the Antarctic eucrites analysed in this study, Schiller et al. (2011) determined that there was no correlation between the $\delta^{26} \mathrm{Mg}^{*}$ variation in diogenites and cosmic ray exposure ages of the same diogenites, so it is unlikely that $\delta^{26} \mathrm{Mg}^{*}$ variations in the HED meteorites are the result of cosmogenic processes. Ruling out these processes that may result in variation in $\delta^{26} \mathrm{Mg}^{*}$ between samples suggests that $\delta^{26} \mathrm{Mg}^{*}$ in eucrites does reflect silicate differentiation and magmatic evolution on the HED parent body. 


\subsubsection{Major and trace element and $\mathrm{Mg}$ isotope variations in eucrites}

The whole rock major and trace element characteristics of non-cumulate eucrites have been described extensively by a number of studies (e.g., Duke and Silver, 1967; Stolper, 1977; Warren and Jerde, 1987; Barrat et al. 2000: Mittlefehldt and Lindstrom, 2003). However, relatively few studies of eucrites have conducted in situ major and trace element measurements of mineral phases in eucrites. Some major elements such as $\mathrm{Si}, \mathrm{Al}$ and $\mathrm{Mg}$ in pyroxene and $\mathrm{Si}, \mathrm{Al}$ and $\mathrm{Ca}$ in plagioclase show little variation between the eucrite samples. However, other major elements such as $\mathrm{Ca}, \mathrm{Fe}$ and $\mathrm{Ti}$ in pyroxene and $\mathrm{K}$ in plagioclase show a larger range in concentrations.

As described previously, eucrites can be grouped according to concentrations of bulk rock $\mathrm{TiO}_{2}$ and $\mathrm{Mg \#}$ (Basaltic Volcanism Study Project, 1981). Hsu and Crozaz (1996) used concentrations of $\mathrm{TiO}_{2}$ plotted versus $\mathrm{Mg \#}$ measured in pyroxene rather than bulk rock samples to classify their samples into eucrite groups. The $\mathrm{TiO}_{2}$ versus $\mathrm{Mg \#}$ differences between Stannern trend, Nuevo Laredo trend and main group samples are the same as they are for whole rocks (Hsu and Crozaz, 1996). Juvinas is considered to be a typical main group eucrite (Basaltic Volcanism Study Project, 1981), and the majority of eucrites in this study cluster around Juvinas on a plot of $\mathrm{TiO}_{2}$ versus $\mathrm{Mg} \#$ for low-Ca pyroxene and pyroxene (from samples with one phase), which indicates these samples belong to the main group (Fig. 6.5). There are three samples (EET 92003, Millbillillie and LEW 85305) from this study that appear to be part of the Stannern trend, based on their significantly higher $\mathrm{TiO}_{2}$ concentrations, which decrease with only a slight decrease in $\mathrm{Mg \#}$. None of the eucrites from this study appear to fall in the Nuevo Laredo trend grouping, and there are some samples that do not fall in the main group or Stannern trend groupings. The Mg-rich eucrites have high $\mathrm{Mg \#}$ and low $\mathrm{TiO}_{2}$, and are similar in composition to cumulate eucrites (Fig. 6.5), although they do not have a cumulate texture. There is a subtle positive correlation between the concentrations of $\mathrm{Ca}$ and $\mathrm{Yb}$ in low-Ca pyroxene. However the concentration 


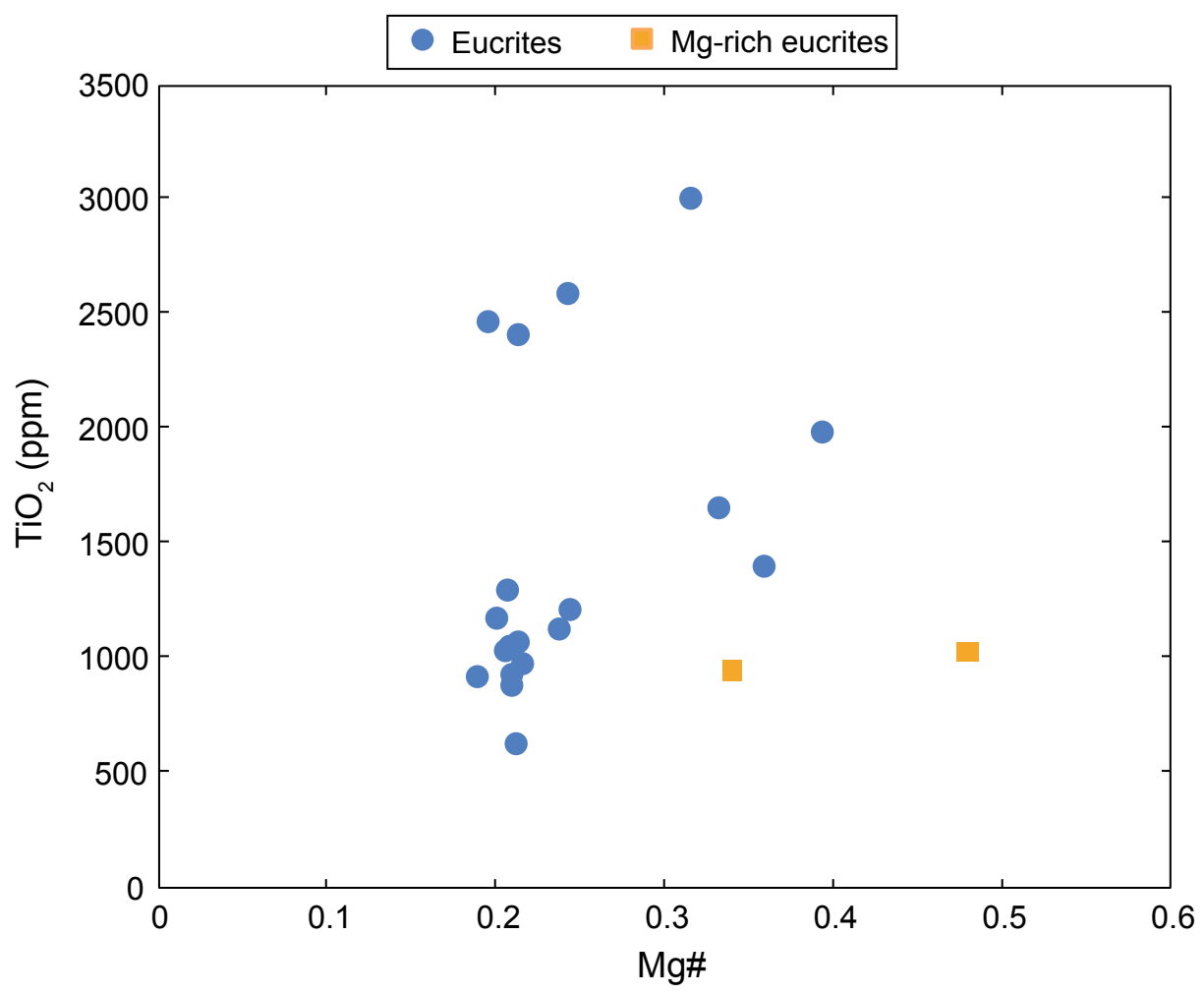

Figure 6.5: $\mathrm{TiO}_{2}$ versus $\mathrm{Mg} \#$ in pyroxene in eucrites from this study.

of $\mathrm{Ca}$ and other major elements do not appear to correlate with $\delta^{26} \mathrm{Mg}^{*}$ or model ${ }^{26} \mathrm{Al} /{ }^{27} \mathrm{Al}_{0}$ values.

Trace element concentrations, particularly REE, in plagioclase and pyroxene vary by up to an order of magnitude or more in the suite of studied eucrites. These variations are consistent with REE concentrations measured in eucritic pyroxene and plagioclase by ion microprobe analysis by Hsu and Crozaz (1996) and whole rock REE concentrations presented by Barrat et al. (2000).

In general terms and based on the REE mineral-melt partition coefficients in pyroxene (Beattie et al., 1991), approximately $80-90 \%$ fractional crystallization would be required to produce the range of REE in melts as represented by the pyroxene observed in this study. A similar level of crystallization would also be required if equilibrium crystallization was the dominant process. These qualitative constraints are unlikely to be er- 
roneous due to changing mineral-melt coefficients during crystallization, given the limited range of pyroxene major element compositions.

Heavy REE are moderately incompatible in pyroxene and, therefore, increasing concentrations of these elements in pyroxene should track increasing degrees of magmatic evolution and $\mathrm{Yb}$ concentration in the melt that the low-Ca pyroxene crystallized from. Relatively high concentrations of $\mathrm{Yb}$ in low-Ca pyroxene compared to other REE, also allows robust measurement of this heavy REE in this mineral phase. The concentrations of $\mathrm{Yb}$ are similar in the low-and high-Ca pyroxene, which suggests it is a suitable element to examine variations in all pyroxene phases in the eucrite samples. $\mathrm{Yb}$ concentrations in low-Ca pyroxene also provide a useful means to compare eucrites and diogenites. Given that there is little variability between the $\mathrm{Yb}$ concentration in both high-Ca and low-Ca pyroxene, $\mathrm{Yb}$ in pyroxene from samples with only a single phase should also be similar, and as such $\mathrm{Yb}$ concentrations in this phase are considered where necessary. For these reasons, the variation in concentration of $\mathrm{Yb}$ in low-Ca pyroxene with $\mathrm{Mg}$ isotope data is now considered.

A positive correlation exists between the concentration of $\mathrm{Yb}$ and other heavy REE in low-Ca pyroxene and the $\delta^{26} \mathrm{Mg}^{*}$ anomaly in the eucrite samples (Fig. 6.6 D). However, three samples (Millbillillie, LEW 85305 and GRA 984043) have anomalously high Yb concentrations. As mentioned above Millbillillie and LEW 85305 both have high pyroxene $\mathrm{TiO}_{2}$, indicating they may belong to the Stannern trend eucrite group, which may account for their high $\mathrm{Yb}$ concentrations. However, GRA 98043 appears to be a main group eucrite, but still has a higher $\mathrm{Yb}$ concentration in pyroxene than the other main group eucrites. The Mg-rich eucrites have very small $\delta^{26} \mathrm{Mg}^{*}$ anomalies and low $\mathrm{Yb}$ concentrations, which indicates that they are the least evolved samples in this eucrite suite. Positive correlations exist between the pyroxene $\mathrm{Yb}$ concentration and the bulk ${ }^{27} \mathrm{Al} /{ }^{24} \mathrm{Mg}$ ratios of eucrite samples, which is consistent with the ${ }^{27} \mathrm{Al} /{ }^{24} \mathrm{Mg}$ ratio increasing with increasing degrees of magmatic evolution (Fig. 6.6 E) . However, there is no clear correlation between model ${ }^{26} \mathrm{Al} /{ }^{27} \mathrm{Al}_{0}$ values and $\mathrm{Yb}$ concentrations in pyroxene (Fig. 6.6 F) . In addition, there appears to be two 
parallel negative correlations between $\mathrm{Eu}$ anomaly $\left(\mathrm{Eu} / \mathrm{Eu}^{*}\right)$ in pyroxene and $\delta^{26} \mathrm{Mg}^{*}$ and model ${ }^{26} \mathrm{Al} /{ }^{27} \mathrm{Al}_{0}$ values (Fig. 6.6 $\mathrm{A}$ and $\mathrm{C}$ ). Excluding the Mg-rich eucrites, concentrations of $\mathrm{Ba}$ in plagioclase correlate positively with both $\delta^{26} \mathrm{Mg}^{*}$ and model ${ }^{26} \mathrm{Al} /{ }^{27} \mathrm{Al}_{0}$ values, but do not clearly correlate with ${ }^{27} \mathrm{Al} /{ }^{24} \mathrm{Mg}$ ratios of the bulk eucrite samples (Fig. 6.6 $\mathrm{G}, \mathrm{H}$ and I). The correlation between elements such as $\mathrm{Ba}$ in plagioclase and $\mathrm{Yb}$ in pyroxene and $\delta^{26} \mathrm{Mg}^{*}$ in eucrites suggests that eucrites represent varying degrees of evolution of a single magma body.

\subsubsection{Comparison with diogenites}

A study similar to the one presented in this thesis was undertaken on diogenites by Schiller et al. (2010, 2011), which allows for a comparison between the in situ trace element and $\mathrm{Mg}$ isotope data for eucrites and diogenites. Diogenites are predominantly composed of low-Ca pyroxene $( \pm$ olivine), and so for the purposes of comparison, only the trace element and $\mathrm{Mg}$ isotopic data for low-Ca pyroxene in both diogenites and eucrites are examined. REE concentrations in low-Ca pyroxene in diogenites vary by an order of magnitude (e.g., $\mathrm{Yb}$ concentrations range from 0.02-0.31 ppm), which would require a high degree of fractional crystallization of the parent melt(s) of diogenites. There is a coherent increase in REE and other elements (e.g., Ti), which is consistent across all the diogenite samples, implying that diogenites shared a common, but variably fractionated parental magma (Schiller et al., 2011). Notably, REE concentrations measured in low-Ca pyroxene from the eucrites (this study) are considerably higher than diogenites. For example, the $\mathrm{Yb}$ concentration in low-Ca pyroxene in the most evolved eucrite (2.92 ppm), is two orders of magnitude higher than the $\mathrm{Yb}$ concentration in the low-Ca pyroxene phase of the least evolved diogenite. In addition, excluding the Mg-rich eucrites there is a large gap in REE concentrations between the most evolved diogenite, and the least evolved eucrite (Fig. 6.7 A). The Mg-rich eucrites appear to have an intermediate REE composition between diogenites and eucrites.

As is the case for eucrites, there is a positive correlation between 


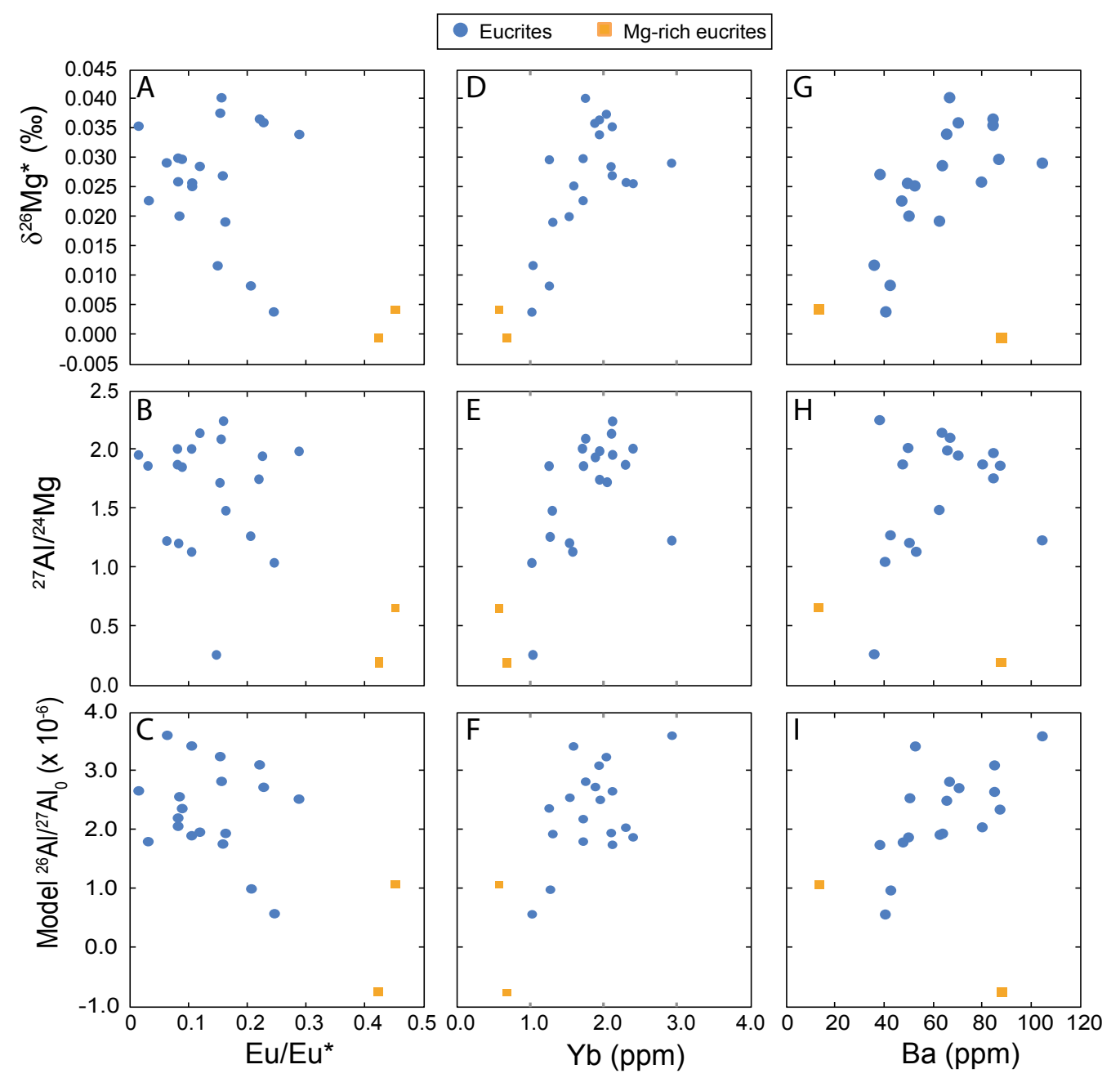

Figure 6.6: Europium anomalies $\left(\mathrm{Eu} / \mathrm{Eu}^{*}\right)$ and $\mathrm{Yb}$ concentration in low-Ca and single phase pyroxene $(\mathrm{A}-\mathrm{F})$ and $\mathrm{Ba}$ concentration in plagioclase $(\mathrm{G}-\mathrm{I})$ versus whole-rock $\delta^{26} \mathrm{Mg}^{*},{ }^{27} \mathrm{Al} /{ }^{24} \mathrm{Mg}$ and model ${ }^{26} \mathrm{Al} /{ }^{27} \mathrm{Al}_{0}$ values. 
$\mathrm{Yb}$ concentration in low-Ca pyroxene and $\delta^{26} \mathrm{Mg}^{*}$ values in diogenites (Schiller et al., 2011). Despite the large difference in REE concentrations between eucrites and diogenites, there is a slight overlap in $\delta^{26} \mathrm{Mg}^{*}$ values between the two meteorite types, although most diogenites do have lower $\delta^{26} \mathrm{Mg}^{*}$ values $(\leq 0.000 \%$ ) than eucrites (Fig. 6.7 B). Comparison of the $\mathrm{Mg}$ isotopic and elemental compositions of the eucrites and diogenites potentially places important constraints on models of silicate differentiation on the HED parent body. The large variation in incompatible elements, such as $\mathrm{Yb}$ in low-Ca pyroxene across the diogenites and eucrites (Fig. 6.7 A) precludes the possibility that diogenites and eucrites represent a fractional crystallization continuum of a single magma body. The stable $\mathrm{Mg}$ isotope composition of diogenites is approximately the same as terrestrial basalts (Teng et al., 2010) and terrestrial mantle olivines (Handler et al. 2009). However $\delta^{25} \mathrm{Mg}$ values of the eucrites are $\sim 0.05 \%$ heavier than that of diogenites and the terrestrial samples (Fig. 6.8). In light of the observations described above, detailed below are four possible models for the formation of eucrites and diogenites.

\subsection{Models for the genesis of eucrites and dio- genites}

\section{Model A - Partial melting of a chondritic mantle}

A possible model for explaining the difference in REE concentrations of pyroxene between eucrites and diogenites, involves partial melting of a "chondritic mantle" on the HED parent body. Eucrites crystallize from the partial melt that underwent variable degrees of fractionation, whereas the diogenites represent the residual HED parent body mantle after extraction of the eucritic magma (Fig. 6.9 A). This is consistent with modelling of volcanic activity on Vesta, which indicates that silicate melts were removed from the mantle, by networks of veins and dykes, possibly having been transported from melts up to $10 \mathrm{~km}$ deep by dykes, and then ex- 


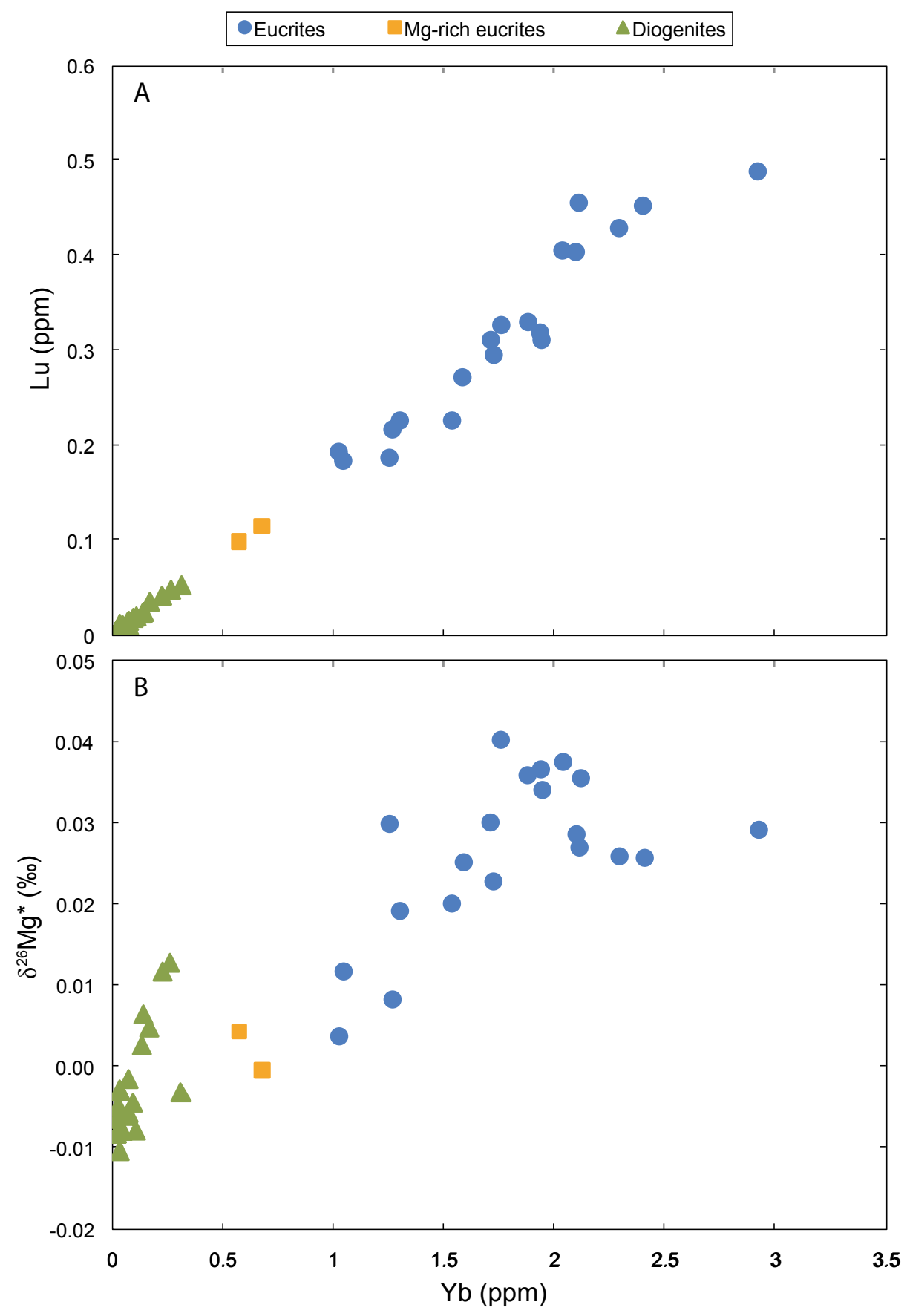

Figure 6.7: $\mathrm{Yb}$ concentration in eucrites and diogenites (Schiller et al., 2011) plotted versus $\mathrm{Lu}$ concentration (A) and $\delta^{26} \mathrm{Mg}^{*}(\%)(B)$. 


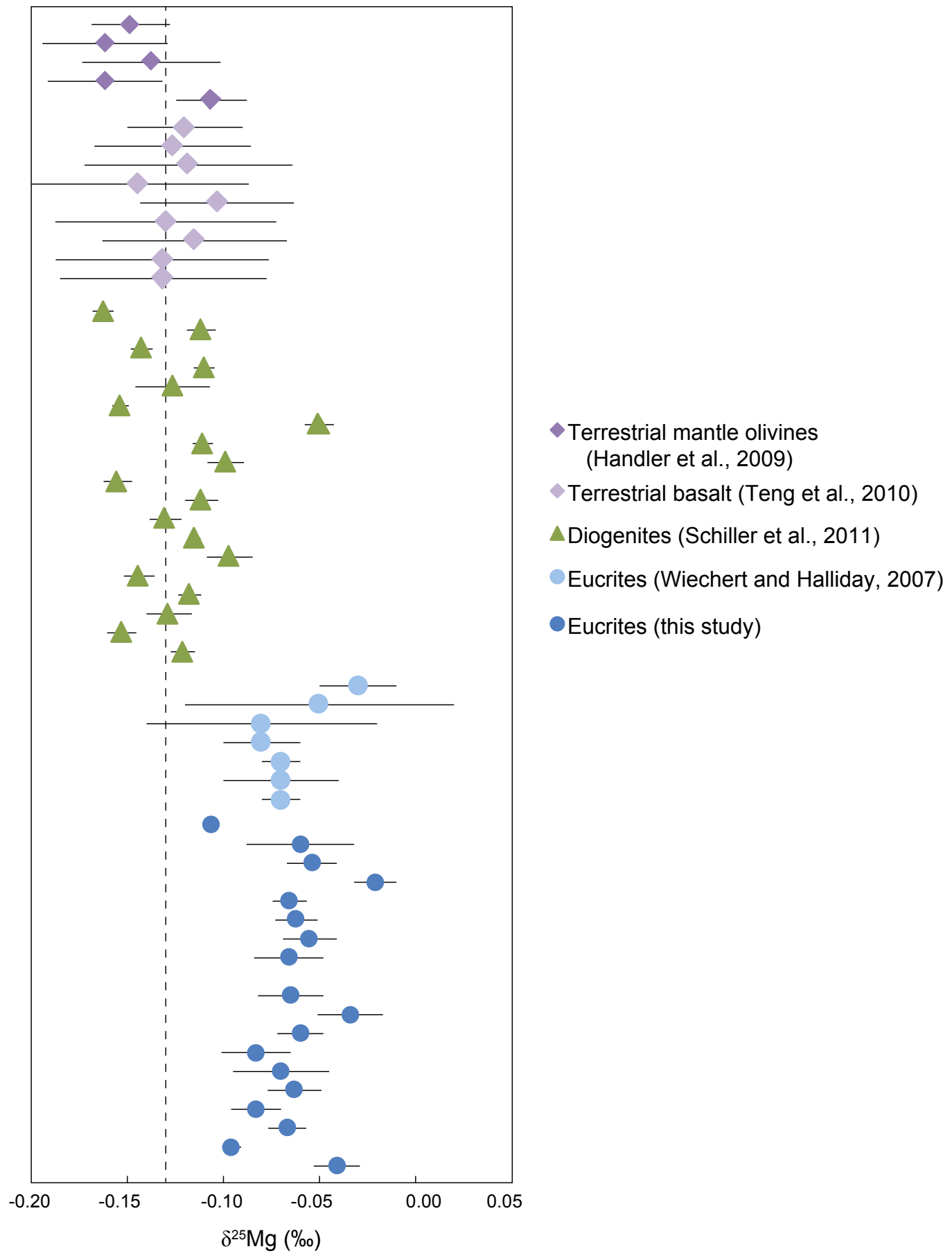

Figure 6.8: $\delta^{25} \mathrm{Mg}$ compositions of eucrites (this study; Wiechert and Halliday. 2007), diogenites (Schiller et al., 2011), terrestrial mantle olivine (Handler et al. 2009) and terrestrial basalts (Teng et al., 2010). Terrestrial basalt and mantle olivine data are averages of sample groups. Vertical line is the average terrestrial $\delta^{25} \mathrm{Mg}$ composition. 
truded onto or near the surface as eucritic lava flows (Wilson and Keil, 1996. 2012). This model could possibly account for the large depletion in incompatible elements in diogenites as compared with the eucrites.

It is possible to evaluate the veracity of this model as it requires that some combination of mean diogenitic and eucritic compositions in appropriate proportions (i.e., the average degree of partial melting) should have a chondritic composition once the effect of core segregation on the elements being considered has been taken into account. In order to do this a simple mixing equation was used to determine if the whole rock eucrite and diogenite chemical compositions could be mixed in some proportion to produce a composition equal to chondrites. In order to account for the process of core formation on the HED parent body, only elements that are not sequestered into the Fe-Ni metal core were considered. Given that core formation results in an approximately two-fold enrichment in elements that are not sequestered into the core in the silicate portion of differentiated bodies, the mixing model was undertaken to solve for $2 \mathrm{x}$ chondritic element concentrations (Mittlefehldt, 2007). In general, the concentrations of most elements in chondrites can be adequately modelled from a eucritediogenite mixture that requires $\sim 80-95 \%$ diogenitic material (Table 6.1). However, $\mathrm{Mg}$ and Sc concentrations in chondrites cannot be modelled by mixing between eucrites and diogenites in any proportions, as chondrites have higher $\mathrm{Mg}$ than both diogenites and eucrites, and a lower Sc concentration than both diogenites and eucrites. Adding in 10-20\% olivine to the eucrite-diogenite mix would, however, result in $\mathrm{Mg}$ and Sc concentrations consistent with chondrites.

This model would allow the diogenite mantle residues to have negative ${ }^{26} \mathrm{Mg}^{*}$ values if melting took place very early. However, some diogenites have positive $\delta^{26} \mathrm{Mg}^{*}$ values (Schiller et al., 2011). While it is possible that the positive $\delta^{26} \mathrm{Mg}^{*}$ in some diogenites could be the result of (late) contamination by eucritic material, the amount of contamination required by adding relatively low-Mg eucrite material to high-Mg diogenites makes this an unlikely scenario and is inconsistent with the systematics of other elements (Schiller et al., 2011). 

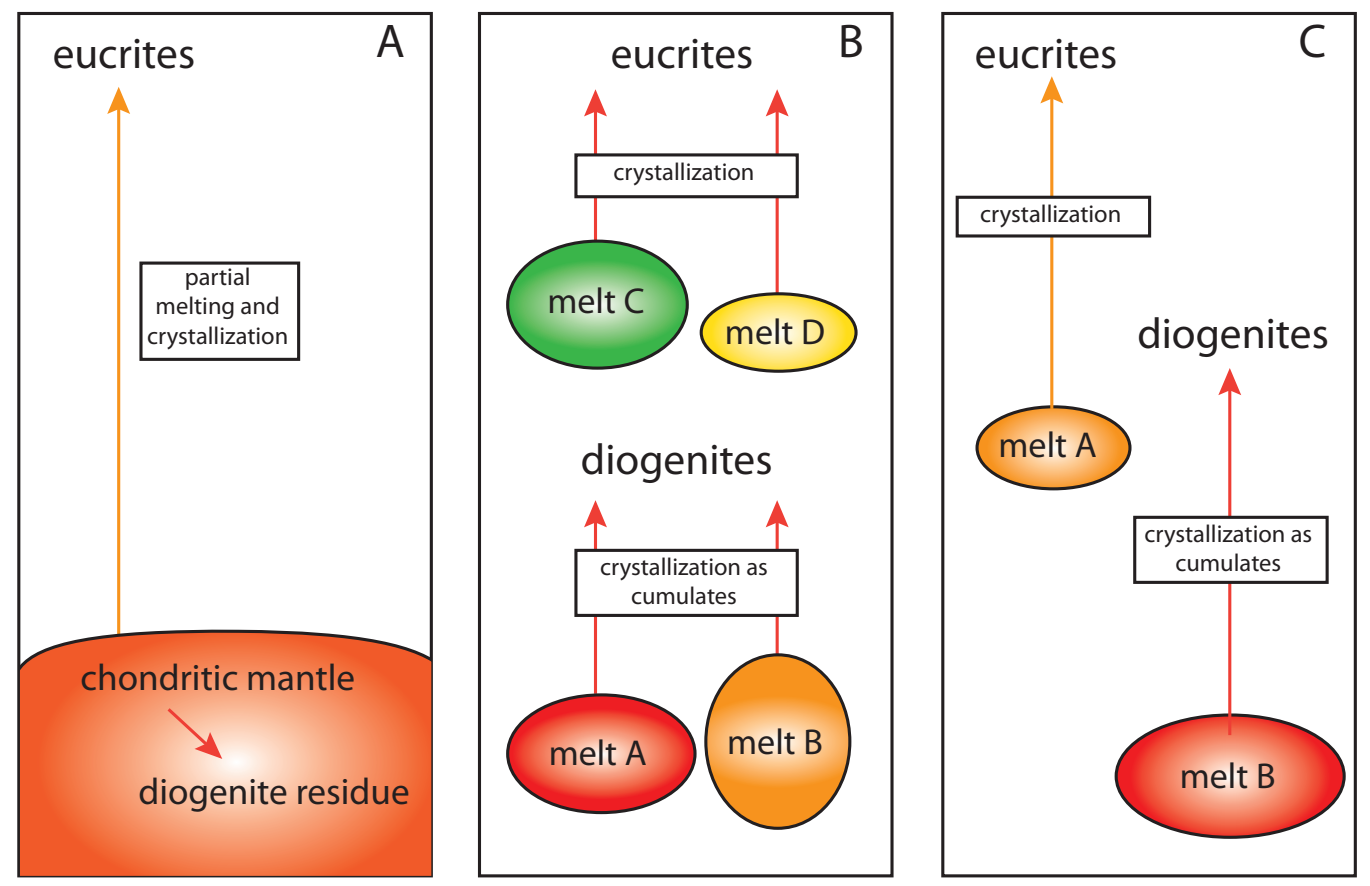

Figure 6.9: Proposed models for the genesis of eucrites and diogenites. Model A involves partial melting of a chondritic mantle, with eucrites crystallizing from the melt, and diogenites representing the residual mantle after removal of the eucritic magma. Model B involves variable degree partial melts which produce eucrites and diogenites separately. Model C involves two large melt bodies separated by depth or geography, from which eucrites and diogenites crystallized.

Another difficulty with this model is the apparent difference in model ages between eucrites and diogenites, with the formation of diogenites pre-dating eucrites by $1.5 \mathrm{Myr}$ (Schiller et al., 2011). If the eucrites and diogenites were produced during the same melting event as mantle residues and partial melts, then both meteorite groups should have the same model ages. In light of the observations described above it is unlikely that the diogenites and eucrites can be related as described by this model. 
Table 6.1: The mixture of diogenite and eucrite compositions required to obtain concentrations equal to twice that of chondrites. Whole-rock diogenite concentrations from Barrat et al. (2008); whole-rock eucrite concentrations from Barrat et al. (2000); whole-rock CI-chondrite concentrations from Barrat et al. (2012).

\begin{tabular}{lccccc}
\hline Element & $\begin{array}{c}\text { Diogenite } \\
\text { concentration }(\mathrm{ppm})\end{array}$ & $\begin{array}{c}\text { Eucrite concentration } \\
(\mathrm{ppm})\end{array}$ & $\begin{array}{c}\text { Chondrite } \\
\text { concentration }(\mathrm{ppm})\end{array}$ & \% Diogenite & \% Eucrite \\
\hline $\mathrm{Ti}$ & 0.06 & 0.41 & 0.04 & 93.0 & 7.0 \\
$\mathrm{Al}$ & 0.46 & 6.51 & 0.78 & 81.7 & 18.3 \\
$\mathrm{Cr}$ & 0.59 & 0.24 & 0.26 & 81.3 & 18.7 \\
$\mathrm{Mg}$ & 16.36 & 4.93 & 9.44 & 122.0 & -22.0 \\
$\mathrm{Sc}$ & 14.50 & 27.30 & 5.88 & 121.5 & -21.5 \\
$\mathrm{Sr}$ & 1.40 & 73.65 & 7.91 & 80.0 & 20.0 \\
$\mathrm{Y}$ & 0.99 & 18.25 & 1.60 & 87.2 & 12.8 \\
$\mathrm{Zr}$ & 0.94 & 48.48 & 3.41 & 87.6 & 12.4 \\
$\mathrm{Nb}$ & 0.10 & 3.55 & 0.30 & 85.4 & 14.6 \\
$\mathrm{Ba}$ & 0.61 & 31.45 & 2.59 & 85.2 & 14.8 \\
$\mathrm{La}$ & 0.04 & 2.84 & 0.25 & 83.8 & 16.2 \\
$\mathrm{Ce}$ & 0.10 & 7.56 & 0.63 & 84.5 & 15.5 \\
$\mathrm{Nd}$ & 0.09 & 5.64 & 0.49 & 84.0 & 16.0 \\
$\mathrm{Sm}$ & 0.04 & 1.81 & 0.16 & 84.1 & 15.9 \\
$\mathrm{Ho}$ & 0.04 & 0.66 & 0.06 & 86.9 & 13.1 \\
$\mathrm{Yb}$ & 0.15 & 1.79 & 0.17 & 88.3 & 11.7 \\
$\mathrm{Lu}$ & 0.02 & 0.27 & 0.02 & 90.1 & 9.9 \\
$\mathrm{Th}$ & 0.01 & 0.36 & 0.03 & 85.2 & 14.8 \\
$\mathrm{U}$ & 0.00 & 0.10 & 0.01 & 86.2 & 13.8 \\
\hline & & & & &
\end{tabular}

\section{Model B - Variable degrees of partial melting of the HED parent body}

This model postulates that eucrites and diogenites formed from a number of different magma bodies produced by variable degrees of partial melting, with the diogenites representing crystal cumulates from large degree partial melts (Fig. 6.9 B). This model could account for the large range in incompatible elements exhibited by both the eucrite and diogenite suites. However, this model is not readily reconcilable with the positive correlations between incompatible elements, such as $\mathrm{Yb}$, and $\delta^{26} \mathrm{Mg}^{*}$ in pyroxene in eucrites. In such a model the oldest eucrites clearly should have the most positive $\delta^{26} \mathrm{Mg}^{*}$ and also should originate from the largest degree partial melts due to the higher levels of ${ }^{26} \mathrm{Al}$ present. However large degrees of partial melting result in lower concentrations of incompatible elements and, therefore, the eucrites with the highest $\delta^{26} \mathrm{Mg}^{*}$ should have the lowest incompatible element concentrations, which is the opposite of what is observed in the dataset. 


\section{Model C - Extensive melting of the HED parent body}

Another possible model for the genesis of eucrites and diogenites, again, proposes that the eucrites and diogenites did not form from a common parental magma and therefore are not genetically related (Fig. 6.9 C). This model requires extensive melting ( $>50 \%$ ) of the HED parent body, with two large magma bodies forming, which are either separated geographically or by depth in the parent body. Diogenites are cumulates that crystallized from a melt body produced by large degrees of partial melting, whereas eucrites are crystallized melt residues produced by crystallization of a second, separate magma body produced by smaller degrees of partial melting. Given that diogenites are older than eucrites, they likely formed from a larger magma body produced by larger degrees of melting than eucrites, as more ${ }^{26} \mathrm{Al}$ would have been present early in the HED parent body. Therefore, this model can account for the higher incompatible element concentration in eucrites, as lower degrees of melting are associated with higher concentrations of incompatible elements. This model also explains the positive correlation between $\delta^{26} \mathrm{Mg}^{*}$ and incompatible elements in eucrite pyroxene, and the negative correlation between Eu anomaly and $\delta^{26} \mathrm{Mg}^{*}$, because eucrites would represent varying degrees of magmatic evolution from a common parent magma, with the most evolved samples crystallizing with the highest incompatible element concentrations, the most "negative" Eu anomalies and the highest $\delta^{26} \mathrm{Mg}^{*}$ values. The temporal and spatial separation of the two large magma bodies may be the result of non-instantaneous accretion of the HED parent body, which is believed to have taken 1-2 Myr (Mittlefehldt, 2007). Later accreted material would have relatively less ${ }^{26} \mathrm{Al}$, and therefore would undergo less melting, and crystallization products of the melt, the eucrites, would be younger than diogenites which may have crystallized from melting of earlier accreted material.

This model overcomes the difficulty of the previous model in explaining the compositional coherency within the eucrite and diogenite suites, as both suites come from single magma bodies. This model is also consistent 
with the range of $\delta^{26} \mathrm{Mg}^{*}$ recorded by eucrites and diogenites, which requires their $\delta^{26} \mathrm{Mg}^{*}$ values to be inherited from the evolving magma body from which they crystallized (Schiller et al., 2011).

This offset in stable $\mathrm{Mg}$ isotope $\left(\delta^{25} \mathrm{Mg}\right)$ composition between eucrites and diogenites and terrestrial samples (Fig. 6.8) may also indicate that the eucritic basalts did not form from small to medium degrees of partial melting as, for example, terrestrial basalts form on Earth. Instead, the slightly heavier stable $\mathrm{Mg}$ isotopic composition of basaltic eucrites might reflect their generation by extensive crystallization of a magma body on the HED parent body, which is consistent with this model. However, the difficulty with this model, is that it still remains problematic to reconcile the large range in REE concentrations across the diogenite suite with their formation from a single magma body. Schiller et al. (2011) determined that fractional crystallization of $50-75 \%$ would be required to produce the range in incompatible elements found in the diogenites, which is plausible.

\section{Model D - Formation of eucrites and diogenites on separate parent bod- ies}

A fourth possible model for the eucrites and diogenites could be that the two meteorite groups formed on different bodies. It is possible that two separate parent bodies may have accreted relatively close to each other, and thus have the same oxygen isotope compositions. To account for the age difference between eucrites and diogenites the diogenite parent body would have accreted earlier than the eucrite parent body. This model can explain the variability in incompatible elements between eucrites and diogenites, and the differences in $\delta^{25} \mathrm{Mg}$ between the two meteorite groups. However, if the eucrites and diogenites are from separate parent bodies, the diogenite parent body is missing evidence for a relatively incompatible element enriched reservoir, such as the eucrites. This is also difficult to reconcile with the petrography of howardites, which contain both diogenitic and eucritic material (Mittlefehldt, 2007), although it is possible that howardites could originate from the diogenite parent body, and con- 
tain evidence of the "missing" incompatible element enriched reservoir. If this were the case, it would have implications for the classification of meteorites based on oxygen isotope composition.

In summary, Model C appears to best explain all aspects of the eucrite data from this study, and can account for the compositional differences of eucrites and diogenites without requiring that they originate from separate parent bodies.

\subsubsection{Timing of silicate differentiation on the HED parent body}

${ }^{26} \mathrm{Al}-{ }^{26} \mathrm{Mg}$ model ages of eucrites from this study relative to CAIs range from 2.8-4.7 Myr, with an average age of 3.4 Myr. This is consistent with a number of other studies that have applied various chronometers to eucrites (such as; the Al-Mg chronometer (Bizzarro et al., 2005b), the MnCr chronometer (Lugmair and Shukolyukov, 1997, 2001; Trinquier et al. 2007), the Sm-Nd chronometer (Wadhwa and Lugmair, 1996; Kumar et al. 1999), the Hf-W chronometer (Kleine et al., 2004) and the Pb-Pb chronometer (Wadhwa et al., 2009) ) that have determined that eucrites date to within $\sim 3$ Myr of solar system formation (Wadhwa et al., 2006). Schiller et al. (2011) determined that diogenite formation began in the first $0.6 \mathrm{Myr}$ of the solar system and continued until to 2.5 Myr after the formation of CAIs. The ages of the eucrites from this and the several other aforementioned studies are considerably younger than the predicted age of $6.6 \mathrm{Myr}$ for crustal formation on the asteroid Vesta as determined by thermal modeling (Ghosh and McSween, 1998).

\subsection{Relationship to the asteroid Vesta}

Similarities between the mineralogy of the HED meteorites and the surface mineralogy of the asteroid Vesta, as determined by spectral reflectance 
measurements (McCord et al., 1970), suggest that the HED meteorites originated from Vesta (Drake, 1979). Observations made of Vesta from NASA's Dawn spacecraft provide further evidence for its identification as the HED parent body, as Vesta's mass, volume and gravitational field are consistent with it being a differentiated body and the mineralogy of the surface reflects that of the HED meteorites (Russell et al., 2012). There is considerable variation across Vesta, with a higher diogenitic component at the south pole, while eucritic material is concentrated at the equator (De Sanctis et al. 2012). This supports the possibility that the parent magmas for eucrites and diogenites were spatially separated as suggested in Model C. There is evidence on Vesta for stratigraphic layering, which is consistent with large scale melting (De Sanctis et al. 2012). It is clear from observations made of Vesta by the Dawn spacecraft that Vesta has undergone a complex magmatic evolution, which is supported by the complexity seen in the HED meteorite suite. 


\section{Chapter 7}

\section{Conclusions and suggestions for further work}

This thesis has presented in situ major and trace element and highprecision whole rock $\mathrm{Mg}$ isotope analyses of a suite of eucrite meteorites. The objectives of this study were to discern the nature and timing of basalt magma generation and silicate differentiation on the HED parent body.

\subsection{Conclusions}

1. There is little variation in the major element compositions of pyroxene and plagioclase in the eucrite meteorites. However, trace element concentrations in these minerals exhibit large variations, particularly for REE which vary by more than an order of magnitude across the suite of eucrites.

2. $\mathrm{Mg}$ anomalies $\left(\delta^{26} \mathrm{Mg}^{*}\right)$ and model ${ }^{26} \mathrm{Al} /{ }^{27} \mathrm{Al}_{0}$ values also vary considerably among eucrites. This is reflected by a large range in model ages, which range from 2.8-4.7 Myr after CAIs.

3. There are positive correlations between the concentrations of incompatible elements in pyroxene and $\delta^{26} \mathrm{Mg}^{*}$, and such correlations are also observed in pyroxene from diogenites (Schiller et al., 2011). 
However, the incompatible element concentrations in eucrite pyroxene are considerably higher than diogenite pyroxene.

4. The range in incompatible element concentrations in pyroxene across the eucrite and diogenite suites cannot realistically be generated by crystallization of a single magma body. This suggests that eucrites and diogenites originate from separate magma bodies, and are therefore not genetically related.

5. The $\delta^{25} \mathrm{Mg}$ composition of diogenites is approximately the same as the $\delta^{25} \mathrm{Mg}$ composition of terrestrial basalts and terrestrial mantle olivines. However the $\delta^{25} \mathrm{Mg}$ composition of the eucrites is $\sim 0.05 \%$ heavier than that of diogenites and the terrestrial samples. This implies that basalt generation on the HED parent body was unlikely to be the result of small to medium degrees (up to 20-30\%) of partial melting as it is on Earth.

6. The model for eucrite and diogenite genesis that best fits the data presented, suggests that eucrites and diogenites formed from two large, separate magma bodies on the HED parent body. The magma bodies, generated by large scale melting, may be separated temporally and spatially. In this model the $\delta^{26} \mathrm{Mg}^{*}$ values in eucrites and diogenites are inherited from their parent magma bodies, and thus represent increasing degrees of magmatic evolution.

\subsection{Suggestions for further work}

Based on the findings of this thesis there is research that could further constrain the timing and processes of silicate differentiation on the HED parent body.

\section{Internal ${ }^{26} \mathrm{Al}-{ }^{26} \mathrm{Mg}$ mineral isochrons of eucrites}

Internal ${ }^{26} \mathrm{Al}-{ }^{26} \mathrm{Mg}$ isochrons of primary igneous minerals can be used to determine more precise ages than whole-rock model isochrons. Mineral 
isochrons also provide information about the precursor material of the rock, and may record processes occurring in the melt. However, due to the relatively short distance required for isotopic exchange and reequilibration in minerals, mineral isochrons may record the ages of postmagmatic processes such as metamorphism. Most mineral grains in eucrites appear to have been re-equilibrated by metamorphism, so internal isochrons of these minerals will provide re-setting rather than crystallization ages. However, it is possible that there are mineral grains in some eucrites that have not re-equilibrated, and $\mathrm{Mg}$ isotope analysis of these could be used to reconstruct precise ages for these eucrites.

\section{Investigate the offset in $\delta^{25} \mathrm{Mg}$ between eucrites and terrestrial rocks.}

The $\delta^{25} \mathrm{Mg}$ measured in eucrites in this and other studies is heavier than $\delta^{25} \mathrm{Mg}$ in terrestrial basalts, terrestrial mantle olivines and diogenites. This has the important implication that the formation of the basaltic eucrites is not analogous to the formation of terrestrial basalts, which occurs through partial melting. However, there is the possibility that this offset in $\delta^{25} \mathrm{Mg}$ is an analytical artifact, resulting from the measurement of samples in different laboratories. In order to test this, 10 terrestrial basalts, 10 eucrites and 10 diogenites could be analysed for $\delta^{25} \mathrm{Mg}$ in the same laboratory.

\section{Trace and major element and high-precision Mg-isotope analyses of cumulate eucrites.}

There are a number of chemical and petrologic differences between cumulate and non-cumulate eucrites, for example most cumulate eucrites are unbrecciated, while the majority of non-cumulate eucrites are brecciated (Hsu and Crozaz, 1997). Cumulate eucrites also have higher Mg\# and lower concentrations of REE than non-cumulates (Hsu and Crozaz, 1997). Sm-Nd and $\mathrm{Pb}-\mathrm{Pb}$ dating has shown that the isotopic closure of cumulate eucrites occurred up to $\sim 150 \mathrm{Myr}$ after non-cumulate eucrites (Jacobsen and Wasserburg, 1984; Lugmair and Shukolyukov, 1997; Tera et al., 1997). Analyses of major element, trace element and Mg isotopic 
composition of cumulate eucrites will help to constrain the poorly understood relationship between the cumulate and non-cumulate eucrites and diogenites. High-precision $\mathrm{Mg}$ isotope analyses of cumulate eucrites will also allow for more reliable age determination. A better understanding of the processes involved with the formation of cumulate eucrites will help to constrain models for silicate differentiation on the HED parent body. 


\section{References}

Alexander, C. M. O., Grossman, J. N., Ebel, D. S., and Ciesla, F. J., 2008. The formation conditions of chondrules and chondrites. Science, 320, 1617-1619. doi: 10.1126/science.1156561.

Amelin, Y., 2008. U-Pb ages of angrites. Geochimica et Cosmochimica Acta, 72, 221-232. doi: 10.1016/j.gca.2007.09.034.

Amelin, Y., Krot, A. N., Hutcheon, I. D., and Ulyanov, A. A., 2002. Lead isotopic ages of chondrules and calcium-aluminum-rich inclusions. Science, 297, 1678-1683. doi: 10.1126/science.1073950.

Anders, E. and Grevesse, N., 1989. Abundances of the elements: Meteoritic and solar. Geochimica et Cosmochimica Acta, 53, 197-214. doi: 10.1016/ 0016-7037(89)90286-X.

Baker, J., Bizzarro, M., Wittig, N., Connelly, J., and Haack, H., 2005. Early planetesimal melting from an age of $4.5662 \mathrm{Gyr}$ for differentiated meteorites. Nature, 436, 1127-1131. doi: 10.1038/nature03882.

Barrat, J. A., Blichert-Toft, J., Gillett, P., and Keller, F., 2000. The differentiation of eucrites: The role of in situ crystallization. Meteoritics $\mathcal{E}$ Planetary Science, 35, 1087-1100. doi: 10.1111/j.1945-5100.2000.tb01495.x.

Barrat, J. A., Yamaguchi, A., Greenwood, R. C., Benoit, M., Cotten, J., Bohn, M., and Franchi, I. A., 2008. Geochemistry of diogenites: Still more diversity in their parental melts. Meteoritics \& Planetary Science, 43, 17591775. doi: 10.1111/j.1945-5100.2008.tb00641.x. 
Barrat, J., Zanda, B., Moynier, F., Bollinger, C., Liorzou, C., and Bayon, G., 2012. Geochemistry of CI chondrites: Major and trace elements, and $\mathrm{Cu}$ and $\mathrm{Zn}$ isotopes. Geochimica et Cosmochimica Acta, 83, 79-92. doi: 10.1016/j.gca.2011.12.011.

Basaltic Volcanism Study Project, 1981. Basaltic Volcanism on the Terrestrial Planets. Pergamon Press Inc., New York.

Beattie, P., Ford, C., and Russell, D., 1991. Partition coefficients for olivinemelt and orthopyroxene-melt systems. Contributions to Mineralogy and Petrology, 109, 212-224. doi: 10.1007/BF00306480.

Beck, A. W., Mittlefehldt, D. W., McSween, H. Y., Rumble, D., Lee, C.-T. A., and Bodnar, R. J., 2011. MIL 03443, a dunite from asteroid 4 Vesta: Evidence for its classification and cumulate origins. Meteoritics and Planetary Science, 46, 1133-1151. doi: DOI:10.1111/j.1945-5100.2011.01219.x.

Bizzarro, M., Baker, J. A., and Haack, H., 2005a. Corrigendum: Mg isotope evidence for contemporaneous formation of chondrules and refractory inclusions. Nature, 435, 1280-1280. doi: 10.1038/nature03919.

Bizzarro, M., Baker, J. A., Haack, H., and Lundgaard, K. L., 2005b. Rapid timescales for accretion and melting of differentiated planetesimals inferred from ${ }^{26} \mathrm{Al}-{ }^{26} \mathrm{Mg}$ chronometry. The Astrophysical Journal, 632, L41L44. doi: 10.1086/497638.

Bizzarro, M., Paton, C., Larsen, K., Schiller, M., Trinquier, A., and Ulfbeck, D., 2011. High-precision Mg-isotope measurements of terrestrial and extraterrestrial material by HR-MC-ICPMS-implications for the relative and absolute $\mathrm{Mg}$-isotope composition of the bulk silicate Earth. Journal of Analytical Atomic Spectrometry, 26, 565. doi: 10.1039/c0ja00190b.

Boss, A. P., Ipatov, S. I., Keiser, S. A., Myhill, E. A., and Vanhala, H. A. T., 2008. Simultaneous triggered collapse of the presolar dense cloud core and injection of short-lived radioisotopes by a supernova shock wave. The Astrophysical Journal, 686, L119-L122. doi: 10.1086/593057. 
Bunch, T. E., 1975. Petrography and petrology of basaltic achondrite polymict breccias (Howardites). In Lunar and Planetary Science Conference Proceedings, 6, 469-492.

Burbidge, E., Burbidge, G., Fowler, W., and Hoyle, F., 1957. Synthesis of the elements in stars. Reviews of Modern Physics, 29, 547-650. doi: 10.1103/RevModPhys.29.547.

Catanzaro, E. J., Murphy, T. J., Garner, E. L., and Shields, W. R., 1966. Absolute isotopic abundance ratios and atomic weight of magnesium. Journal of Research of the National Bureau of Standards, 70A, 453-458.

Chambers, J., 2007. Planet formation. In Treatise on Geochemistry, Holland, H. D. and Turekian, K. K. (Eds.) 11-17. Pergamon, Oxford.

Chaussidon, M., Robert, F., and McKeegan, K. D., 2006. Li and B isotopic variations in an allende CAI: evidence for the in situ decay of short-lived ${ }^{10} \mathrm{Be}$ and for the possible presence of the short-lived nuclide ${ }^{7} \mathrm{Be}$ in the early solar system. Geochimica et Cosmochimica Acta, 70, 224-245. doi: 10.1016/j.gca.2005.08.016.

Chen, J. and Wasserburg, G., 1990. The isotopic composition of Ag in meteorites and the presence of ${ }^{107} \mathrm{Pd}$ in protoplanets. Geochimica et Cosmochimica Acta, 54, 1729-1743. doi: 10.1016/0016-7037(90)90404-9.

Clayton, R. N., 2003. Oxygen isotopes in meteorites. In Treatise on Geochemistry, Holland, H. D. and Turekian, K. K. (Eds.) 1 129-142. Pergamon, Oxford. doi: 10.1016/B0-08-043751-6/01063-X.

Clayton, R. N., Mayeda, T. K., and Rubin, A. E., 1984. Oxygen isotopic compositions of enstatite chondrites and aubrites. In Lunar and Planetary Science Conference Proceedings, 15, 245.

Clayton, R. N. and Mayeda, T. K., 1996. Oxygen isotope studies of achondrites. Geochimica et Cosmochimica Acta, 60, 1999-2017. doi: 10.1016/0016-7037(96)00074-9. 
Consolmagno, G. J. and Drake, M. J., 1977. Composition and evolution of the eucrite parent body: evidence from rare earth elements. Geochimica et Cosmochimica Acta, 41, 1271-1282. doi: 16/0016-7037(77)90072-2.

Crozaz, G., Floss, C., and Wadhwa, M., 2003. Chemical alteration and REE mobilization in meteorites from hot and cold deserts. Geochimica et Cosmochimica Acta, 67, 4727-4741. doi: 10.1016/j.gca.2003.08.008.

Dauphas, N., Foley, C. N., Wadhwa, M., Davis, A. M., Janney, P. E., Qin, L., Göpel, C., and Birck, J.-L., 2005. Protracted core differentiation in asteroids from ${ }^{182} \mathrm{Hf}-{ }^{182} \mathrm{~W}$ systematics in the eagle station pallasite. In Lunar and Planetary Science Conference Proceedings, 36, 1100.

De Sanctis, M. C., C, M., Ammannito, E., Capria, M. T., Tosi, F., Capaccioni, F., Zambon, F., Carraro, F., Fonte, S., Frigeri, A., Jaumann, R., Magni, G., Marchi, S., McCord, T. B., McFadden, L. A., McSween, H. Y., Mittlefehldt, D. W., Nathues, A., Palomba, E., Pieters, C. M., Raymond, C. A., Russell, C. T., Toplis, M. J., and Turrini, D., 2012. Spectroscopic characterization of mineralogy and its diversity across Vesta. Science, 336, 697-700. doi: 10.1126/science.1219270.

Delaney, J. S., Prinz, M., and Takeda, H., 1984. The polymict eucrites. Lunar and Planetary Science Conference Proceedings, 15, 251.

Desch, S. J. and Connolly, H. C., 2002. A model of the thermal processing of particles in solar nebula shocks: Application to the cooling rates of chondrules. Meteoritics E Planetary Science, 37, 183-207. doi: 10.1111/j. 1945-5100.2002.tb01104.x.

Drake, M. J., 1979. Geochemical evolution of the eucrite parent body possible nature and evolution of asteroid 4 Vesta. In Asteroids 765-782. University of Arizona Press.

Drake, M. J., 2001. The eucrite/Vesta story. Meteoritics and Planetary Science, 36, 501-513. 
Duke, M. B. and Silver, L. T., 1967. Petrology of eucrites, howardites and mesosiderites. Geochimica et Cosmochimica Acta, 31, 1637-1665. doi: 10. 1016/0016-7037(67)90112-3.

Fernández, J. and Ip, W.-H., 1984. Some dynamical aspects of the accretion of Uranus and Neptune: The exchange of orbital angular momentum with planetesimals. Icarus, 58, 109-120. doi: 10.1016/0019-1035(84) 90101-5.

Floss, C. and Crozaz, G., 1991. Ce anomalies in the LEW85300 eucrite: evidence for REE mobilization during antarctic weathering. Earth and Planetary Science Letters, 107, 13-24. doi: 10.1016/0012-821X(91)90040-O.

Fowler, G., Shearer, C., Papike, J., and Layne, G., 1995. Diogenites as asteroidal cumulates: insights from orthopyroxene trace element chemistry. Geochimica et Cosmochimica Acta, 59, 3071-3084. doi: 10.1016/ 0016-7037(95)00196-4.

Fukuoka, T., Boynton, W. V., Ma, M.-S., and Schmitt, R. A., 1977. Genesis of howardites, diogenites, and eucrites. In Lunar and Planetary Science Conference Proceedings, 8, 187-210.

Ghosh, A. and McSween, Jr., H. Y., 1998. A thermal model for the differentiation of asteroid 4 Vesta, based on radiogenic heating. Icarus, 134, 187-206. doi: 10.1006/icar.1998.5956.

Goodrich, C. A., 1992. Ureilites: A critical review. Meteoritics, 27, 327-352. doi: 10.1111/j.1945-5100.1992.tb00215.x.

Goodrich, C. A., Scott, E. R., and Fioretti, A. M., 2004. Ureilitic breccias: clues to the petrologic structure and impact disruption of the ureilite parent asteroid. Chemie der Erde - Geochemistry, 64, 283-327. doi: 10. 1016/j.chemer.2004.08.001.

Greenberg, R., Wacker, J. F., Hartmann, W. K., and Chapman, C. R., 1978. Planetesimals to planets: Numerical simulation of collisional evolution. Icarus, 35, 1-26. doi: 10.1016/0019-1035(78)90057-X. 
Greenwood, R. C., Franchi, I. A., Jambon, A., and Buchanan, P. C., 2005. Widespread magma oceans on asteroidal bodies in the early solar system. Nature, 435, 916-918. doi: 10.1038/nature03612.

Handler, M. R., Baker, J. A., Schiller, M., Bennett, V. C., and Yaxley, G. M., 2009. Magnesium stable isotope composition of Earth's upper mantle. Earth and Planetary Science Letters, 282, 306-313. doi: 10.1016/j.epsl.2009. 03.031.

Hevey, P. J. and Sanders, I. S., 2006. A model for planetesimal meltdown by ${ }^{26} \mathrm{Al}$ and its implications for meteorite parent bodies. Meteoritics $\mathcal{E}$ Planetary Science, 41, 95-106. doi: 10.1111/j.1945-5100.2006.tb00195.x.

Honda, M. and Imamura, M., 1971. Half-life of $\mathrm{Mn}^{53}$. Physical Review C, 4, 1182-1188. doi: 10.1103/PhysRevC.4.1182.

Hsu, W. and Crozaz, G., 1996. Mineral chemistry and the petrogenesis of eucrites: I. noncumulate eucrites. Geochimica et Cosmochimica Acta, 60, 4571-4591. doi: 10.1016/S0016-7037(96)00277-3.

Hsu, W. and Crozaz, G., 1997. Mineral chemistry and the petrogenesis of eucrites: II. cumulate eucrites. Geochimica et Cosmochimica Acta, 61, 1293-1302. doi: 10.1016/S0016-7037(96)00411-5.

Hsu, W., Guan, Y., Leshin, L. A., Ushikubo, T., and Wasserburg, G. J., 2006. A late episode of irradiation in the early solar system: Evidence from extinct ${ }^{36} \mathrm{Cl}$ and ${ }^{26} \mathrm{Al}$ in meteorites. The Astrophysical Journal, 640, 525. doi: $10.1086 / 500043$.

Hudson, G. B., Kennedy, B. M., Podosek, F. A., and Hohenberg, C. M., 1988. The early solar system abundance of ${ }^{244} \mathrm{Pu}$ as inferred from the St. Severin chondrites. In Lunar and Planetary Science Conference Proceedings, 19, 547-557.

Ikeda, Y. and Takeda, H., 1985. A model for the origin of basaltic achondrites based on the Yamato 7308 howardite. In Lunar and Planetary Science Conference Proceedings, 15, 649-663. 
Ireland, T. R. and Fegley, B., 2000. The solar system's earliest chemistry: Systematics of refractory inclusions. International Geology Review, 42, 865-894. doi: 10.1080/00206810009465116.

Jacobsen, B., Yin, Q.-Z., Moynier, F., Amelin, Y., Krot, A. N., Nagashima, K., Hutcheon, I. D., and Palme, H., 2008. ${ }^{26} \mathrm{Al}-{ }^{26} \mathrm{Mg}$ and ${ }^{207} \mathrm{~Pb}-{ }^{206} \mathrm{~Pb}$ systematics of Allende CAIs: canonical solar initial ${ }^{26} \mathrm{Al} /{ }^{27} \mathrm{Al}$ ratio reinstated. Earth and Planetary Science Letters, 272, 353-364. doi: 10.1016/j. epsl.2008.05.003.

Jacobsen, S. and Wasserburg, G., 1984. Sm-Nd isotopic evolution of chondrites and achondrites, II. Earth and Planetary Science Letters, 67, 137-150. doi: 10.1016/0012-821X(84)90109-2.

Jarosewich, E., Nelen, J., and Norberg, J. A., 1980. Reference samples for electron microprobe analysis. Geostandards Newsletter, 4, 43-47. doi: 10.1111/j.1751-908X.1980.tb00273.x.

Jeffery, P. M. and Reynolds, J. H., 1961. Origin of excess ${ }^{129}$ Xe in stone meteorites. Journal of Geophysical Research, 66, 3582-3583. doi: 10.1029/ JZ066i010p03582.

Jones, J. H., 1984. The composition of the mantle of the eucrite parent body and the origin of eucrites. Geochimica et Cosmochimica Acta, 48, 641-648. doi: 16/0016-7037(84)90092-9.

Jurewicz, A., Mittlefehldt, D., and Jones, J., 1993. Experimental partial melting of the Allende (CV) and Murchison (CM) chondrites and the origin of asteroidal basalts. Geochimica et Cosmochimica Acta, 57, 21232139. doi: 10.1016/0016-7037(93)90098-H.

Jurewicz, A., Mittlefehldt, D., and Jones, J., 1995. Experimental partial melting of the St. Severin (LL) and Lost City $(\mathrm{H})$ chondrites. Geochimica et Cosmochimica Acta, 59, 391-408. doi: 10.1016/0016-7037(94)00328-J.

Kleine, T., Mezger, K., Münker, C., Palme, H., and Bischoff, A., 2004. ${ }^{182} \mathrm{Hf}-$ ${ }^{182} \mathrm{~W}$ isotope systematics of chondrites, eucrites, and martian meteorites: 
chronology of core formation and early mantle differentiation in Vesta and Mars. Geochimica et Cosmochimica Acta, 68, 2935-2946. doi: 16/j.gca. 2004.01.009.

Kleine, T., Mezger, K., Palme, H., Scherer, E., and Münker, C., 2005. Early core formation in asteroids and late accretion of chondrite parent bodies: Evidence from ${ }^{182} \mathrm{Hf}-{ }^{182} \mathrm{~W}$ in CAIs, metal-rich chondrites, and iron meteorites. Geochimica et Cosmochimica Acta, 69, 5805-5818. doi: 10.1016/j.gca.2005.07.012.

Krot, A. N., Keil, K., Goodrich, C. A., Scott, E. R. D., and Weisberg, M. K., 2003. Classification of meteorites. In Treatise on Geochemistry, Holland, H. D. and Turekian, K. K. (Eds.) 1 83-128. Pergamon, Oxford.

Krot, A. N., Petaev, M. I., Russell, S. S., Itoh, S., Fagan, T. J., Yurimoto, H., Chizmadia, L., Weisberg, M. K., Komatsu, M., Ulyanov, A. A., and Keil, K., 2004. Amoeboid olivine aggregates and related objects in carbonaceous chondrites: records of nebular and asteroid processes. Chemie der Erde - Geochemistry, 64, 185-239. doi: 10.1016/j.chemer.2004.05.001.

Kuiper, G. P., 1954. On the origin of the lunar surface features. Proceedings of the National Academy of Sciences of the United States of America, 40, 10961112.

Kumar, A., Gopalan, K., and Bhandari, N., 1999. ${ }^{147} \mathrm{Sm}-{ }^{143} \mathrm{Nd}$ and ${ }^{87} \mathrm{Rb}-{ }^{87} \mathrm{Sr}$ ages of the eucrite piplia kalan. Geochimica et Cosmochimica Acta, 63, 3997-4001. doi: 10.1016/S0016-7037(99)00172-6.

Langmuir, C. H., 1989. Geochemical consequences of in situ crystallization. Nature, 340, 199-205. doi: 10.1038/340199a0.

Larsen, K. K., Trinquier, A., Paton, C., Schiller, M., Wielandt, D., Ivanova, M. A., Connelly, J. N., Nordlund, Å., Krot, A. N., and Bizzarro, M., 2011. Evidence for magnesium isotope heterogeneity in the solar protoplanetary disk. The Astrophysical Journal, 735, L37. doi: 10.1088/2041-8205/ $735 / 2 /$ L37. 
Lee, T., Papanastassiou, D. A., and Wasserburg, G. J., 1977. ${ }^{26} \mathrm{Al}$ in the early solar system: Fossil or fuel. The Astrophysical Journal Letters, 211, L107-10.

Lin, Y., Guan, Y., Leshin, L. A., Ouyang, Z., and Wang, D., 2005. Short-lived chlorine-36 in a Ca- and Al-rich inclusion from the Ningqiang carbonaceous chondrites. Proceedings of the National Academy of Sciences of the United States of America, 102, 1306-1311. doi: 10.1073/pnas.0407173101.

Lugmair, G. W. and Shukolyukov, A., 1997. Mn-53-Cr-53 isotope systematics of the HED parent body. In Lunar and Planetary Institute Science Conference Abstracts, 28, 851.

Lugmair, G. W. and Shukolyukov, A., 2001. Early solar system events and timescales. Meteoritics and Planetary Science, 36, 1017-1026.

McCord, T. B., Adams, J. B., and Johnson, T. V., 1970. Asteroid Vesta: Spectral reflectivity and compositional implications. Science, 168, 1445 -1447. doi: 10.1126/science.168.3938.1445.

McKeegan, K. and Davis, A., 2007. Early solar system chronology. In Treatise on Geochemistry, Holland, H. D. and Turekian, K. K. (Eds.) 11 38. Pergamon, Oxford.

Mendybaev, R., Beckett, J., Grossman, L., Stolper, E., Cooper, R., and Bradley, J., 2002. Volatilization kinetics of silicon carbide in reducing gases: an experimental study with applications to the survival of presolar grains in the solar nebula. Geochimica et Cosmochimica Acta, 66, 661682. doi: 10.1016/S0016-7037(01)00802-X.

Metzler, K., Bobe, K., Palme, H., Spettel, B., and Stöffler, D., 1995. Thermal and impact metamorphism on the HED parent asteroid. Planetary and Space Science, 43, 499-525. doi: 10.1016/0032-0633(94)00219-H.

Mittlefehldt, D. W. and Lindstrom, M. M., 1991. Generation of abnormal trace element abundances in Antarctic eucrites by weathering processes. 
Geochimica et Cosmochimica Acta, 55, 77-87. doi: 10.1016/0016-7037(91) 90401-P.

Mittlefehldt, D. W. and Lindstrom, M. M., 2003. Geochemistry of eucrites: genesis of basaltic eucrites, and Hf and Ta as petrogenetic indicators for altered antarctic eucrites. Geochimica et Cosmochimica Acta, 67, 1911-1934. doi: 10.1016/S0016-7037(02)01411-4.

Mittlefehldt, D. W., Killgore, M., and Lee, M. T., 2002. Petrology and geochemistry of D'Orbigny, geochemistry of Sahara 99555, and the origin of angrites. Meteoritics \& Planetary Science, 37, 345-369. doi: 10.1111/j.1945-5100.2002.tb00821.x.

Mittlefehldt, D., 2007. Achondrites. In Treatise on Geochemistry, Holland, H. D. and Turekian, K. K. (Eds.) 1 1-40. Pergamon, Oxford.

Mostefaoui, S., Lugmair, G. W., and Hoppe, P., 2005. ${ }^{60} \mathrm{Fe}$ : a heat source for planetary differentiation from a nearby supernova explosion. The Astrophysical Journal, 625, 271. doi: 10.1086/429555.

Newsom, H. E. and Drake, M. J., 1983. Experimental investigation of the partitioning of phosphorus between metal and silicate phases: implications for the earth, moon and eucrite parent body. Geochimica et Cosmochimica Acta, 47, 93-100. doi: 10.1016/0016-7037(83)90093-5.

Nielsen, S. G., Rehkämper, M., and Halliday, A. N., 2006. Large thallium isotopic variations in iron meteorites and evidence for lead-205 in the early solar system. Geochimica et Cosmochimica Acta, 70, 2643-2657. doi: 10.1016/j.gca.2006.02.012.

Papike, J. J., 1998. Comparative planetary mineralogy; chemistry of meltderived pyroxene, feldspar, and olivine. Reviews in Mineralogy and Geochemistry, 36, 7.1-7.11.

Paton, C., Hellstrom, J., Paul, B., Woodhead, J., and Hergt, J., 2011. Iolite: Freeware for the visualisation and processing of mass spectromet- 
ric data. Journal of Analytical Atomic Spectrometry, 26, 2508-2518. doi: 10.1039/C1JA10172B.

Reed, S. J. B., 2005. Electron Microprobe Analysis and Scanning Electron Microscopy in Geology. Cambridge University Press. ISBN 9780521848756.

Righter, K. and Drake, M. J., 1997. A magma ocean on vesta: Core formation and petrogenesis of eucrites and diogenites. Meteoritics $\mathcal{E}$ Planetary Science, 32, 929-944. doi: 10.1111/j.1945-5100.1997.tb01582.x.

Rugel, G., Faestermann, T., Knie, K., Korschinek, G., Poutivtsev, M., Schumann, D., Kivel, N., Günther-Leopold, I., Weinreich, R., and Wohlmuther, M., 2009. New measurement of the ${ }^{60}$ Fe half-life. Physical Review Letters, 103, 072502. doi: 10.1103/PhysRevLett.103.072502.

Russell, C. T., Capaccioni, F., Coradini, A., Sanctis, M. C. D., Feldman, W. C., Jaumann, R., Keller, H. U., McCord, T. B., McFadden, L. A., Mottola, S., Pieters, C. M., Prettyman, T. H., Raymond, C. A., Sykes, M. V., Smith, D. E., and Zuber, M. T., 2007. Dawn mission to Vesta and Ceres. Earth, Moon, and Planets, 101, 65-91. doi: 10.1007/s11038-007-9151-9.

Russell, C. T., Raymond, C. A., Coradini, A., McSween, H. Y., Zuber, M. T., Nathues, A., Sanctis, D., C, M., Jaumann, R., Konopliv, A. S., Preusker, F., Asmar, S. W., Park, R. S., Gaskell, R., Keller, H. U., Mottola, S., Roatsch, T., Scully, J. E. C., Smith, D. E., Tricarico, P., Toplis, M. J., Christensen, U. R., Feldman, W. C., Lawrence, D. J., McCoy, T. J., Prettyman, T. H., Reedy, R. C., Sykes, M. E., and Titus, T. N., 2012. Dawn at Vesta: Testing the protoplanetary paradigm. Science, 336, 684-686. doi: $10.1126 /$ science. 1219381.

Sahijpal, S., Goswami, J. N., Davis, A. M., Grossman, L., and Lewis, R. S., 1998. A stellar origin for the short-lived nuclides in the early solar system. Nature, 391, 559-561. doi: 10.1038/35325.

Schenk, P., O’Brien, D. P., Marchi, S., Gaskell, R., Preusker, F., Roatsch, T., Jaumann, R., Buczkowski, D., McCord, T., McSween, H. Y., Williams, D., 
Yingst, A., Raymond, C., and Russell, C., 2012. The geologically recent giant impact basins at Vesta's south pole. Science, 336, 694-697. doi: 10.1126/science. 1223272.

Schiller, M., Baker, J. A., and Bizzarro, M., 2010. ${ }^{26} \mathrm{Al}-{ }^{26} \mathrm{Mg}$ dating of asteroidal magmatism in the young solar system. Geochimica et Cosmochimica Acta, 74, 4844-4864. doi: 16/j.gca.2010.05.011.

Schiller, M., Baker, J., Creech, J., Paton, C., Millet, M.-A., Irving, A., and Bizzarro, M., 2011. Rapid timescales for magma ocean crystallization on the howardite-eucrite-diogenite parent body. The Astrophysical Journal, 740, L22. doi: 10.1088/2041-8205/740/1/L22.

Schönbächler, M., Rehkämper, M., Halliday, A. N., Lee, D.-C., BourotDenise, M., Zanda, B., Hattendorf, B., and Günther, D., 2002. Niobiumzirconium chronometry and early solar system development. Science, 295, 1705-1708. doi: 10.1126/science.1067400.

Scott, E. and Krot, A., 2007. Chondrites and their components. In Treatise on Geochemistry, Holland, H. D. and Turekian, K. K. (Eds.) 1 1-72. Pergamon, Oxford.

Shearer, C. K., Fowler, G. W., and Papike, J. J., 1997. Petrogenetic models for magmatism on the eucrite parent body: Evidence from orthopyroxene in diogenites. Meteoritics $\mathcal{E}$ Planetary Science, 32, 877-889. doi: 10.1111/j.1945-5100.1997.tb01578.x.

Shukolyukov, A. and Lugmair, G. W., 1993. Live iron-60 in the early solar system. Science, 259, 1138-1142. doi: 10.1126/science.259.5098.1138.

Spivak-Birndorf, L., Wadhwa, M., and Janney, P., 2009. ${ }^{26} \mathrm{Al}-{ }^{26} \mathrm{Mg}$ systematics in D'Orbigny and Sahara 99555 angrites: Implications for highresolution chronology using extinct chronometers. Geochimica et Cosmochimica Acta, 73, 5202-5211. doi: 10.1016/j.gca.2009.02.038.

Srinivasan, G., Ulyanov, A. A., and Goswami, J. N., 1994. Ca-41 in the early solar system. The Astrophysical Journal, 431, L67. doi: 10.1086/187474. 
Srinivasan, G., Goswami, J. N., and Bhandari, N., 1999. ${ }^{26} \mathrm{Al}$ in eucrite Piplia Kalan: Plausible heat source and formation chronology. Science, 284, 1348 -1350. doi: 10.1126/science.284.5418.1348.

Stolper, E., 1977. Experimental petrology of eucritic meteorites. Geochimica et Cosmochimica Acta, 41, 587-611. doi: 16/0016-7037(77)90300-3.

Suess, H., Wänke, H., and Wlotzka, F., 1964. On the origin of gas-rich meteorites. Geochimica et Cosmochimica Acta, 28, 595-607. doi: 10.1016/ 0016-7037(64)90080-8.

Tachibana, S., Huss, G. R., Kita, N. T., Shimoda, G., and Morishita, Y., 2006. ${ }^{60} \mathrm{Fe}$ in chondrites: debris from a nearby supernova in the early solar system? The Astrophysical Journal Letters, 639, L87. doi: 10.1086/503201.

Takeda, H. and Mori, H., 1985. The diogenite-eucrite links and the crystallization history of a crust of their parent body. In Lunar and Planetary Science Conference Proceedings, 15, 636-648.

Takeda, H. and Graham, A. L., 1991. Degree of equilibration of eucritic pyroxenes and thermal metamorphism of the earliest planetary crust. Meteoritics, 26, 129-134. doi: 10.1111/j.1945-5100.1991.tb01028.x.

Taylor, G. J., 1992. Core formation in asteroids. Journal of Geophysical Research: Planets, 97, 14717-14726. doi: 10.1029/92JE01501.

Teng, F.-Z., Li, W.-Y., Ke, S., Marty, B., Dauphas, N., Huang, S., Wu, F.-Y., and Pourmand, A., 2010. Magnesium isotopic composition of the Earth and chondrites. Geochimica et Cosmochimica Acta, 74, 4150-4166. doi: 10.1016/j.gca.2010.04.019.

Tera, F., Carlson, R. W., and Boctor, N. Z., 1997. Radiometric ages of basaltic achondrites and their relation to the early history of the solar system. Geochimica et Cosmochimica Acta, 61, 1713-1731. doi: 10.1016/S0016-7037(97)00018-5. 
Trinquier, A., Birck, J.-L., and Allègre, C. J., 2007. Widespread ${ }^{54} \mathrm{Cr}$ heterogeneity in the inner solar system. The Astrophysical Journal, 655, 1179. doi: $10.1086 / 510360$.

Urey, H. C., 1955. The cosmic abundances of potassium, uranium, and thorium and the heat balances of the Earth, the Moon, and Mars. Proceedings of the National Academy of Sciences of the United States of America, $41,127-144$.

Villeneuve, J., Chaussidon, M., and Libourel, G., 2009. Homogeneous distribution of ${ }^{26} \mathrm{Al}$ in the solar system from the $\mathrm{Mg}$ isotopic composition of chondrules. Science, 325, 985-988. doi: 10.1126/science.1173907.

Vockenhuber, C., Oberli, F., Bichler, M., Ahmad, I., Quitté, G., Meier, M., Halliday, A. N., Lee, D.-C., Kutschera, W., Steier, P., Gehrke, R. J., and Helmer, R. G., 2004. New half-life measurement of ${ }^{182} \mathrm{Hf}$ : Improved chronometer for the early solar system. Physical Review Letters, 93, 172501. doi: 10.1103/PhysRevLett.93.172501.

Wadhwa, M., Srinivasan, G., and Carlson, R. W., 2006. Timescales of planetesimal differentiation in the early solar system. In Meteorites and the Early Solar System II 715-731.

Wadhwa, M., Amelin, Y., Bogdanovski, O., Shukolyukov, A., Lugmair, G., and Janney, P., 2009. Ancient relative and absolute ages for a basaltic meteorite: Implications for timescales of planetesimal accretion and differentiation. Geochimica et Cosmochimica Acta, 73, 5189-5201. doi: 10.1016/j.gca.2009.04.043.

Wadhwa, M. and Lugmair, G. W., 1996. Age of the eucrite "Caldera" from convergence of long-lived and short-lived chronometers. Geochimica et Cosmochimica Acta, 60, 4889-4893. doi: 10.1016/S0016-7037(96)00331-6.

Walker, F., Parrington, J., and Feiner, F., 1989. Nuclides and isotopes. General Electric Company. 
Warren, P. H. and Jerde, E. A., 1987. Composition and origin of Nuevo Laredo Trend eucrites. Geochimica et Cosmochimica Acta, 51, 713-725. doi: 10.1016/0016-7037(87)90082-2.

Wasson, J. T., 1972. Formation of ordinary chondrites. Reviews of Geophysics, 10, 711-759. doi: 10.1029/RG010i003p00711.

Weidenschilling, S. J., 1977. The distribution of mass in the planetary system and solar nebula. Astrophysics and Space Science, 51, 153-158. doi: 10.1007 /BF00642464.

Weidenschilling, S., 1980. Dust to planetesimals: settling and coagulation in the solar nebula. Icarus, 44, 172-189. doi: 10.1016/0019-1035(80) 90064-0.

Weidenschilling, S., 2000. Formation of planetesimals and accretion of the terrestrial planets. Space Science Reviews, 92, 295-310. doi: 10.1023/ A: 1005259615299.

Wiechert, U., Halliday, A., Palme, H., and Rumble, D., 2004. Oxygen isotope evidence for rapid mixing of the HED meteorite parent body. Earth and Planetary Science Letters, 221, 373-382. doi: 10.1016/S0012-821X(04) 00090-1.

Wiechert, U. and Halliday, A. N., 2007. Non-chondritic magnesium and the origins of the inner terrestrial planets. Earth and Planetary Science Letters, 256, 360-371. doi: 10.1016/j.eps1.2007.01.007.

Wilson, L. and Keil, K., 1996. Volcanic eruptions and intrusions on the asteroid 4 Vesta. Journal of Geophysical Research: Planets, 101, 18927-18940. doi: 10.1029/96JE01390.

Wilson, L. and Keil, K., 2012. Volcanic activity on differentiated asteroids: a review and analysis. Chemie der Erde - Geochemistry, 72, 289-321. doi: 10.1016/j.chemer.2012.09.002. 
Wood, J. A., 2004. Formation of chondritic refractory inclusions: the astrophysical setting. Geochimica et Cosmochimica Acta, 68, 4007-4021. doi: 10.1016/j.gca.2004.04.003.

Yamaguchi, A., Barrat, J., Greenwood, R., Shirai, N., Okamoto, C., Setoyanagi, T., Ebihara, M., Franchi, I., and Bohn, M., 2009. Crustal partial melting on vesta: evidence from highly metamorphosed eucrites. Geochimica et Cosmochimica Acta, 73, 7162-7182. doi: 10.1016/j.gca.2009. 07.037.

Yamaguchi, A., Taylor, G., and Keil, K., 1996. Global crustal metamorphism of the eucrite parent body. Icarus, 124, 97-112. doi: 10.1006/icar. 1996.0192. 
Appendices 


\section{Appendix A}

\section{Major element data}

The following are tables of all of the major element data acquired for eucrite samples and geostandards in this study. 


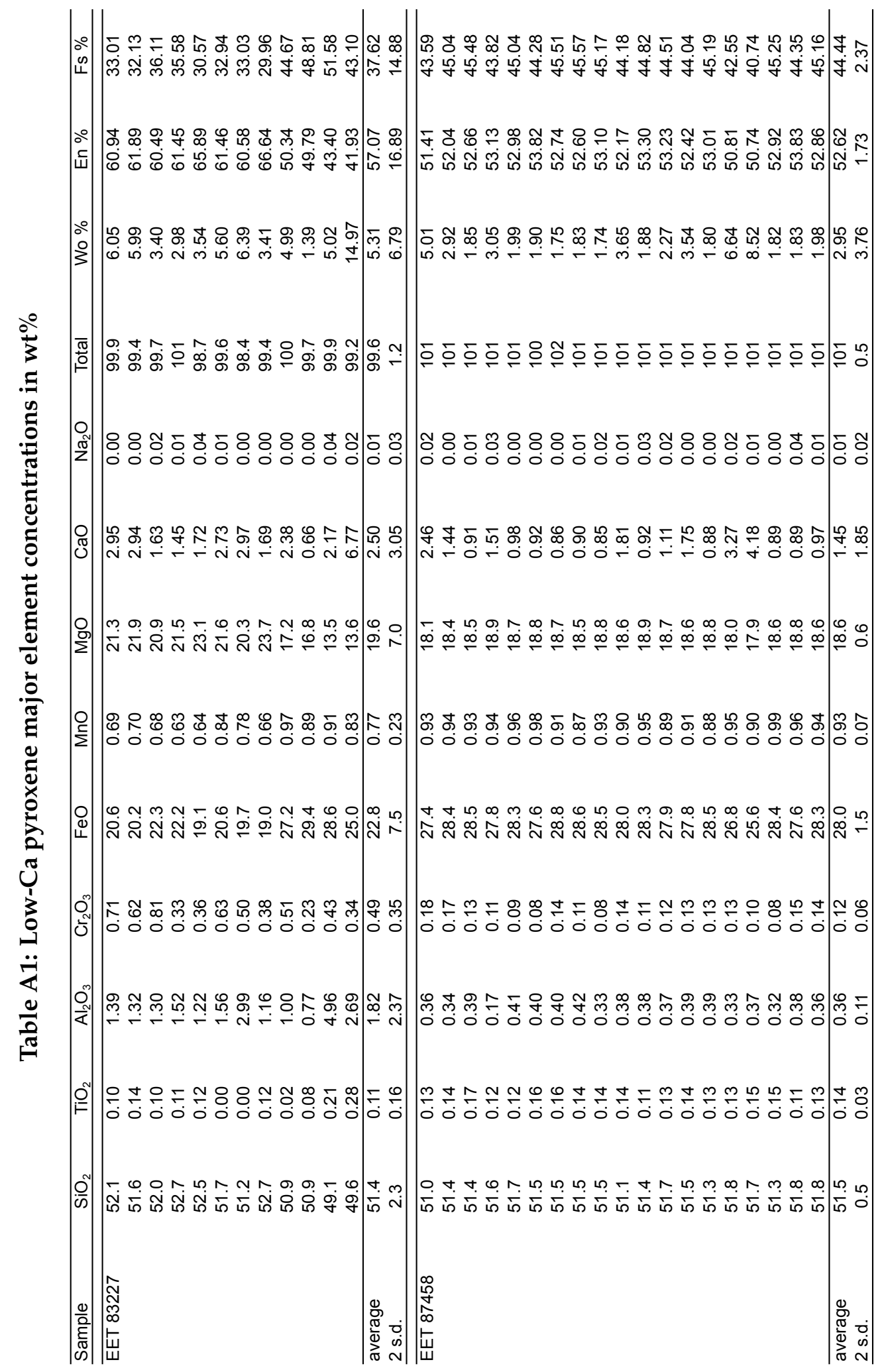




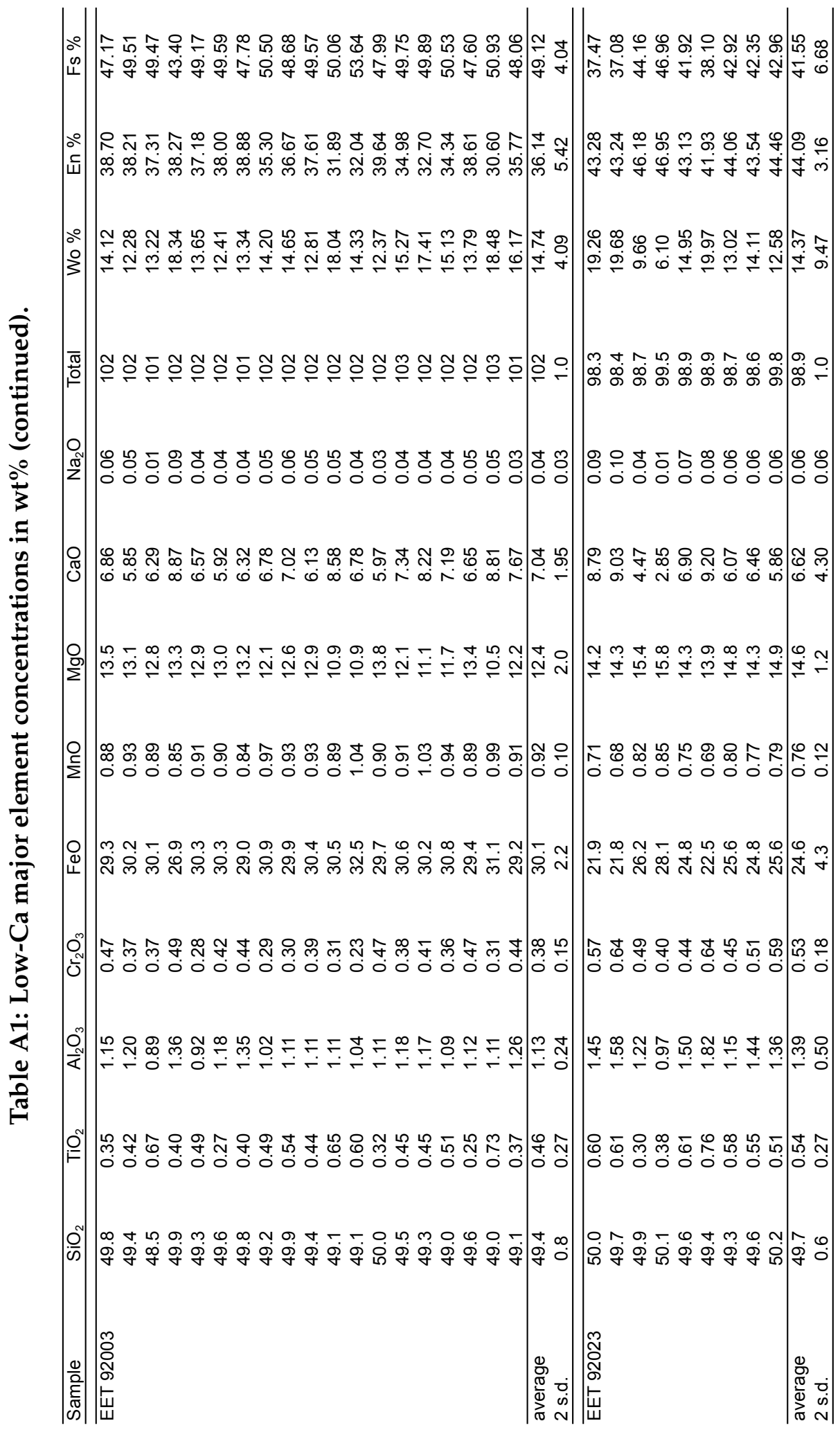




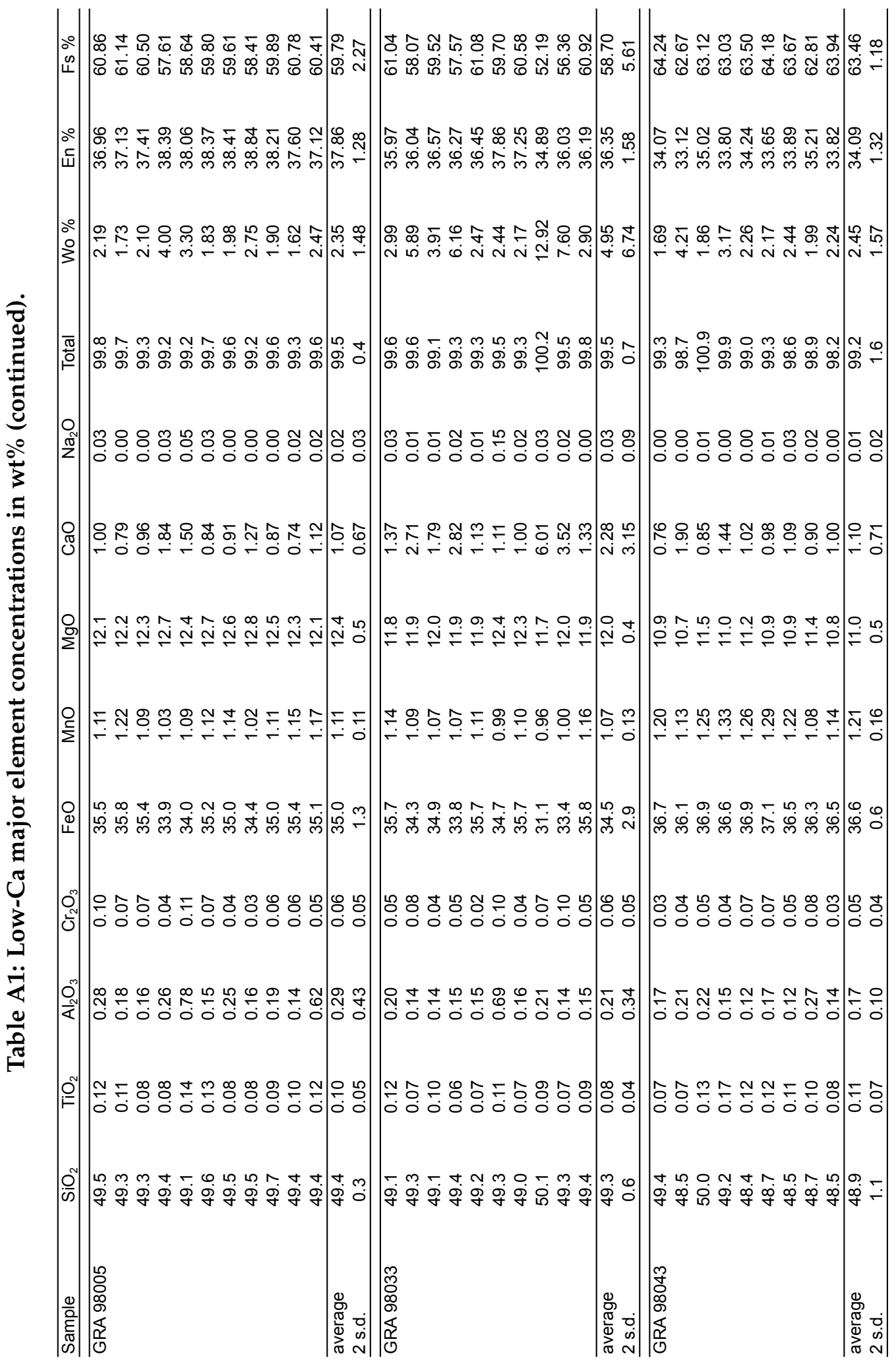




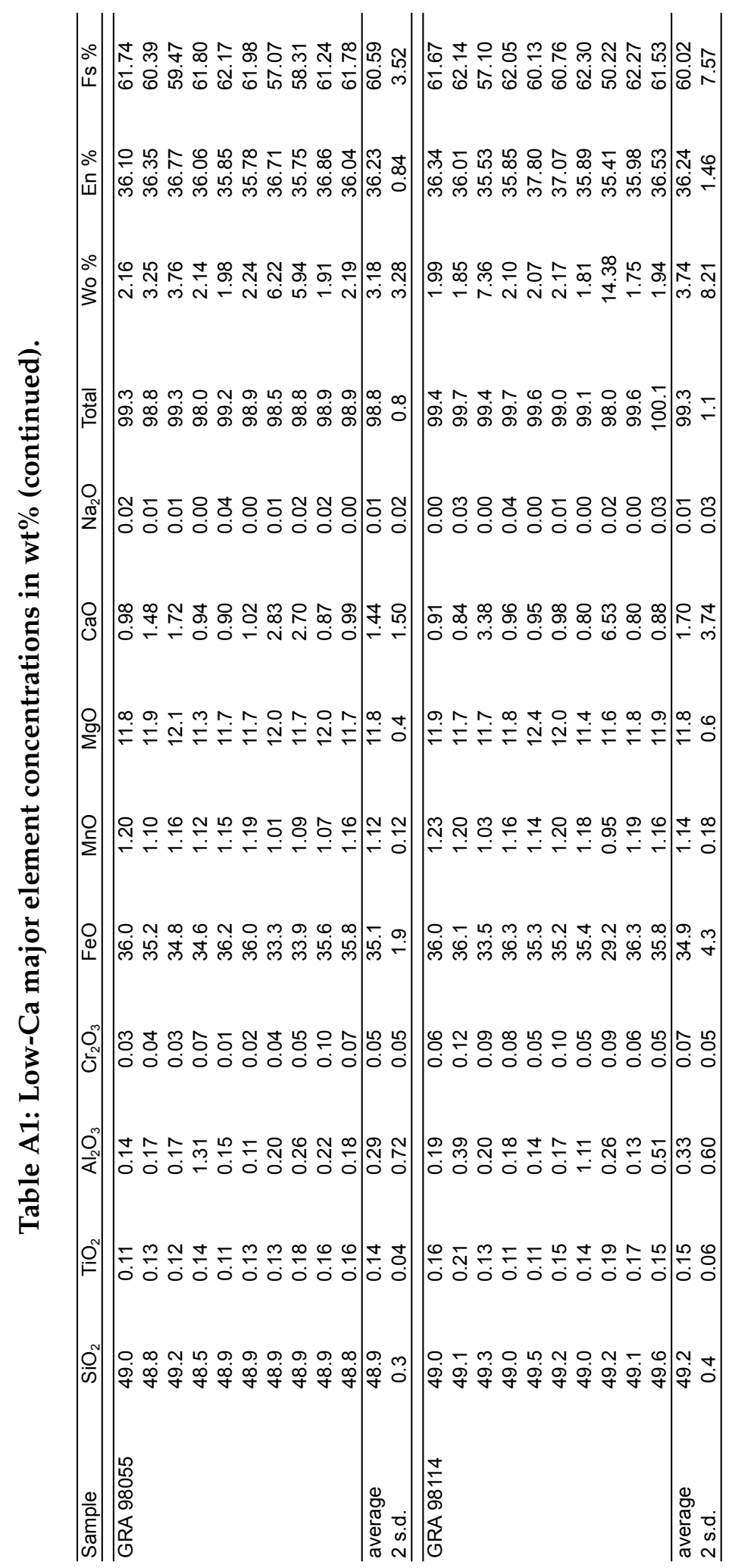




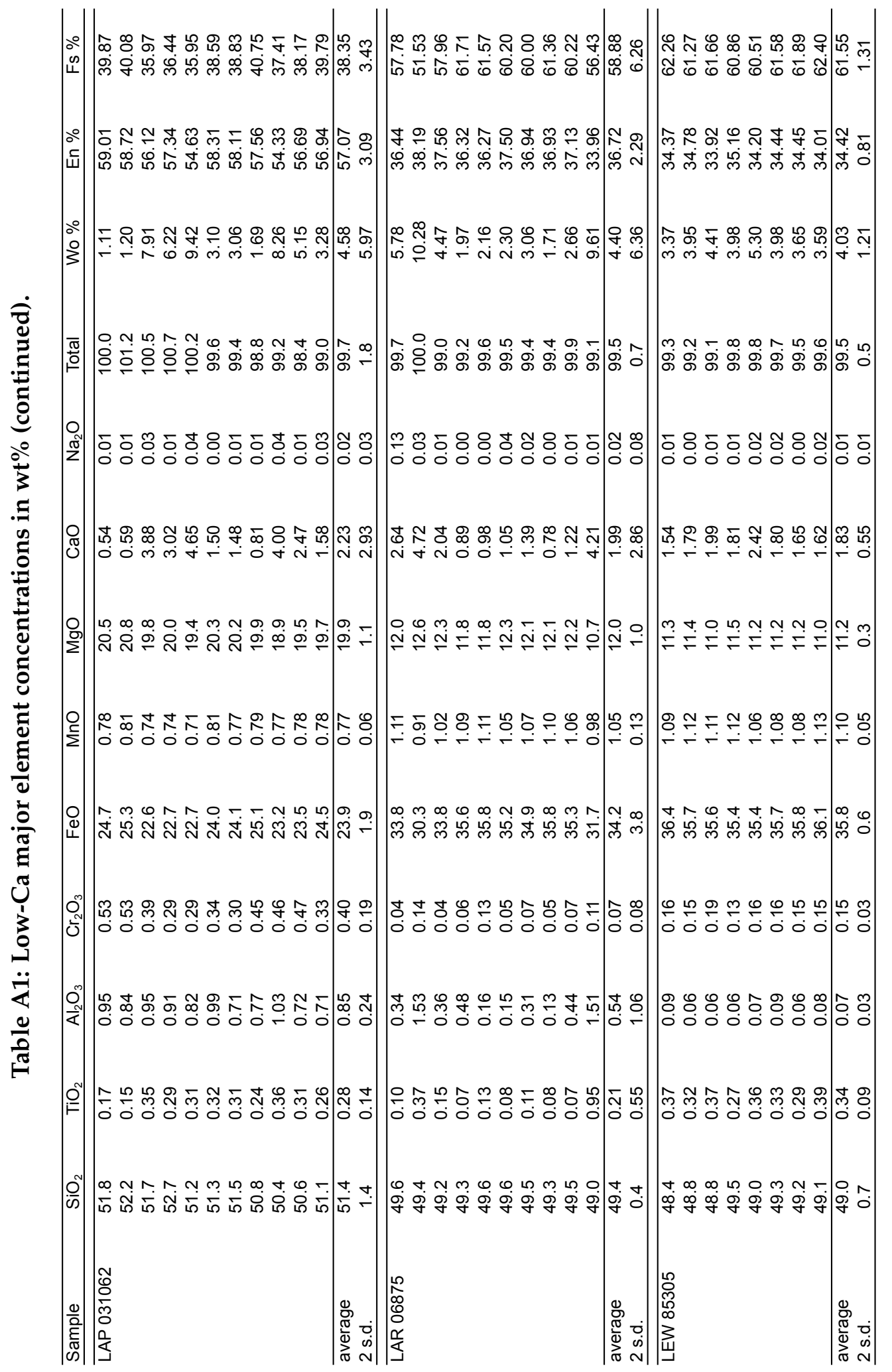




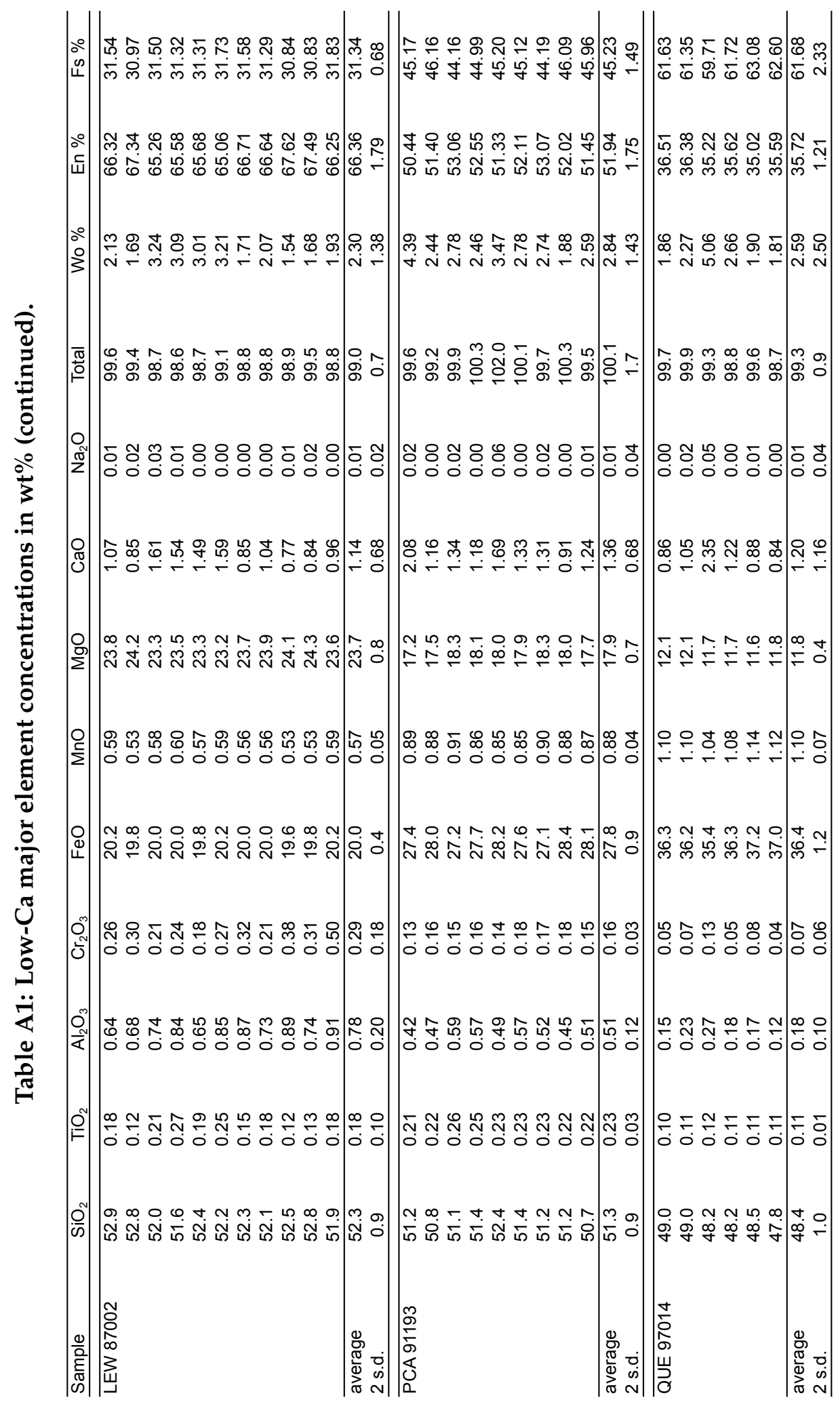




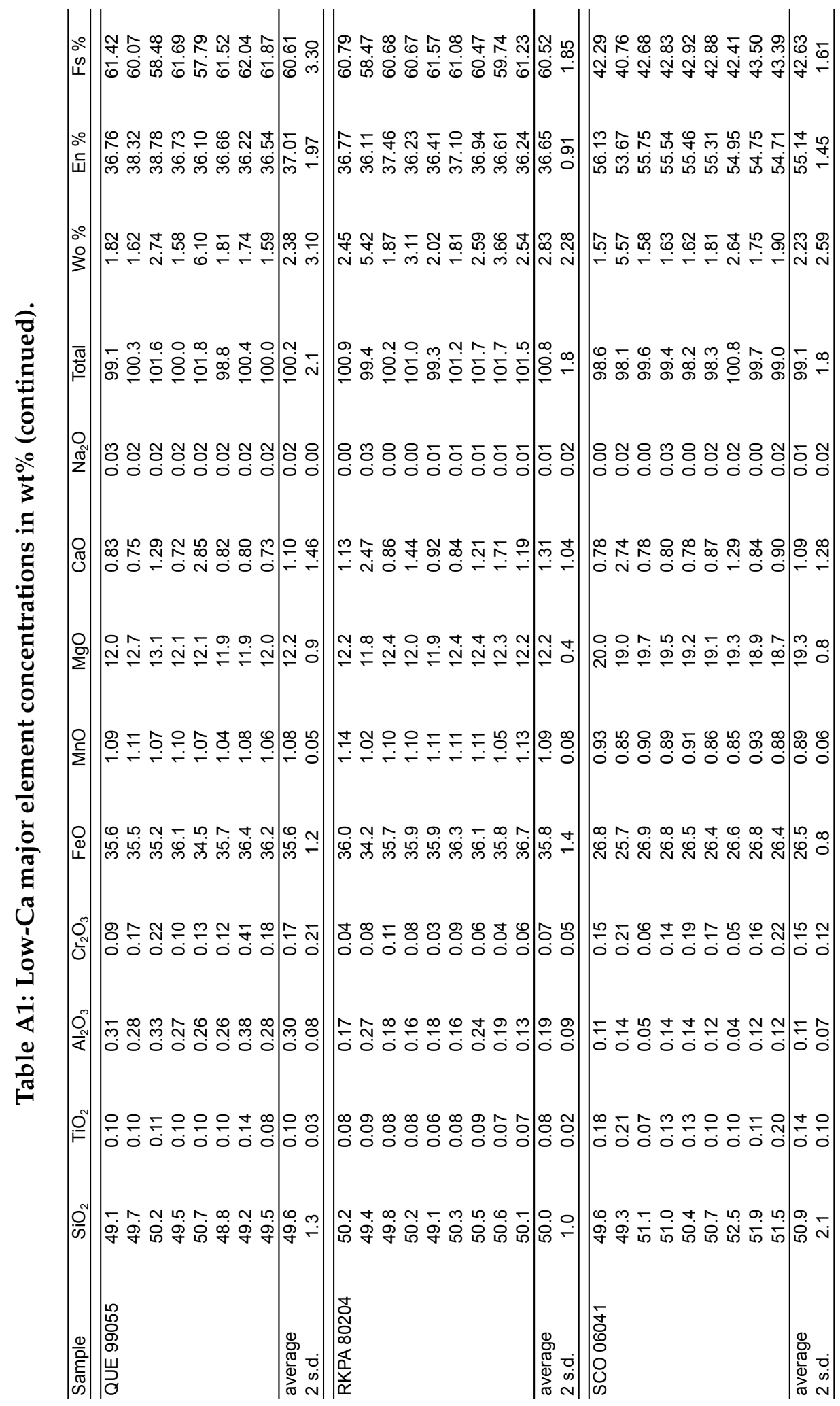




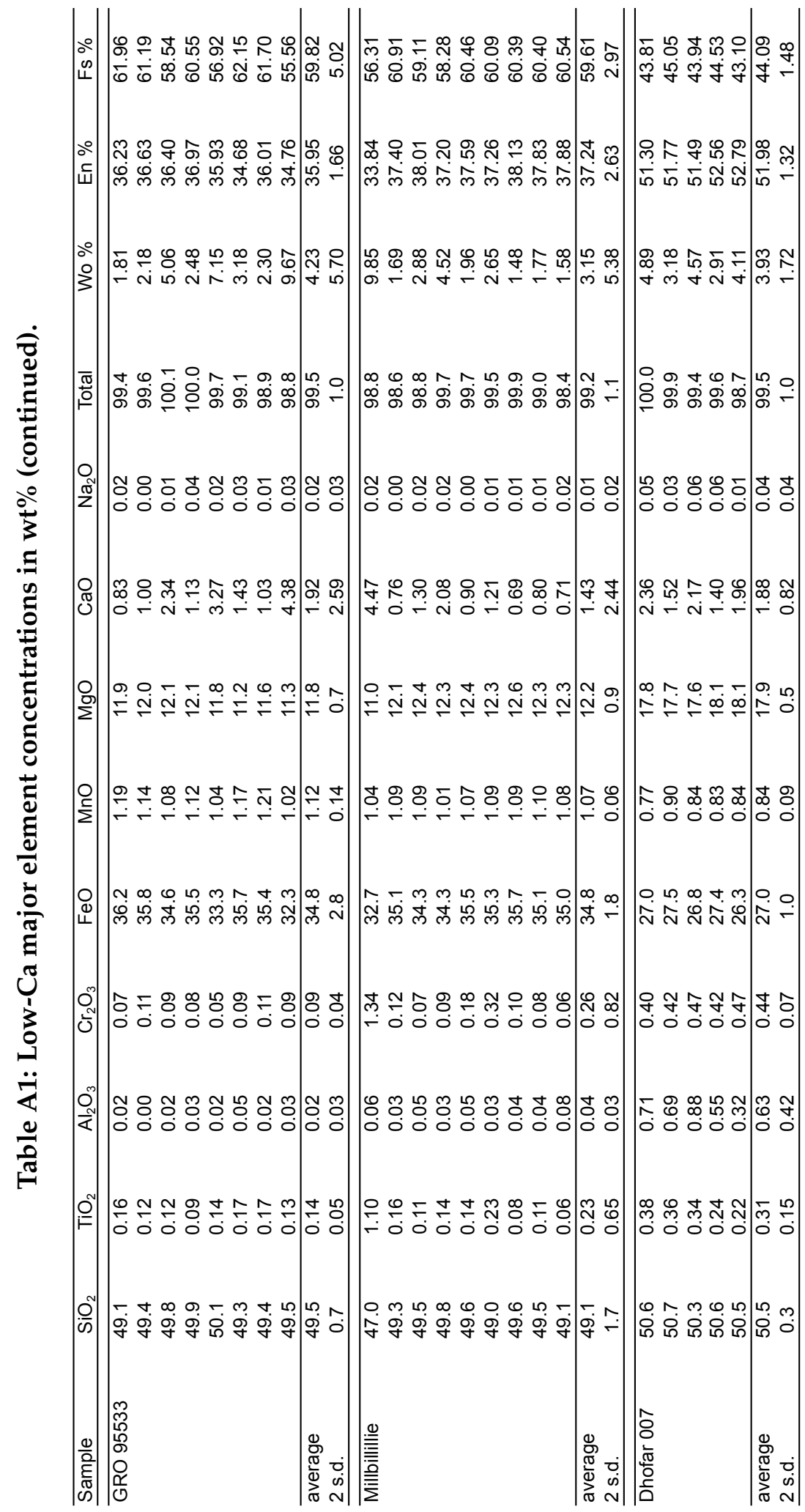




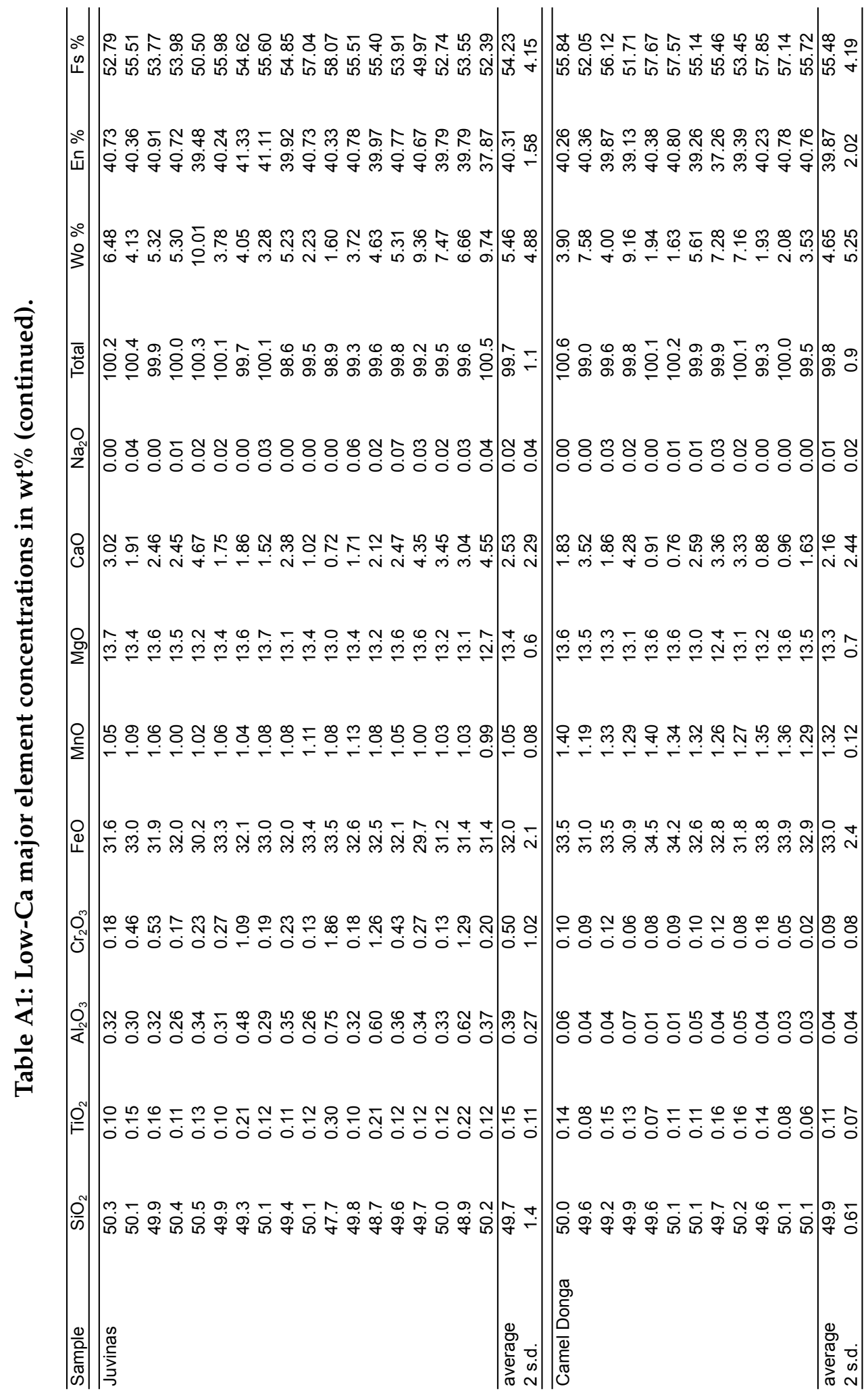




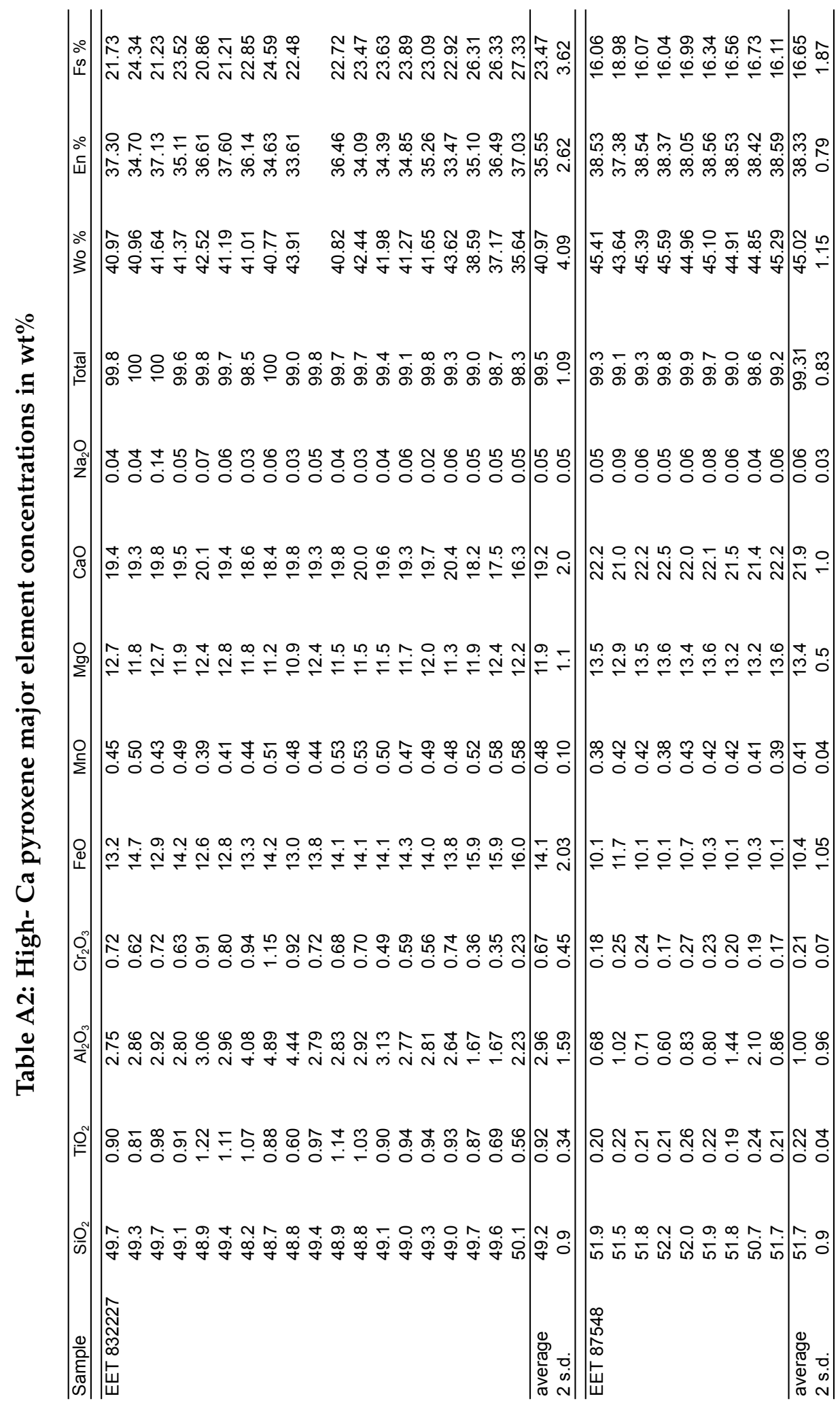




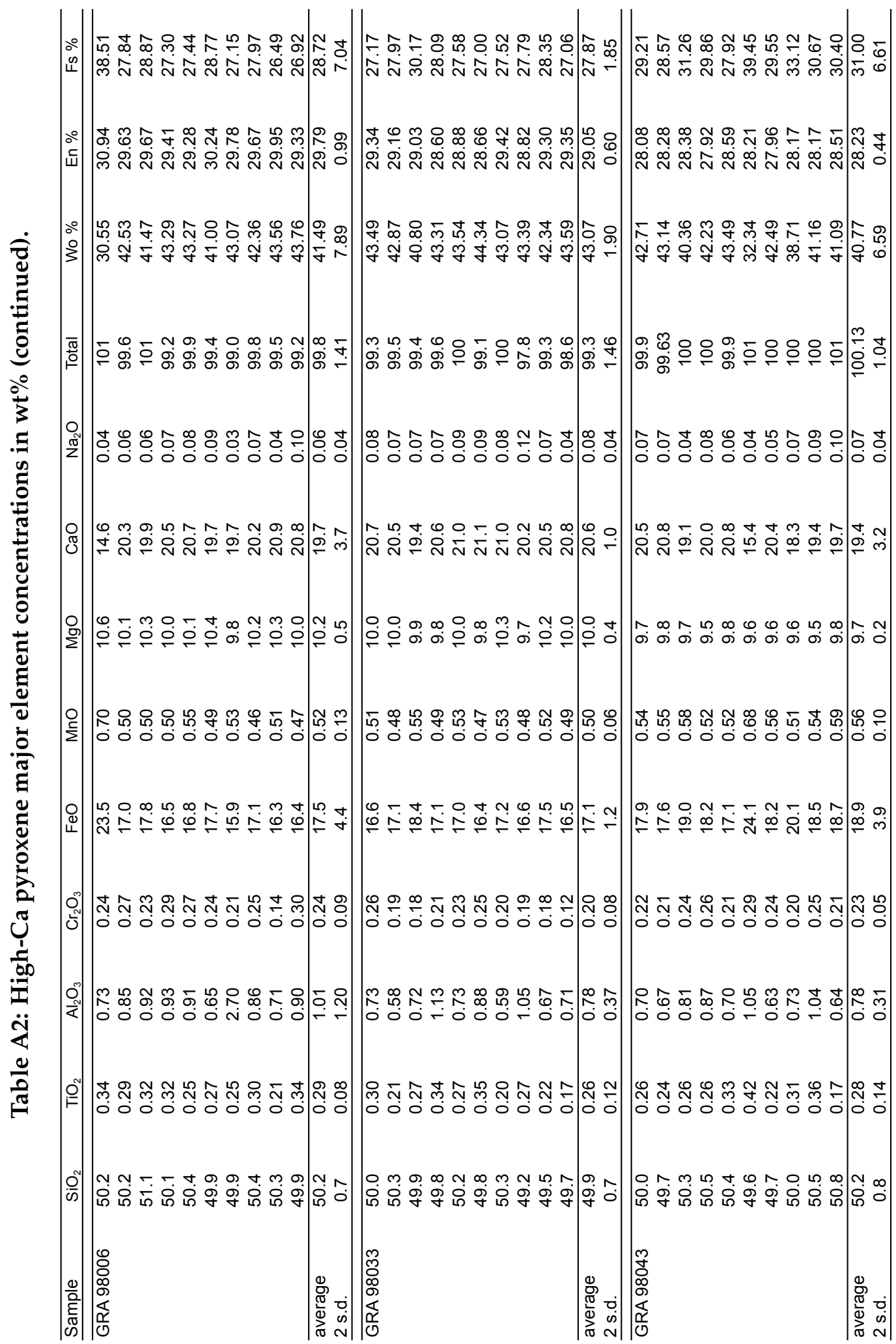




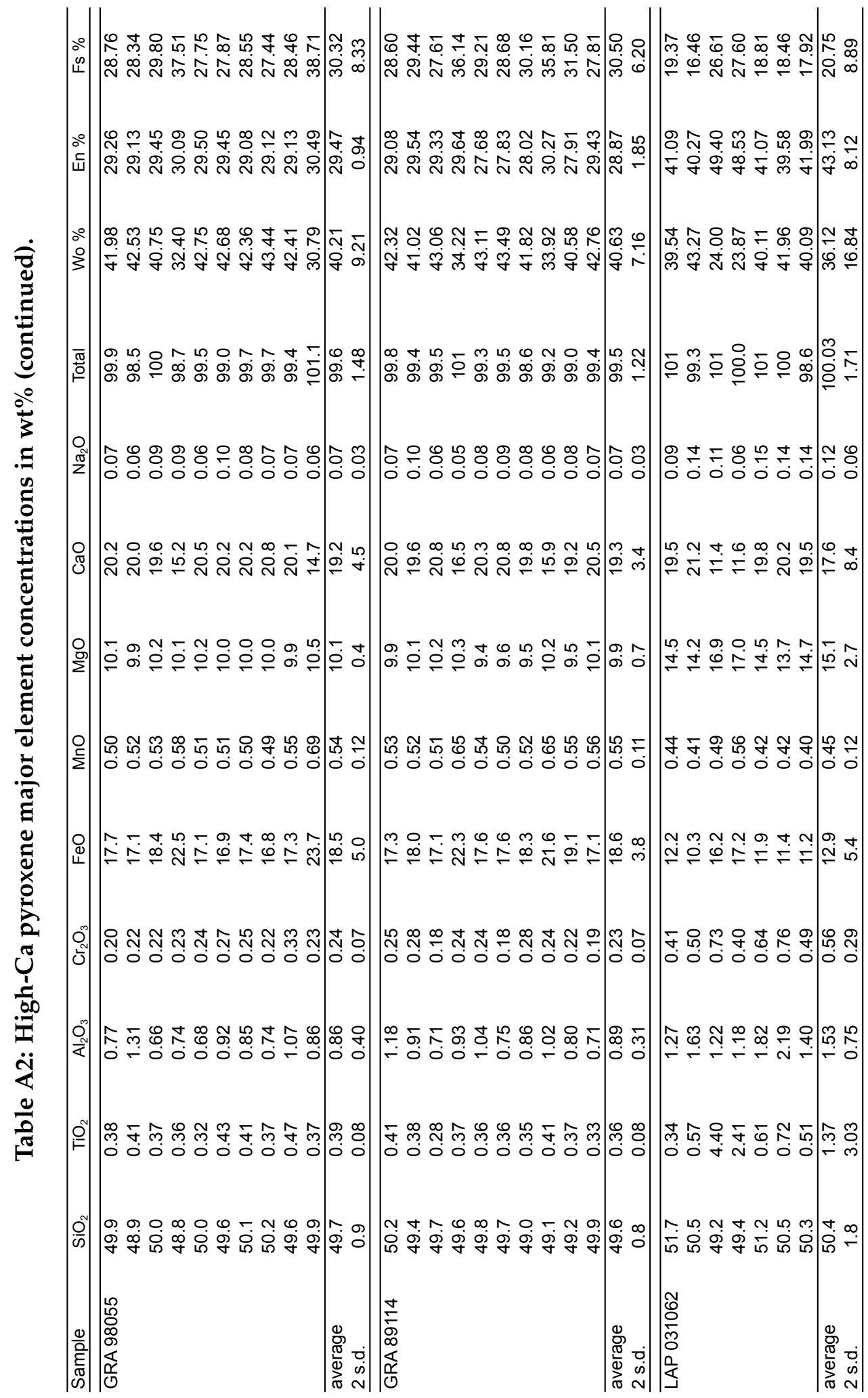




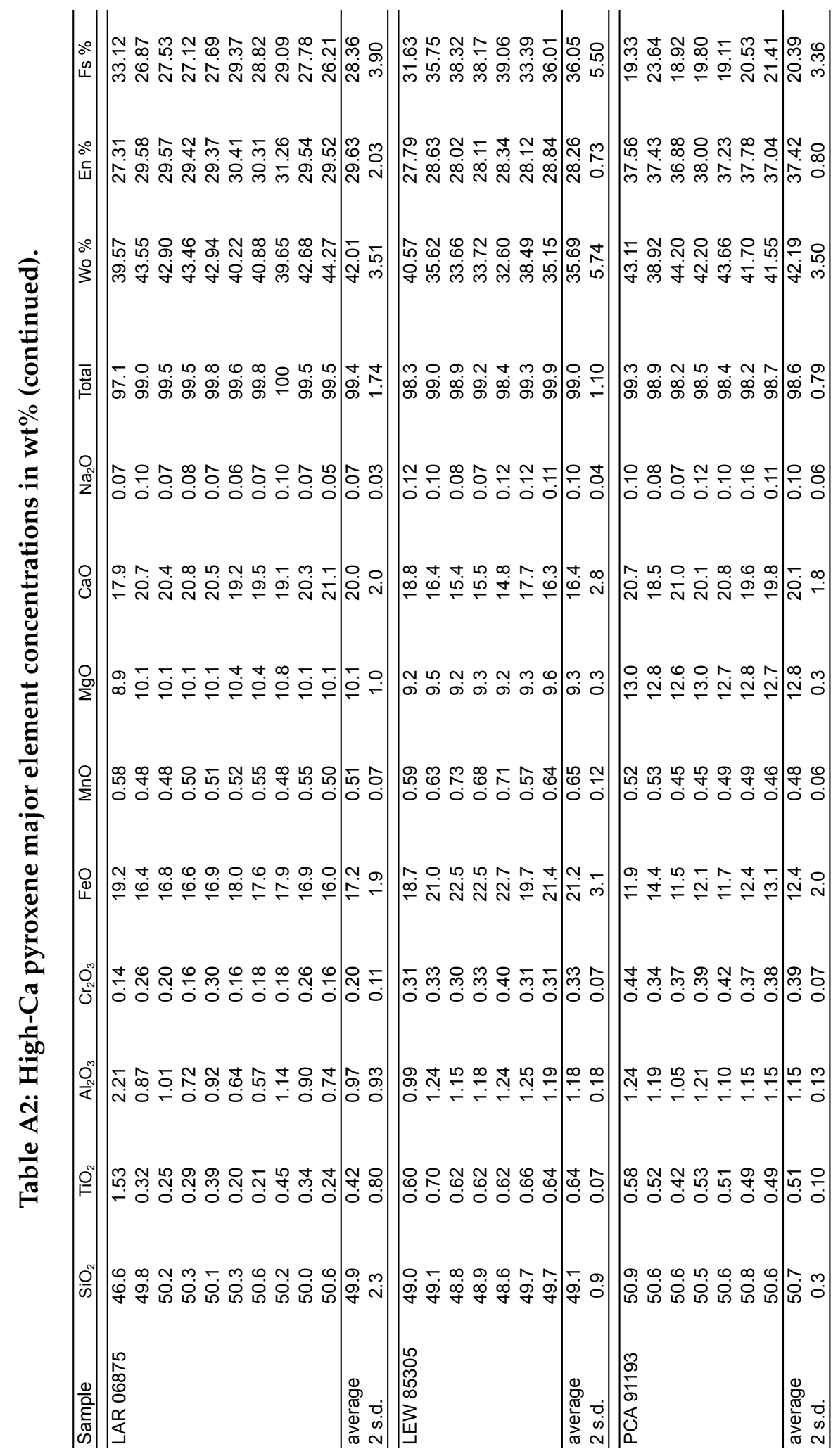




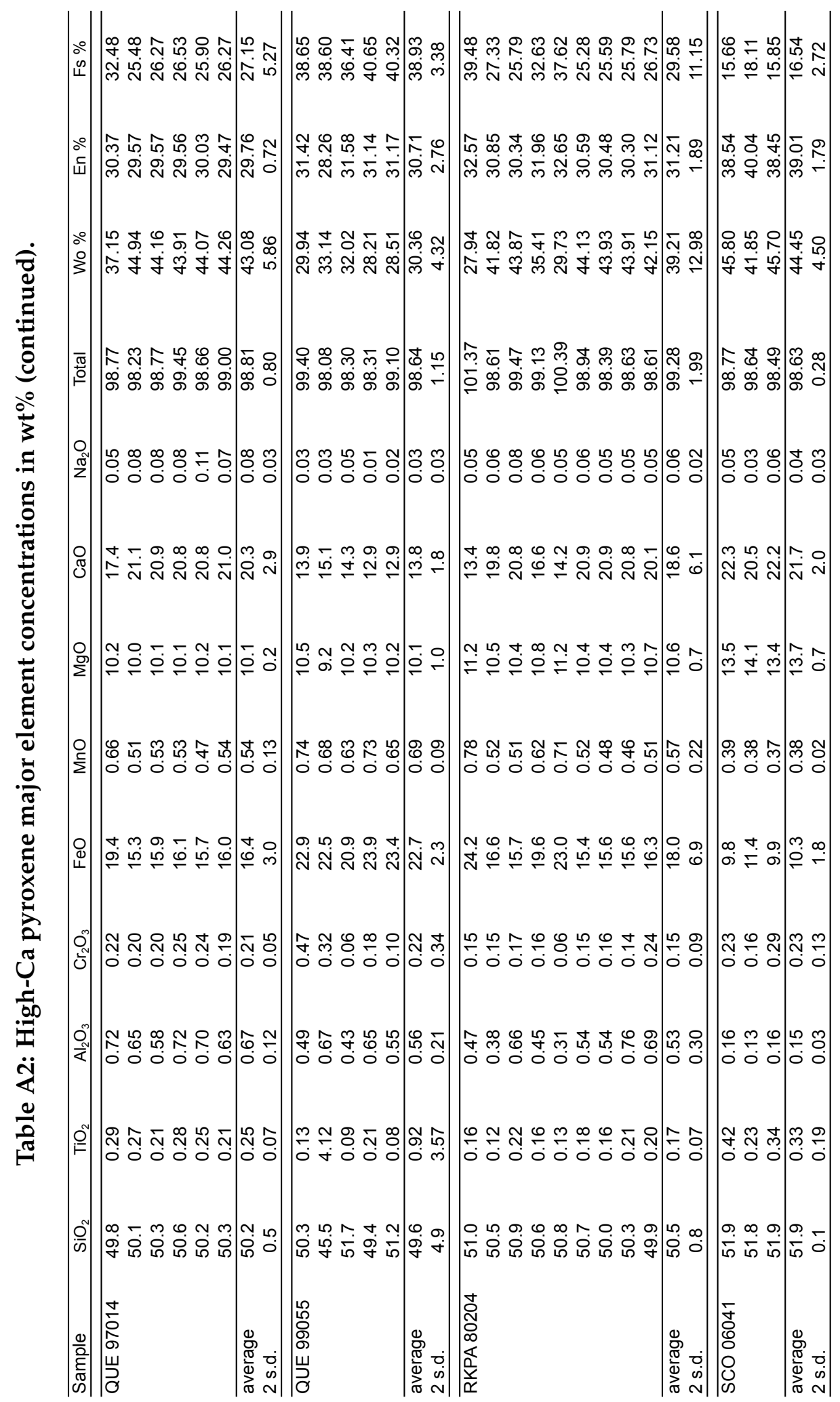




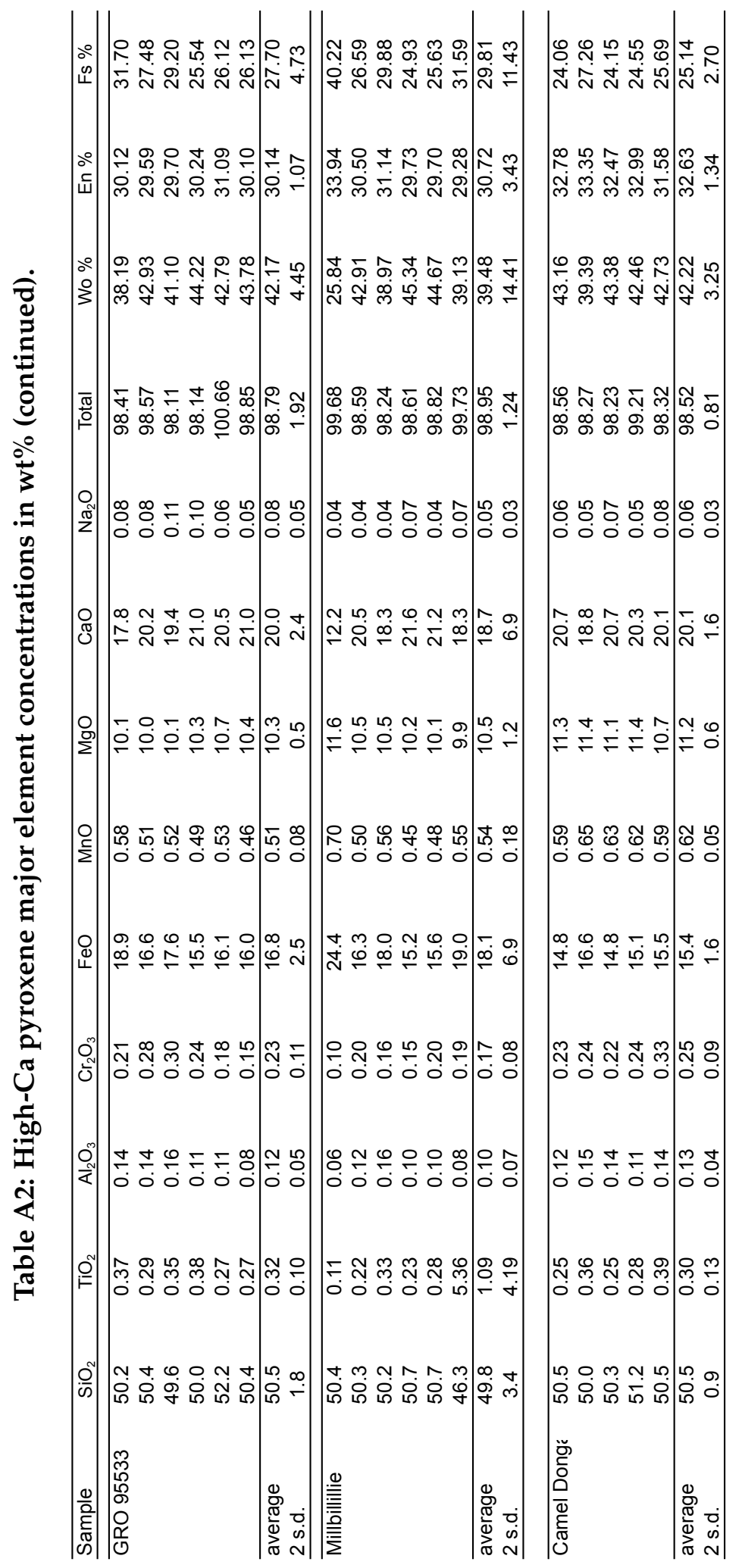




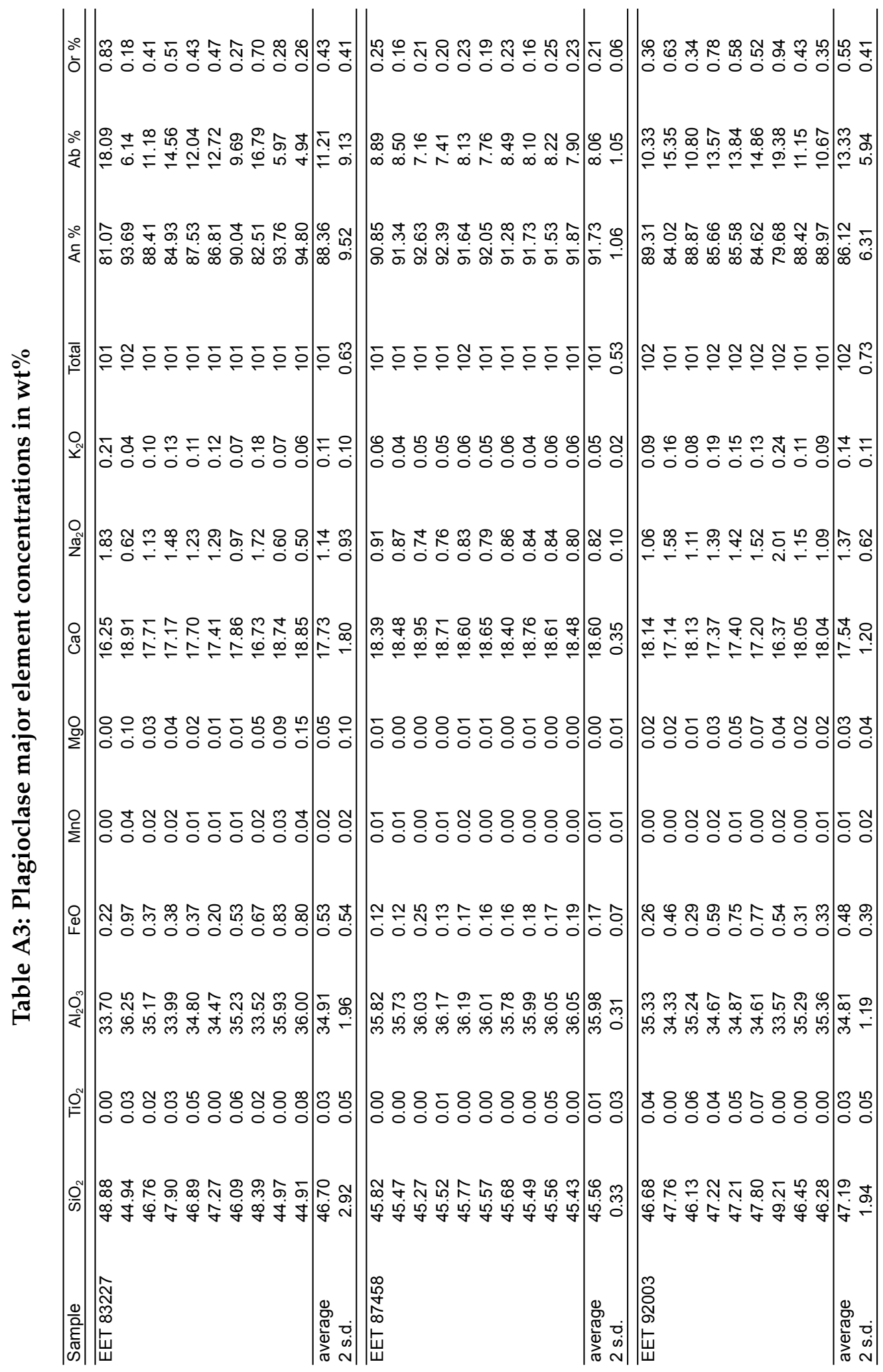




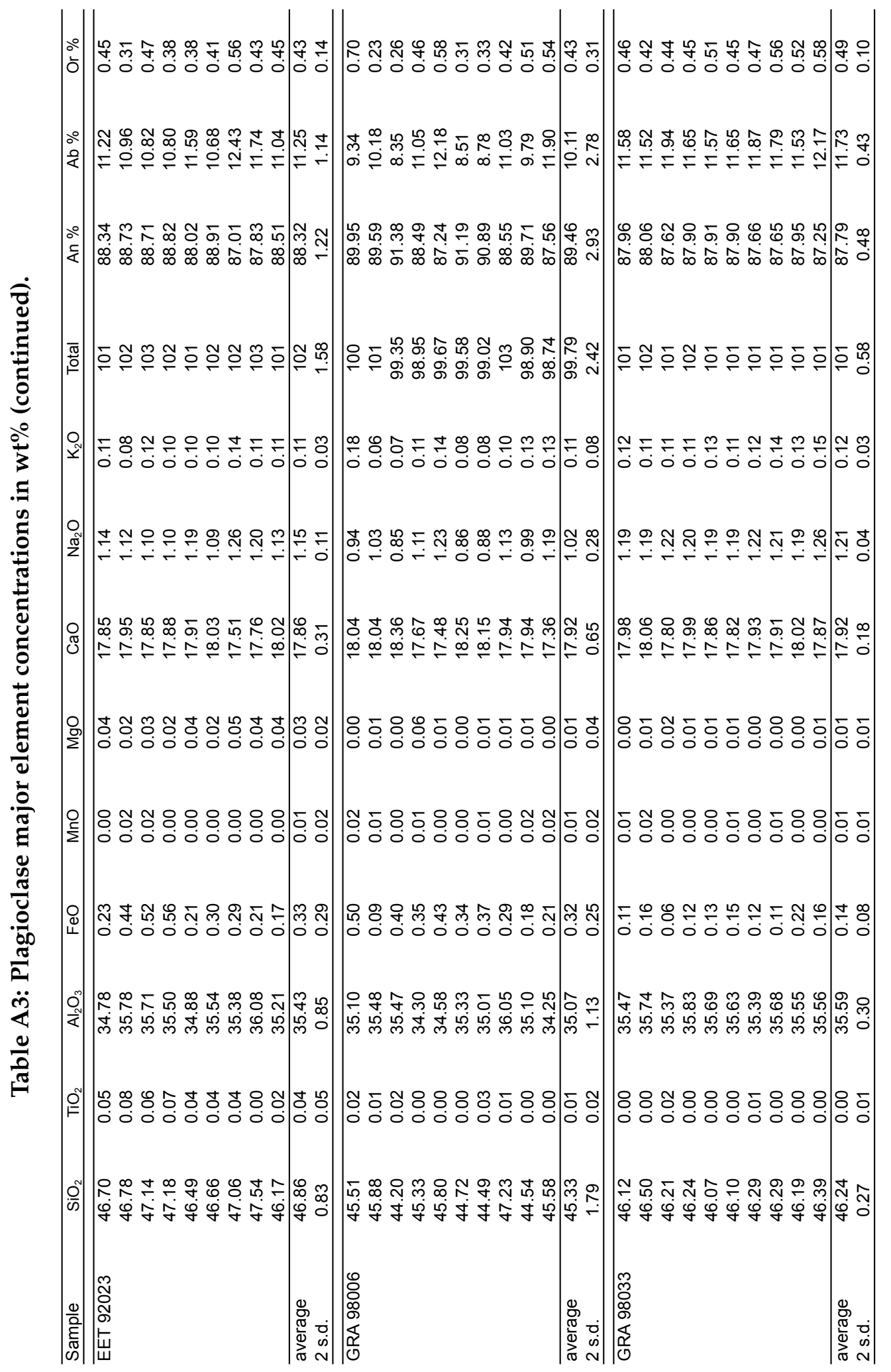




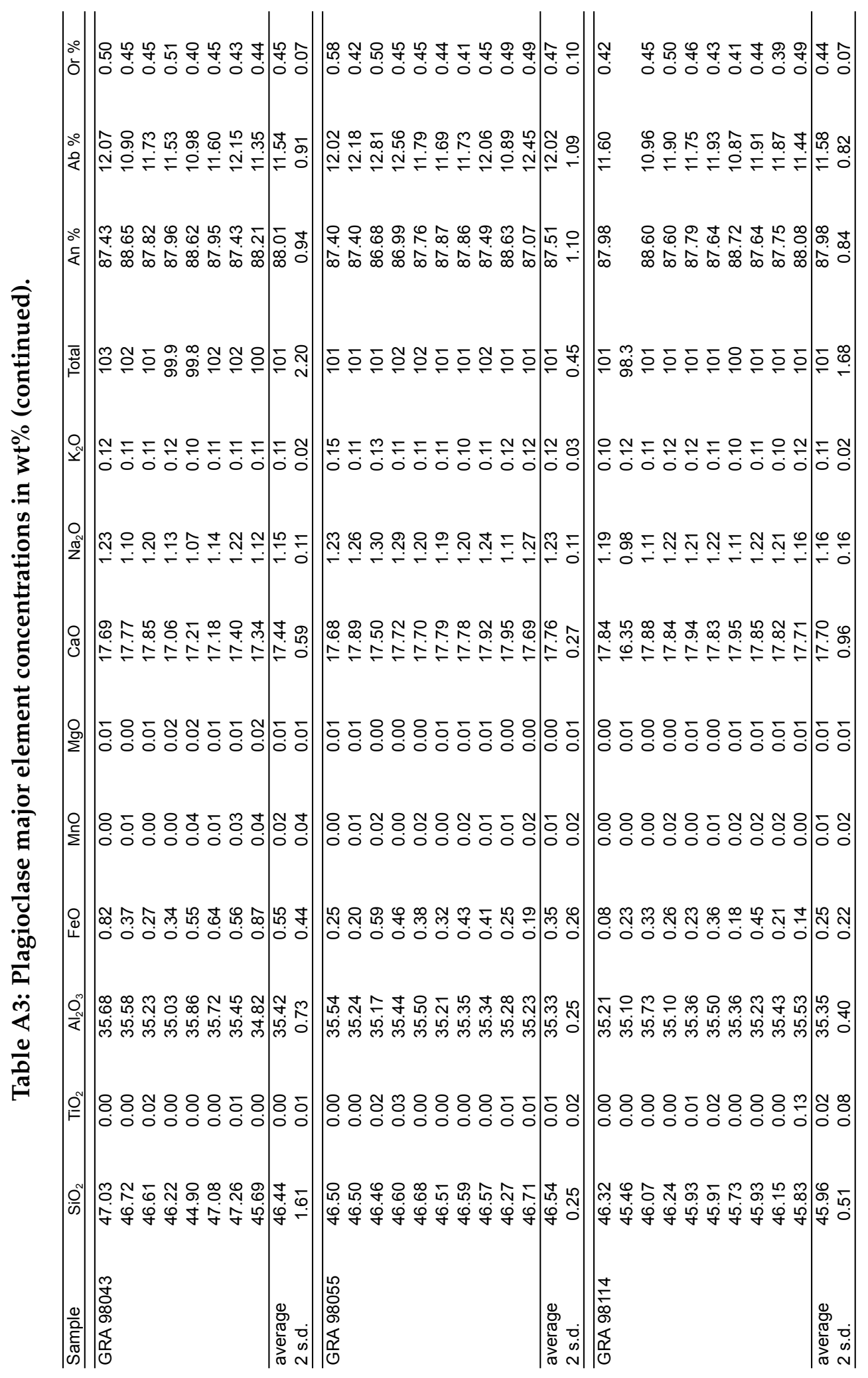




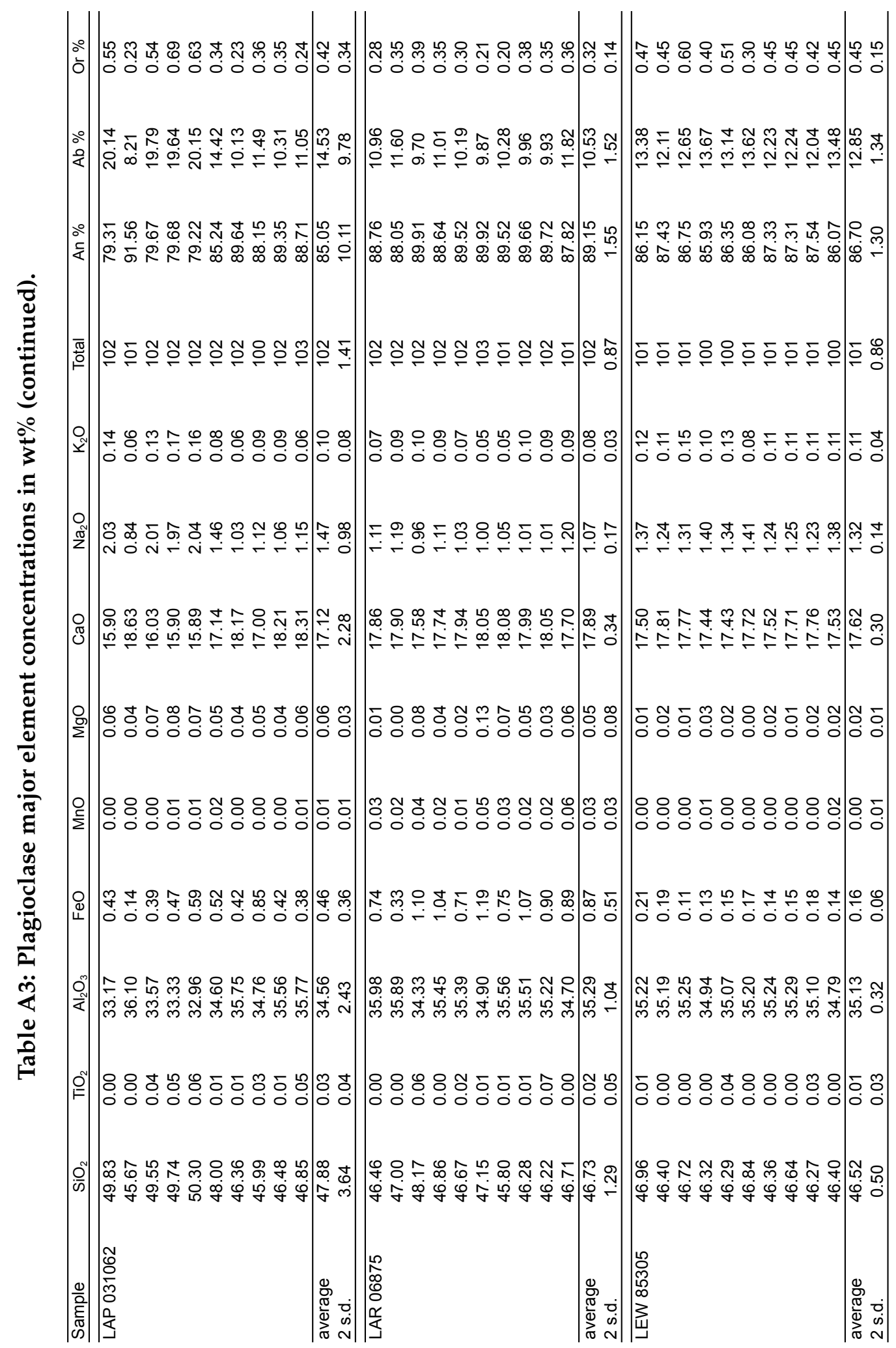




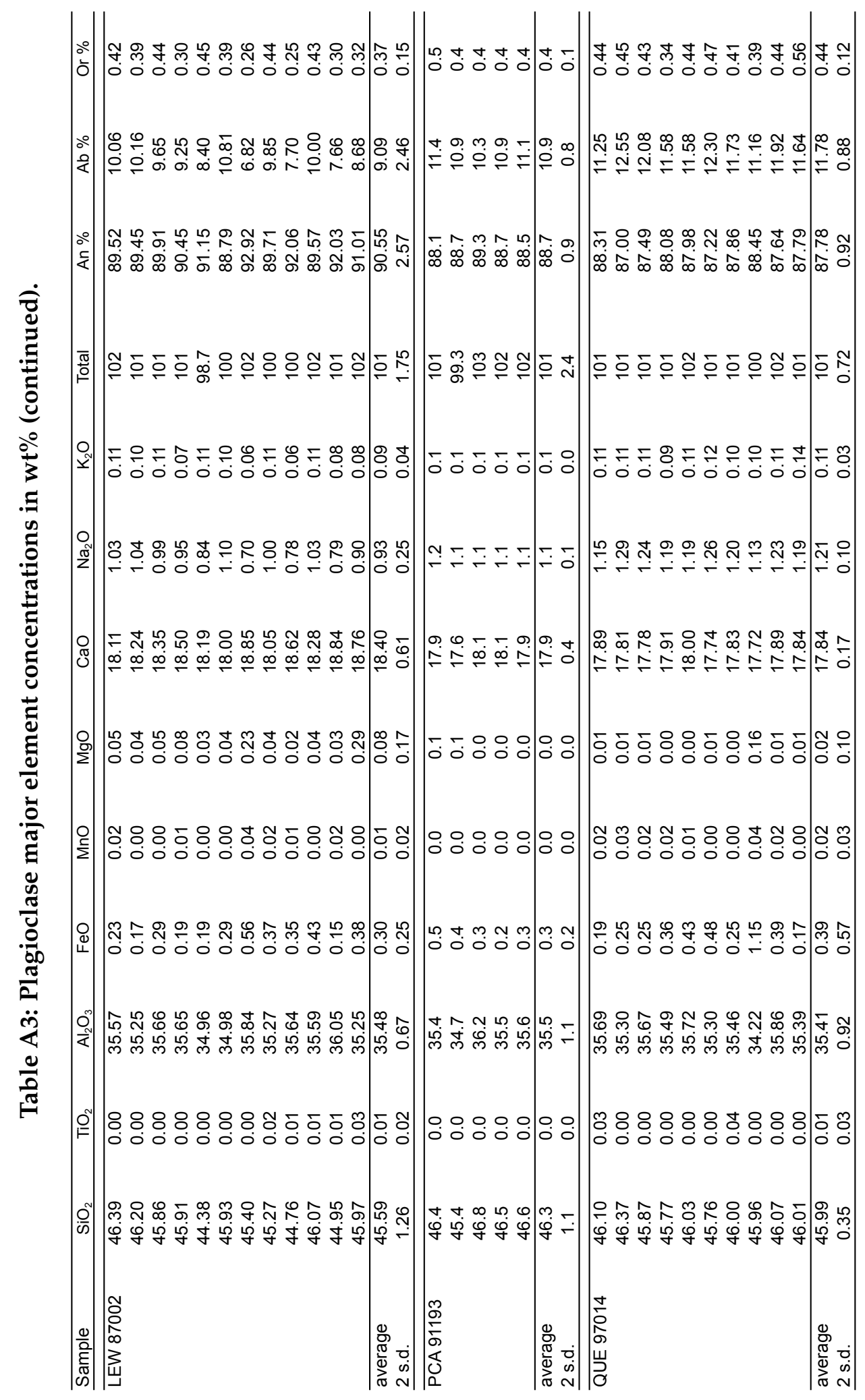




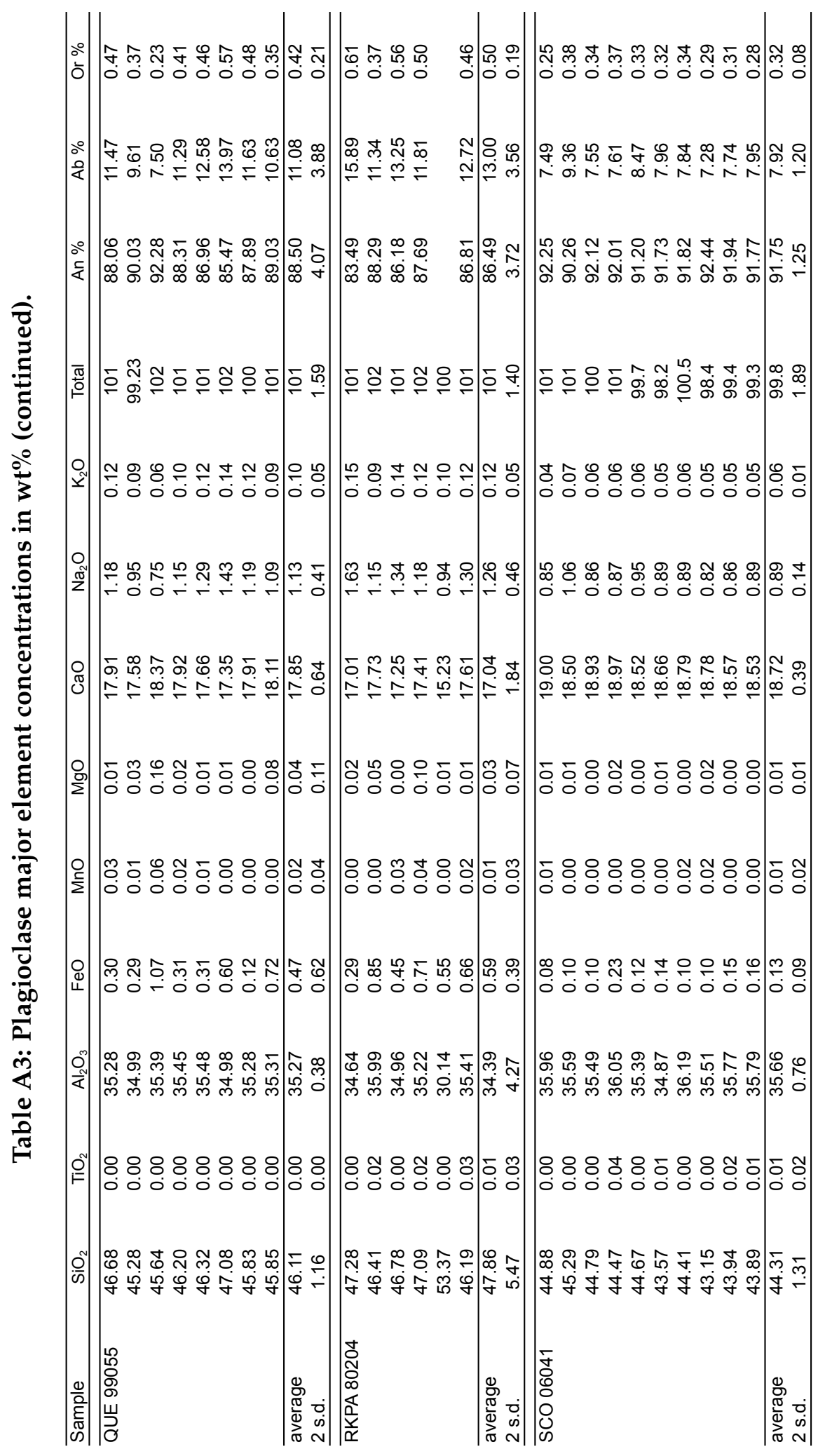




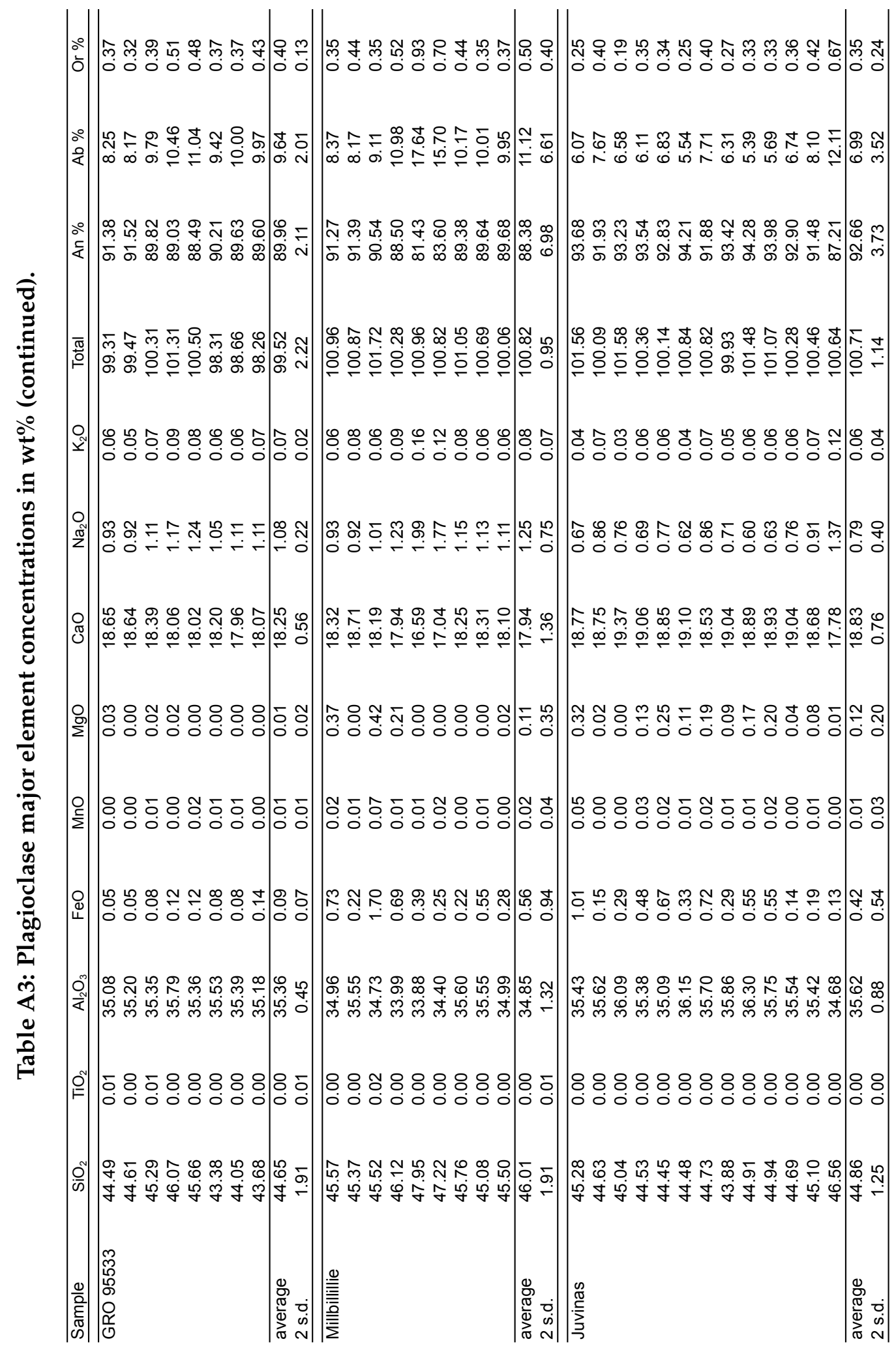




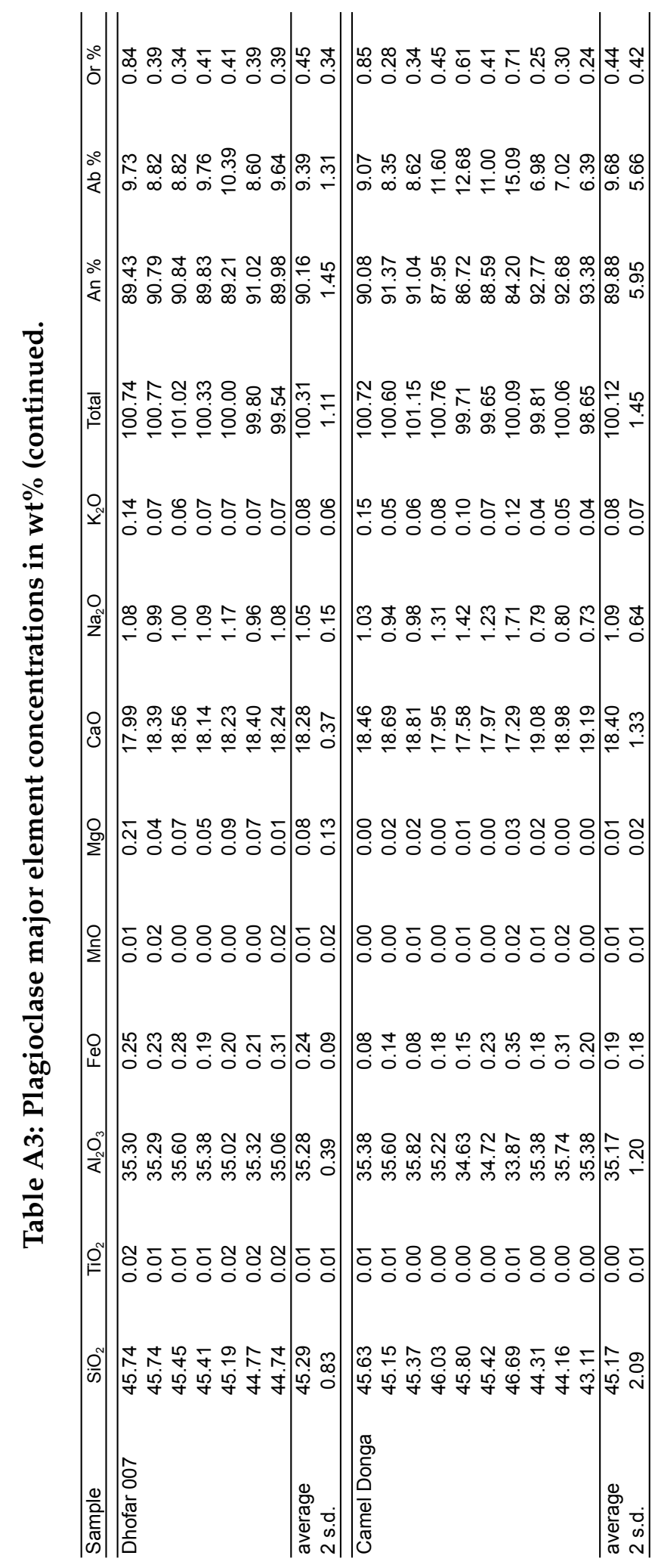


Table A4: Repeat measurements of the major element standards Natural Bridge diopside, Johnstown hypersthene and Plagioclase (Labradorite) Lake County, OR. Concentrations in $w t \%$.

\begin{tabular}{|c|c|c|c|c|c|c|c|c|c|c|}
\hline & $\mathrm{SiO}_{2}$ & $\mathrm{TiO}_{2}$ & $\mathrm{Al}_{2} \mathrm{O}_{3}$ & $\mathrm{Cr}_{2} \mathrm{O}_{3}$ & $\mathrm{FeO}$ & $\mathrm{MnO}$ & $\mathrm{MgO}$ & $\mathrm{CaO}$ & $\mathrm{Na}_{2} \mathrm{O}$ & Total \\
\hline Hypersthene & 53.3 & 0.06 & 1.21 & 0.70 & 14.9 & 0.47 & 27.15 & 1.28 & 0.00 & 99.0 \\
\hline \multirow[t]{22}{*}{ standard } & 53.5 & 0.07 & 1.18 & 0.74 & 14.9 & 0.51 & 26.85 & 1.31 & 0.04 & 99.1 \\
\hline & 53.5 & 0.08 & 1.22 & 0.73 & 14.7 & 0.49 & 26.99 & 1.31 & 0.04 & 99.1 \\
\hline & 53.9 & 0.07 & 1.16 & 0.71 & 14.7 & 0.51 & 27.26 & 1.30 & 0.02 & 99.6 \\
\hline & 54.0 & 0.08 & 1.20 & 0.73 & 14.8 & 0.50 & 27.29 & 1.25 & 0.02 & 99.9 \\
\hline & 53.8 & 0.07 & 1.19 & 0.71 & 15.2 & 0.48 & 27.02 & 1.29 & 0.02 & 99.8 \\
\hline & 53.8 & 0.07 & 1.19 & 0.69 & 14.8 & 0.52 & 27.00 & 1.33 & 0.00 & 99.4 \\
\hline & 54.1 & 0.06 & 1.21 & 0.71 & 14.9 & 0.46 & 27.22 & 1.24 & 0.01 & 99.9 \\
\hline & 53.9 & 0.06 & 1.19 & 0.72 & 14.8 & 0.47 & 27.32 & 1.28 & 0.00 & 99.8 \\
\hline & 53.4 & 0.07 & 1.16 & 0.69 & 14.6 & 0.50 & 27.16 & 1.27 & 0.03 & 98.9 \\
\hline & 53.7 & 0.06 & 1.17 & 0.74 & 15.0 & 0.47 & 27.36 & 1.28 & 0.03 & 99.8 \\
\hline & 54.1 & 0.05 & 1.24 & 0.69 & 14.9 & 0.50 & 27.07 & 1.28 & 0.01 & 99.8 \\
\hline & 54.3 & 0.07 & 1.20 & 0.77 & 15.0 & 0.51 & 26.83 & 1.27 & 0.01 & 100 \\
\hline & 54.0 & 0.04 & 1.18 & 0.72 & 14.9 & 0.50 & 26.71 & 1.30 & 0.01 & 99.3 \\
\hline & 53.7 & 0.04 & 0.26 & 0.71 & 14.7 & 0.52 & 27.25 & 1.33 & 0.02 & 98.5 \\
\hline & 53.8 & 0.07 & 0.23 & 0.69 & 15.0 & 0.50 & 27.21 & 1.27 & 0.00 & 98.7 \\
\hline & 53.2 & 0.06 & 1.21 & 0.67 & 14.9 & 0.46 & 27.42 & 1.27 & 0.03 & 99.2 \\
\hline & 53.5 & 0.08 & 1.13 & 0.69 & 14.8 & 0.48 & 27.82 & 1.24 & 0.00 & 99.8 \\
\hline & 53.5 & 0.06 & 0.20 & 0.74 & 15.0 & 0.51 & 27.77 & 1.26 & 0.04 & 99.0 \\
\hline & 53.6 & 0.08 & 0.21 & 0.72 & 15.0 & 0.50 & 27.89 & 1.26 & 0.02 & 99.3 \\
\hline & 54.1 & 0.07 & 0.21 & 0.72 & 15.0 & 0.49 & 27.46 & 1.25 & 0.01 & 99.3 \\
\hline & 54.1 & 0.05 & 0.21 & 0.72 & 14.8 & 0.49 & 27.25 & 1.30 & 0.01 & 98.9 \\
\hline & 53.8 & 0.07 & 0.19 & 0.75 & 15.0 & 0.47 & 27.47 & 1.32 & 0.02 & 99.1 \\
\hline average & 53.8 & 0.06 & 0.89 & 0.72 & 14.9 & 0.49 & 27.25 & 1.28 & 0.02 & 99.4 \\
\hline \multirow[t]{2}{*}{2 s.d. } & 0.6 & 0.02 & 0.92 & 0.05 & 0.27 & 0.04 & 0.60 & 0.05 & 0.02 & 0.87 \\
\hline & $\mathrm{SiO}_{2}$ & $\mathrm{TiO}_{2}$ & $\mathrm{Al}_{2} \mathrm{O}_{3}$ & $\mathrm{Cr}_{2} \mathrm{O}_{3}$ & $\mathrm{FeO}$ & $\mathrm{MnO}$ & $\mathrm{MgO}$ & $\mathrm{CaO}$ & $\mathrm{Na}_{2} \mathrm{O}$ & Total \\
\hline Diopside & 54.7 & 0.03 & 0.30 & 0.00 & 0.22 & 0.03 & 18.5 & 25.6 & 0.19 & 99.5 \\
\hline \multirow{38}{*}{ standard } & 54.8 & 0.01 & 0.33 & 0.00 & 0.25 & 0.04 & 18.5 & 25.6 & 0.18 & 99.7 \\
\hline & 54.7 & 0.01 & 0.29 & 0.00 & 0.24 & 0.02 & 18.5 & 25.7 & 0.20 & 99.7 \\
\hline & 55.0 & 0.02 & 0.29 & 0.02 & 0.20 & 0.02 & 18.8 & 25.6 & 0.18 & 100 \\
\hline & 55.1 & 0.02 & 0.34 & 0.00 & 0.29 & 0.01 & 18.9 & 25.7 & 0.20 & 101 \\
\hline & 54.8 & 0.01 & 0.28 & 0.01 & 0.24 & 0.04 & 18.4 & 25.6 & 0.17 & 99.6 \\
\hline & 55.2 & 0.01 & 0.30 & 0.02 & 0.22 & 0.00 & 18.6 & 25.7 & 0.19 & 100 \\
\hline & 54.7 & 0.00 & 0.29 & 0.00 & 0.19 & 0.04 & 18.7 & 25.5 & 0.18 & 99.6 \\
\hline & 54.7 & 0.00 & 0.30 & 0.00 & 0.27 & 0.02 & 18.6 & 25.5 & 0.19 & 99.6 \\
\hline & 55.0 & 0.00 & 0.31 & 0.03 & 0.27 & 0.03 & 18.7 & 25.5 & 0.22 & 100 \\
\hline & 55.0 & 0.01 & 0.27 & 0.00 & 0.24 & 0.01 & 18.7 & 25.6 & 0.15 & 100 \\
\hline & 54.9 & 0.01 & 0.26 & 0.00 & 0.08 & 0.04 & 18.7 & 25.6 & 0.18 & 99.7 \\
\hline & 54.9 & 0.01 & 0.29 & 0.01 & 0.22 & 0.06 & 18.5 & 25.5 & 0.20 & 99.7 \\
\hline & 55.1 & 0.01 & 0.29 & 0.00 & 0.24 & 0.04 & 18.7 & 25.5 & 0.20 & 100 \\
\hline & 55.1 & 0.00 & 0.30 & 0.00 & 0.23 & 0.04 & 18.4 & 25.8 & 0.19 & 100 \\
\hline & 55.2 & 0.01 & 0.30 & 0.01 & 0.24 & 0.03 & 18.5 & 25.6 & 0.19 & 100 \\
\hline & 55.0 & 0.02 & 0.30 & 0.00 & 0.24 & 0.03 & 18.6 & 25.6 & 0.17 & 100.0 \\
\hline & 54.9 & 0.02 & 0.29 & 0.00 & 0.24 & 0.02 & 18.3 & 25.5 & 0.18 & 99.4 \\
\hline & 54.6 & 0.01 & 0.30 & 0.00 & 0.22 & 0.04 & 18.2 & 25.5 & 0.19 & 99.0 \\
\hline & 55.0 & 0.00 & 0.25 & 0.00 & 0.20 & 0.02 & 18.5 & 25.5 & 0.18 & 99.7 \\
\hline & 55.0 & 0.01 & 0.28 & 0.00 & 0.25 & 0.05 & 18.6 & 25.6 & 0.17 & 100 \\
\hline & 55.2 & 0.00 & 0.27 & 0.00 & 0.12 & 0.00 & 18.7 & 25.8 & 0.17 & 100 \\
\hline & 55.0 & 0.01 & 0.30 & 0.00 & 0.24 & 0.04 & 18.6 & 25.5 & 0.20 & 99.9 \\
\hline & 54.7 & 0.00 & 0.31 & 0.01 & 0.29 & 0.04 & 18.6 & 25.6 & 0.20 & 99.7 \\
\hline & 54.7 & 0.00 & 0.32 & 0.00 & 0.23 & 0.04 & 18.6 & 25.6 & 0.20 & 99.6 \\
\hline & 54.7 & 0.00 & 0.30 & 0.00 & 0.20 & 0.04 & 18.4 & 25.5 & 0.18 & 99.2 \\
\hline & 55.0 & 0.01 & 0.31 & 0.00 & 0.23 & 0.01 & 18.5 & 25.5 & 0.17 & 99.8 \\
\hline & 55.1 & 0.00 & 0.28 & 0.00 & 0.22 & 0.01 & 18.7 & 25.5 & 0.19 & 100 \\
\hline & 55.1 & 0.02 & 0.29 & 0.01 & 0.21 & 0.02 & 18.3 & 25.4 & 0.19 & 99.5 \\
\hline & 54.7 & 0.00 & 0.05 & 0.00 & 0.27 & 0.04 & 18.5 & 25.4 & 0.18 & 99.2 \\
\hline & 54.4 & 0.01 & 0.05 & 0.00 & 0.28 & 0.00 & 18.6 & 25.5 & 0.16 & 99.1 \\
\hline & 54.9 & 0.01 & 0.06 & 0.00 & 0.22 & 0.03 & 18.5 & 25.4 & 0.18 & 99.3 \\
\hline & 54.4 & 0.00 & 0.04 & 0.00 & 0.25 & 0.02 & 18.8 & 25.5 & 0.17 & 99.2 \\
\hline & 54.9 & 0.01 & 0.04 & 0.00 & 0.24 & 0.02 & 18.7 & 25.6 & 0.20 & 99.7 \\
\hline & 53.8 & 0.01 & 0.26 & 0.00 & 0.26 & 0.01 & 18.7 & 25.3 & 0.17 & 98.5 \\
\hline & 53.1 & 0.01 & 0.29 & 0.00 & 0.23 & 0.02 & 18.8 & 24.8 & 0.19 & 97.5 \\
\hline & 54.6 & 0.00 & 0.05 & 0.00 & 0.21 & 0.02 & 18.7 & 25.3 & 0.18 & 99.0 \\
\hline & 53.8 & 0.00 & 0.06 & 0.04 & 0.21 & 0.04 & 18.4 & 25.2 & 0.21 & 98.0 \\
\hline & 54.6 & 0.02 & 0.07 & 0.00 & 0.25 & 0.04 & 18.5 & 25.3 & 0.18 & 99.1 \\
\hline average & 54.8 & 0.01 & 0.24 & 0.00 & 0.23 & 0.03 & 18.6 & 25.5 & 0.19 & 99.6 \\
\hline 2 s.d. & 0.8 & 0.02 & 0.20 & 0.02 & 0.08 & 0.03 & 0.33 & 0.33 & 0.03 & 1.21 \\
\hline
\end{tabular}


Table A4: Repeat measurements of major element standards (continued). Concentrations in wt $\%$.

\begin{tabular}{|c|c|c|c|c|c|c|c|c|c|c|}
\hline & $\mathrm{SiO}_{2}$ & $\mathrm{TiO}_{2}$ & $\mathrm{Al}_{2} \mathrm{O}_{3}$ & $\mathrm{FeO}$ & $\mathrm{MnO}$ & $\mathrm{MgO}$ & $\mathrm{CaO}$ & $\mathrm{Na}_{2} \mathrm{O}$ & $\mathrm{K}_{2} \mathrm{O}$ & Total \\
\hline Plagioclase & 51.9 & 0.05 & 31.3 & 0.43 & 0.03 & 0.14 & 3.54 & 13.6 & 0.18 & 101 \\
\hline \multirow[t]{21}{*}{ standard } & 50.8 & 0.04 & 30.3 & 0.46 & 0.00 & 0.15 & 3.30 & 13.5 & 0.16 & 98.8 \\
\hline & 49.8 & 0.08 & 29.5 & 0.43 & 0.02 & 0.17 & 3.35 & 13.7 & 0.23 & 97.3 \\
\hline & 49.7 & 0.05 & 29.6 & 0.40 & 0.00 & 0.18 & 3.42 & 13.7 & 0.24 & 97.3 \\
\hline & 50.6 & 0.04 & 30.5 & 0.48 & 0.00 & 0.16 & 3.44 & 13.5 & 0.20 & 99.0 \\
\hline & 51.8 & 0.08 & 31.5 & 0.44 & 0.01 & 0.14 & 3.53 & 13.7 & 0.16 & 101 \\
\hline & 50.0 & 0.06 & 30.0 & 0.46 & 0.00 & 0.14 & 3.40 & 13.7 & 0.22 & 97.9 \\
\hline & 49.3 & 0.05 & 29.9 & 0.45 & 0.00 & 0.13 & 3.39 & 13.4 & 0.18 & 96.8 \\
\hline & 51.1 & 0.08 & 31.5 & 0.46 & 0.01 & 0.14 & 3.61 & 13.6 & 0.18 & 101 \\
\hline & 50.2 & 0.03 & 30.8 & 0.45 & 0.00 & 0.14 & 3.44 & 13.7 & 0.19 & 98.9 \\
\hline & 52.4 & 0.09 & 31.5 & 0.45 & 0.00 & 0.13 & 3.24 & 13.7 & 0.18 & 102 \\
\hline & 52.0 & 0.04 & 31.4 & 0.52 & 0.00 & 0.12 & 3.51 & 13.7 & 0.16 & 101 \\
\hline & 50.6 & 0.04 & 30.4 & 0.44 & 0.01 & 0.17 & 3.38 & 13.6 & 0.18 & 98.8 \\
\hline & 50.1 & 0.06 & 29.9 & 0.44 & 0.01 & 0.19 & 3.31 & 13.5 & 0.19 & 97.8 \\
\hline & 51.2 & 0.02 & 30.7 & 0.44 & 0.00 & 0.14 & 3.47 & 13.6 & 0.17 & 99.7 \\
\hline & 50.9 & 0.01 & 30.4 & 0.44 & 0.02 & 0.14 & 3.39 & 13.6 & 0.21 & 99.1 \\
\hline & 52.1 & 0.08 & 31.3 & 0.47 & 0.02 & 0.13 & 3.47 & 13.8 & 0.18 & 102 \\
\hline & 51.9 & 0.04 & 31.1 & 0.50 & 0.01 & 0.13 & 3.48 & 13.6 & 0.17 & 101 \\
\hline & 49.8 & 0.03 & 29.8 & 0.43 & 0.01 & 0.15 & 3.40 & 13.6 & 0.22 & 97.4 \\
\hline & 51.0 & 0.04 & 30.6 & 0.43 & 0.02 & 0.14 & 3.42 & 13.6 & 0.17 & 99.5 \\
\hline & 49.1 & 0.10 & 29.6 & 0.45 & 0.02 & 0.12 & 3.37 & 13.6 & 0.21 & 96.6 \\
\hline & 51.0 & 0.06 & 30.7 & 0.47 & 0.00 & 0.16 & 3.44 & 13.5 & 0.16 & 99.5 \\
\hline average & 50.8 & 0.05 & 30.6 & 0.45 & 0.01 & 0.15 & 3.42 & 13.6 & 0.19 & 99.2 \\
\hline 2 s.d. & 1.93 & 0.05 & 1.36 & 0.05 & 0.02 & 0.04 & 0.17 & 0.16 & 0.05 & 3.34 \\
\hline
\end{tabular}




\section{Appendix B}

\section{Trace element data}

The following are tables of all of the LA-ICPMS trace element data acquired for eucrite samples and geostandards in this study. 


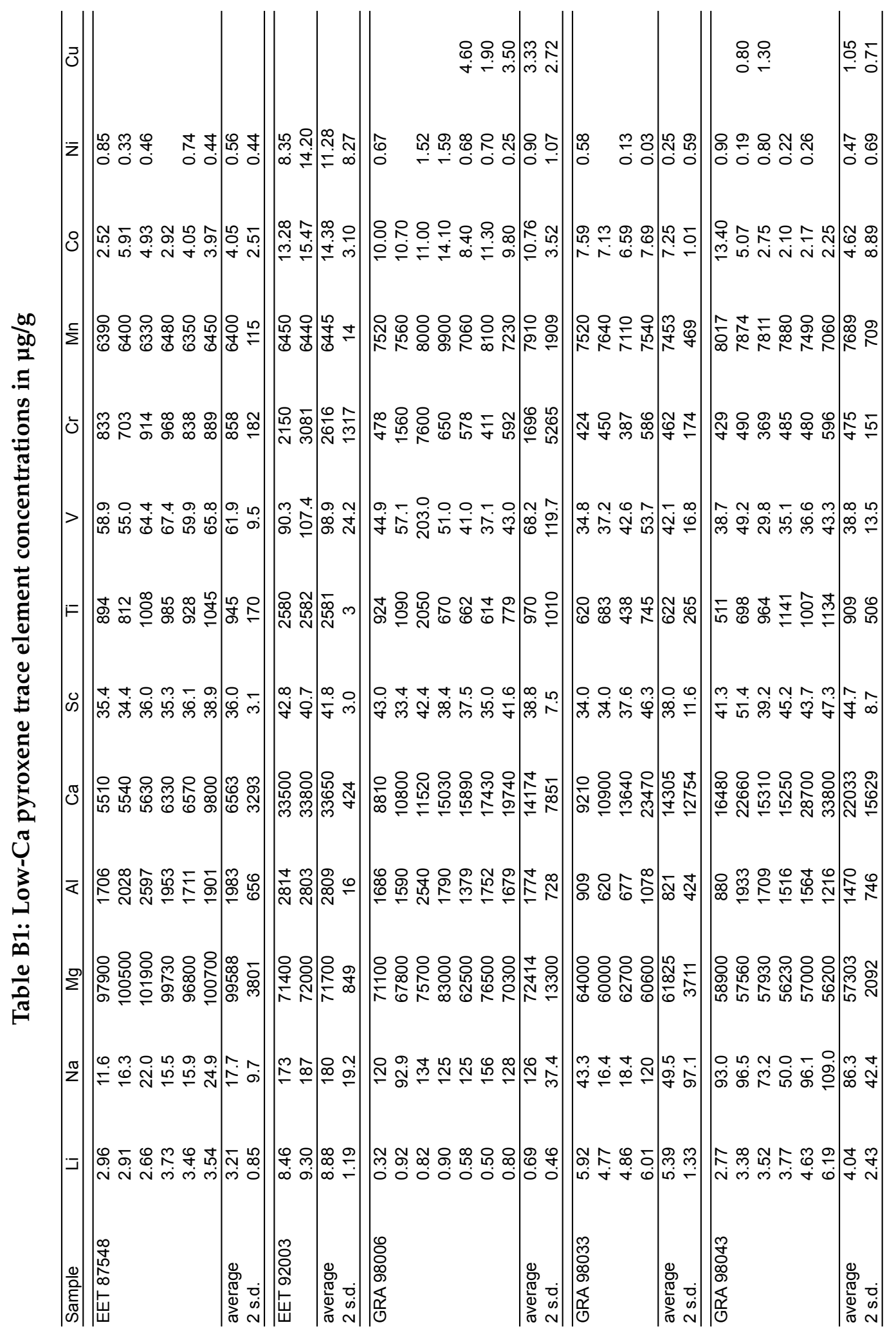




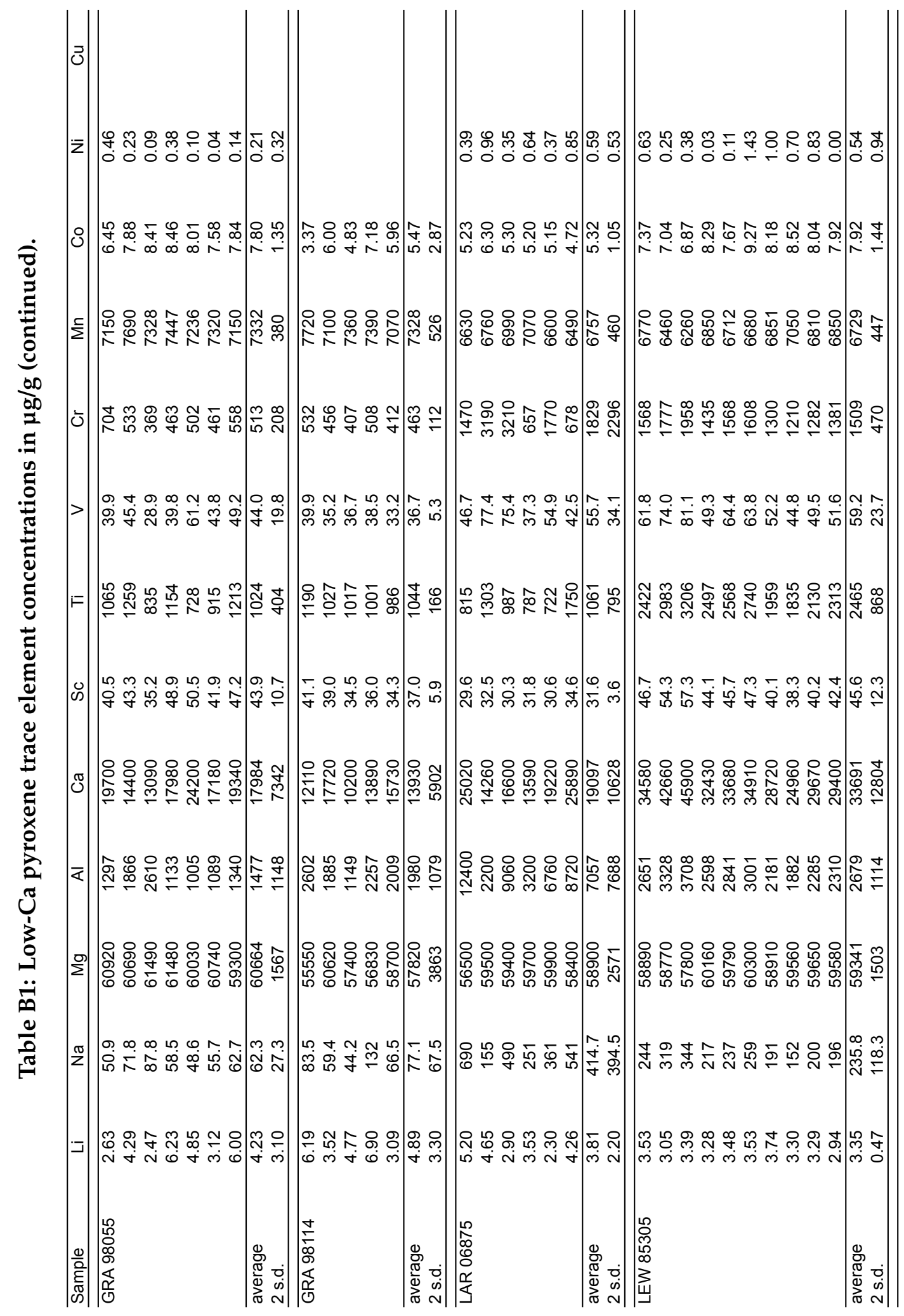




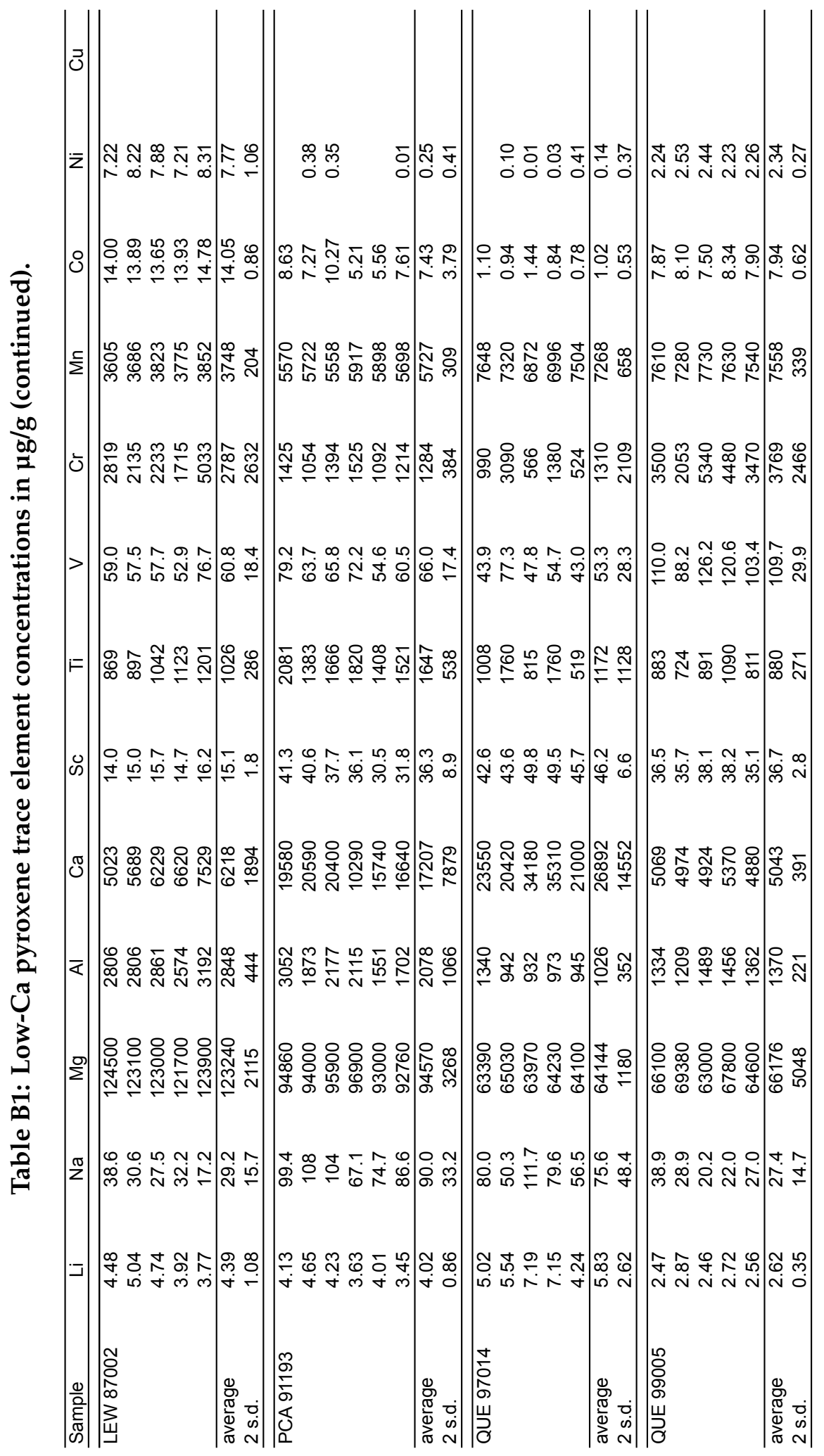




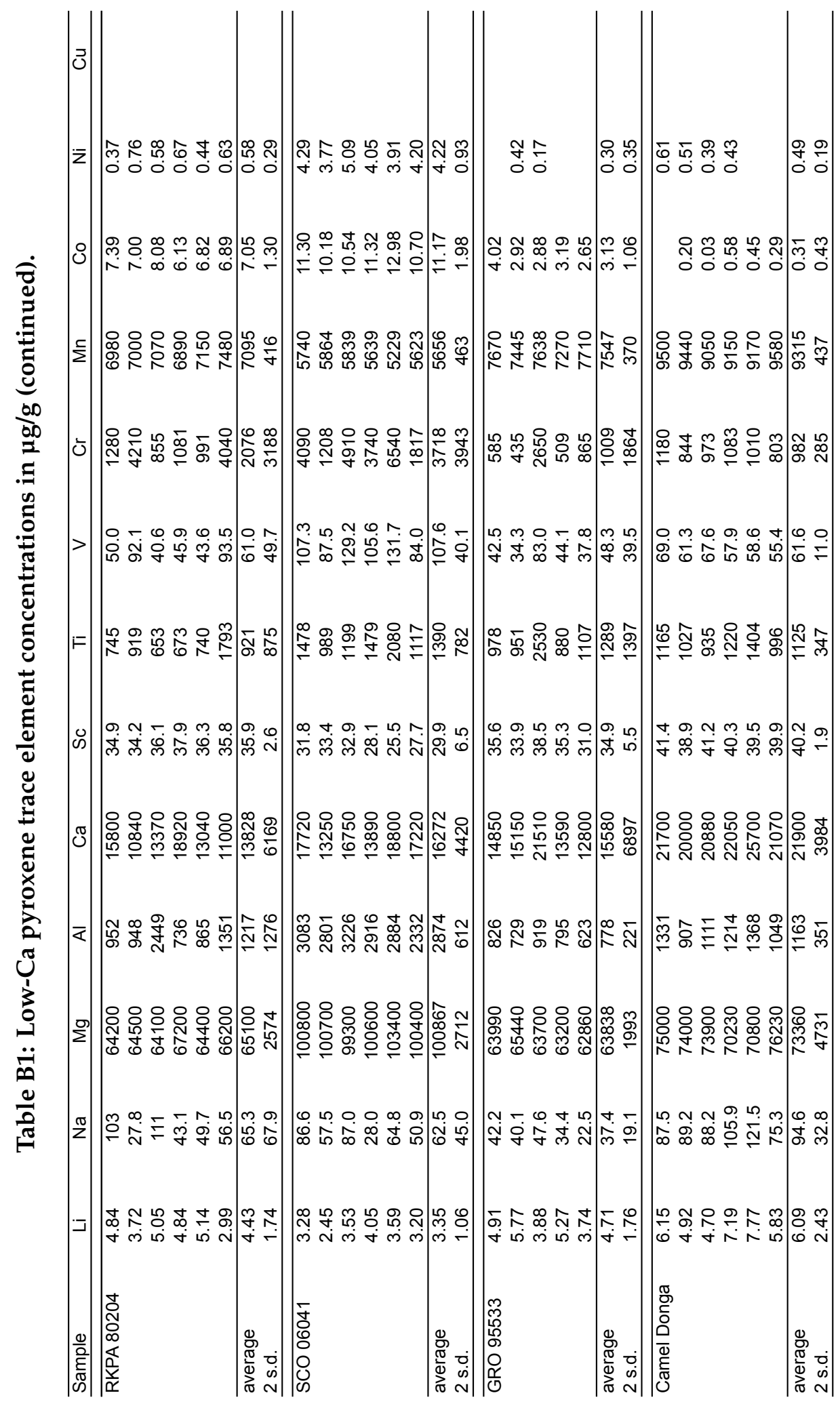




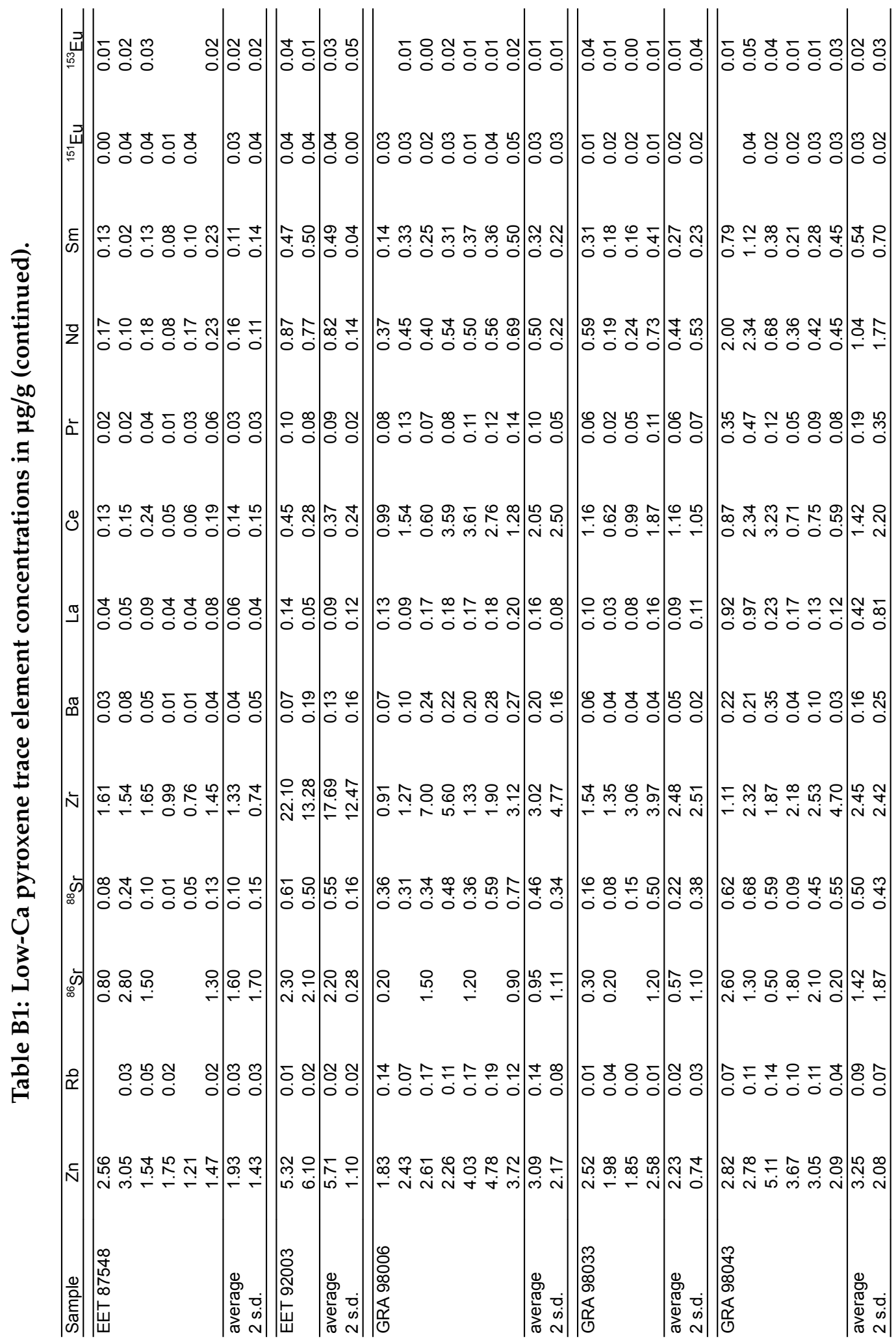




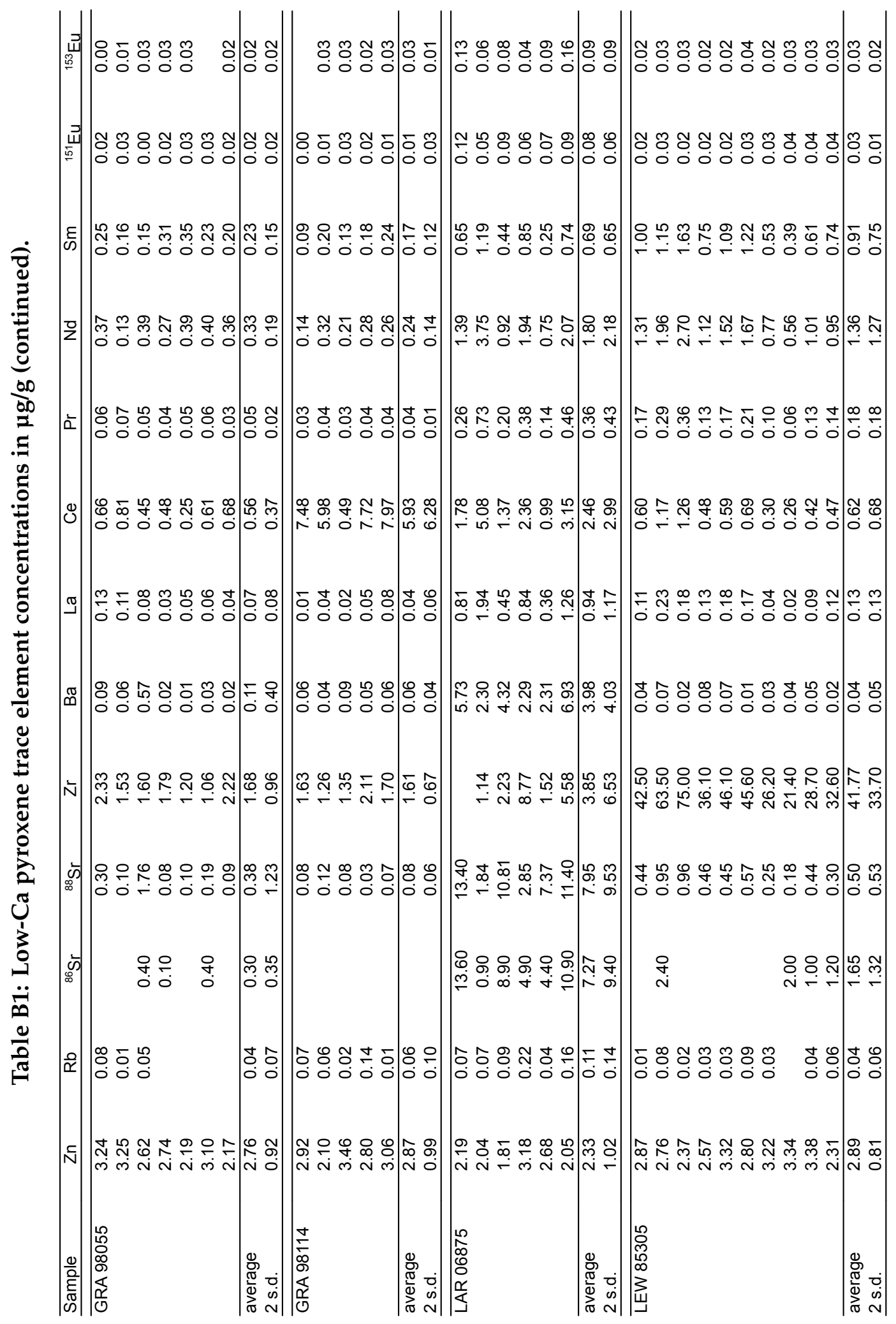




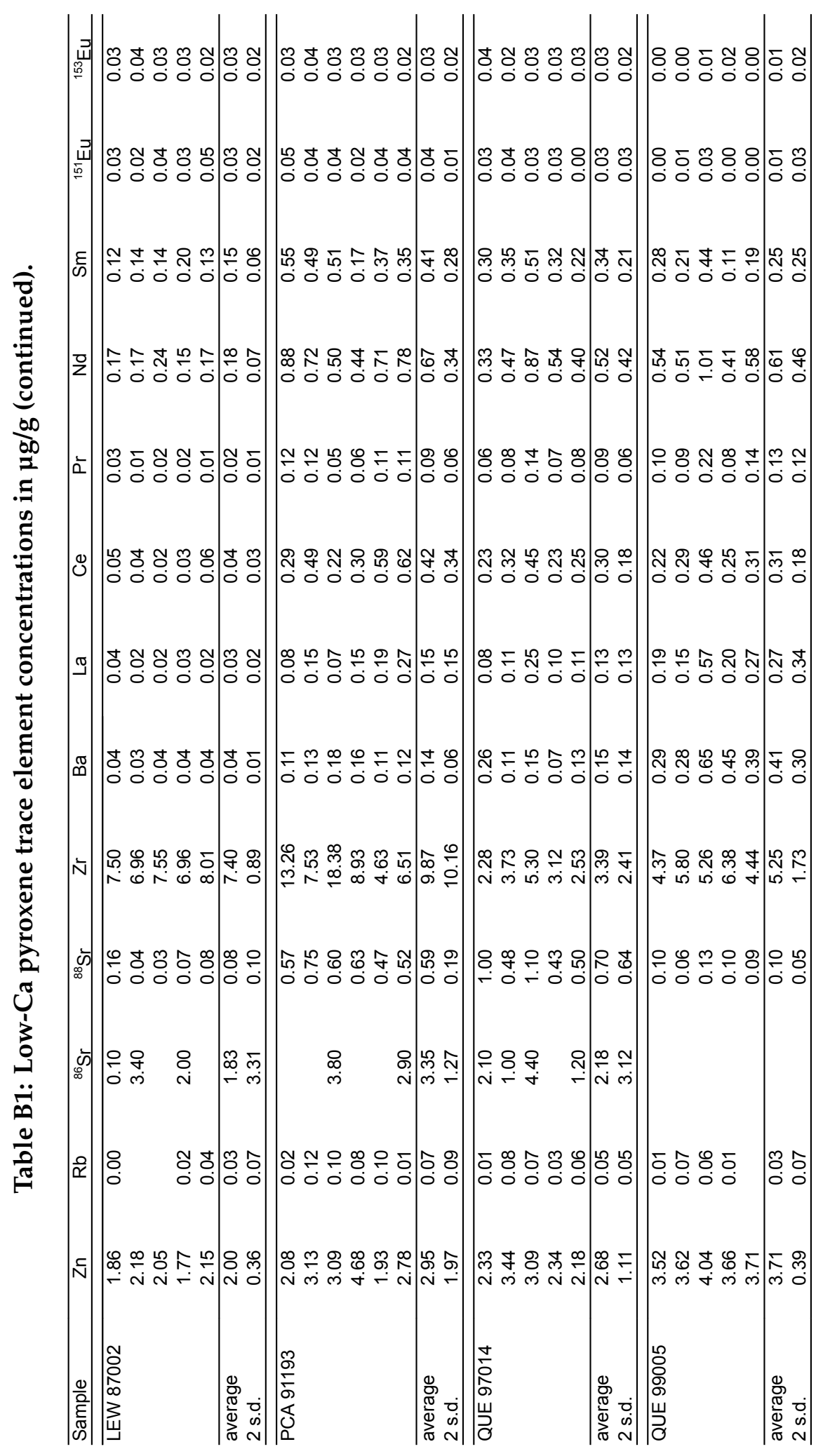




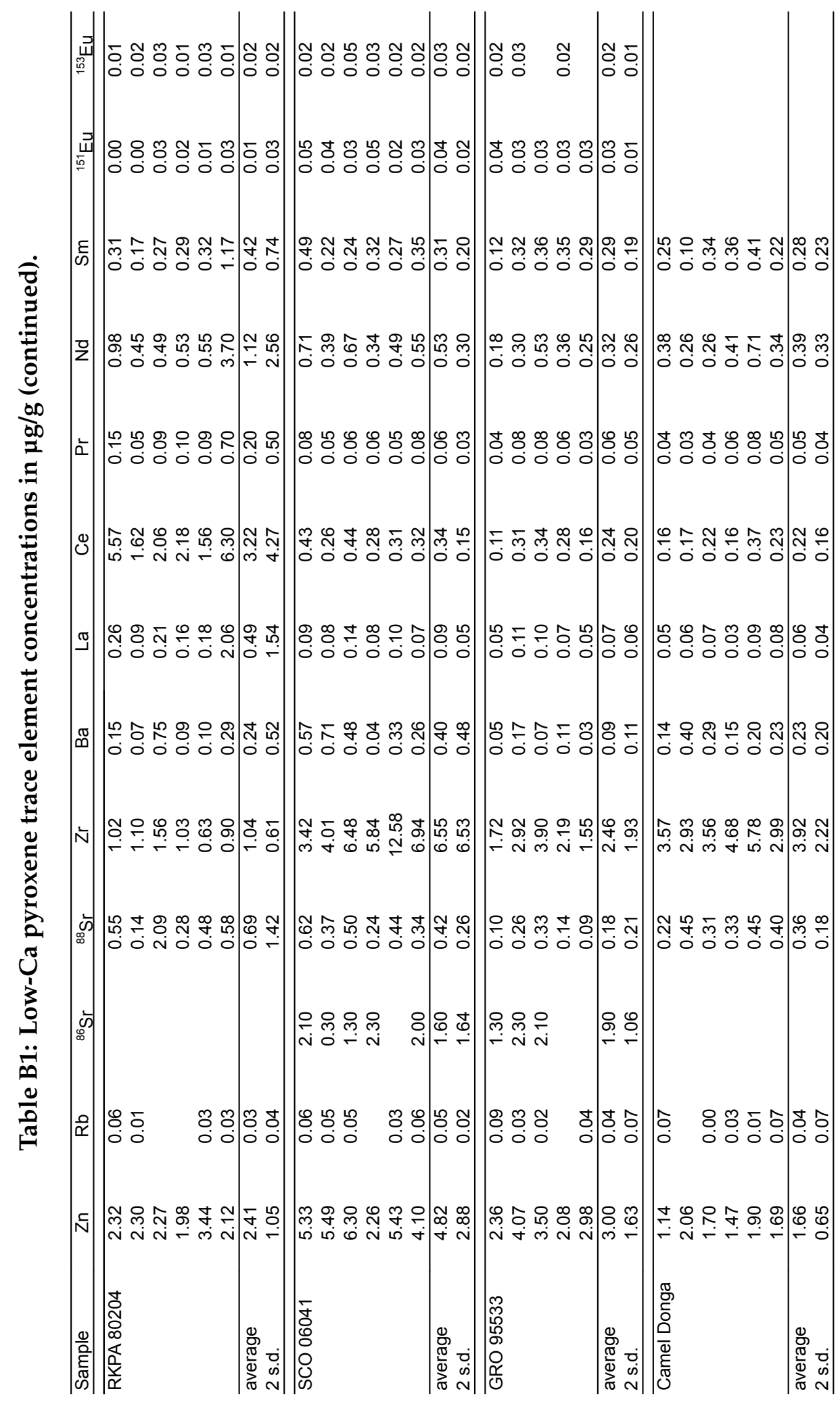




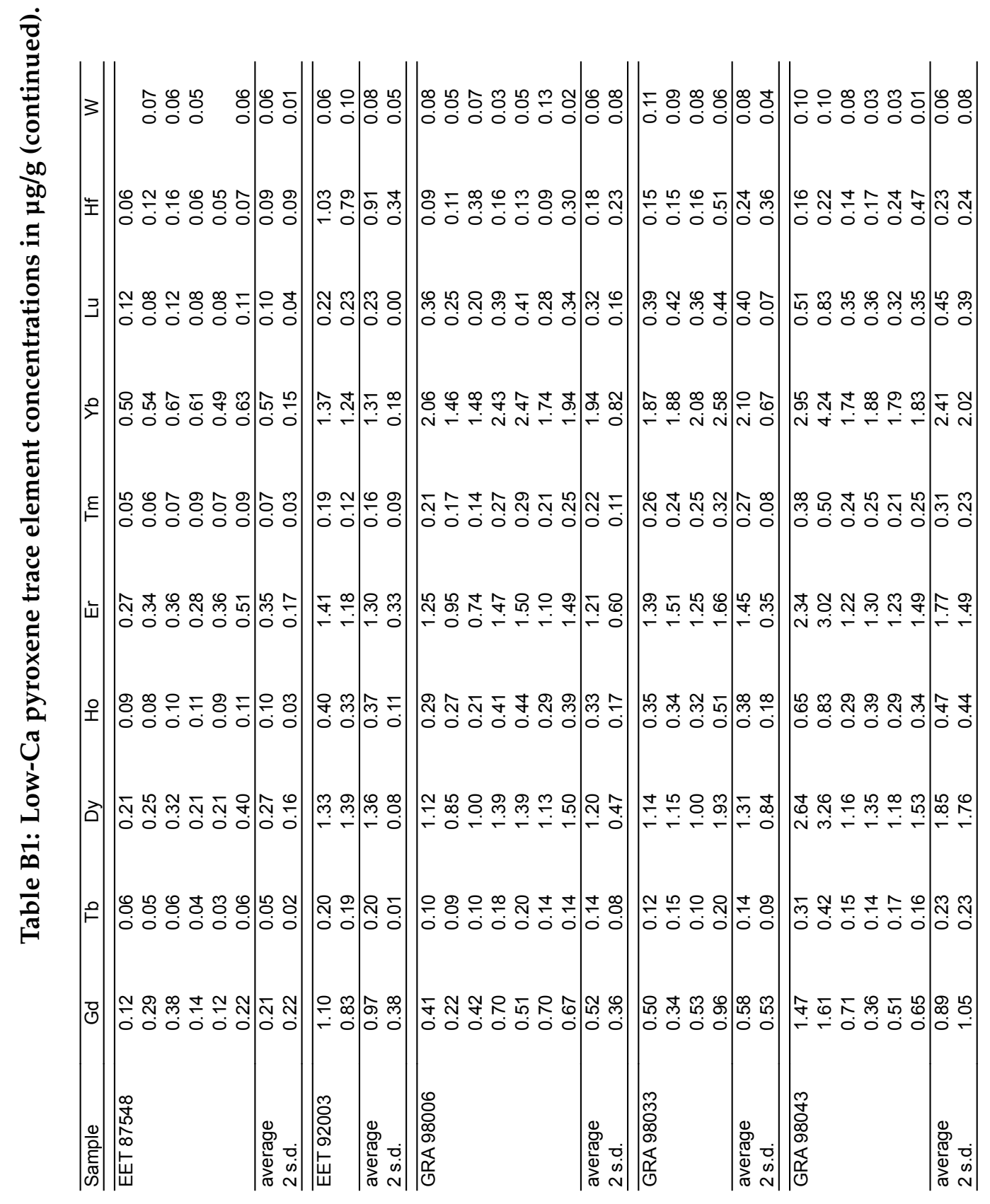




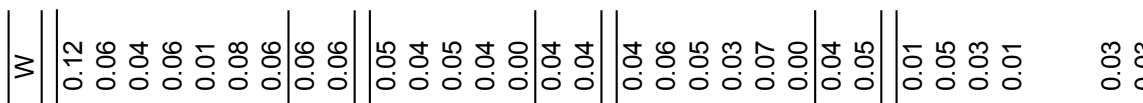
ח̊:

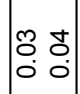

幽|

ธุ

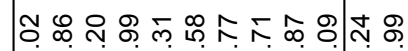

Z

0000000

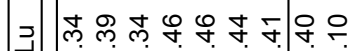

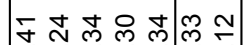

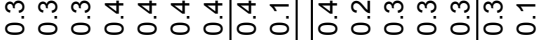

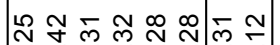

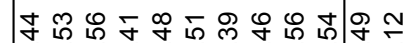

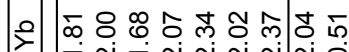

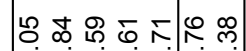
0000000

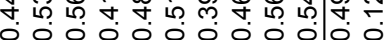

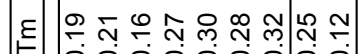

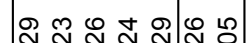

œ

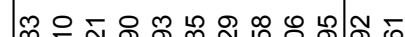

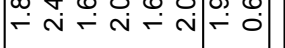
ن

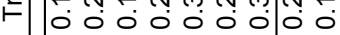
$\begin{array}{llllllllll}0 & 0 & 0 & 0 & 0 & 0\end{array}$

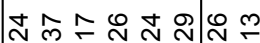

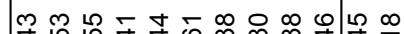

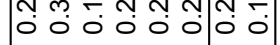

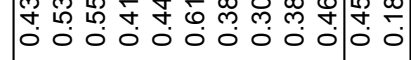

岀

సุ

局

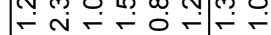

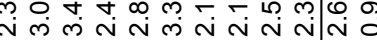

오 융

ల్లై

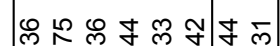

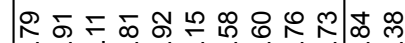

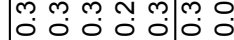

aे

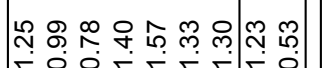

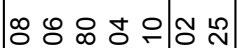

$\begin{array}{lllllllll}0 & 0 & 0 & 0 & 0 & 0 & 0\end{array}$

o.

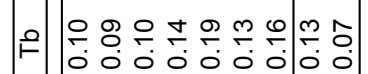

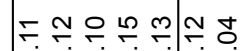

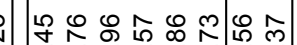

ஸ્م

-

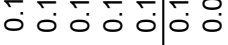

กิ

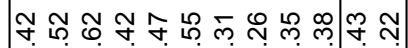

- 0

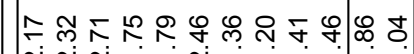




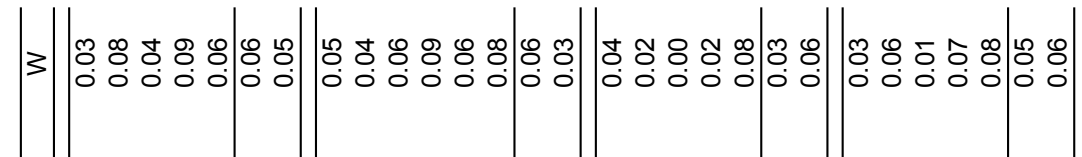

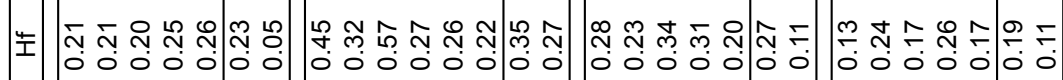

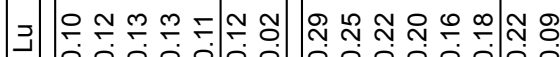

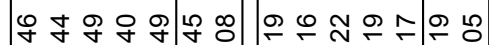

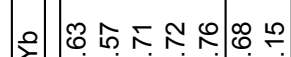

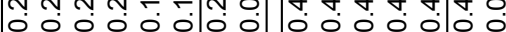

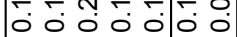

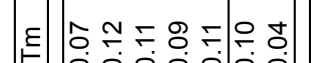

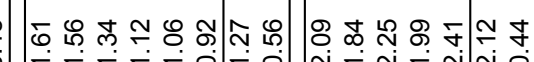

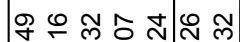

000000

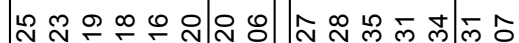

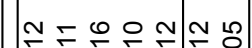

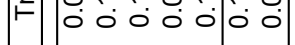

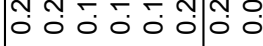

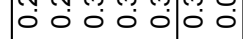

岗

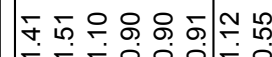

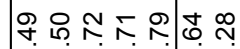

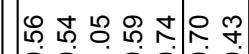

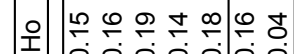

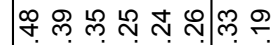

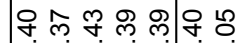

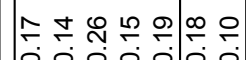

>حا

N

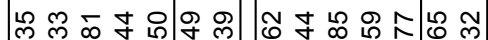

$\frac{\ddot{\infty}}{\frac{0}{\pi}}$

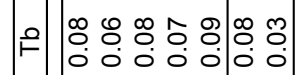

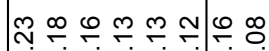

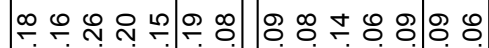

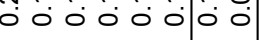

$\begin{array}{lllllllll}0 & 0 & 0 & 0 & 0 & 0 & 0 & 0\end{array}$

유

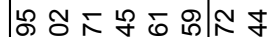

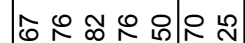

0.0.

0

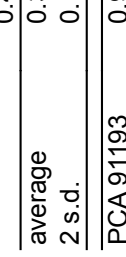

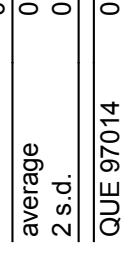

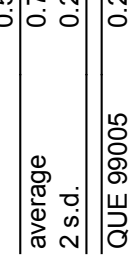

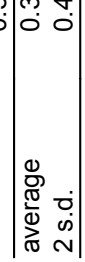




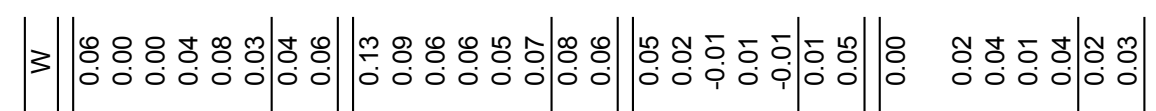

声

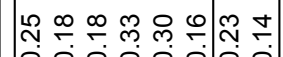

크

ำ 균 늄

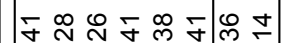

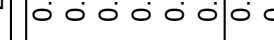

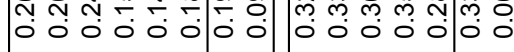

기

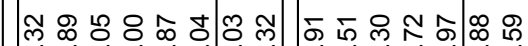

낭

ह

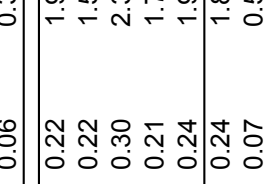

岗

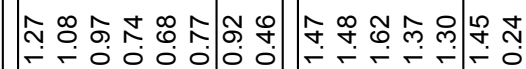

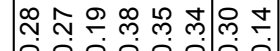

F

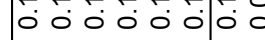

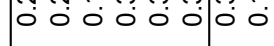

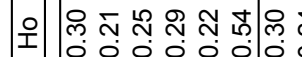

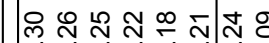

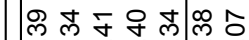

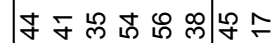

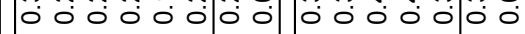

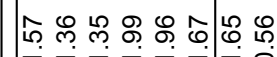

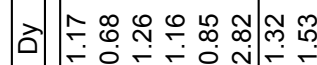

ஓ б

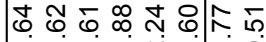

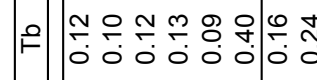

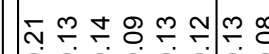

$\leqslant \stackrel{\infty}{\div} \div \div \frac{0}{\div}$

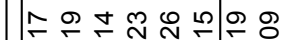

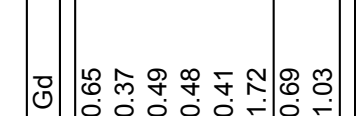
\begin{tabular}{llllll|lll}
0 & 0 & 0 & 0 & 0 & 0 & 0 & 0 & 0
\end{tabular}

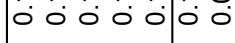

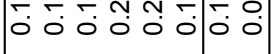

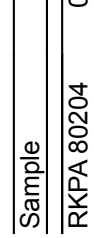

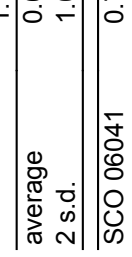

을 운

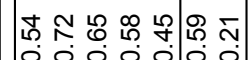

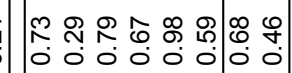

蓉

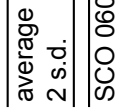

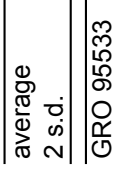

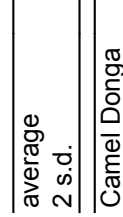




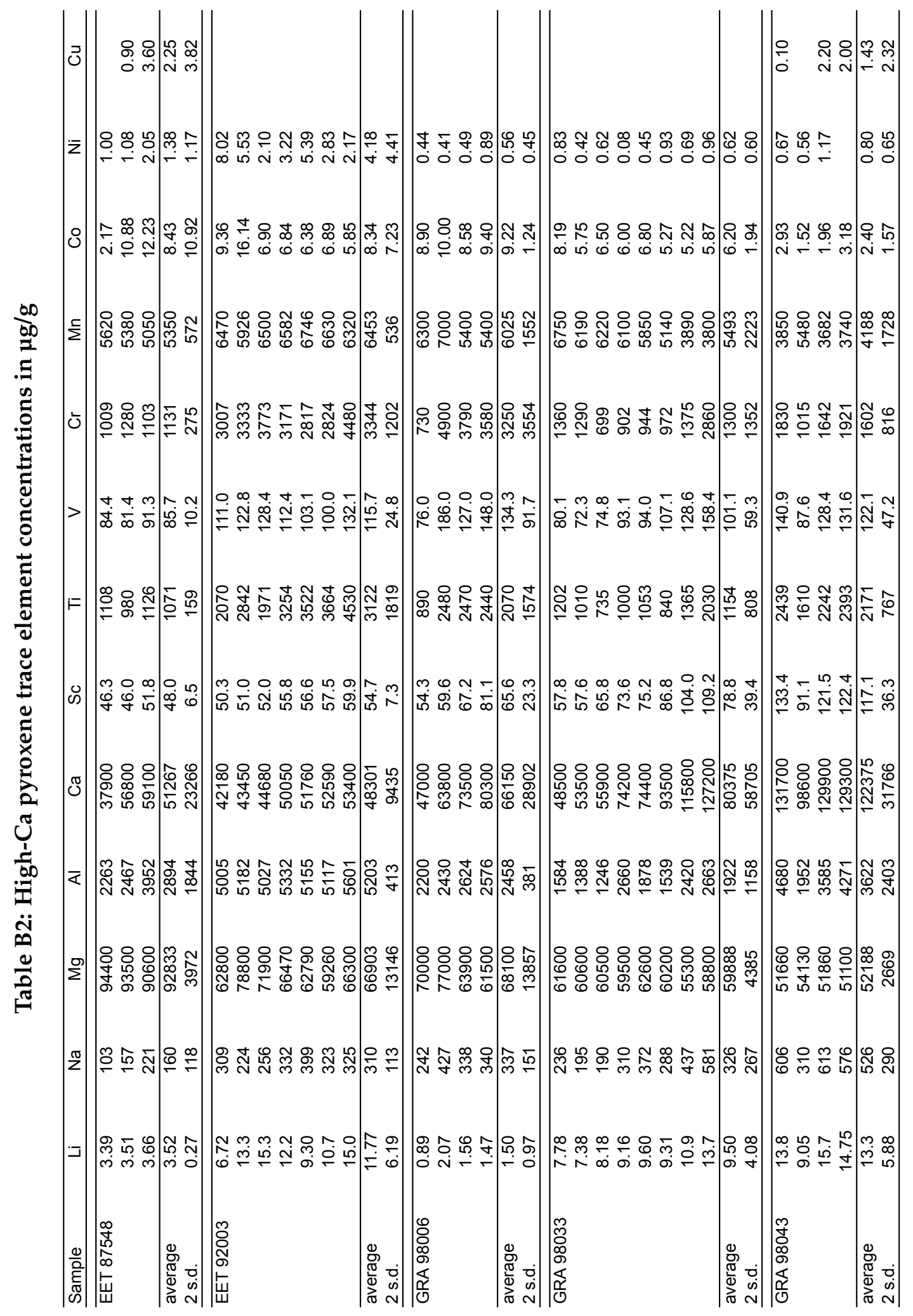




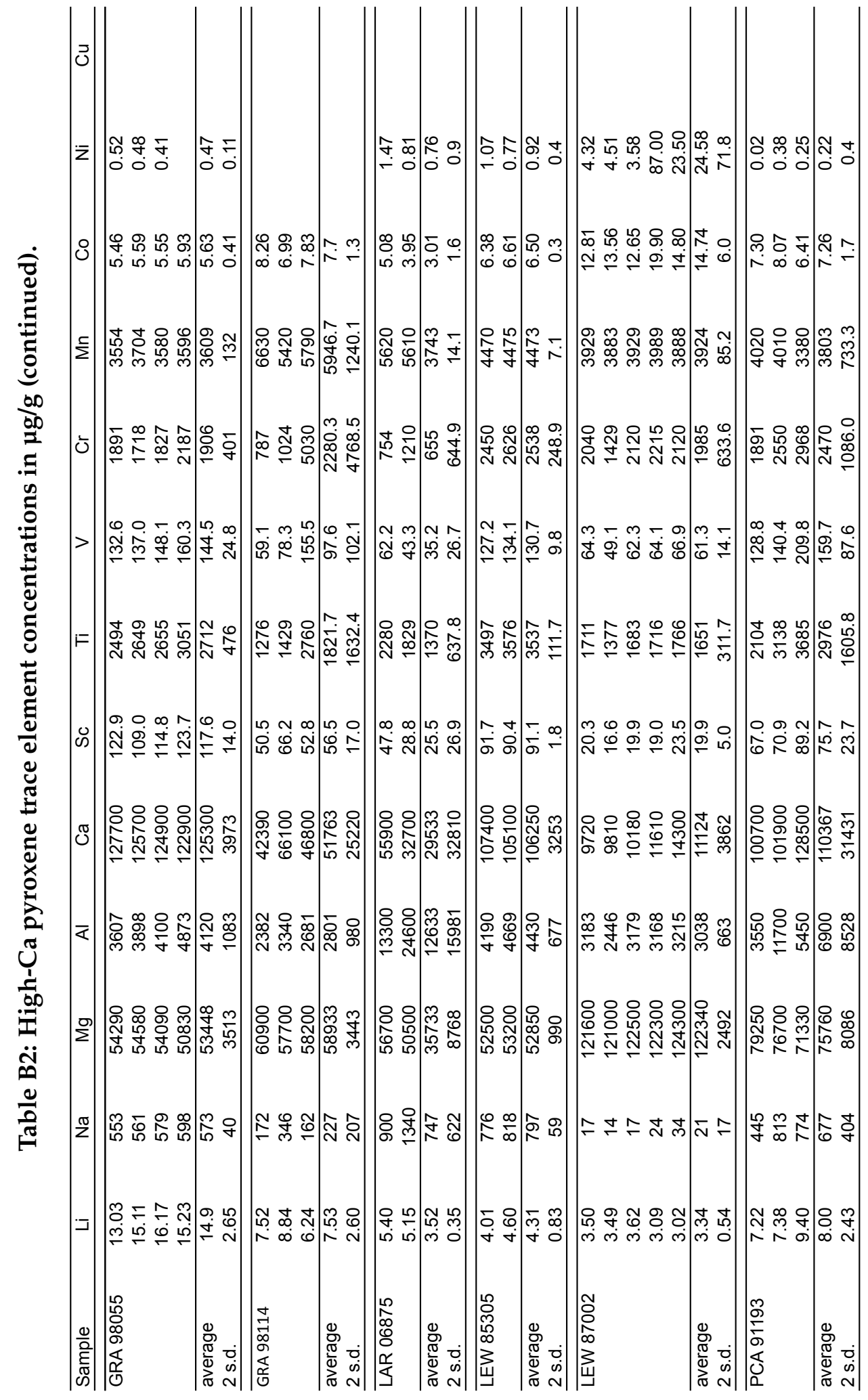




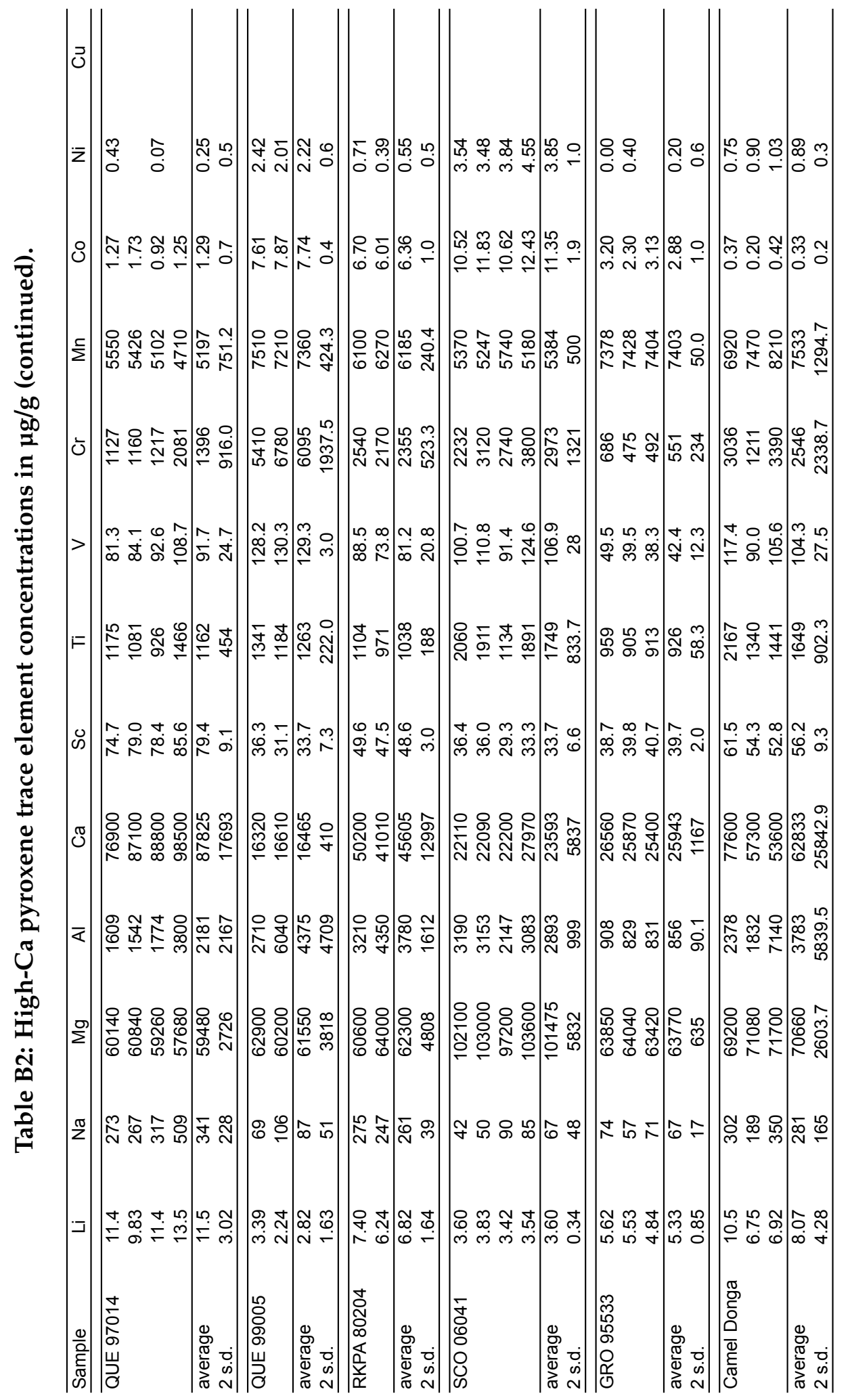




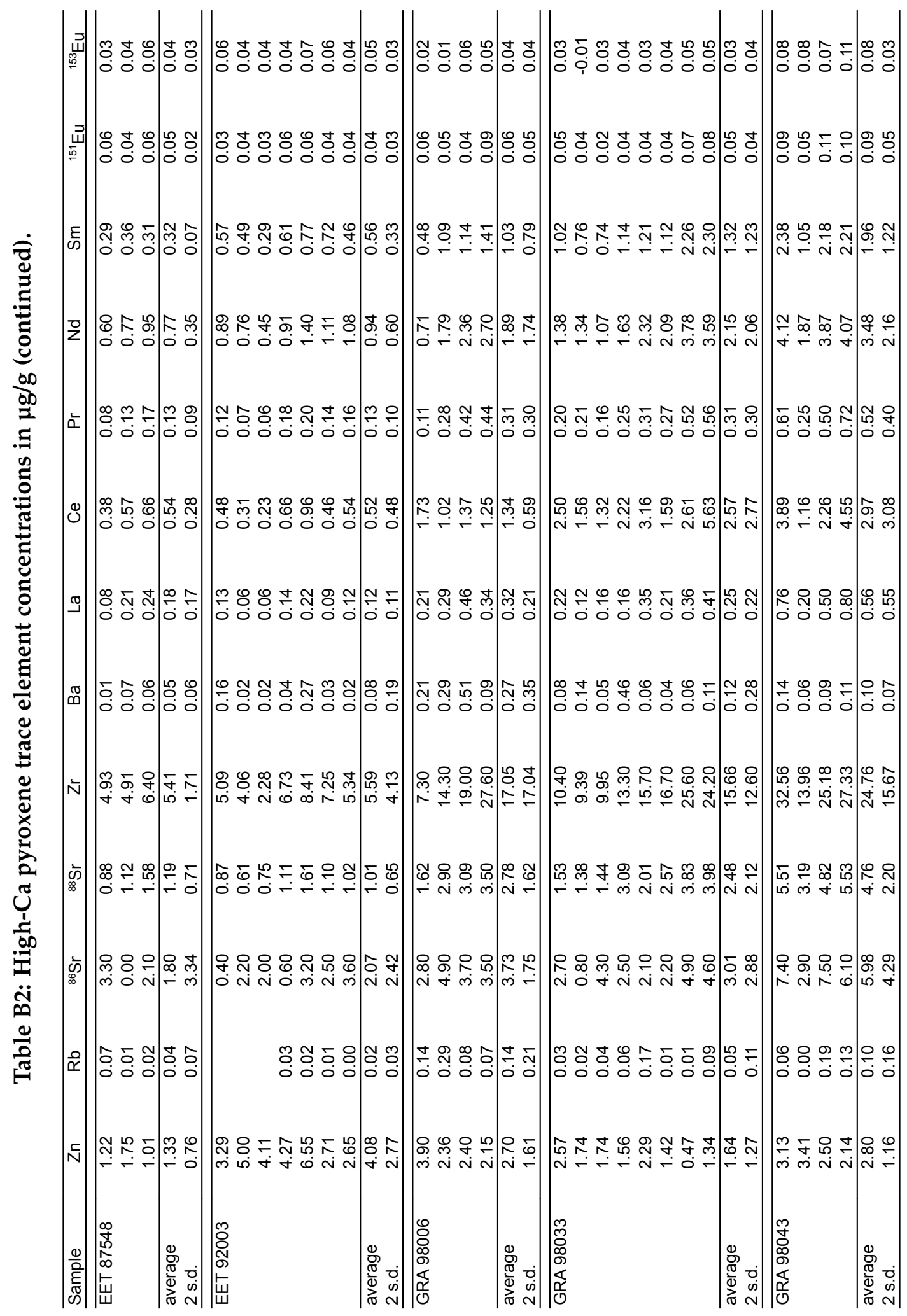




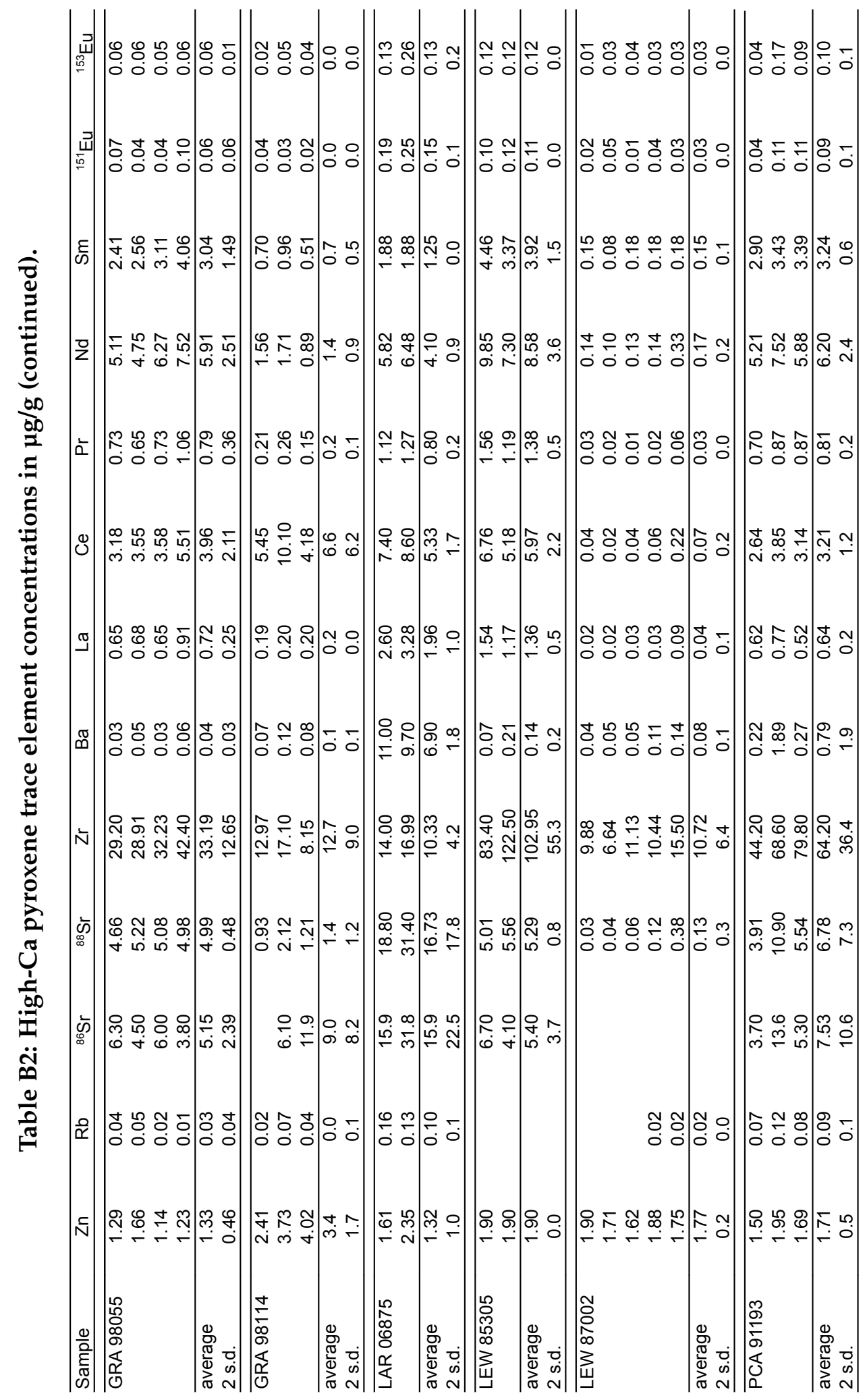




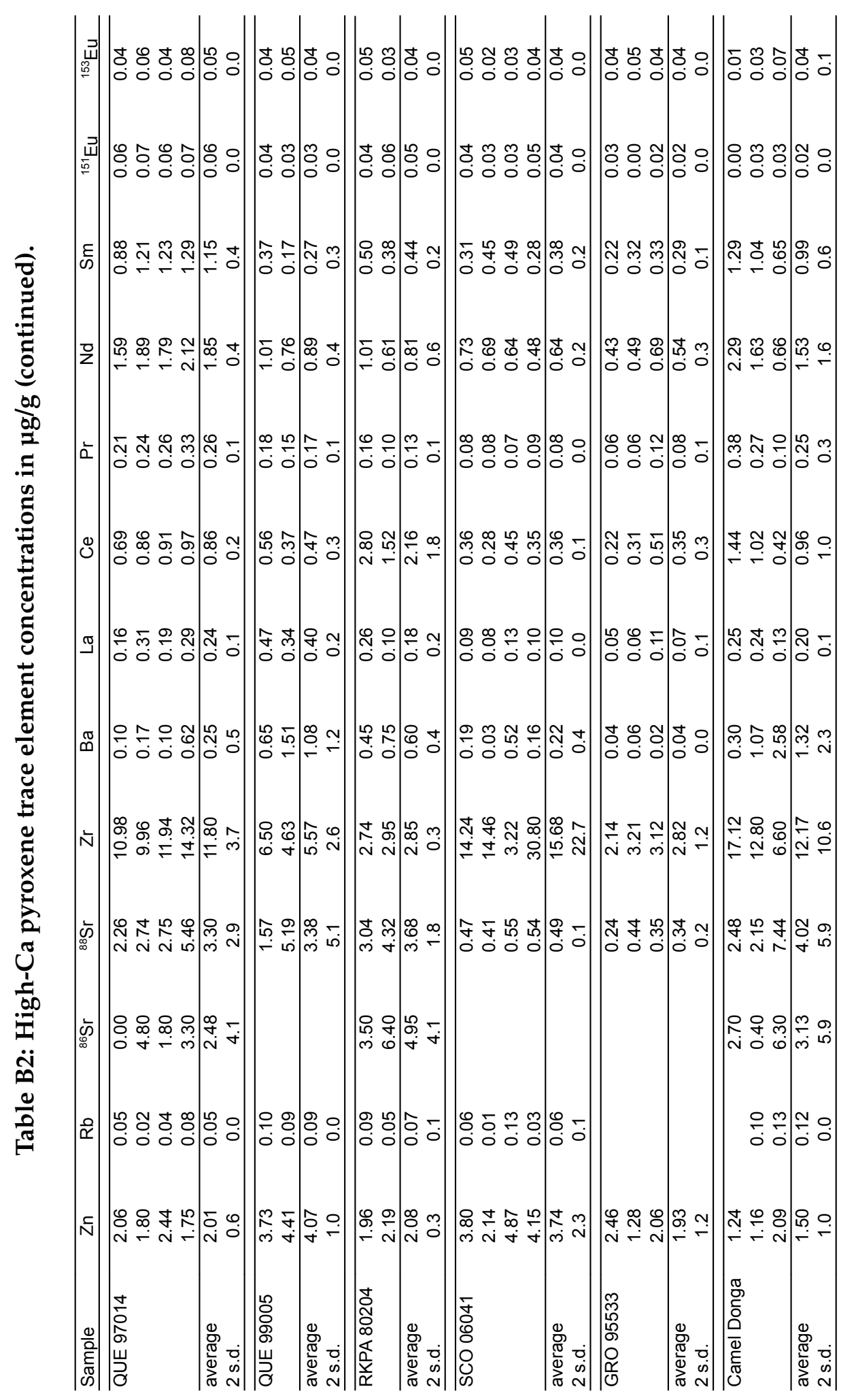




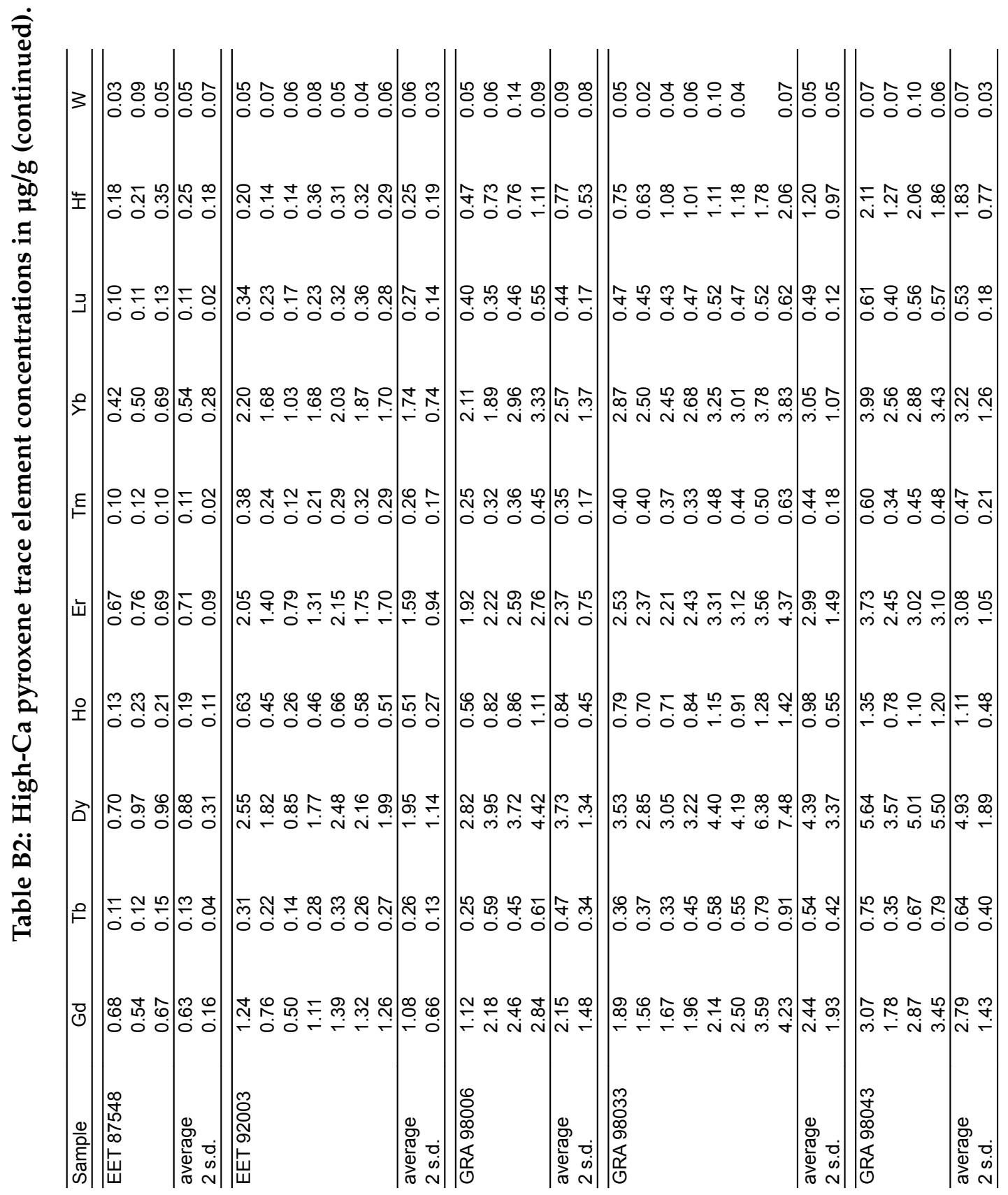




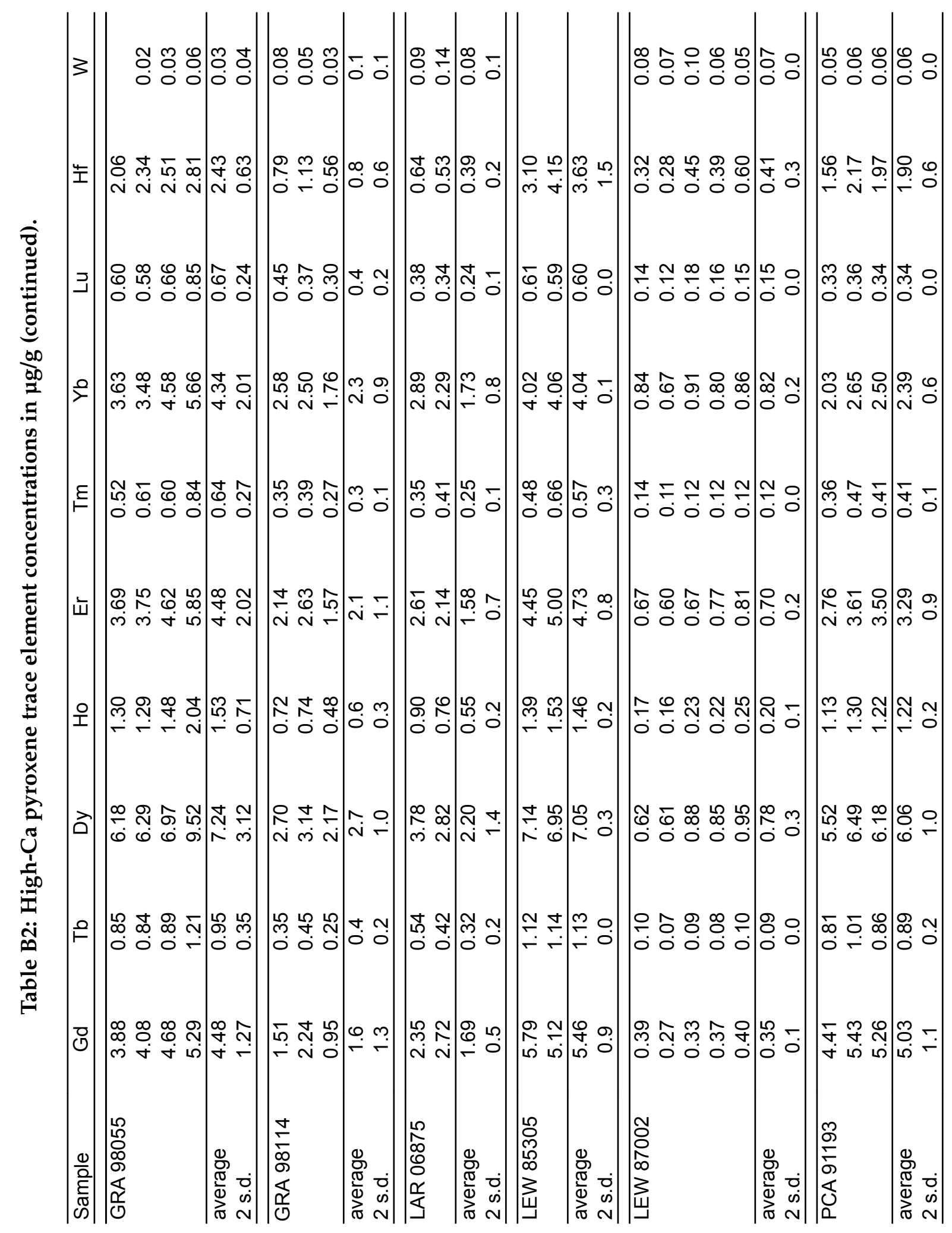




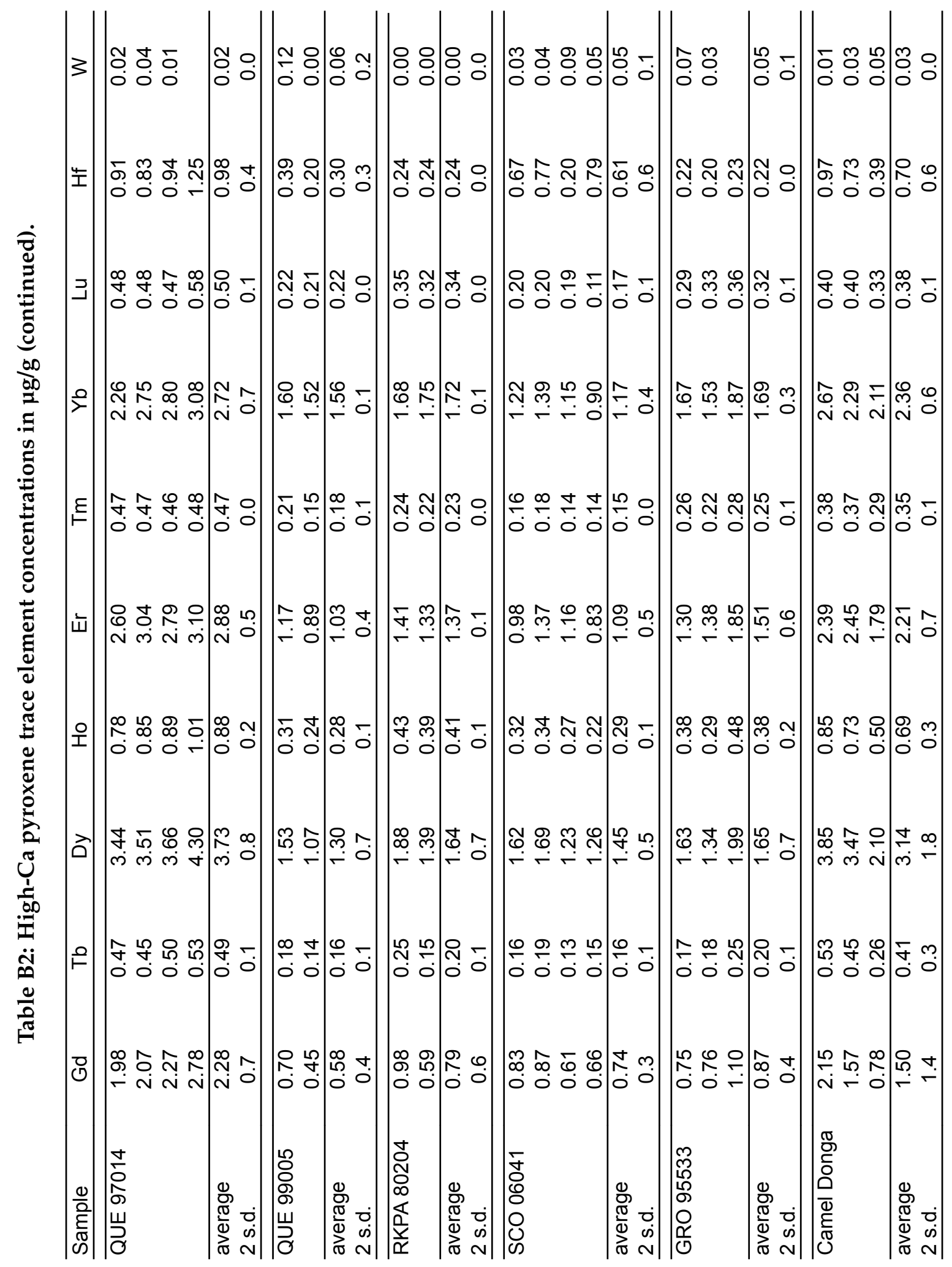




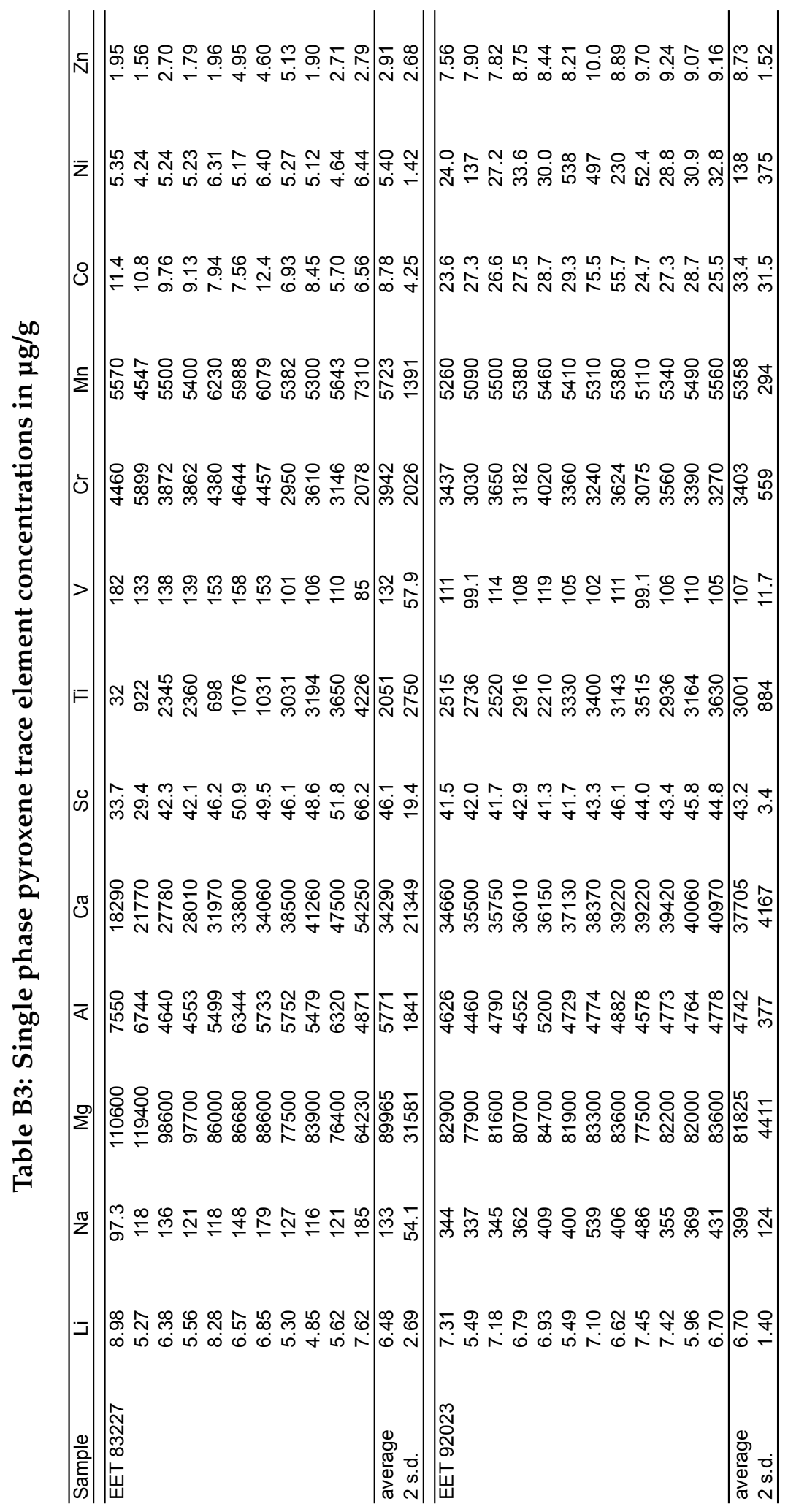




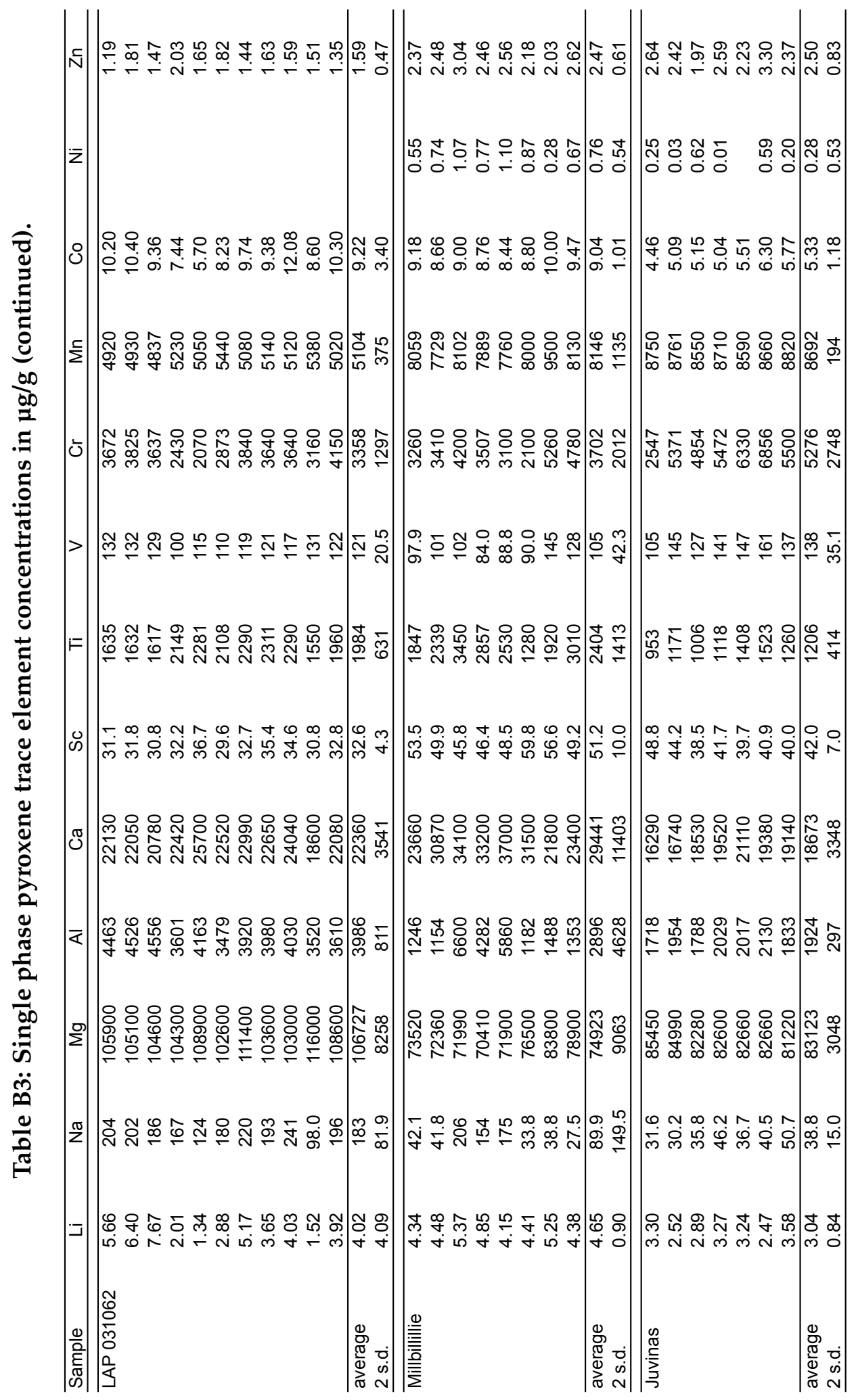




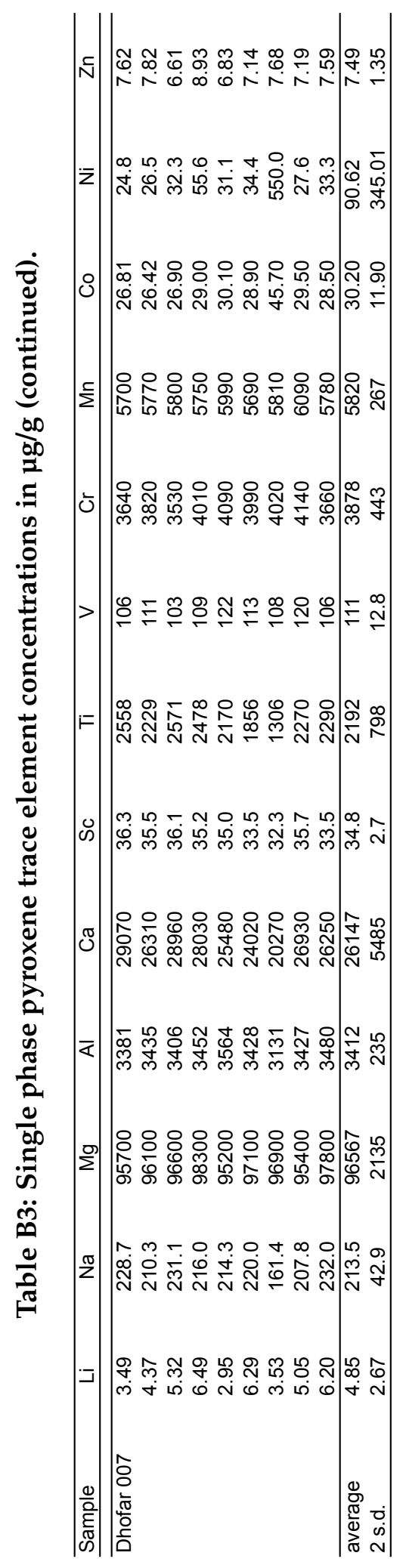




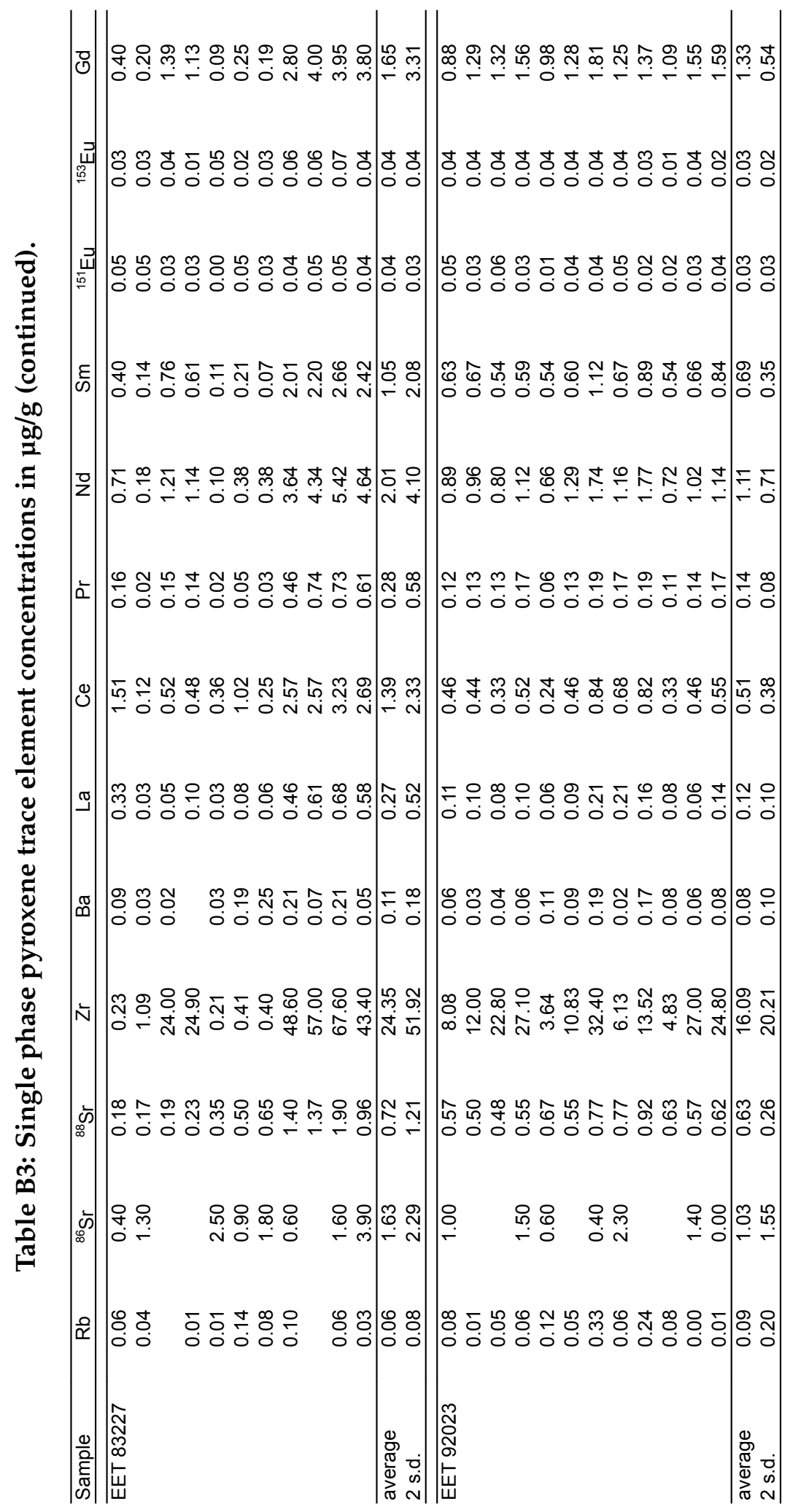




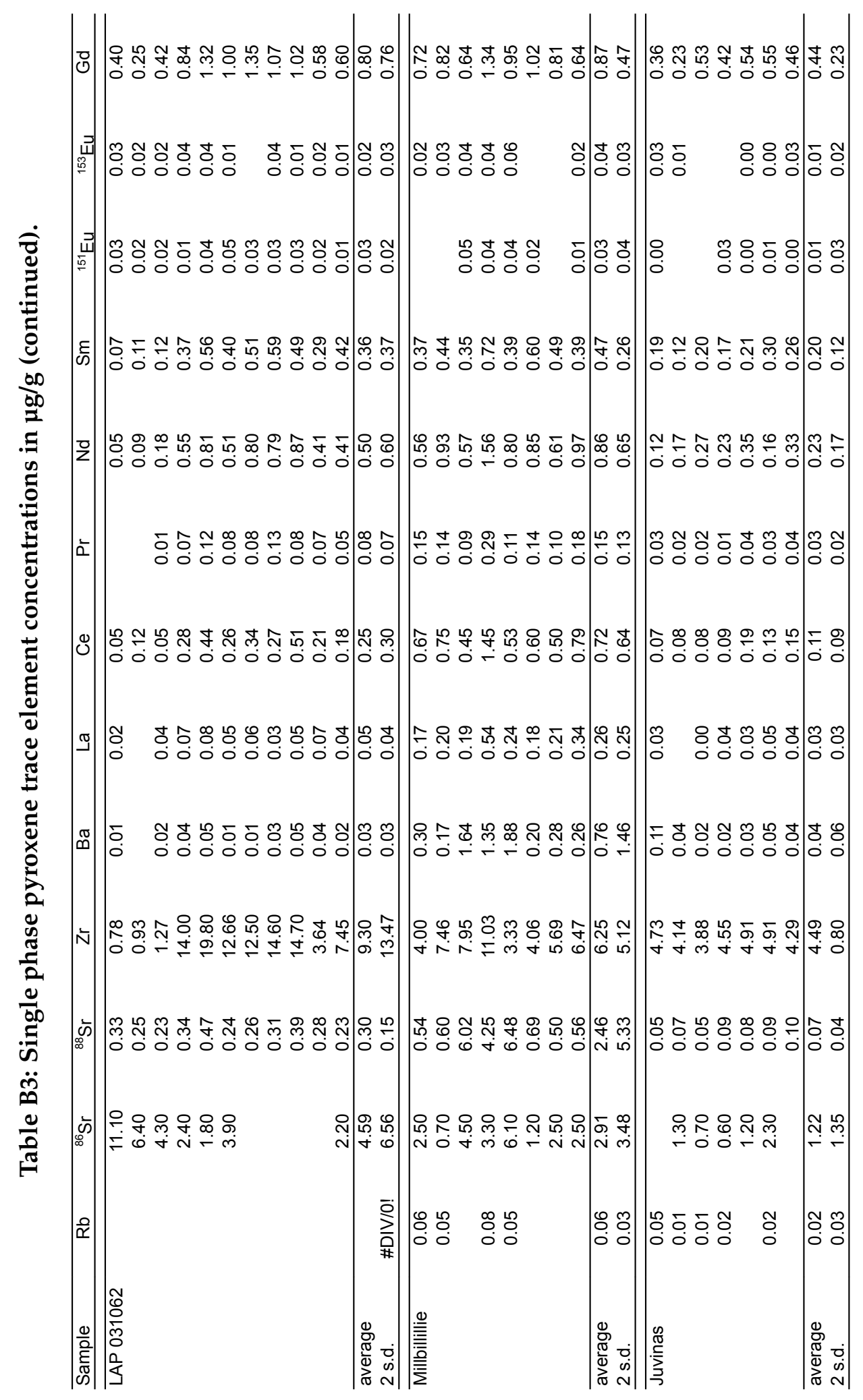




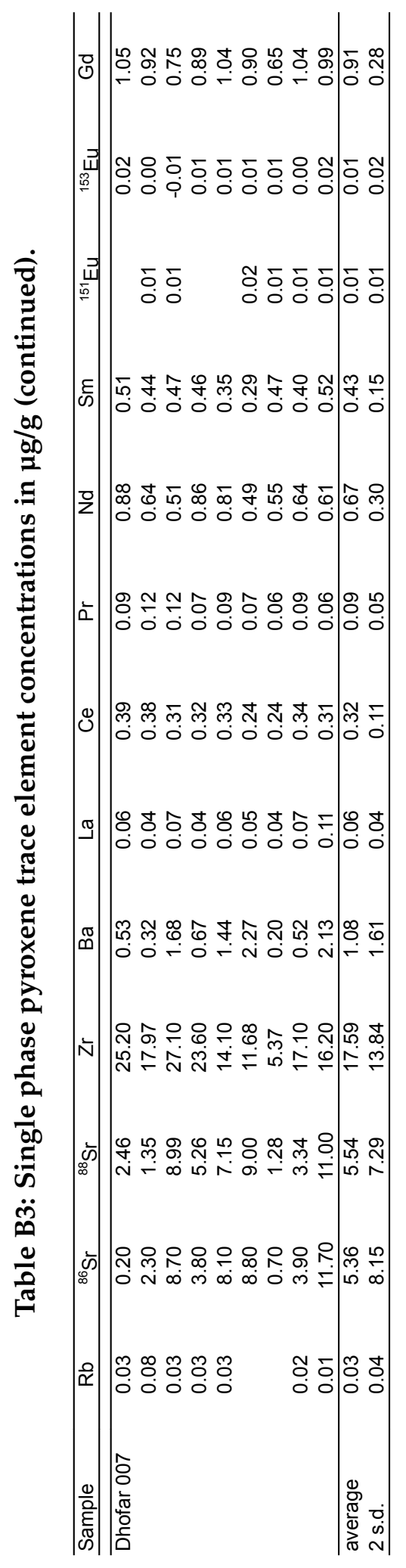




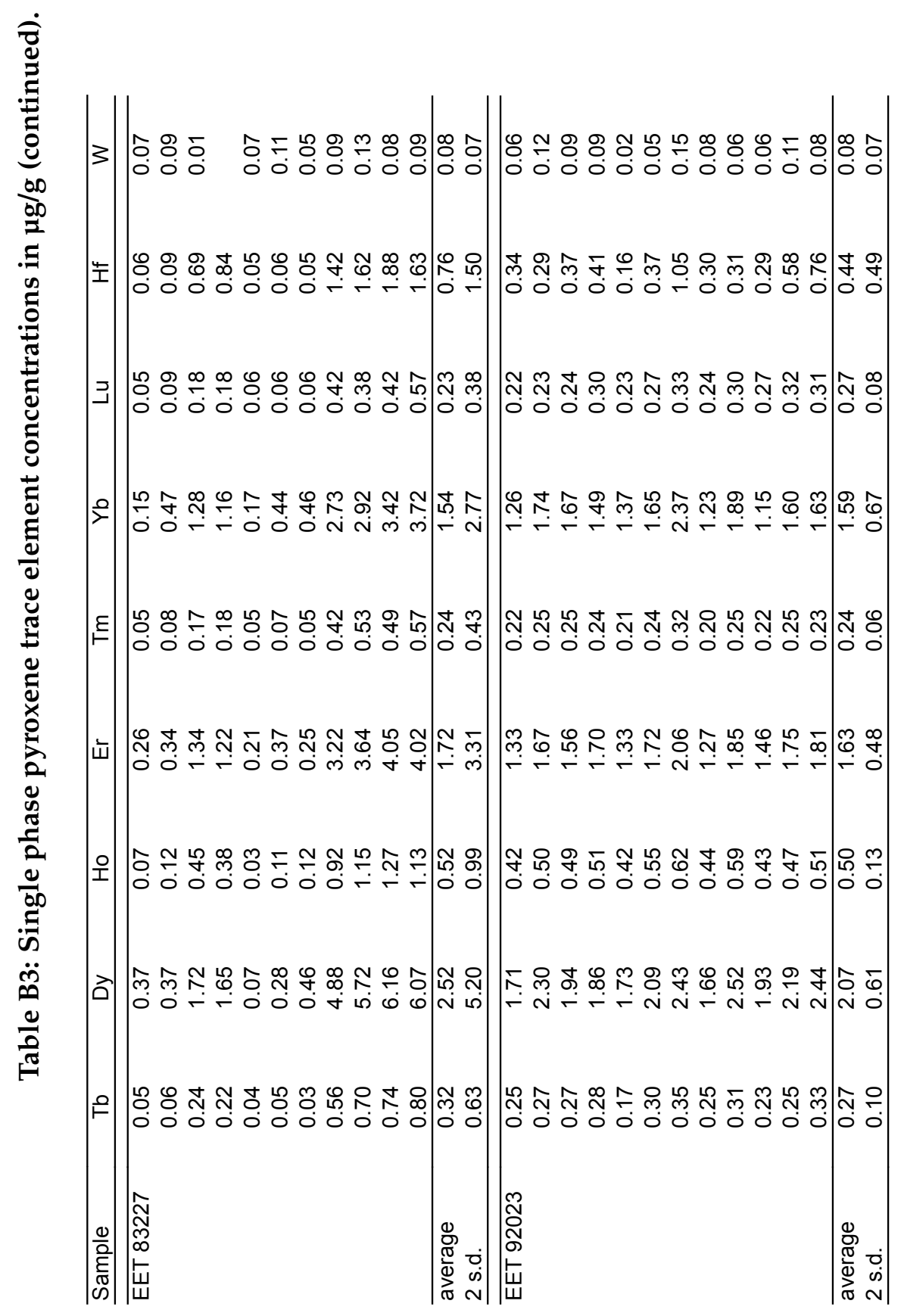




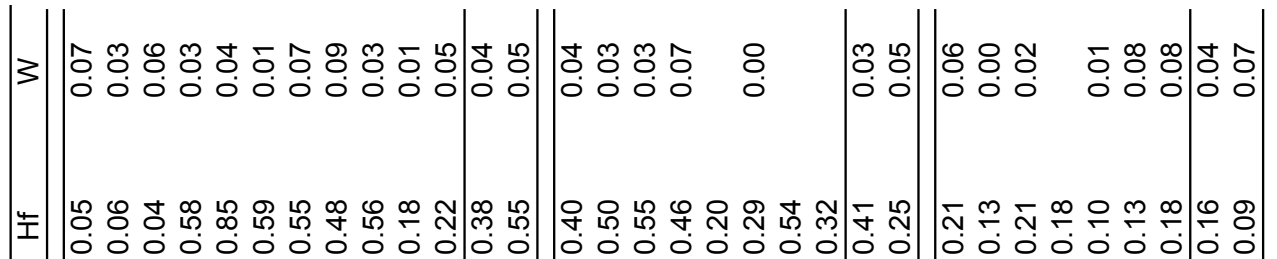

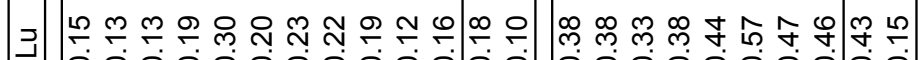

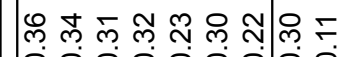

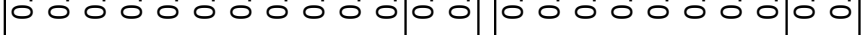

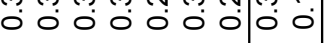

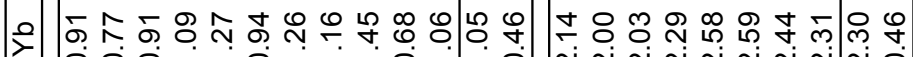

×

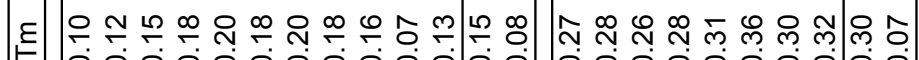

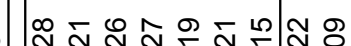

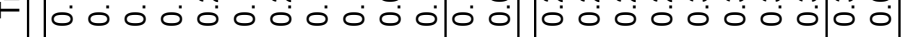

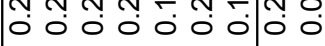

产

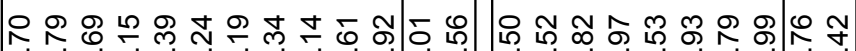

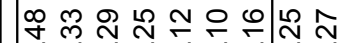

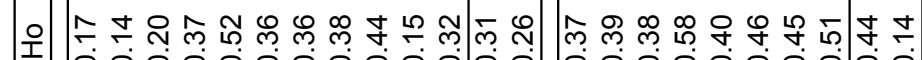

预

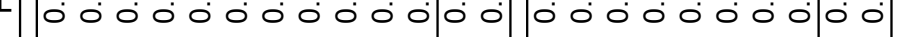

0000000000000

aे

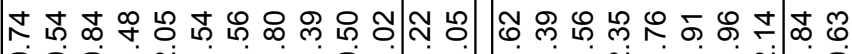

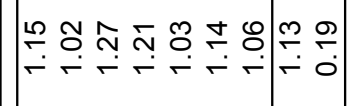

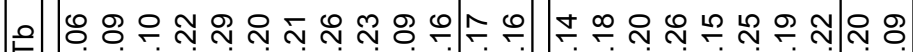

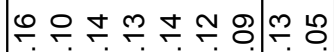

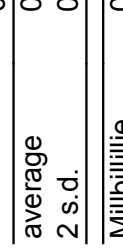

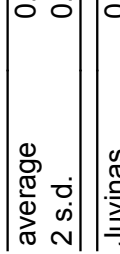

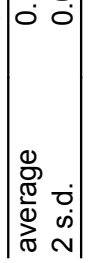




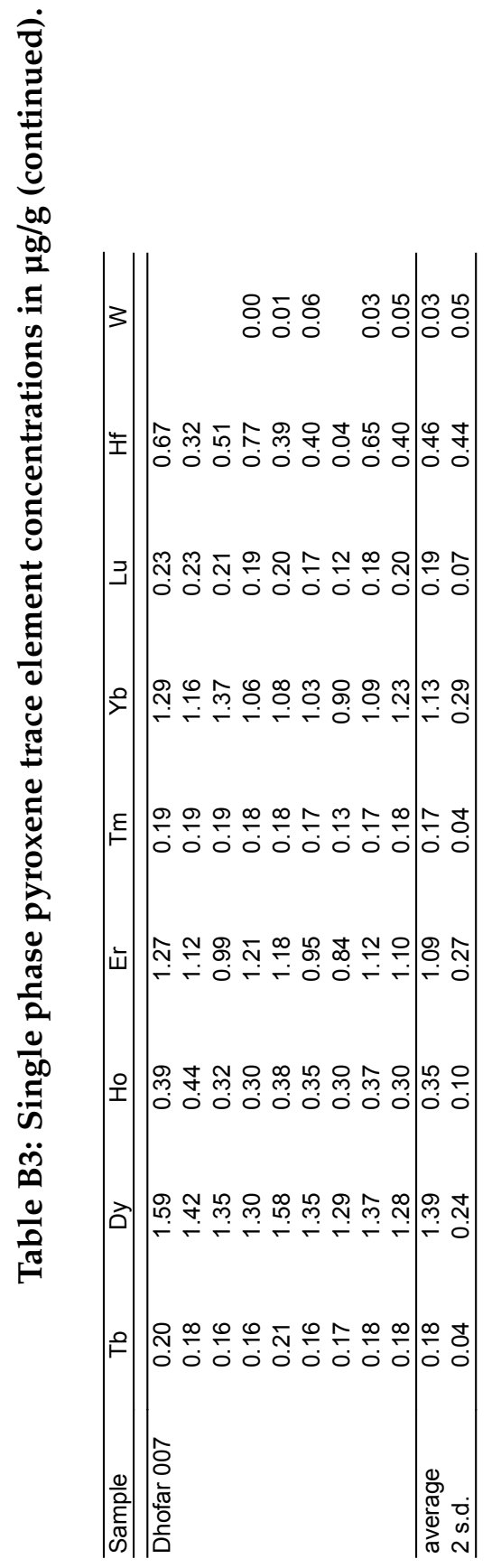




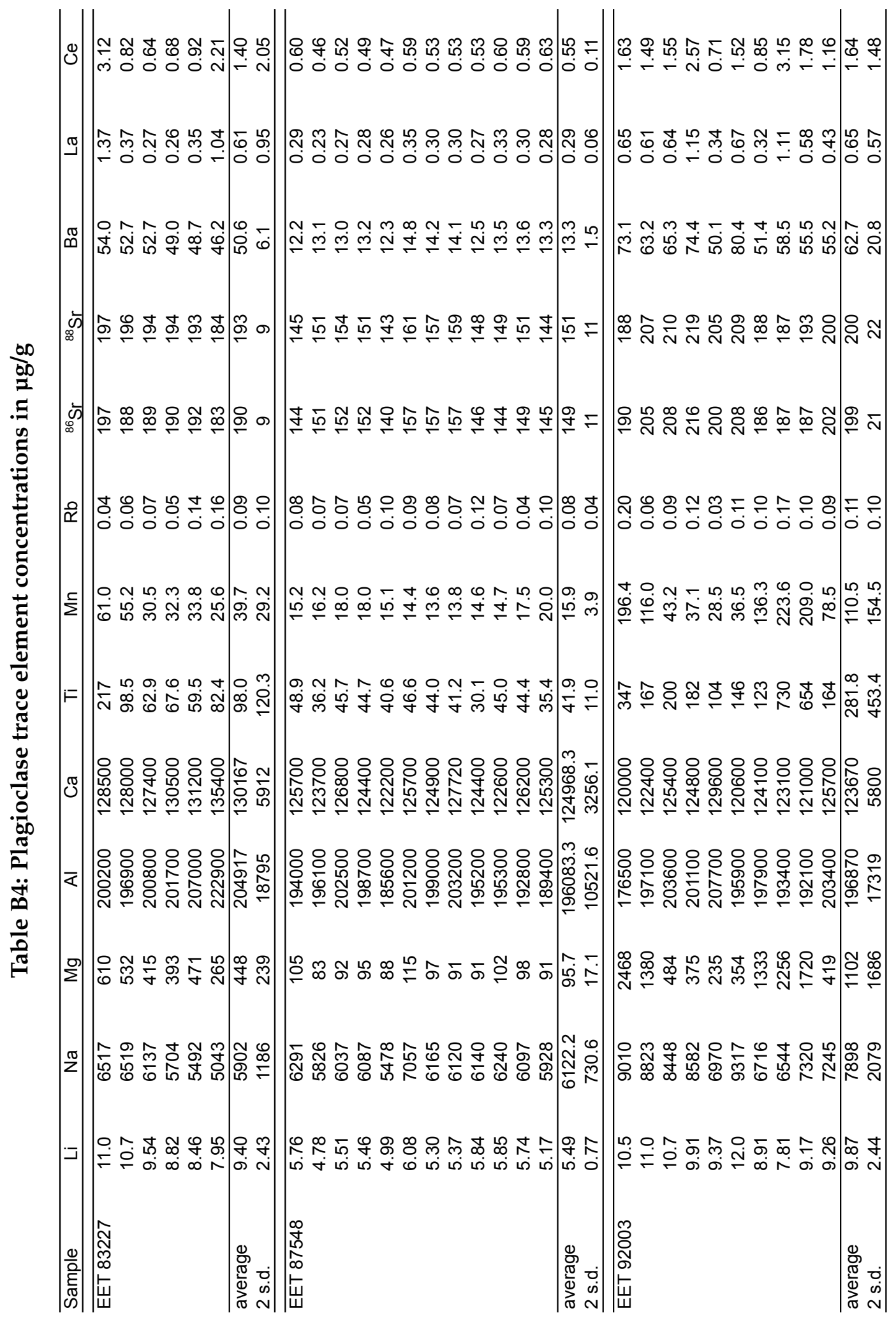




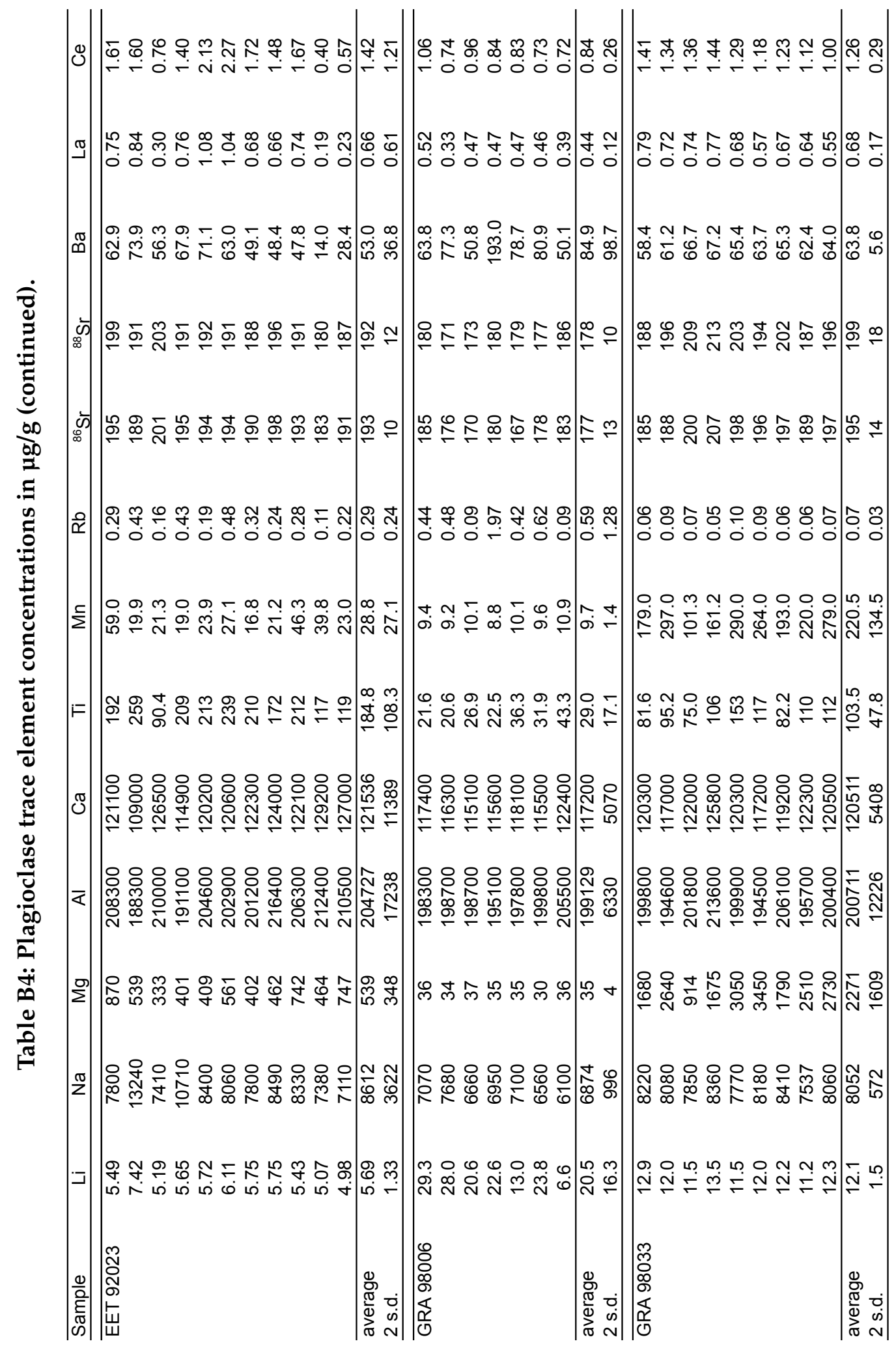




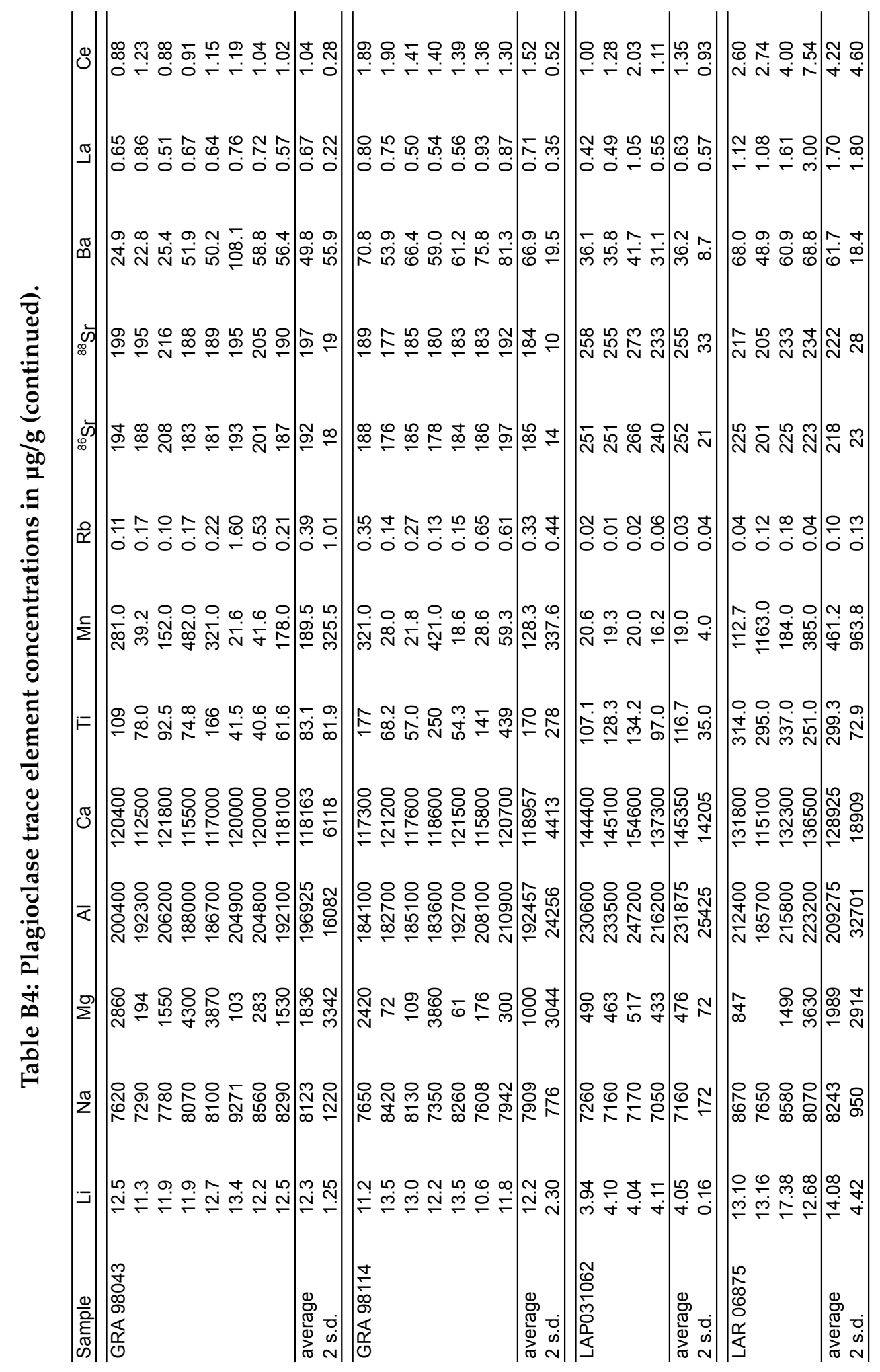




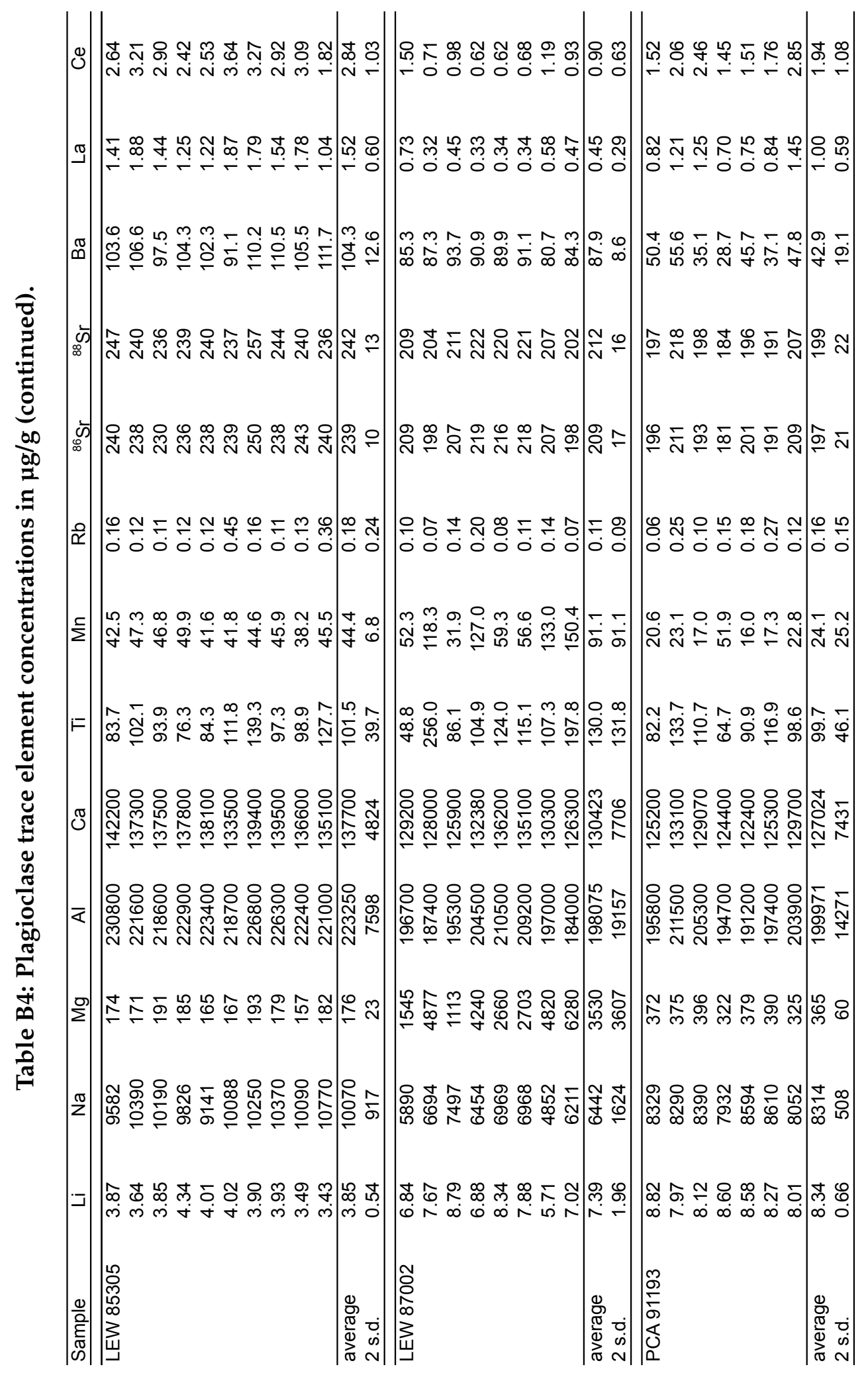




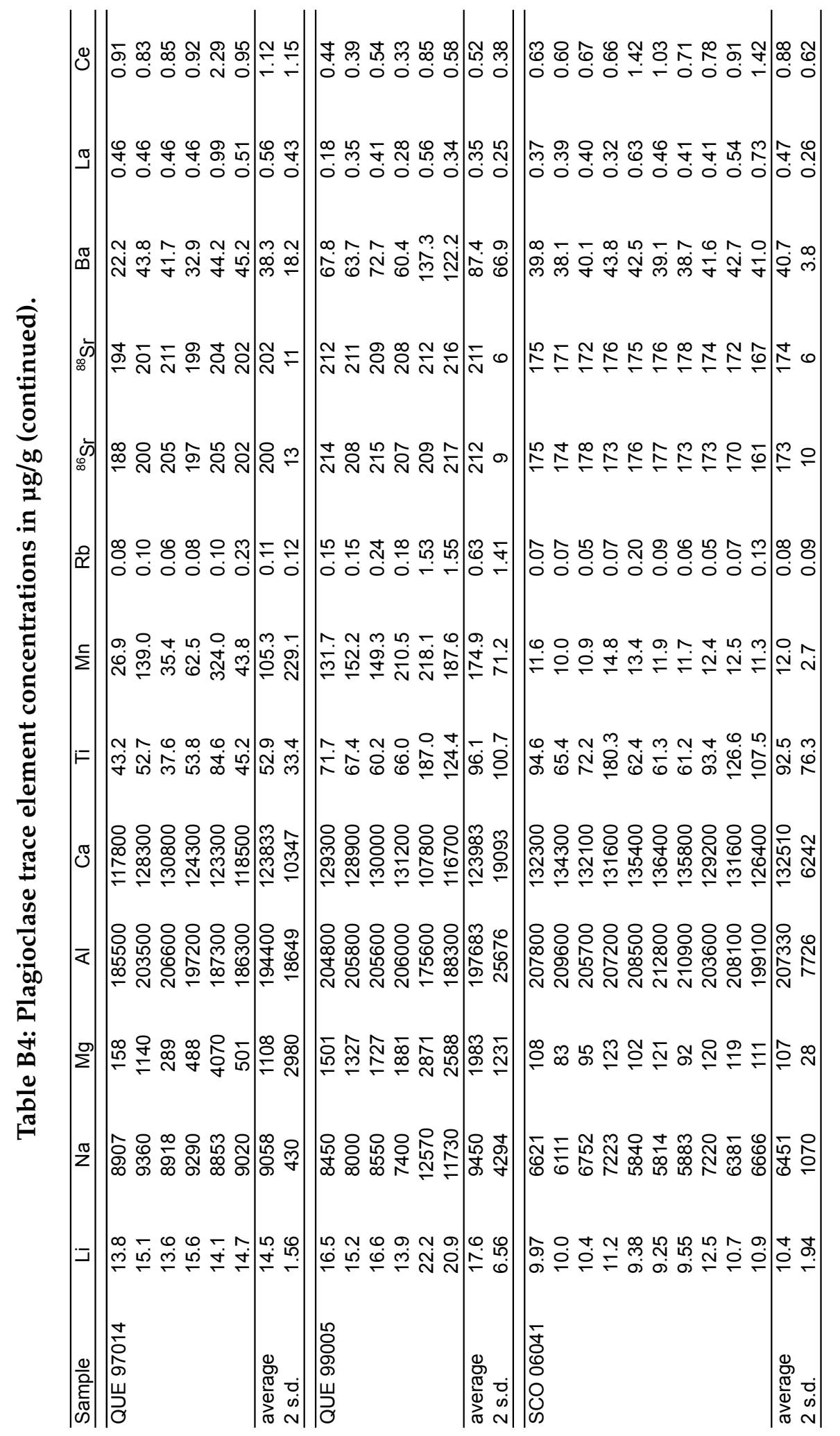




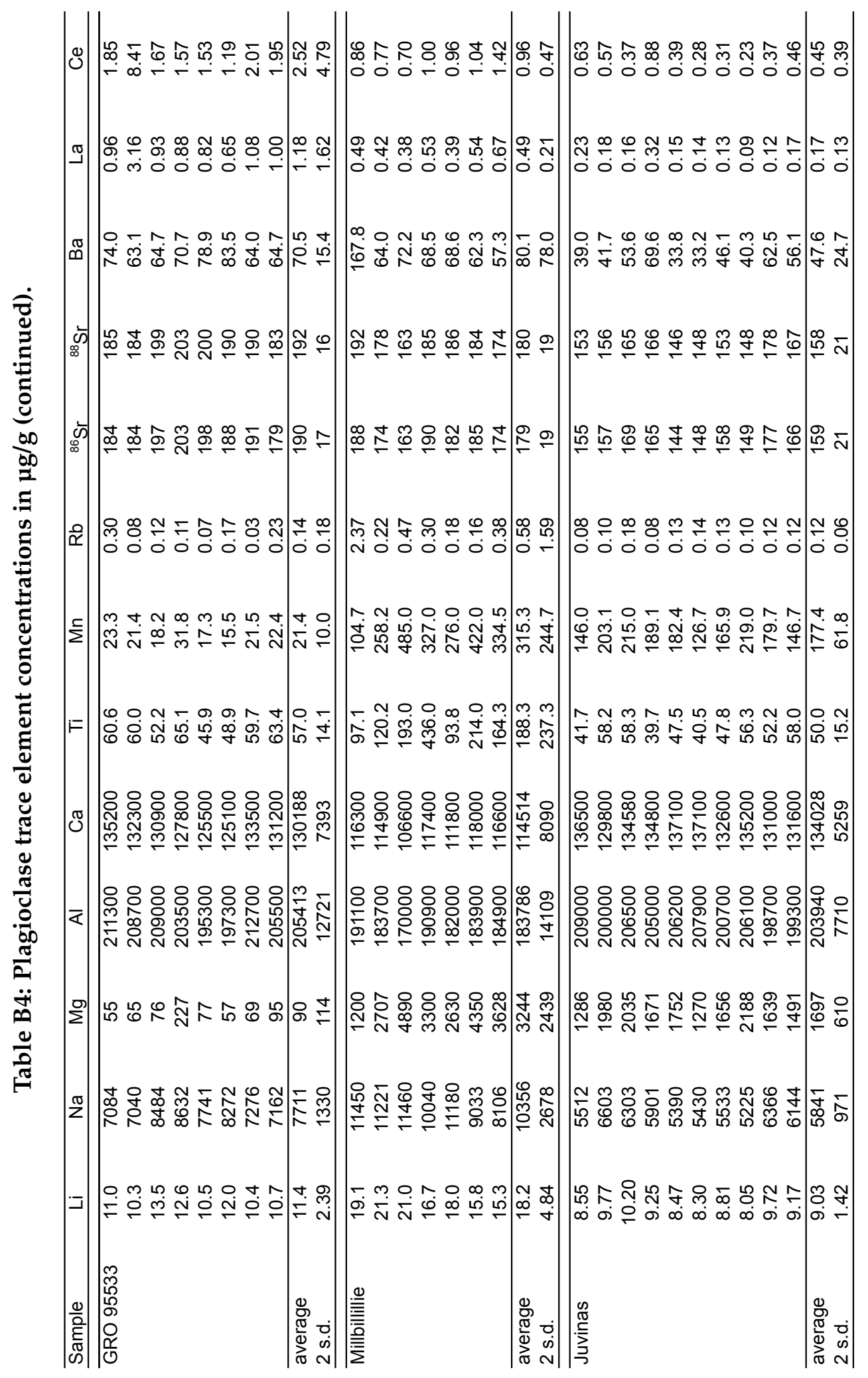




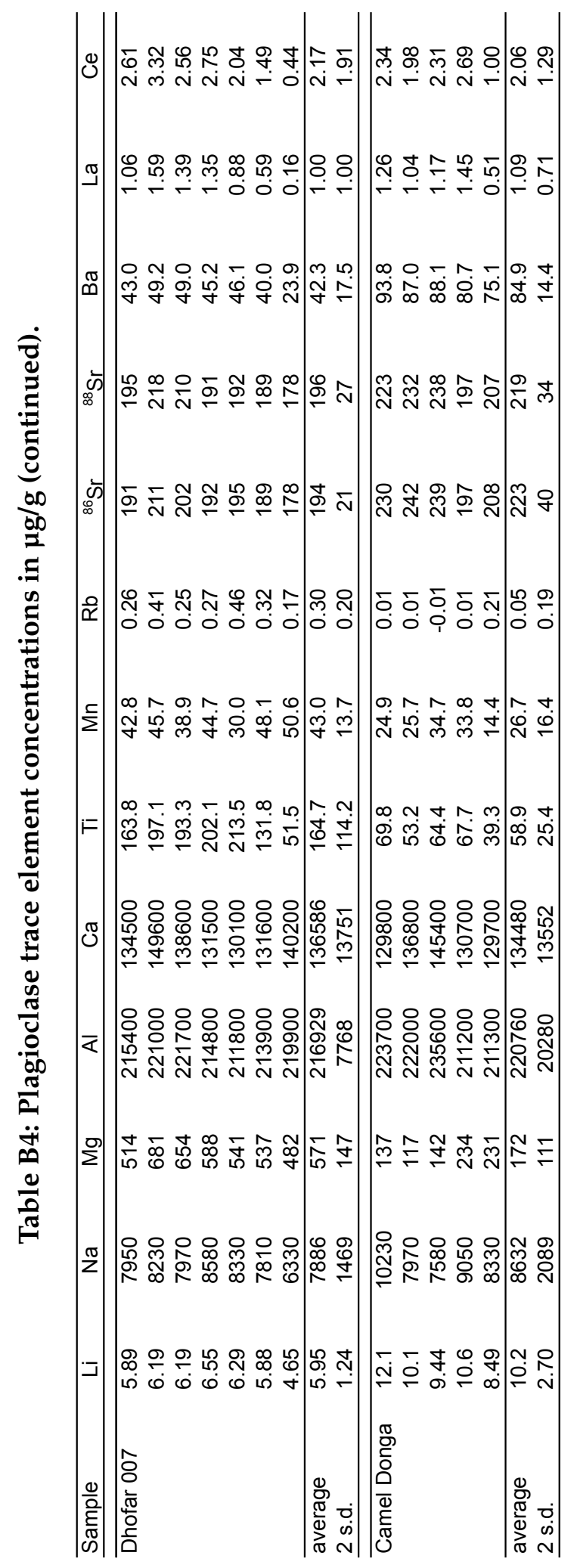


Table B4: Plagioclase trace element concentrations in $\mu g / g$ (continued).

\begin{tabular}{|c|c|c|c|c|c|c|}
\hline Sample & $\mathrm{Pr}$ & $\mathrm{Nd}$ & $\mathrm{Sm}$ & ${ }^{151} \mathrm{Eu}$ & ${ }^{153} \mathrm{Eu}$ & $\mathrm{Gd}$ \\
\hline \multirow[t]{6}{*}{ EET 83227} & 0.37 & 1.56 & 0.29 & 1.53 & 1.41 & 0.24 \\
\hline & 0.10 & 0.44 & 0.12 & 1.46 & 1.56 & 0.09 \\
\hline & 0.10 & 0.38 & 0.10 & 1.42 & 1.47 & 0.11 \\
\hline & 0.09 & 0.39 & 0.12 & 1.42 & 1.40 & 0.11 \\
\hline & 0.13 & 0.59 & 0.27 & 1.48 & 1.37 & 0.20 \\
\hline & 0.25 & 1.24 & 0.30 & 1.30 & 1.32 & 0.26 \\
\hline average & 0.17 & 0.76 & 0.20 & 1.43 & 1.42 & 0.17 \\
\hline 2 s.d. & 0.23 & 1.02 & 0.19 & 0.16 & 0.17 & 0.15 \\
\hline \multirow[t]{12}{*}{ EET 87548} & 0.05 & 0.29 & 0.12 & 0.83 & 0.84 & 0.06 \\
\hline & 0.06 & 0.11 & 0.09 & 0.92 & 0.91 & 0.07 \\
\hline & 0.05 & 0.18 & 0.09 & 0.93 & 0.93 & 0.06 \\
\hline & 0.05 & 0.27 & 0.04 & 0.90 & 0.90 & 0.07 \\
\hline & 0.05 & 0.13 & 0.00 & 0.88 & 0.84 & 0.08 \\
\hline & 0.06 & 0.19 & 0.03 & 0.96 & 1.00 & 0.09 \\
\hline & 0.05 & 0.21 & 0.07 & 0.95 & 0.99 & 0.03 \\
\hline & 0.05 & 0.20 & 0.08 & 0.96 & 1.01 & 0.00 \\
\hline & 0.05 & 0.20 & 0.01 & 0.90 & 0.89 & 0.00 \\
\hline & 0.06 & 0.22 & 0.07 & 0.90 & 0.90 & 0.06 \\
\hline & 0.06 & 0.20 & 0.08 & 0.94 & 0.95 & 0.01 \\
\hline & 0.06 & 0.23 & 0.10 & 0.92 & 0.91 & 0.03 \\
\hline average & 0.05 & 0.20 & 0.07 & 0.92 & 0.92 & 0.05 \\
\hline 2 s.d. & 0.01 & 0.10 & 0.07 & 0.07 & 0.11 & 0.06 \\
\hline \multirow[t]{10}{*}{ EET 92003} & 0.21 & 1.00 & 0.28 & 1.29 & 1.27 & 0.24 \\
\hline & 0.19 & 0.83 & 0.20 & 1.43 & 1.54 & 0.13 \\
\hline & 0.19 & 0.83 & 0.20 & 1.43 & 1.45 & 0.16 \\
\hline & 0.29 & 1.25 & 0.25 & 1.65 & 1.57 & 0.27 \\
\hline & 0.07 & 0.26 & 0.07 & 1.46 & 1.37 & 0.09 \\
\hline & 0.18 & 0.60 & 0.18 & 1.51 & 1.47 & 0.13 \\
\hline & 0.11 & 0.47 & 0.15 & 1.37 & 1.32 & 0.12 \\
\hline & 0.41 & 2.07 & 0.56 & 1.35 & 1.37 & 0.65 \\
\hline & 0.25 & 1.28 & 0.31 & 1.41 & 1.32 & 0.27 \\
\hline & 0.13 & 0.69 & 0.20 & 1.38 & 1.40 & 0.14 \\
\hline average & 0.20 & 0.93 & 0.24 & 1.43 & 1.41 & 0.22 \\
\hline 2 s.d. & 0.19 & 1.03 & 0.26 & 0.20 & 0.20 & 0.33 \\
\hline
\end{tabular}


Table B4: Plagioclase trace element concentrations in $\mu \mathrm{g} / \mathrm{g}$ (continued).

\begin{tabular}{|c|c|c|c|c|c|c|}
\hline Sample & $\mathrm{Pr}$ & $\mathrm{Nd}$ & $\mathrm{Sm}$ & ${ }^{151} \mathrm{Eu}$ & ${ }^{153} \mathrm{Eu}$ & $\mathrm{Gd}$ \\
\hline \multirow[t]{11}{*}{ EET 92023} & 0.20 & 0.83 & 0.18 & 1.41 & 1.34 & 0.14 \\
\hline & 0.19 & 0.73 & 0.10 & 1.37 & 1.41 & 0.11 \\
\hline & 0.11 & 0.41 & 0.16 & 1.46 & 1.38 & 0.11 \\
\hline & 0.15 & 0.62 & 0.14 & 1.37 & 1.42 & 0.15 \\
\hline & 0.28 & 1.13 & 0.18 & 1.35 & 1.45 & 0.13 \\
\hline & 0.27 & 1.28 & 0.19 & 1.41 & 1.46 & 0.27 \\
\hline & 0.22 & 0.90 & 0.16 & 1.32 & 1.48 & 0.21 \\
\hline & 0.19 & 0.78 & 0.19 & 1.36 & 1.37 & 0.16 \\
\hline & 0.21 & 0.80 & 0.20 & 1.32 & 1.40 & 0.14 \\
\hline & 0.05 & 0.38 & 0.10 & 1.21 & 1.17 & 0.02 \\
\hline & 0.07 & 0.30 & 0.13 & 1.28 & 1.28 & 0.14 \\
\hline average & 0.17 & 0.74 & 0.16 & 1.35 & 1.38 & 0.14 \\
\hline 2 s.d. & 0.15 & 0.61 & 0.07 & 0.13 & 0.18 & 0.13 \\
\hline \multirow[t]{7}{*}{$\overline{\text { GRA } 98006}$} & 0.11 & 0.54 & 0.09 & 1.34 & 1.22 & 0.08 \\
\hline & 0.08 & 0.34 & 0.05 & 1.23 & 1.28 & 0.14 \\
\hline & 0.10 & 0.38 & 0.10 & 1.19 & 1.19 & 0.02 \\
\hline & 0.10 & 0.40 & 0.12 & 1.21 & 1.28 & 0.14 \\
\hline & 0.10 & 0.34 & 0.11 & 1.22 & 1.33 & 0.06 \\
\hline & 0.08 & 0.33 & 0.12 & 1.22 & 1.24 & 0.05 \\
\hline & 0.06 & 0.27 & 0.04 & 1.26 & 1.35 & 0.01 \\
\hline average & 0.09 & 0.37 & 0.09 & 1.24 & 1.27 & 0.07 \\
\hline 2 s.d. & 0.03 & 0.17 & 0.07 & 0.10 & 0.11 & 0.10 \\
\hline \multirow[t]{9}{*}{ GRA 98033} & 0.14 & 0.60 & 0.13 & 1.47 & 1.47 & 0.13 \\
\hline & 0.13 & 0.56 & 0.13 & 1.48 & 1.42 & 0.13 \\
\hline & 0.15 & 0.50 & 0.10 & 1.57 & 1.58 & 0.11 \\
\hline & 0.16 & 0.66 & 0.12 & 1.61 & 1.64 & 0.17 \\
\hline & 0.13 & 0.64 & 0.15 & 1.53 & 1.61 & 0.15 \\
\hline & 0.14 & 0.63 & 0.14 & 1.47 & 1.43 & 0.15 \\
\hline & 0.12 & 0.56 & 0.14 & 1.51 & 1.64 & 0.11 \\
\hline & 0.14 & 0.67 & 0.18 & 1.52 & 1.56 & 0.11 \\
\hline & 0.12 & 0.52 & 0.12 & 1.51 & 1.52 & 0.15 \\
\hline average & $\overline{0.14}$ & 0.59 & 0.13 & 1.52 & 1.54 & 0.13 \\
\hline 2 s.d. & 0.03 & 0.12 & 0.04 & 0.09 & 0.17 & 0.04 \\
\hline
\end{tabular}


Table B4: Plagioclase trace element concentrations in $\mu \mathrm{g} / \mathrm{g}$ (continued).

\begin{tabular}{|c|c|c|c|c|c|c|}
\hline Sample & $\mathrm{Pr}$ & $\mathrm{Nd}$ & $\mathrm{Sm}$ & ${ }^{151} \mathrm{Eu}$ & ${ }^{153} \mathrm{Eu}$ & $\mathrm{Gd}$ \\
\hline \multirow[t]{8}{*}{ GRA 98043} & 0.20 & 3.20 & 0.37 & 1.56 & 1.56 & 0.39 \\
\hline & 0.27 & 1.40 & 0.38 & 1.45 & 1.45 & 0.44 \\
\hline & 0.11 & 0.56 & 0.13 & 1.61 & 1.61 & 0.15 \\
\hline & 0.17 & 0.72 & 0.19 & 1.44 & 1.41 & 0.26 \\
\hline & 0.17 & 0.80 & 0.25 & 1.46 & 1.39 & 0.40 \\
\hline & 0.18 & 0.94 & 0.31 & 1.40 & 1.53 & 0.32 \\
\hline & 0.22 & 0.96 & 0.29 & 1.57 & 1.52 & 0.32 \\
\hline & 0.15 & 0.64 & 0.18 & 1.54 & 1.46 & 0.16 \\
\hline average & 0.18 & 1.15 & 0.26 & 1.50 & 1.49 & 0.30 \\
\hline 2 s.d. & 0.09 & 1.74 & 0.19 & 0.15 & 0.15 & 0.22 \\
\hline \multirow[t]{7}{*}{ GRA 98114} & 0.17 & 0.66 & 0.16 & 1.42 & 1.39 & 0.13 \\
\hline & 0.16 & 0.53 & 0.11 & 1.25 & 1.35 & 0.14 \\
\hline & 0.09 & 0.33 & 0.17 & 1.42 & 1.37 & 0.17 \\
\hline & 0.11 & 0.41 & 0.12 & 1.33 & 1.34 & 0.14 \\
\hline & 0.11 & 0.40 & 0.12 & 1.34 & 1.34 & 0.18 \\
\hline & 0.23 & 1.02 & 0.32 & 1.36 & 1.44 & 0.43 \\
\hline & 0.19 & 0.81 & 0.24 & 1.50 & 1.43 & 0.27 \\
\hline average & 0.15 & 0.60 & 0.18 & 1.38 & 1.38 & 0.21 \\
\hline 2 s.d. & 0.10 & 0.50 & 0.15 & 0.16 & 0.08 & 0.22 \\
\hline \multirow[t]{4}{*}{ LAP031062 } & 0.12 & 0.51 & 0.19 & 2.02 & 2.01 & 0.18 \\
\hline & 0.18 & 0.71 & 0.23 & 2.04 & 1.99 & 0.17 \\
\hline & 0.39 & 1.73 & 0.54 & 2.15 & 2.21 & 0.40 \\
\hline & 0.16 & 0.62 & 0.16 & 1.73 & 1.84 & 0.09 \\
\hline average & 0.21 & 0.89 & 0.28 & 1.99 & 2.01 & 0.21 \\
\hline 2 s.d. & 0.25 & 1.13 & 0.35 & 0.36 & 0.30 & 0.26 \\
\hline \multirow[t]{4}{*}{$\overline{L A R} 06875$} & 0.28 & 1.40 & 0.29 & 1.70 & 1.84 & 0.54 \\
\hline & 0.33 & 1.71 & 0.51 & 1.64 & 1.64 & 0.64 \\
\hline & 0.53 & 2.56 & 0.75 & 1.80 & 1.60 & 0.80 \\
\hline & 1.05 & 4.61 & 1.51 & 1.76 & 1.85 & 1.50 \\
\hline average & 0.55 & 2.57 & 0.77 & 1.73 & 1.73 & 0.87 \\
\hline 2 s.d. & 0.70 & 2.89 & 1.06 & 0.14 & 0.26 & 0.87 \\
\hline
\end{tabular}


Table B4: Plagioclase trace element concentrations in $\mu \mathrm{g} / \mathrm{g}$ (continued).

\begin{tabular}{|c|c|c|c|c|c|c|}
\hline Sample & $\mathrm{Pr}$ & $\mathrm{Nd}$ & $\mathrm{Sm}$ & ${ }^{151} \mathrm{Eu}$ & ${ }^{153} \mathrm{Eu}$ & $\mathrm{Gd}$ \\
\hline \multirow[t]{10}{*}{ LEW 85305} & 0.27 & 1.16 & 0.29 & 1.92 & 1.93 & 0.22 \\
\hline & 0.37 & 1.54 & 0.24 & 1.85 & 1.89 & 0.32 \\
\hline & 0.32 & 1.23 & 0.22 & 1.83 & 1.79 & 0.20 \\
\hline & 0.28 & 1.12 & 0.25 & 1.89 & 1.85 & 0.22 \\
\hline & 0.28 & 0.98 & 0.30 & 1.88 & 1.90 & 0.16 \\
\hline & 0.43 & 1.85 & 0.25 & 1.84 & 1.81 & 0.30 \\
\hline & 0.37 & 1.49 & 0.26 & 1.99 & 1.99 & 0.22 \\
\hline & 0.37 & 1.20 & 0.29 & 1.99 & 1.85 & 0.25 \\
\hline & 0.34 & 1.43 & 0.44 & 1.90 & 1.88 & 0.21 \\
\hline & 0.21 & 0.84 & 0.18 & 1.96 & 1.83 & 0.15 \\
\hline average & 0.32 & 1.28 & 0.27 & 1.90 & 1.87 & 0.23 \\
\hline 2 s.d. & 0.13 & 0.59 & 0.14 & 0.12 & 0.12 & 0.11 \\
\hline \multirow[t]{8}{*}{ LEW 87002} & 0.14 & 0.64 & 0.12 & 1.46 & 1.55 & 0.11 \\
\hline & 0.09 & 0.41 & 0.17 & 1.59 & 1.53 & 0.18 \\
\hline & 0.12 & 0.56 & 0.18 & 1.62 & 1.52 & 0.11 \\
\hline & 0.06 & 0.26 & 0.10 & 1.54 & 1.52 & 0.09 \\
\hline & 0.08 & 0.37 & 0.13 & 1.65 & 1.60 & 0.14 \\
\hline & 0.06 & 0.39 & 0.10 & 1.45 & 1.52 & 0.14 \\
\hline & 0.12 & 0.49 & 0.15 & 1.53 & 1.52 & 0.15 \\
\hline & 0.11 & 0.53 & 0.19 & 1.44 & 1.42 & 0.24 \\
\hline average & 0.10 & 0.46 & 0.14 & 1.53 & 1.52 & 0.14 \\
\hline 2 s.d. & 0.06 & 0.25 & 0.07 & 0.16 & 0.10 & 0.09 \\
\hline \multirow[t]{7}{*}{ PCA 91193} & 0.18 & 0.56 & 0.16 & 1.28 & 1.38 & 0.06 \\
\hline & 0.23 & 0.86 & 0.19 & 1.51 & 1.52 & 0.18 \\
\hline & 0.25 & 0.93 & 0.22 & 1.39 & 1.40 & 0.15 \\
\hline & 0.15 & 0.56 & 0.14 & 1.23 & 1.22 & 0.09 \\
\hline & 0.16 & 0.50 & 0.16 & 1.36 & 1.45 & 0.12 \\
\hline & 0.16 & 0.80 & 0.14 & 1.38 & 1.25 & 0.08 \\
\hline & 0.27 & 1.05 & 0.21 & 1.49 & 1.50 & 0.17 \\
\hline average & 0.20 & 0.75 & 0.17 & 1.38 & 1.39 & 0.12 \\
\hline 2 s.d. & 0.10 & 0.43 & 0.06 & 0.21 & 0.23 & 0.09 \\
\hline
\end{tabular}


Table B4: Plagioclase trace element concentrations in $\mu g / g$ (continued).

\begin{tabular}{lcccccc}
\hline Sample & $\mathrm{Pr}$ & $\mathrm{Nd}$ & $\mathrm{Sm}$ & ${ }^{151} \mathrm{Eu}$ & ${ }^{153} \mathrm{Eu}$ & $\mathrm{Gd}$ \\
\hline \hline QUE 97014 & 0.11 & 0.44 & 0.10 & 1.38 & 1.45 & 0.13 \\
& 0.10 & 0.38 & 0.08 & 1.62 & 1.58 & 0.09 \\
& 0.10 & 0.47 & 0.12 & 1.65 & 1.58 & 0.14 \\
& 0.10 & 0.41 & 0.12 & 1.47 & 1.45 & 0.15 \\
& 0.26 & 1.31 & 0.33 & 1.53 & 1.52 & 0.43 \\
& 0.11 & 0.42 & 0.15 & 1.59 & 1.54 & 0.11 \\
\hline average & 0.13 & 0.57 & 0.15 & 1.54 & 1.52 & 0.17 \\
2 s.d. & 0.13 & 0.73 & 0.18 & 0.21 & 0.11 & 0.26 \\
\hline QUE 99005 & 0.05 & 0.26 & 0.12 & 1.65 & 1.60 & 0.09 \\
& 0.10 & 0.27 & 0.12 & 1.68 & 1.64 & 0.17 \\
& 0.11 & 0.68 & 0.22 & 1.62 & 1.62 & 0.19 \\
& 0.06 & 0.43 & 0.10 & 1.54 & 1.59 & 0.03 \\
& 0.19 & 0.91 & 0.21 & 1.67 & 1.70 & 0.33 \\
average & 0.13 & 0.39 & 0.22 & 1.64 & 1.66 & 0.13 \\
\hline 2 s.d. & 0.11 & 0.49 & 0.17 & 1.63 & 1.64 & 0.16 \\
\hline SCO 06041 & 0.10 & 0.51 & 0.11 & 0.10 & 0.08 & 0.21 \\
\hline & 0.08 & 0.30 & 0.06 & 1.22 & 1.26 & 0.09 \\
& 0.07 & 0.27 & -0.02 & 1.13 & 1.16 & 0.07 \\
& 0.07 & 0.28 & 0.11 & 1.22 & 1.21 & 0.07 \\
& 0.06 & 0.31 & 0.12 & 1.20 & 1.17 & 0.05 \\
& 0.16 & 0.60 & 0.16 & 1.20 & 1.13 & 0.10 \\
& 0.13 & 0.44 & 0.02 & 1.19 & 1.22 & 0.05 \\
& 0.08 & 0.26 & 0.15 & 1.08 & 1.25 & 0.14 \\
& 0.07 & 0.39 & 0.07 & 1.09 & 1.17 & 0.12 \\
& 0.11 & 0.38 & 0.08 & 1.15 & 1.15 & 0.04 \\
& 0.13 & 0.51 & 0.12 & 1.09 & 1.11 & 0.14 \\
\hline & 0.09 & 0.37 & 0.09 & 1.15 & 1.18 & 0.09 \\
& 0.07 & 0.23 & 0.11 & 0.11 & 0.10 & 0.07 \\
\hline & & & & & &
\end{tabular}


Table B4: Plagioclase trace element concentrations in $\mu \mathrm{g} / \mathrm{g}$ (continued).

\begin{tabular}{|c|c|c|c|c|c|c|}
\hline Sample & $\mathrm{Pr}$ & $\mathrm{Nd}$ & $\mathrm{Sm}$ & ${ }^{151} \mathrm{Eu}$ & ${ }^{153} \mathrm{Eu}$ & $\mathrm{Gd}$ \\
\hline \multirow[t]{8}{*}{ GRO 95533} & 0.18 & 0.70 & 0.18 & 1.31 & 1.34 & 0.14 \\
\hline & 1.04 & 4.29 & 1.00 & 1.33 & 1.30 & 0.69 \\
\hline & 0.19 & 0.66 & 0.13 & 1.46 & 1.57 & 0.17 \\
\hline & 0.16 & 0.61 & 0.11 & 1.55 & 1.55 & 0.14 \\
\hline & 0.16 & 0.65 & 0.11 & 1.57 & 1.55 & 0.10 \\
\hline & 0.11 & 0.51 & 0.17 & 1.54 & 1.46 & 0.05 \\
\hline & 0.20 & 0.85 & 0.17 & 1.39 & 1.48 & 0.16 \\
\hline & 0.21 & 0.77 & 0.17 & 1.24 & 1.32 & 0.08 \\
\hline average & 0.28 & 1.13 & 0.25 & 1.42 & 1.45 & 0.19 \\
\hline 2 s.d. & 0.62 & 2.56 & 0.61 & 0.25 & 0.22 & 0.41 \\
\hline \multirow[t]{7}{*}{ Millbillillie } & 0.09 & 0.52 & 0.05 & 1.61 & 1.50 & 0.13 \\
\hline & 0.09 & 0.40 & 0.14 & 1.36 & 1.32 & 0.10 \\
\hline & 0.10 & 0.43 & 0.11 & 1.22 & 1.26 & 0.13 \\
\hline & 0.11 & 0.51 & 0.13 & 1.50 & 1.55 & 0.15 \\
\hline & 0.11 & 0.42 & 0.15 & 1.36 & 1.42 & 0.19 \\
\hline & 0.10 & 0.54 & 0.13 & 1.42 & 1.41 & 0.12 \\
\hline & 0.16 & 0.62 & 0.17 & 1.28 & 1.27 & 0.16 \\
\hline average & 0.11 & 0.49 & 0.13 & 1.39 & 1.39 & $\overline{0.14}$ \\
\hline 2 s.d. & 0.05 & 0.16 & 0.08 & 0.27 & 0.23 & 0.06 \\
\hline \multirow[t]{10}{*}{ Juvinas } & 0.07 & 0.33 & 0.09 & 1.05 & 1.06 & 0.09 \\
\hline & 0.07 & 0.28 & 0.13 & 1.03 & 1.05 & 0.08 \\
\hline & 0.05 & 0.18 & 0.01 & 1.26 & 1.18 & 0.00 \\
\hline & 0.09 & 0.39 & 0.14 & 1.22 & 1.17 & 0.13 \\
\hline & 0.04 & 0.20 & 0.07 & 0.91 & 1.02 & 0.06 \\
\hline & 0.03 & 0.14 & 0.02 & 1.00 & 0.99 & 0.08 \\
\hline & 0.04 & 0.11 & 0.00 & 1.04 & 0.99 & 0.03 \\
\hline & 0.03 & 0.14 & 0.00 & 1.01 & 0.92 & 0.00 \\
\hline & 0.05 & 0.20 & 0.11 & 1.21 & 1.18 & 0.00 \\
\hline & 0.04 & 0.27 & 0.09 & 1.20 & 1.17 & 0.03 \\
\hline average & 0.05 & 0.22 & 0.07 & 1.09 & 1.07 & 0.05 \\
\hline 2 s.d. & 0.04 & 0.18 & 0.11 & 0.24 & 0.19 & 0.09 \\
\hline
\end{tabular}


Table B4: Plagioclase trace element concentrations in $\mu \mathrm{g} / \mathrm{g}$ (continued).

\begin{tabular}{lcccccc}
\hline Sample & $\mathrm{Pr}$ & $\mathrm{Nd}$ & $\mathrm{Sm}$ & ${ }^{151} \mathrm{Eu}$ & ${ }^{153} \mathrm{Eu}$ & $\mathrm{Gd}$ \\
\hline Dhofar 007 & 0.30 & 1.22 & 0.23 & 1.30 & 1.25 & 0.19 \\
& 0.35 & 1.59 & 0.19 & 1.35 & 1.37 & 0.19 \\
& 0.28 & 1.23 & 0.15 & 1.23 & 1.39 & 0.17 \\
& 0.31 & 1.29 & 0.24 & 1.23 & 1.27 & 0.22 \\
& 0.23 & 0.91 & 0.16 & 1.25 & 1.21 & 0.21 \\
& 0.20 & 0.93 & 0.19 & 1.21 & 1.31 & 0.23 \\
& 0.07 & 0.28 & 0.05 & 1.19 & 1.29 & 0.00 \\
\hline average & 0.25 & 1.06 & 0.17 & 1.25 & 1.30 & 0.17 \\
2 s.d. & 0.19 & 0.83 & 0.13 & 0.11 & 0.13 & 0.16 \\
\hline \hline Camel Donga & 0.27 & 0.89 & 0.21 & 1.43 & 1.70 & 0.15 \\
& 0.23 & 0.88 & 0.22 & 1.60 & 1.68 & 0.20 \\
& 0.26 & 1.06 & 0.13 & 1.72 & 1.79 & 0.17 \\
& 0.29 & 0.99 & 0.24 & 1.42 & 1.49 & 0.13 \\
& 0.13 & 0.42 & 0.09 & 1.66 & 1.64 & 0.05 \\
\hline average & 0.23 & 0.85 & 0.18 & 1.57 & 1.66 & 0.14 \\
2 s.d. & 0.13 & 0.50 & 0.13 & 0.27 & 0.22 & 0.12 \\
\hline
\end{tabular}




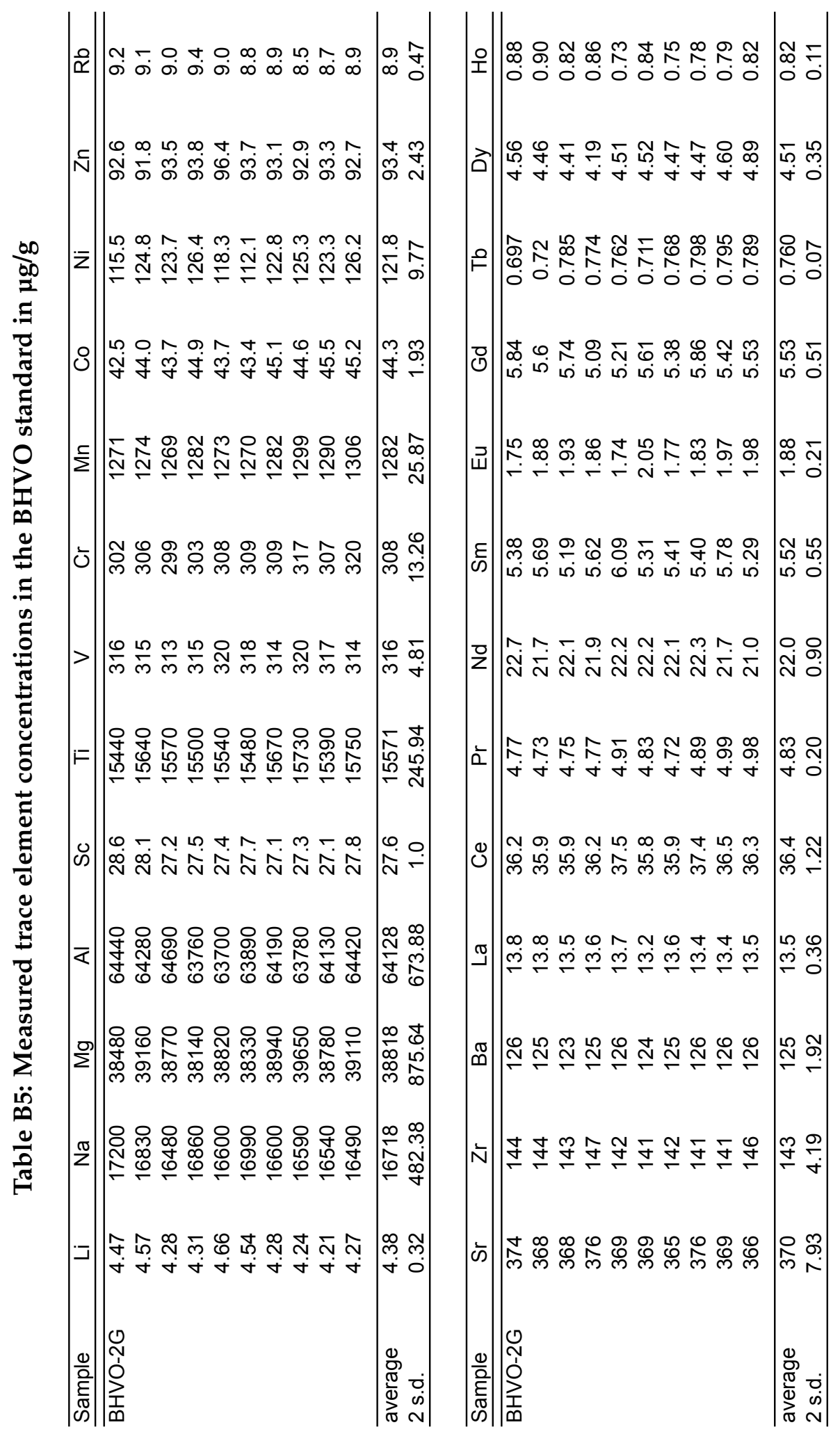




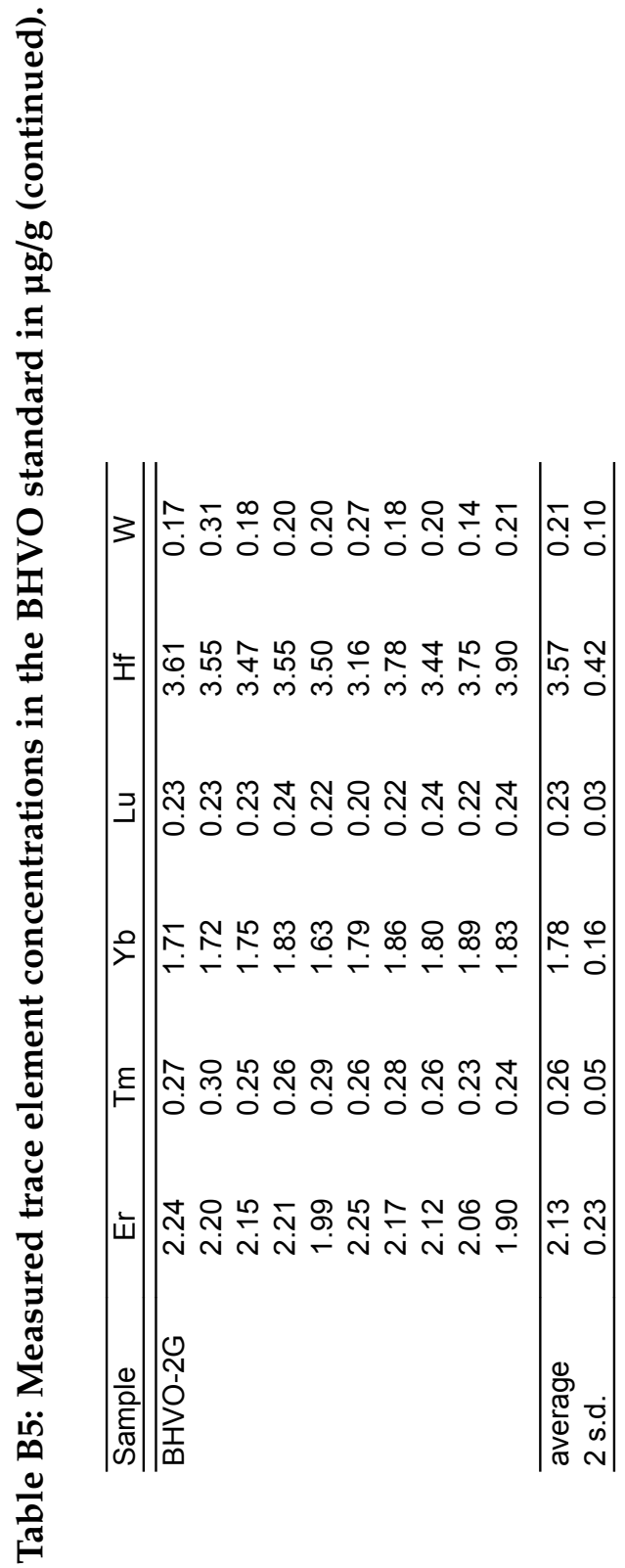




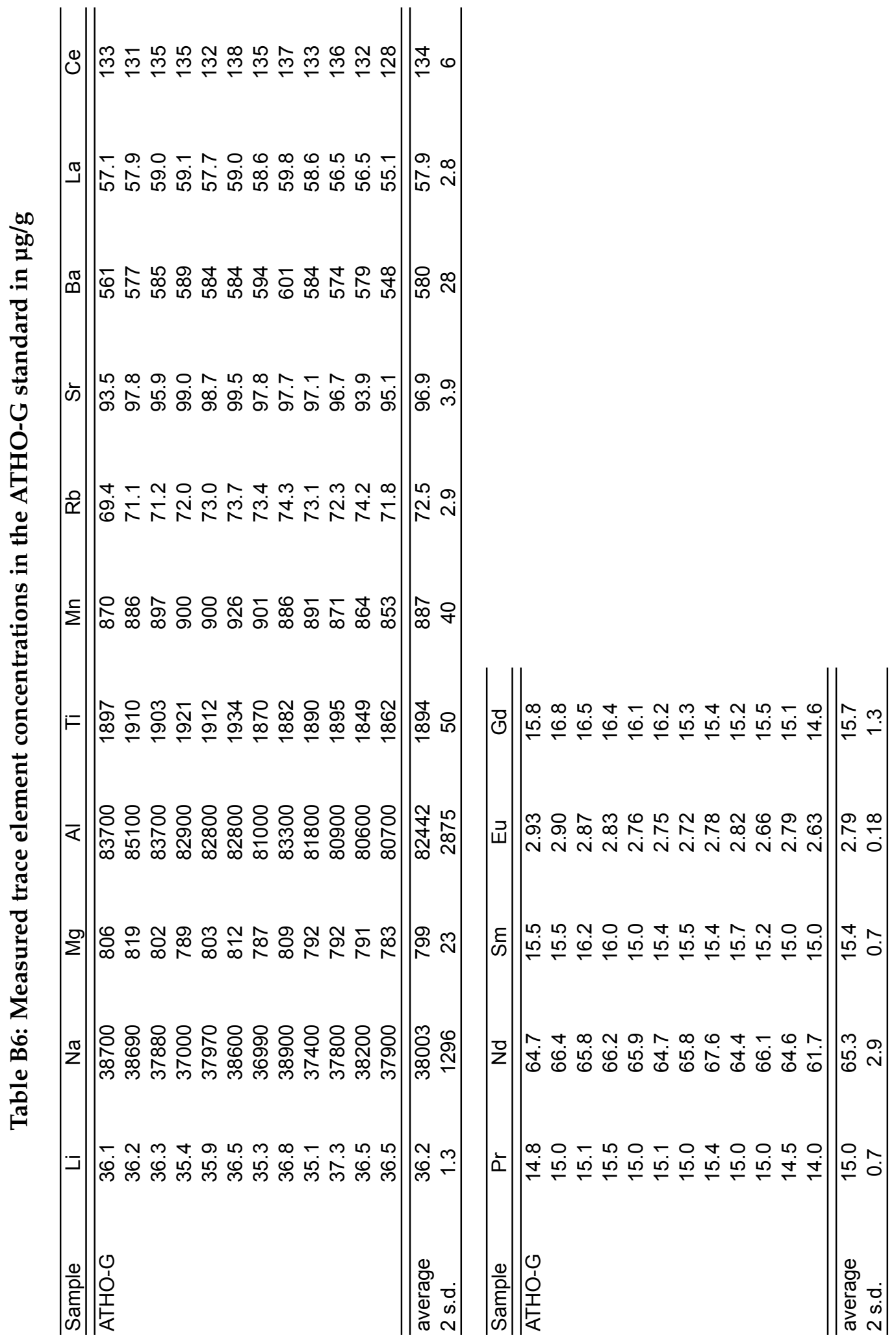




\section{Appendix C}

\section{Eucrite sample images}

The following are backscattered electron images of each eucrite sample used in this study taken using the JEOL SuperProbe JXA-8230 EPMA at Victoria University of Wellington. 


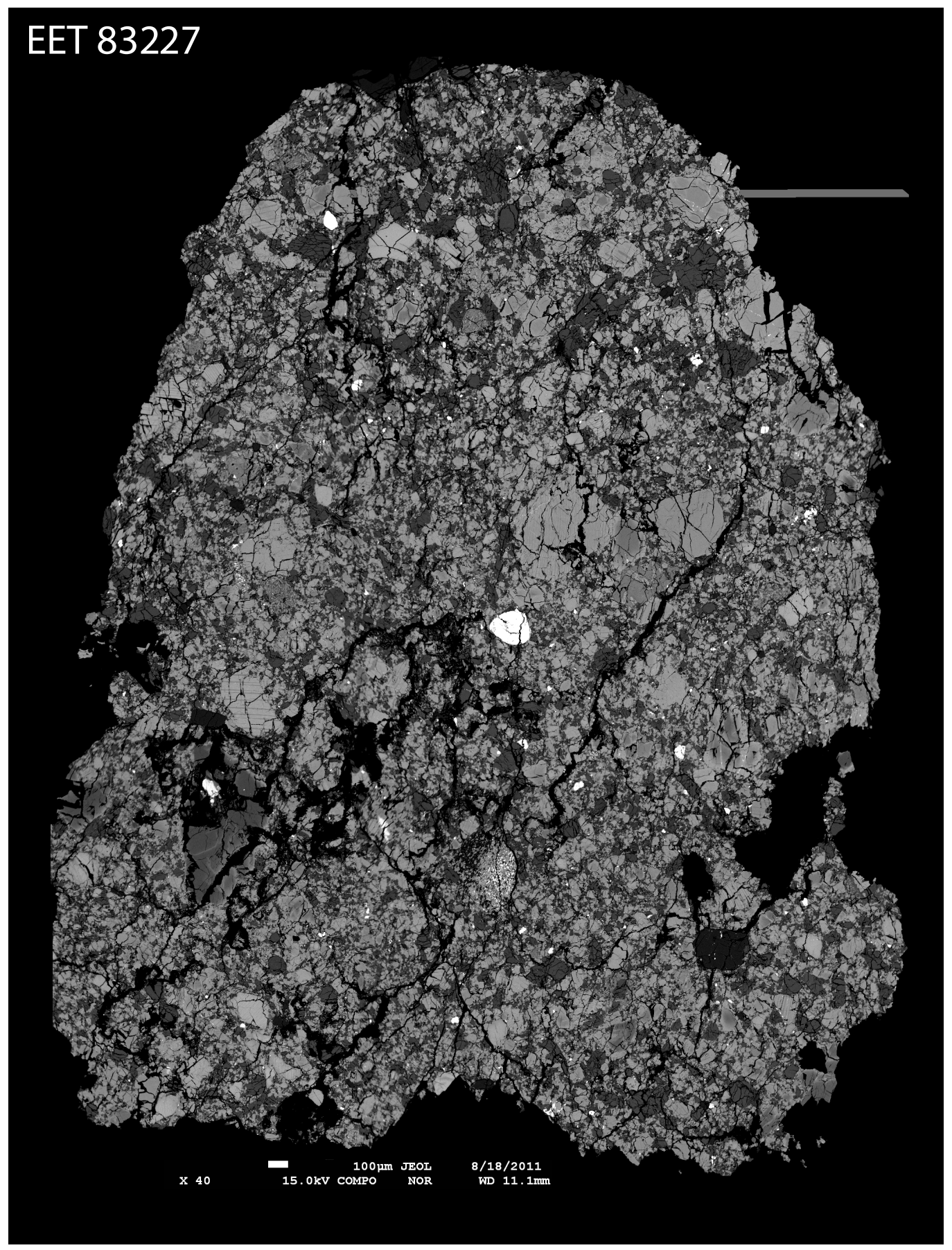

Figure C1: EET83227 


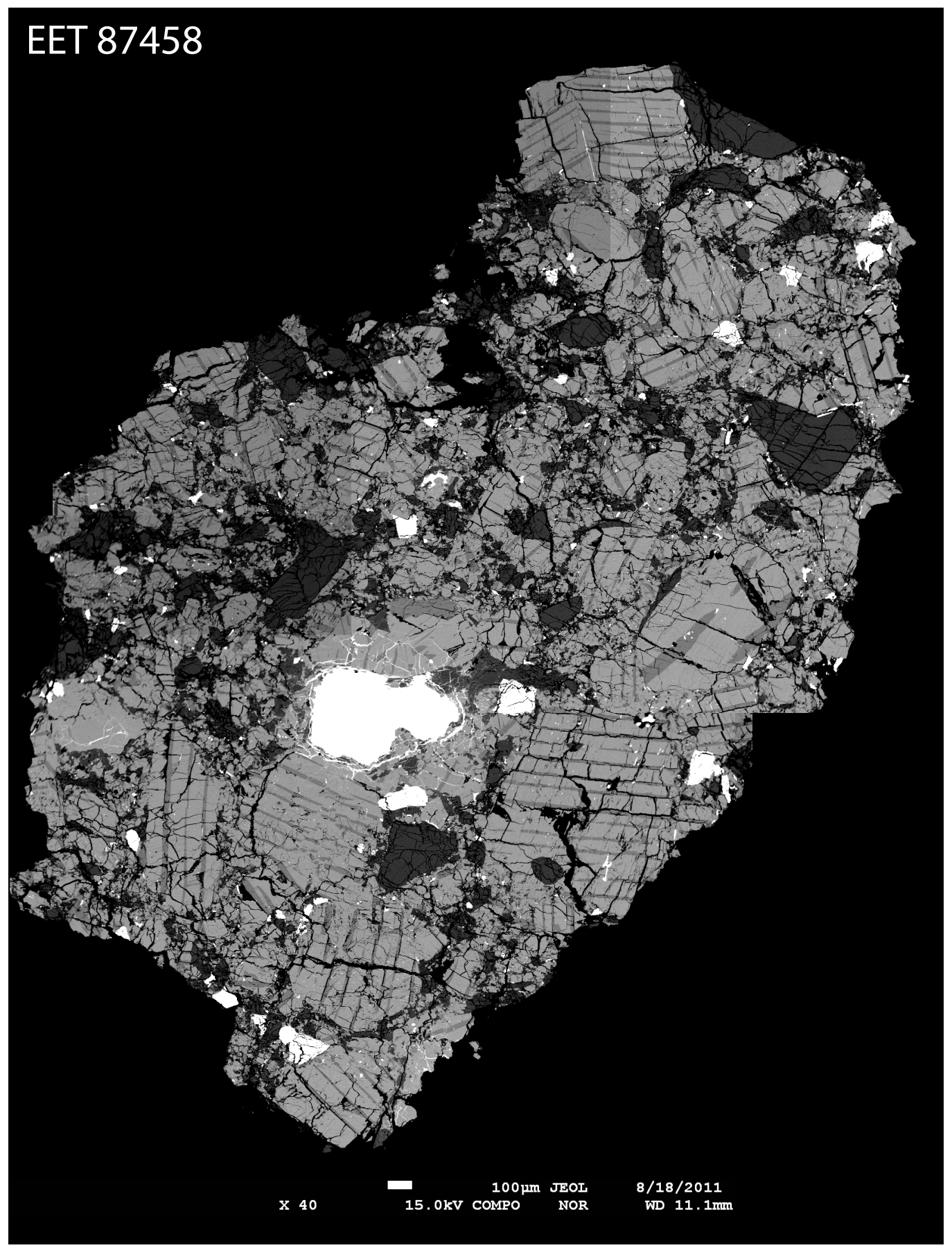

Figure C2: EET87458 


\section{EET 92003}

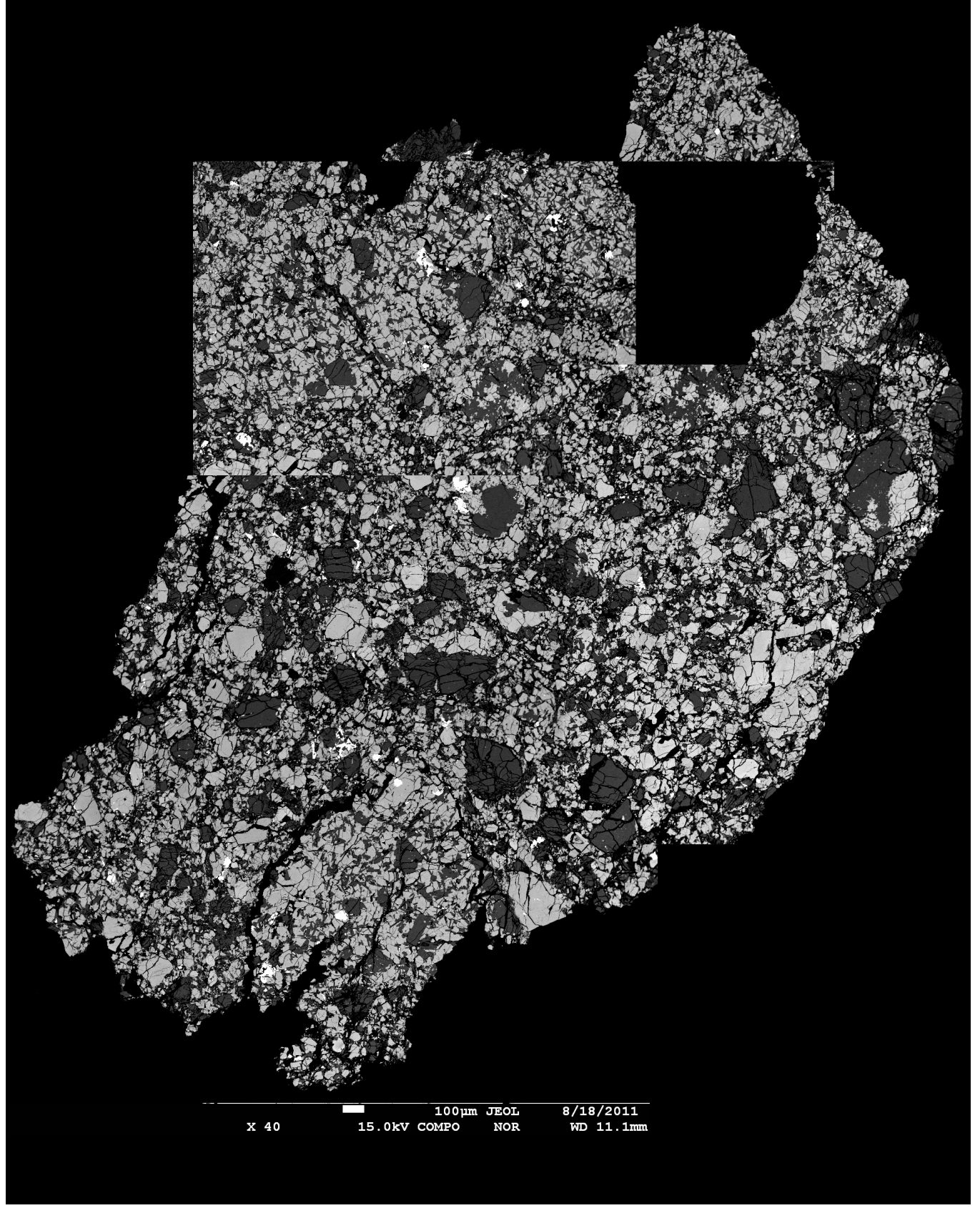

Figure C3: EET92003 


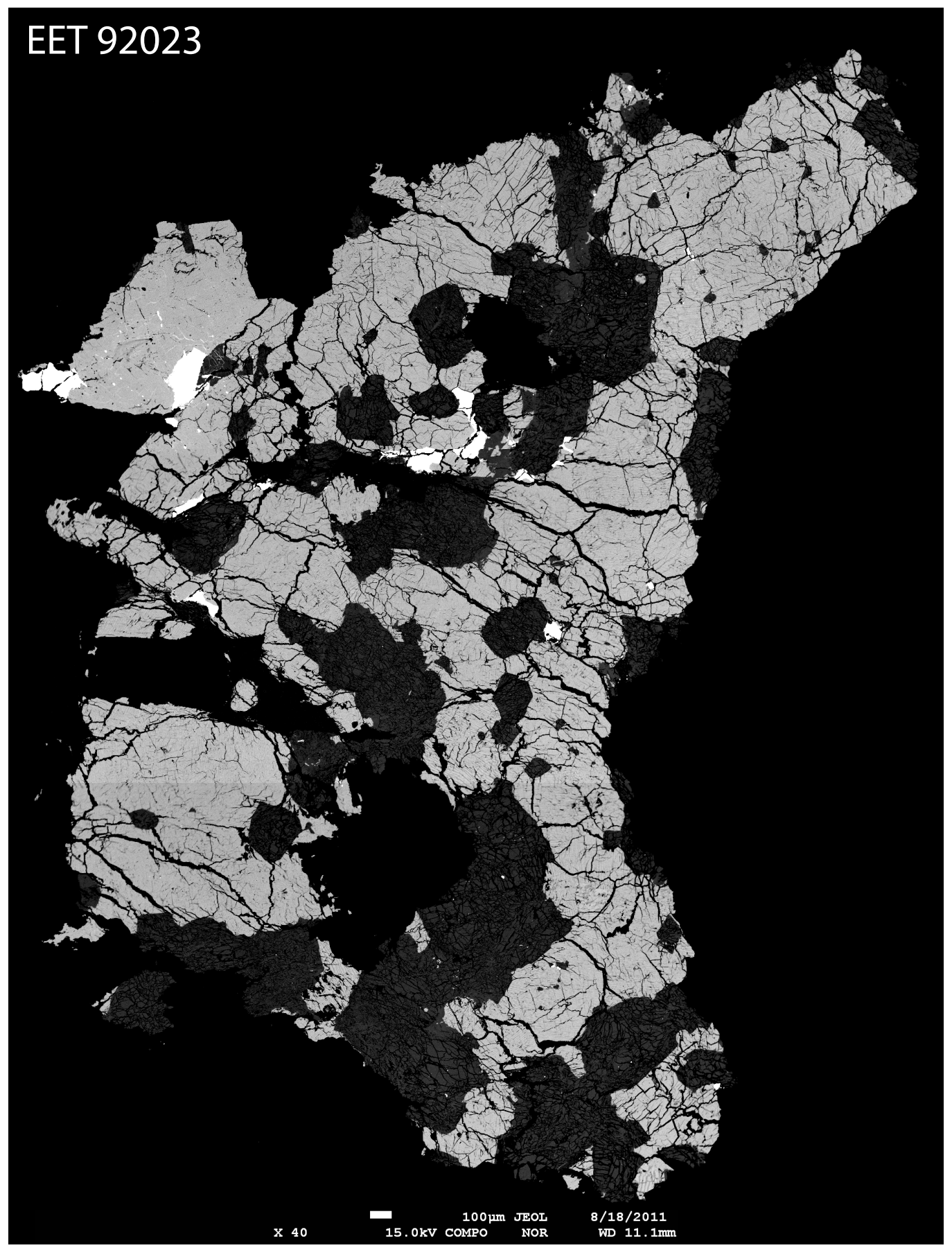

Figure C4: EET92023 


\section{GRA 98006}

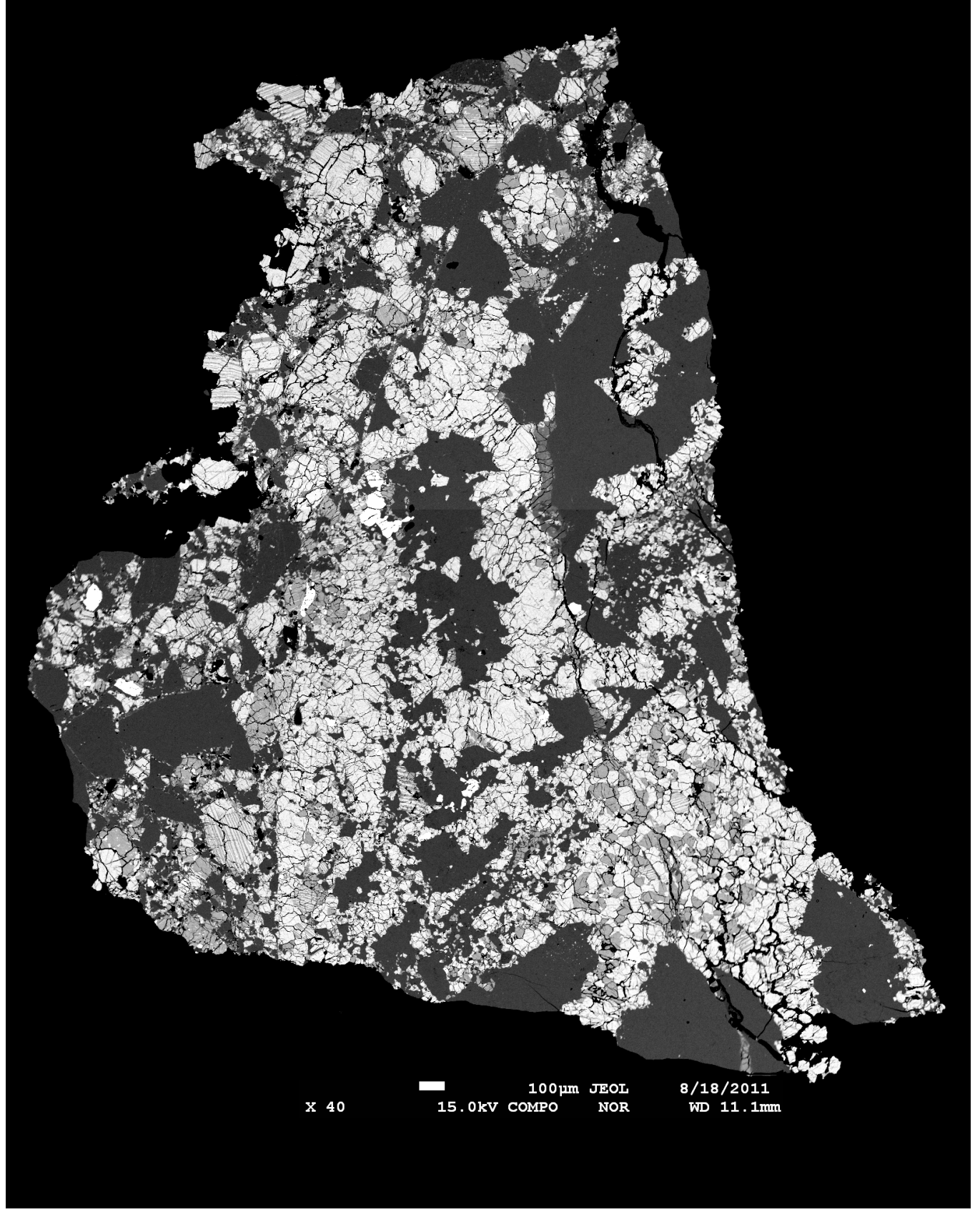

Figure C5: GRA98006 


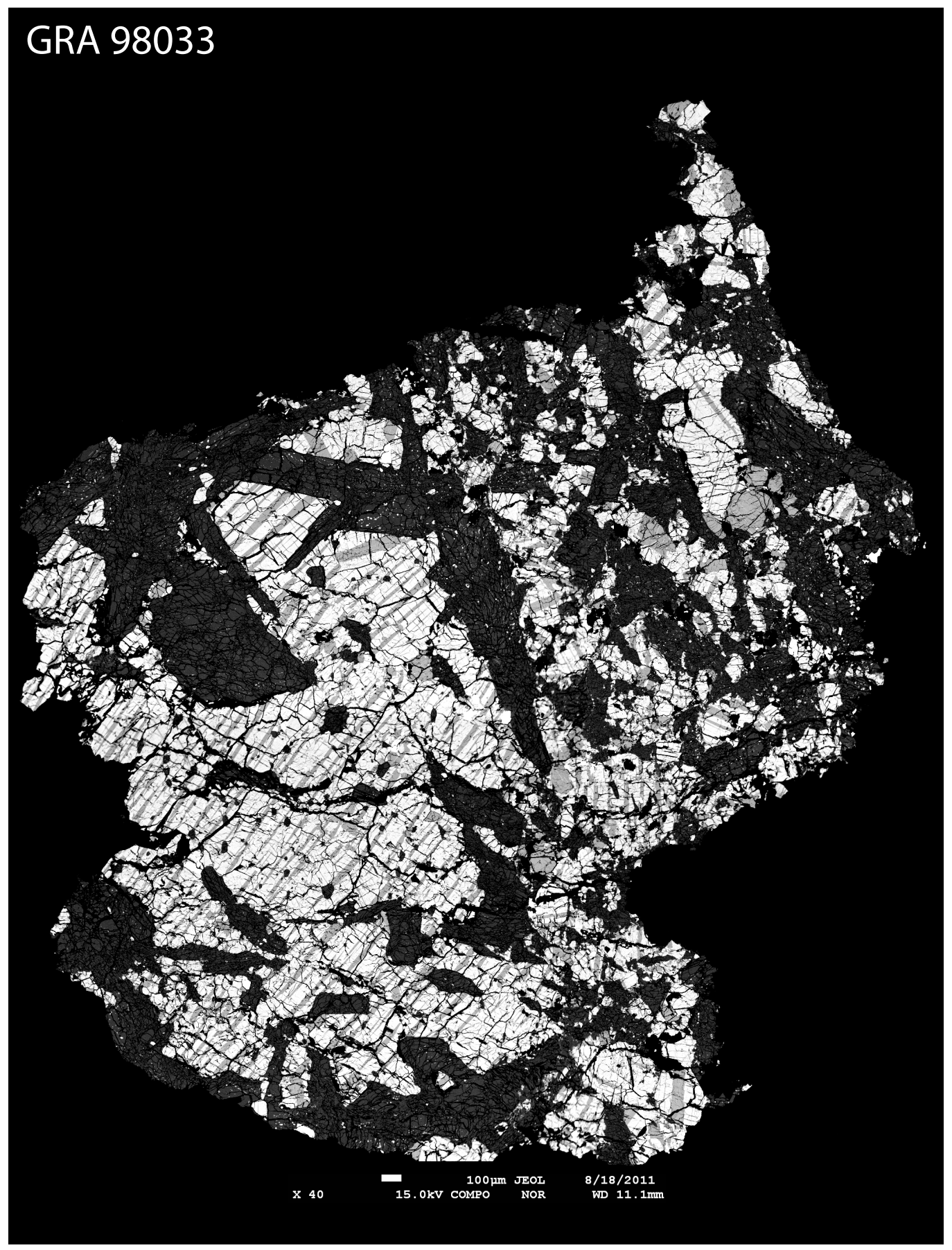

Figure C6: GRA98033 


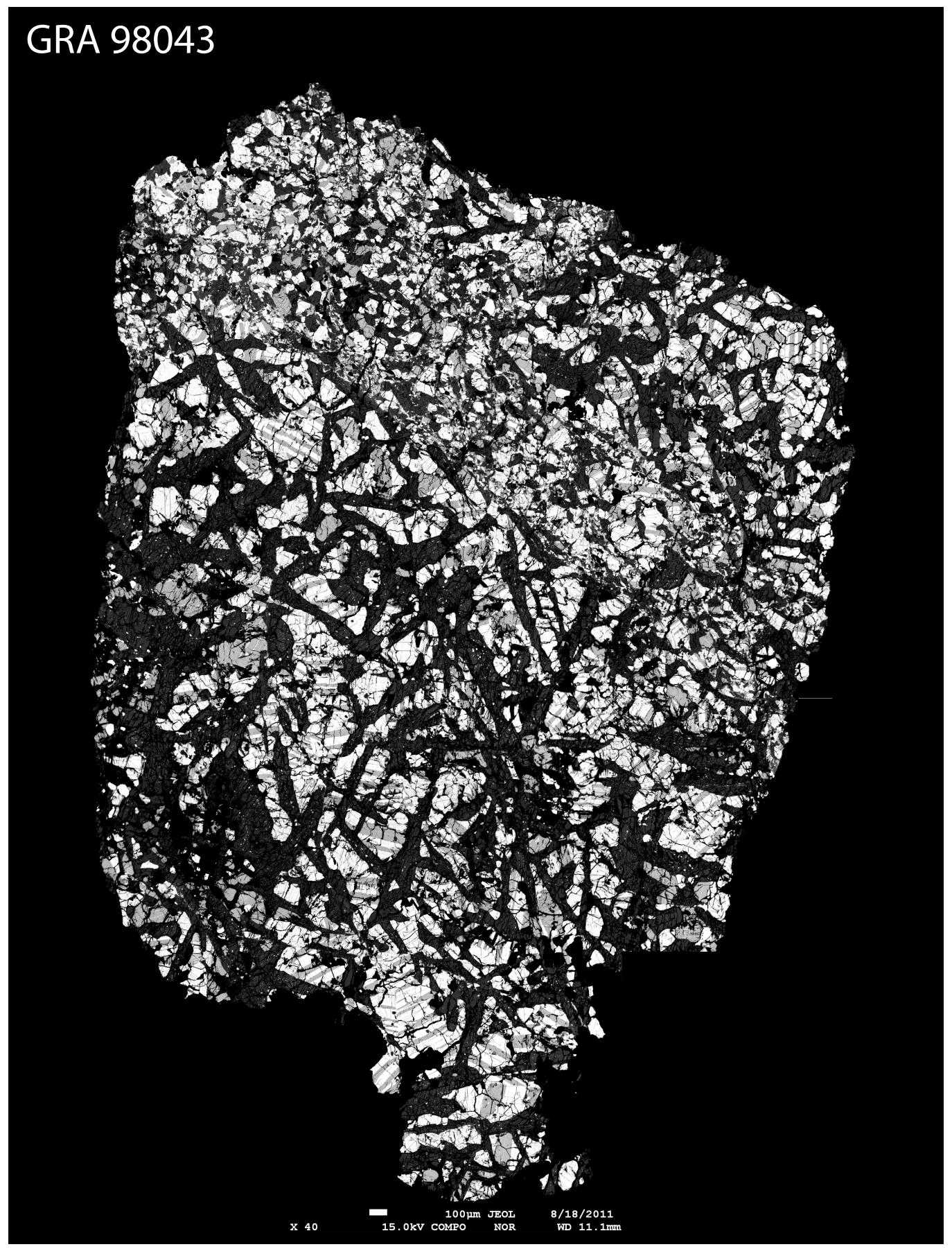

Figure C7: GRA98043 


\section{GRA 98055}

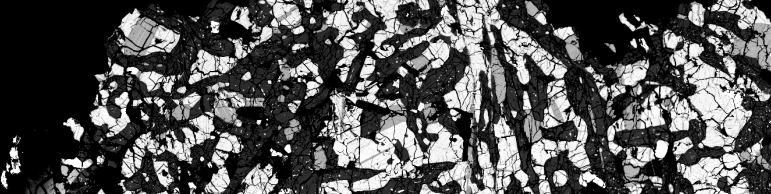

1.

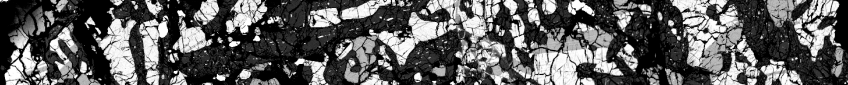

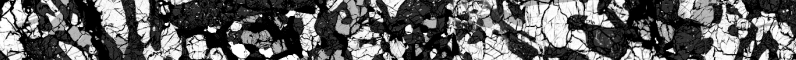

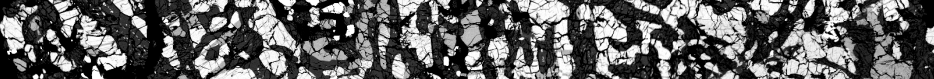

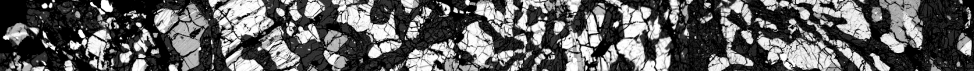

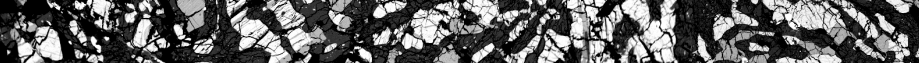

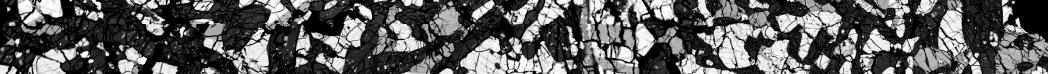

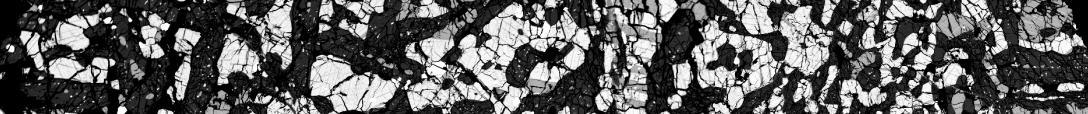

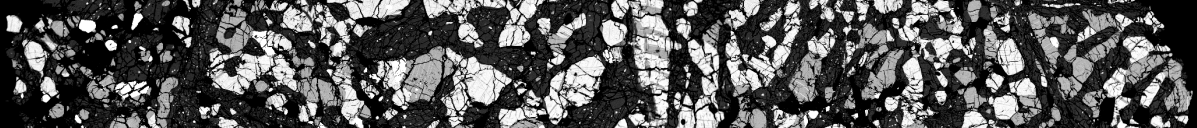

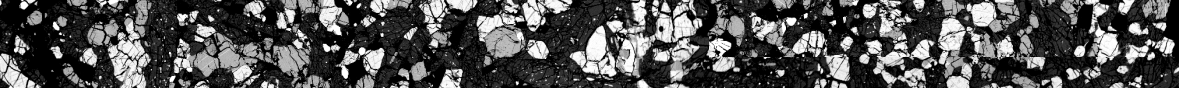

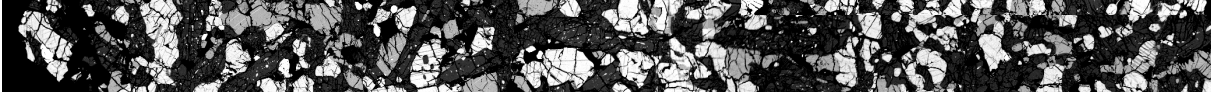

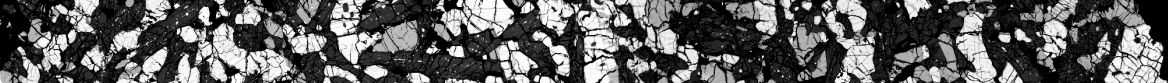

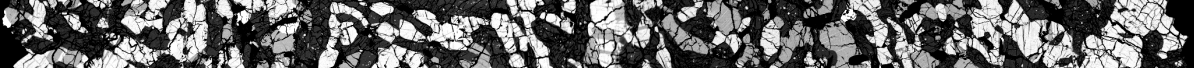

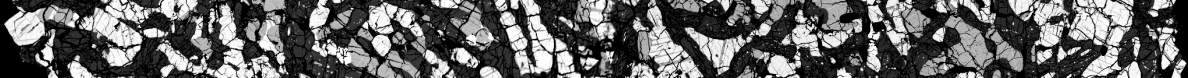

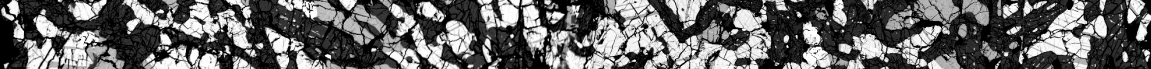

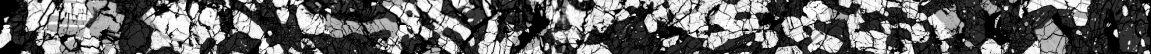

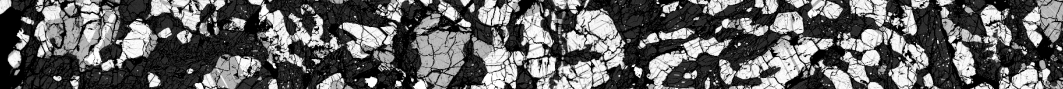

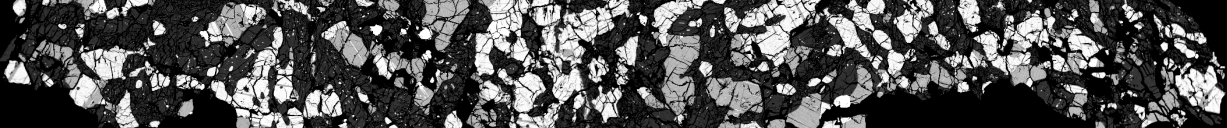

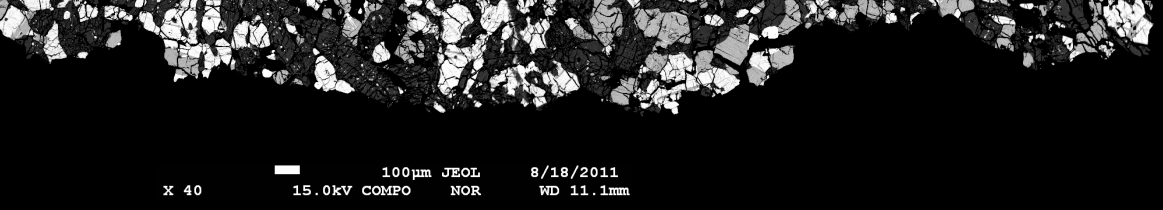

Figure C8: GRA98055 


\section{GRA 98114}

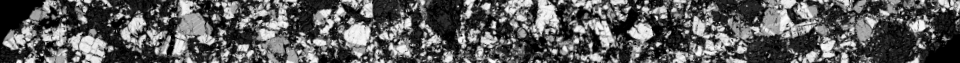

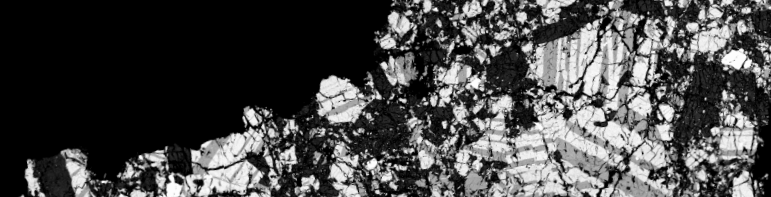

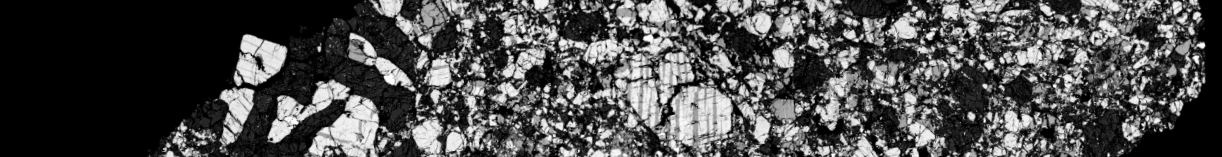

$x \rightarrow+\infty$

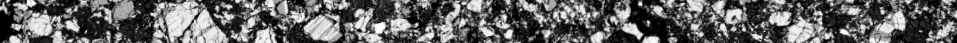

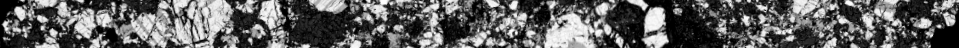

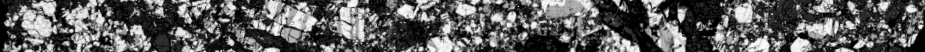

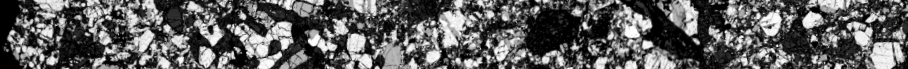

36. ${ }^{2}$.

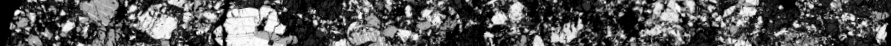

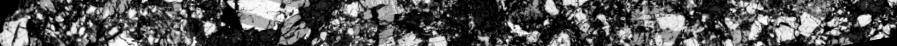

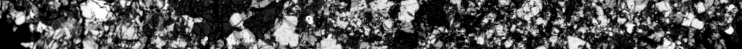

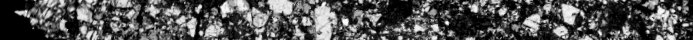

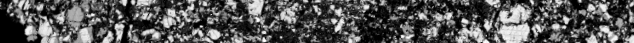

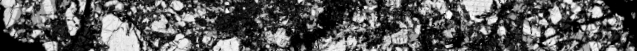

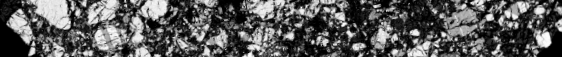

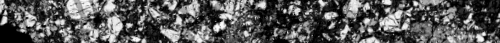

w.

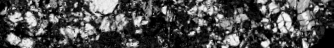

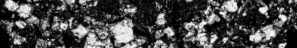

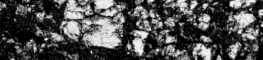

$3^{2}+2,48$

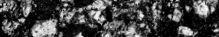

W. +4

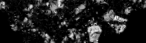

$4)^{3}$

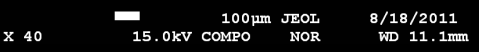

Figure C9: GRA98114 


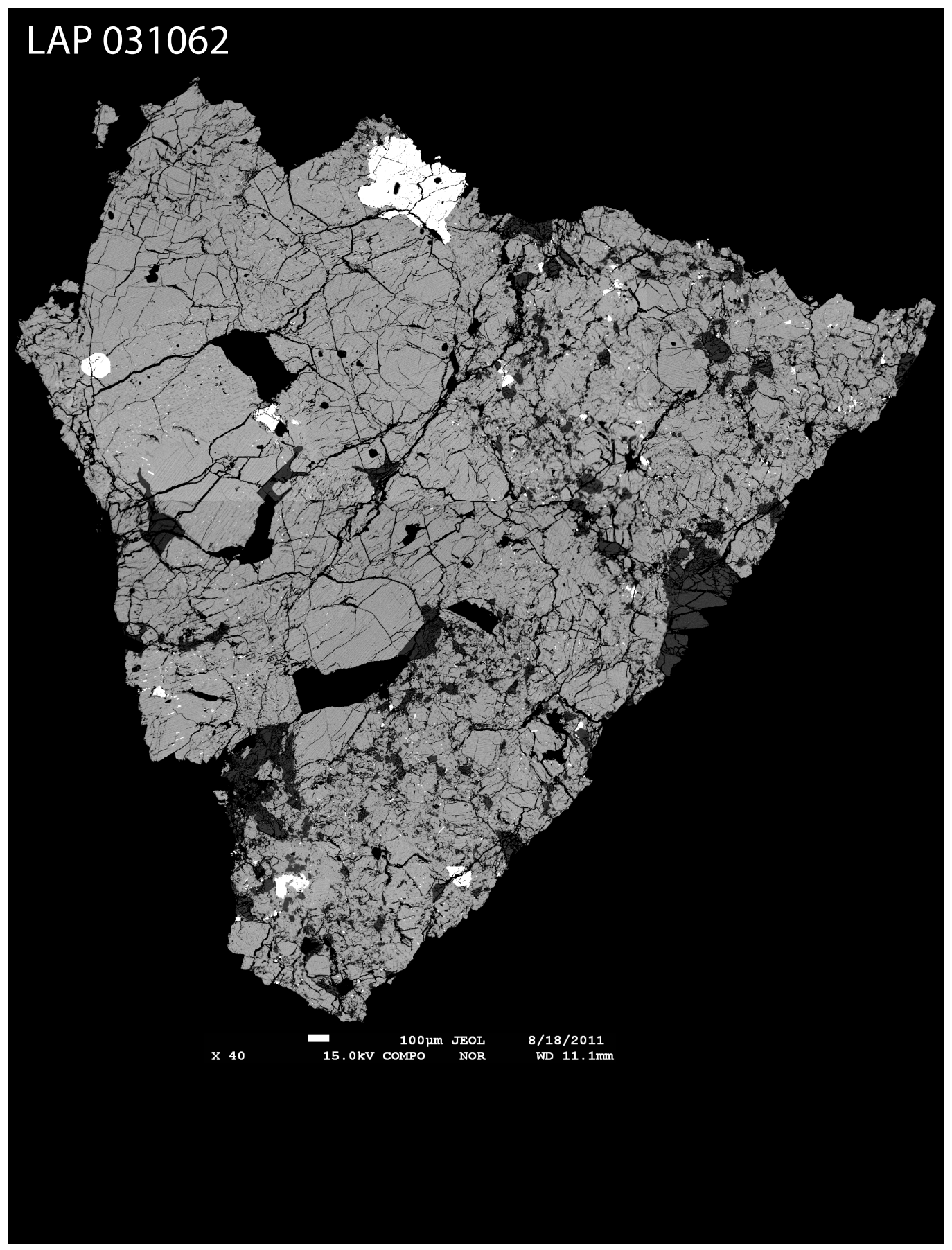

Figure C10: LAP031062 


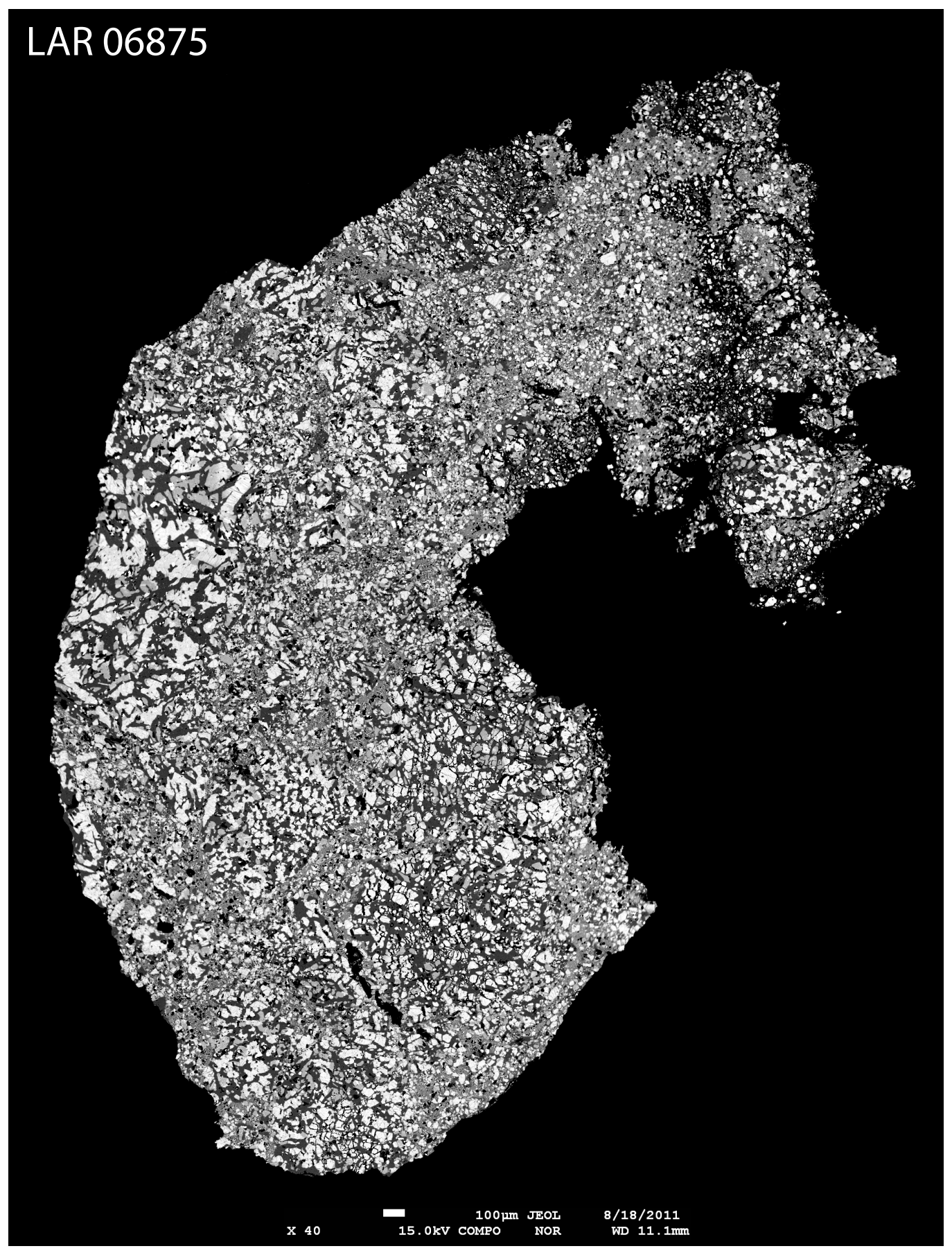

Figure C11: LAR06875 


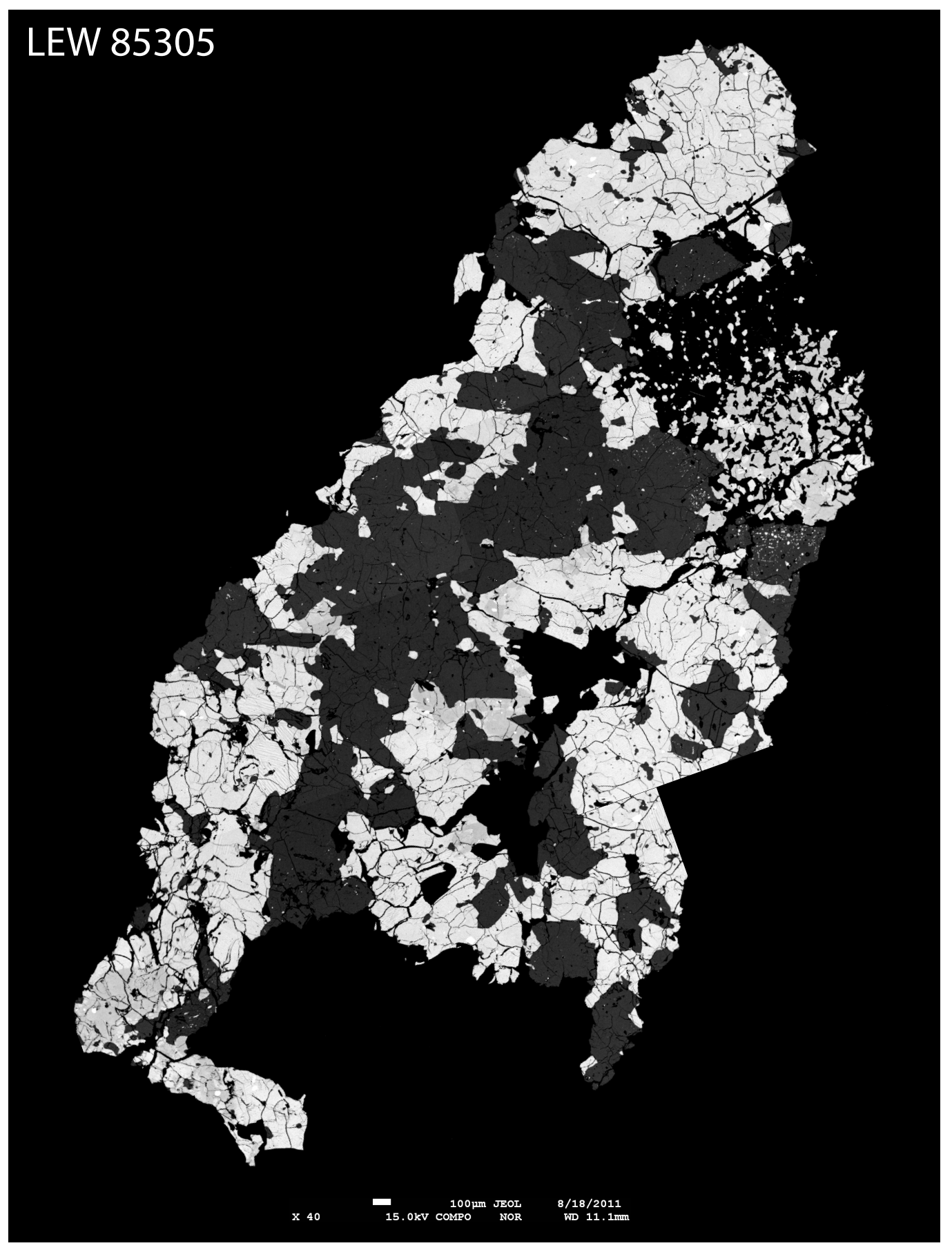

Figure C12: LEW85305 


\section{LEW 87002}
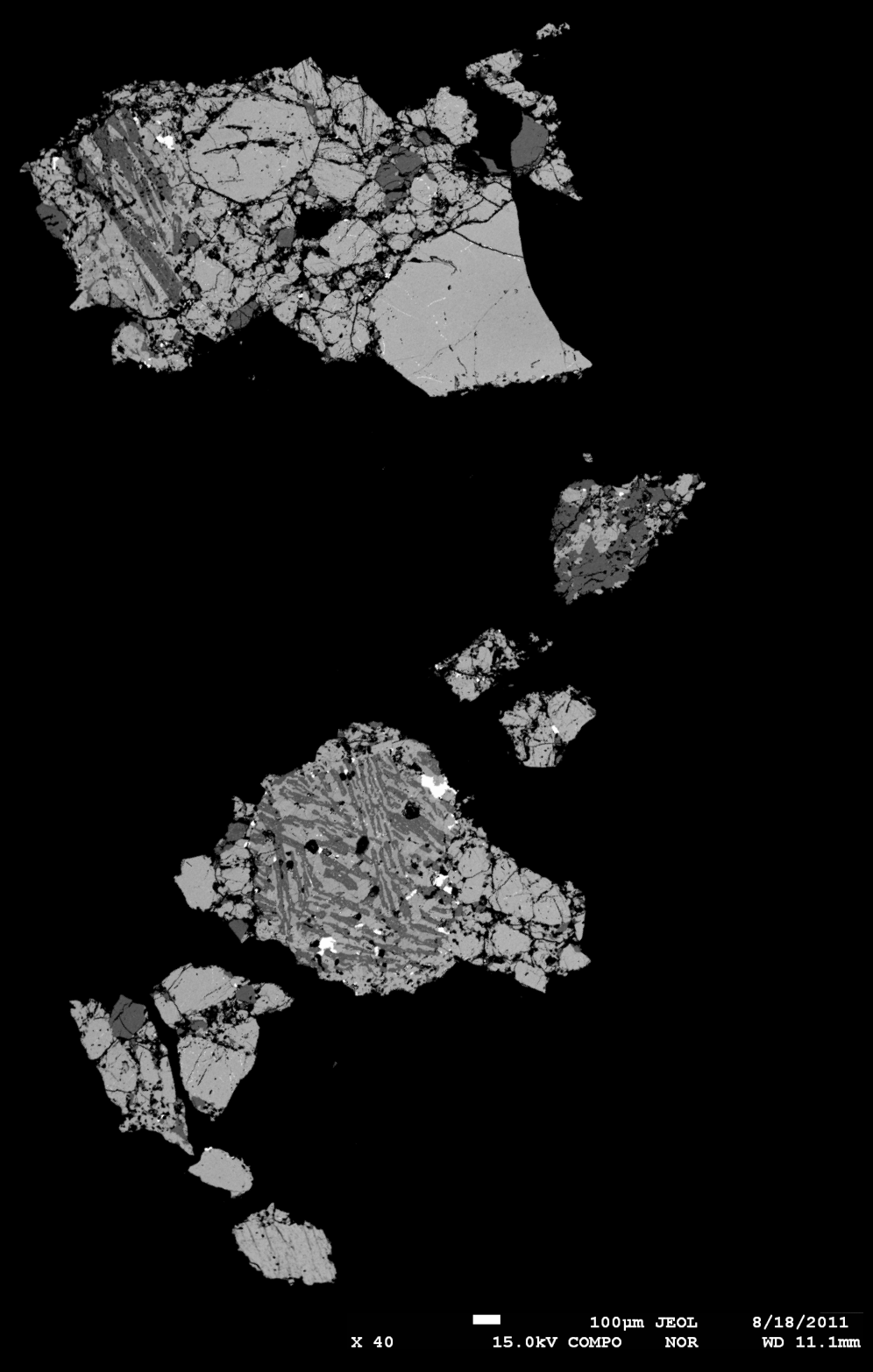

Figure C13: LEW87002 


\section{PCA 91193}

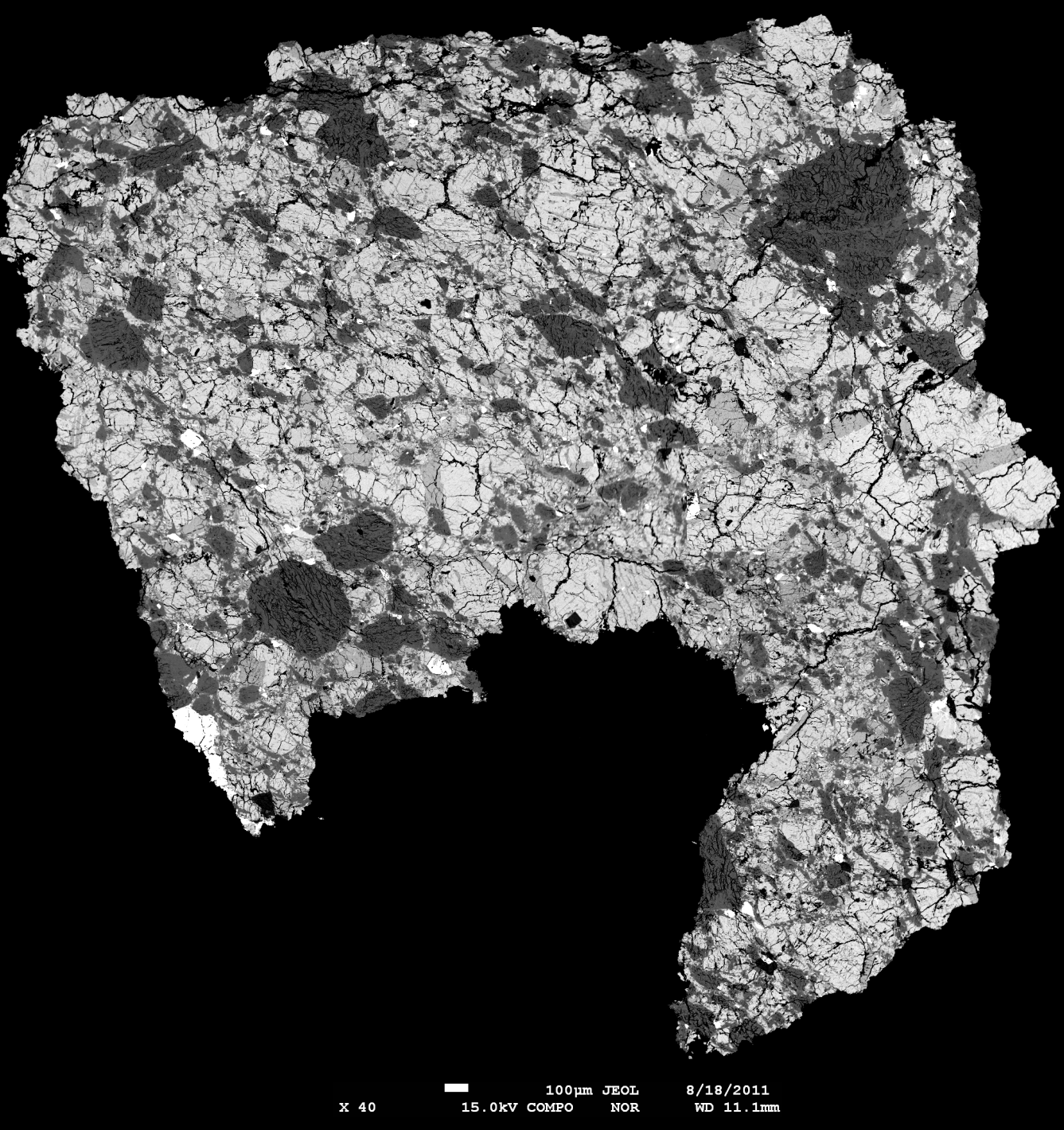

Figure C14: PCA91193 


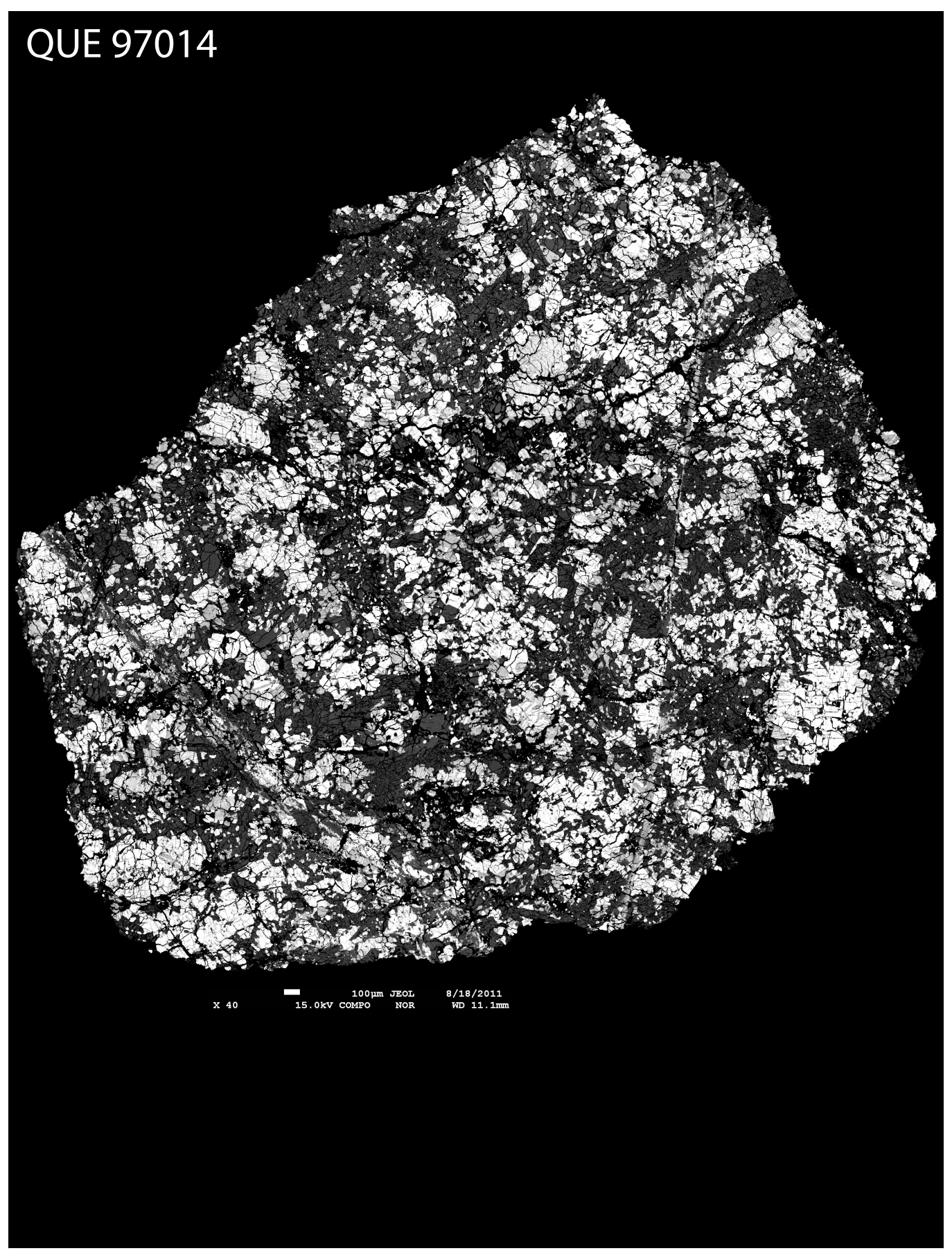

Figure C15: QUE97014 


\section{QUE 99055}

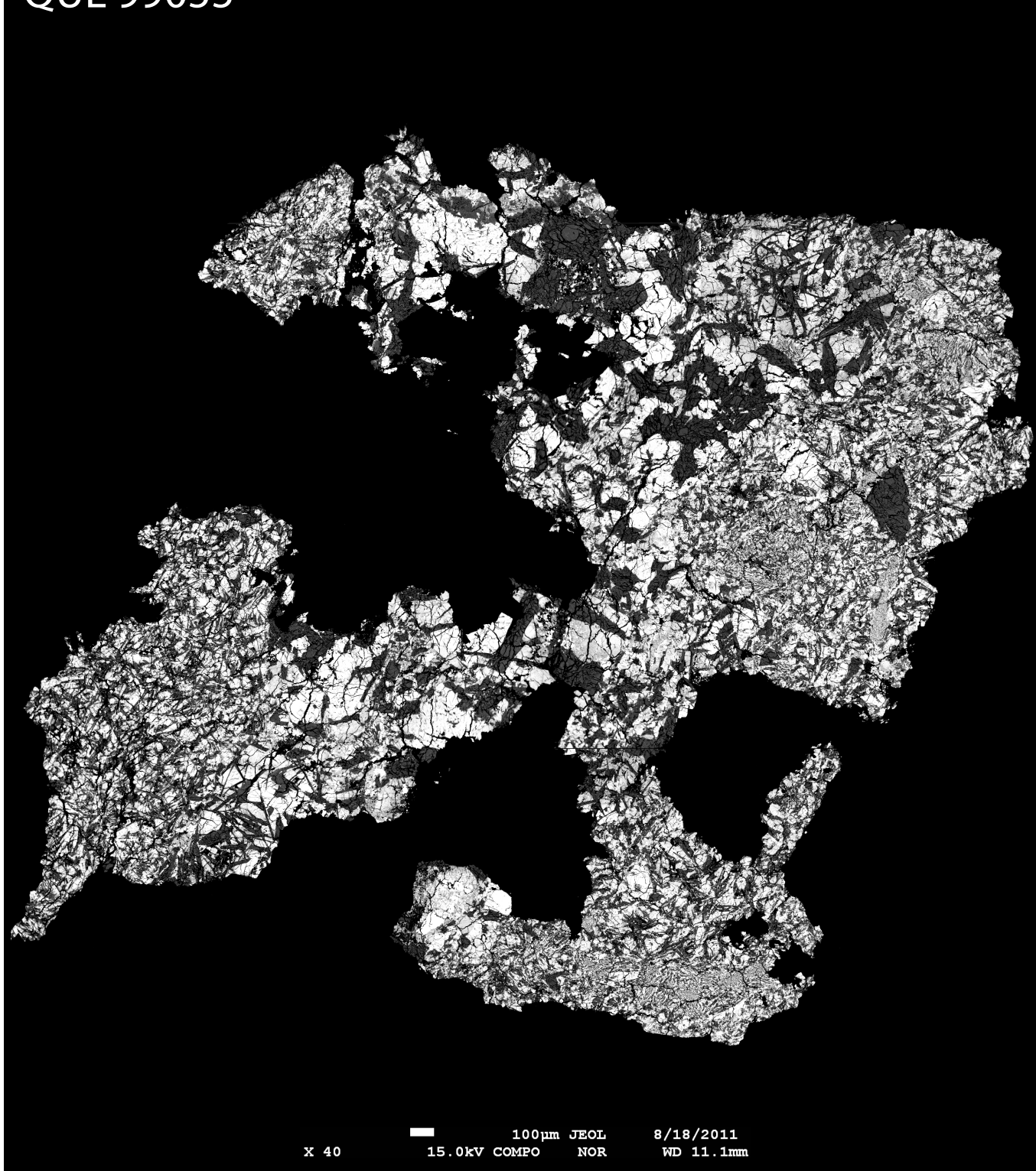

Figure C16: QUE99055 


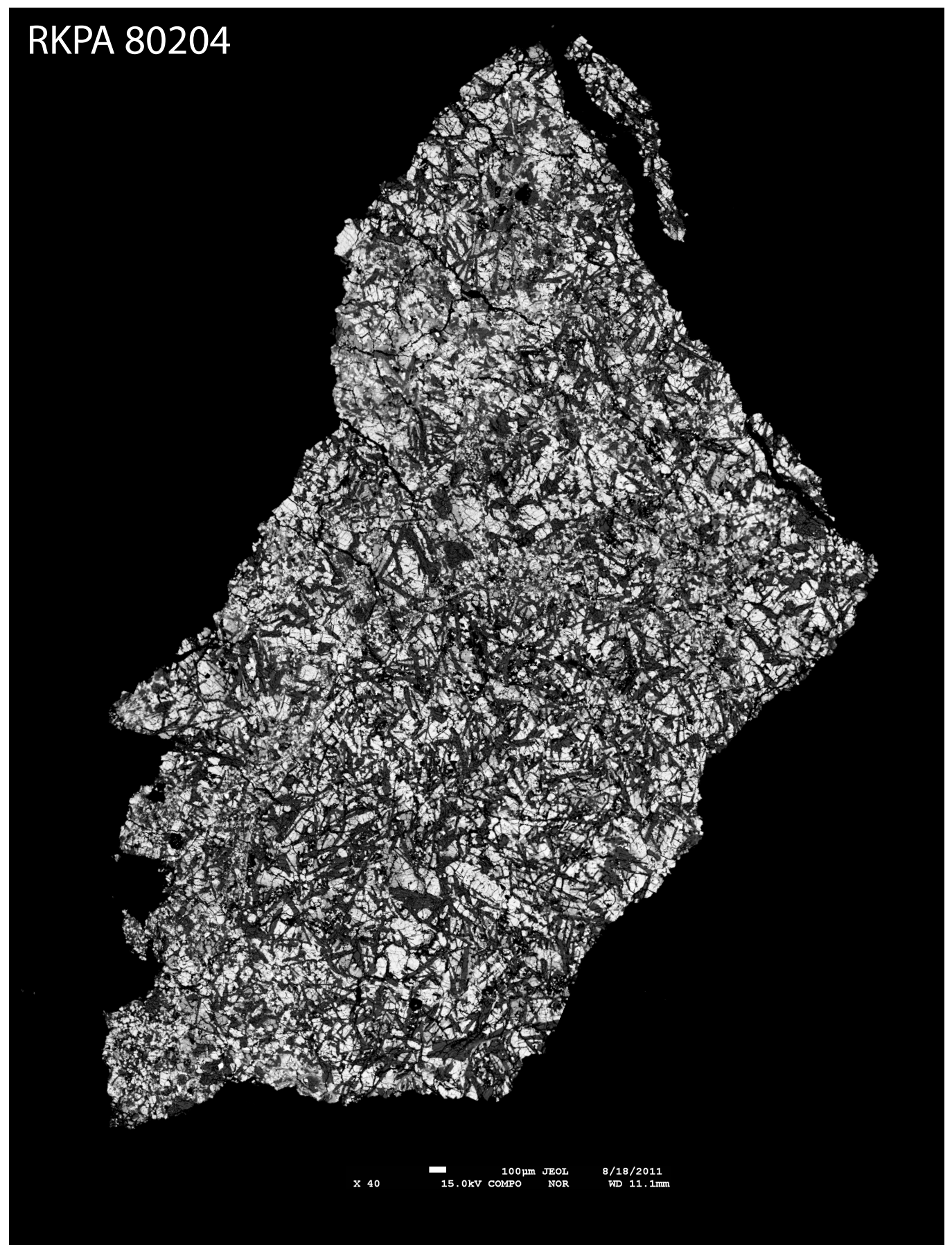

Figure C17: RKPA80204 


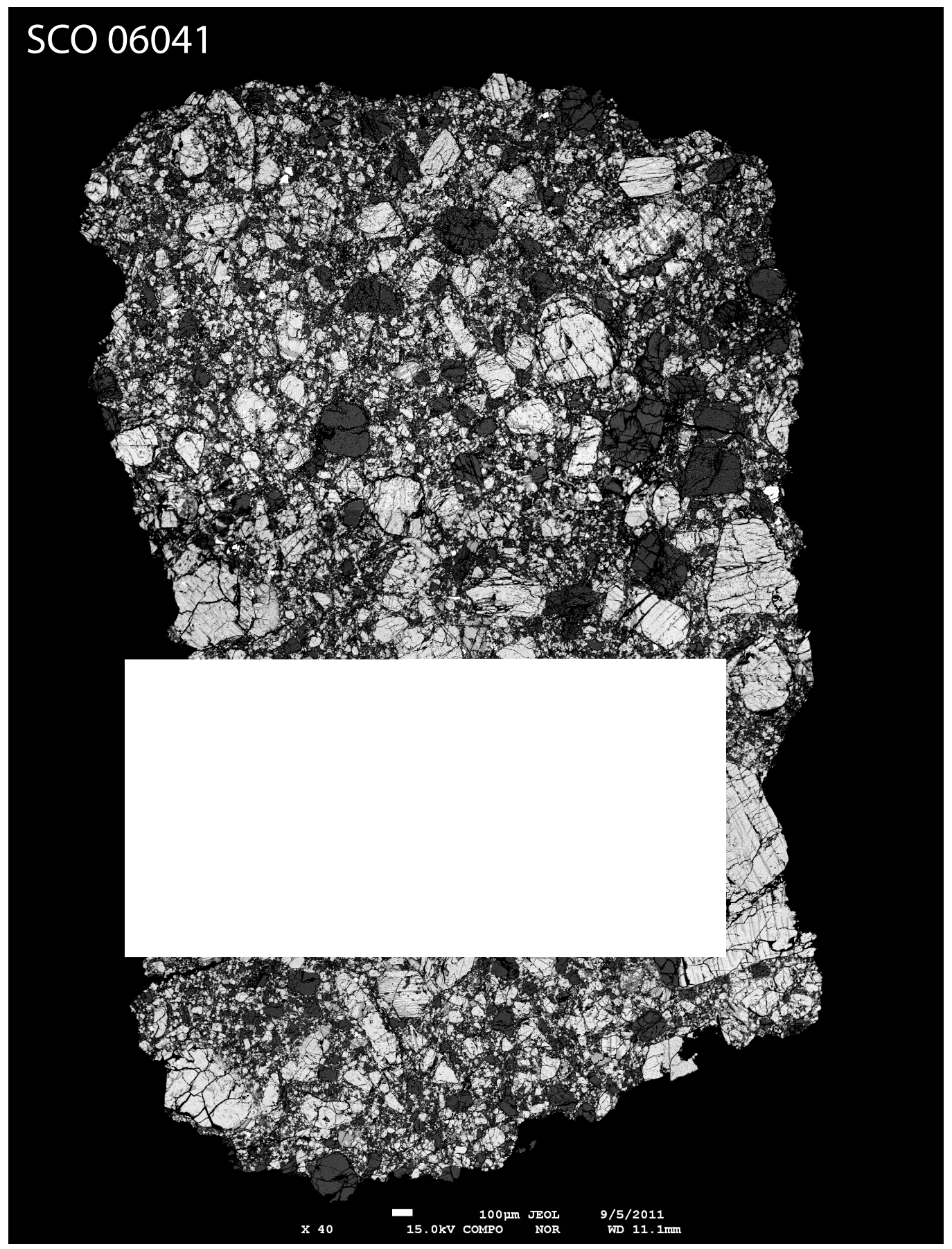

Figure C18: SCO06041 


\section{GRO 95533}

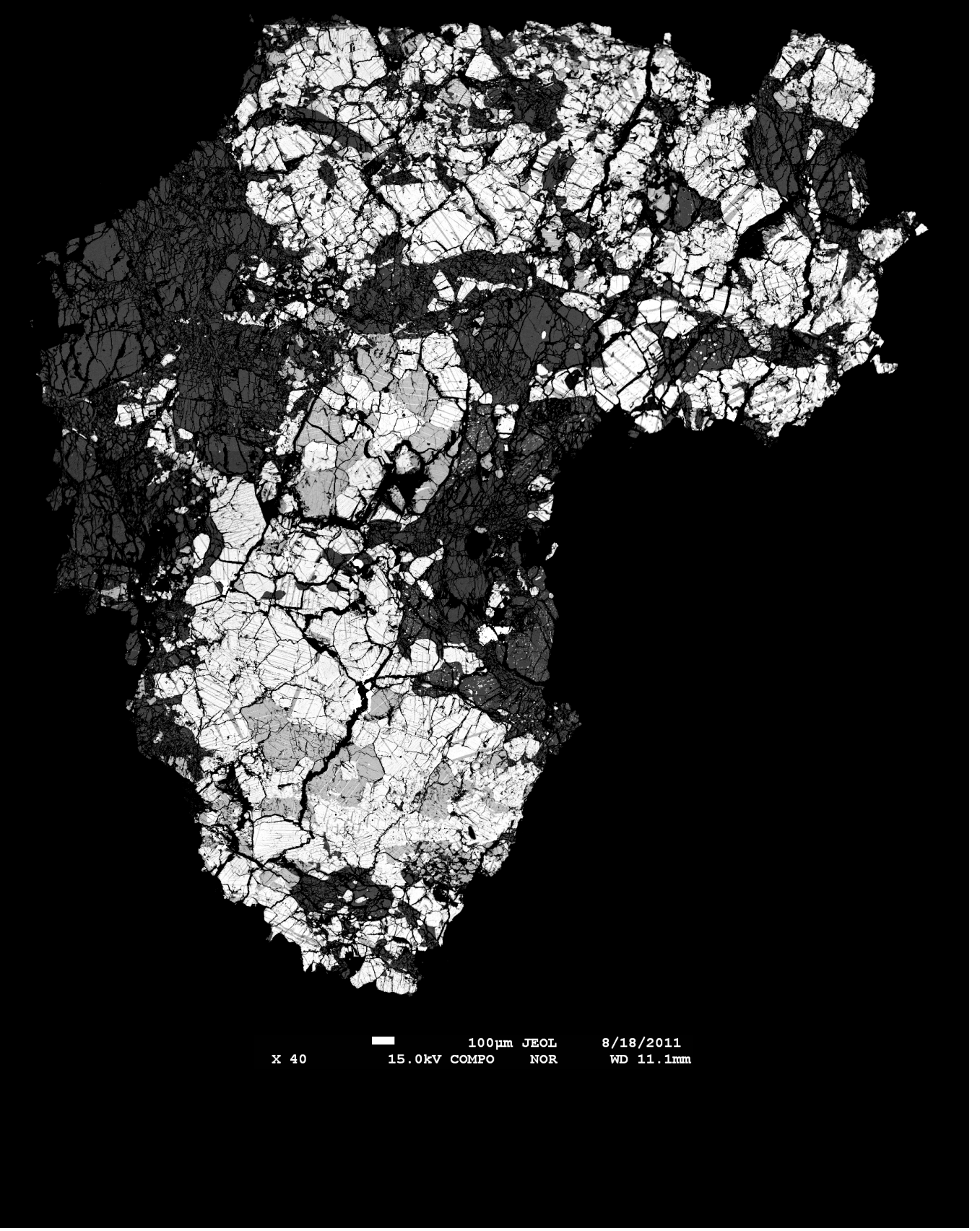

Figure C19: GRO95533 


\section{Millbillillie}

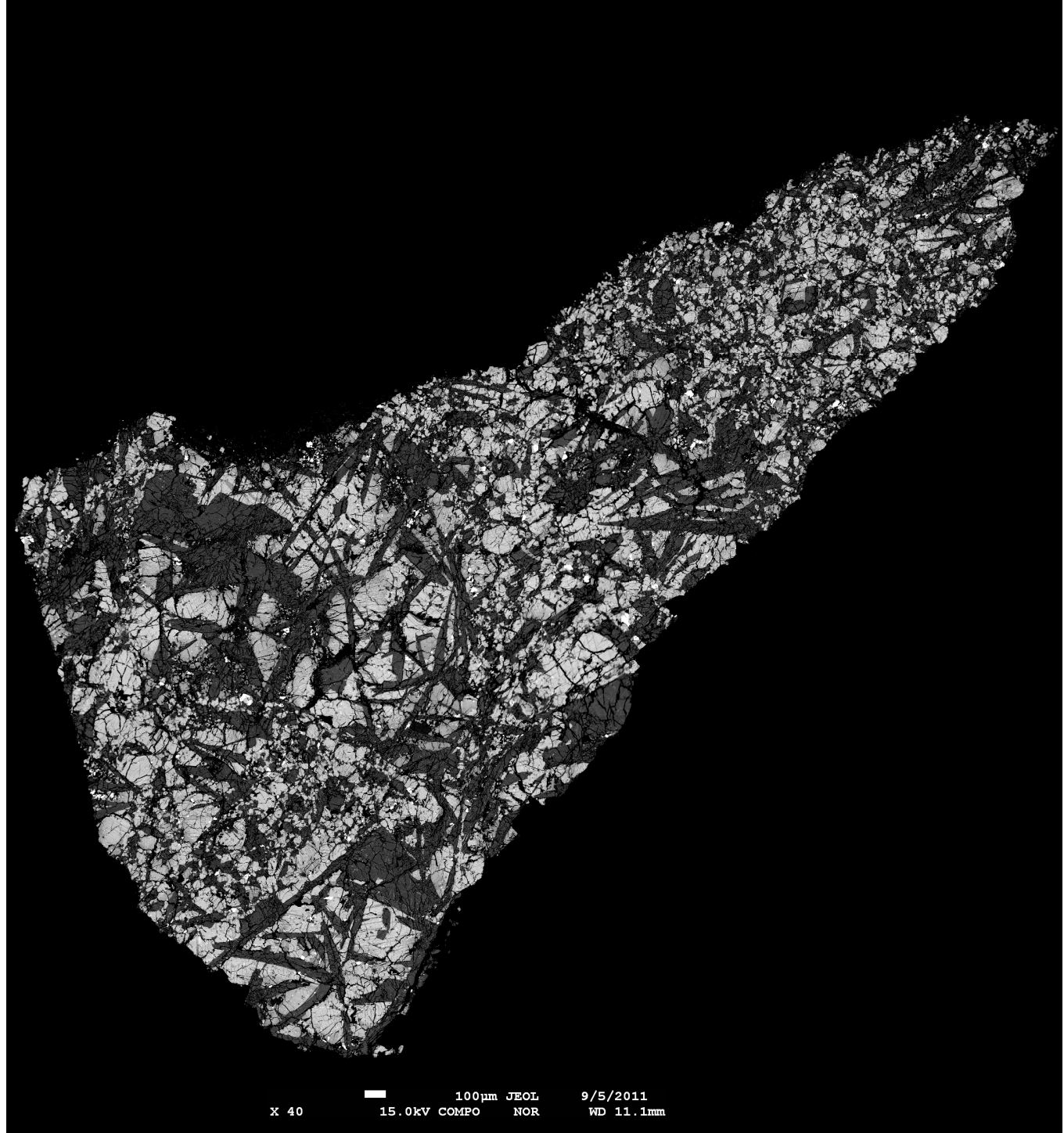

Figure C20: Millbillillie 


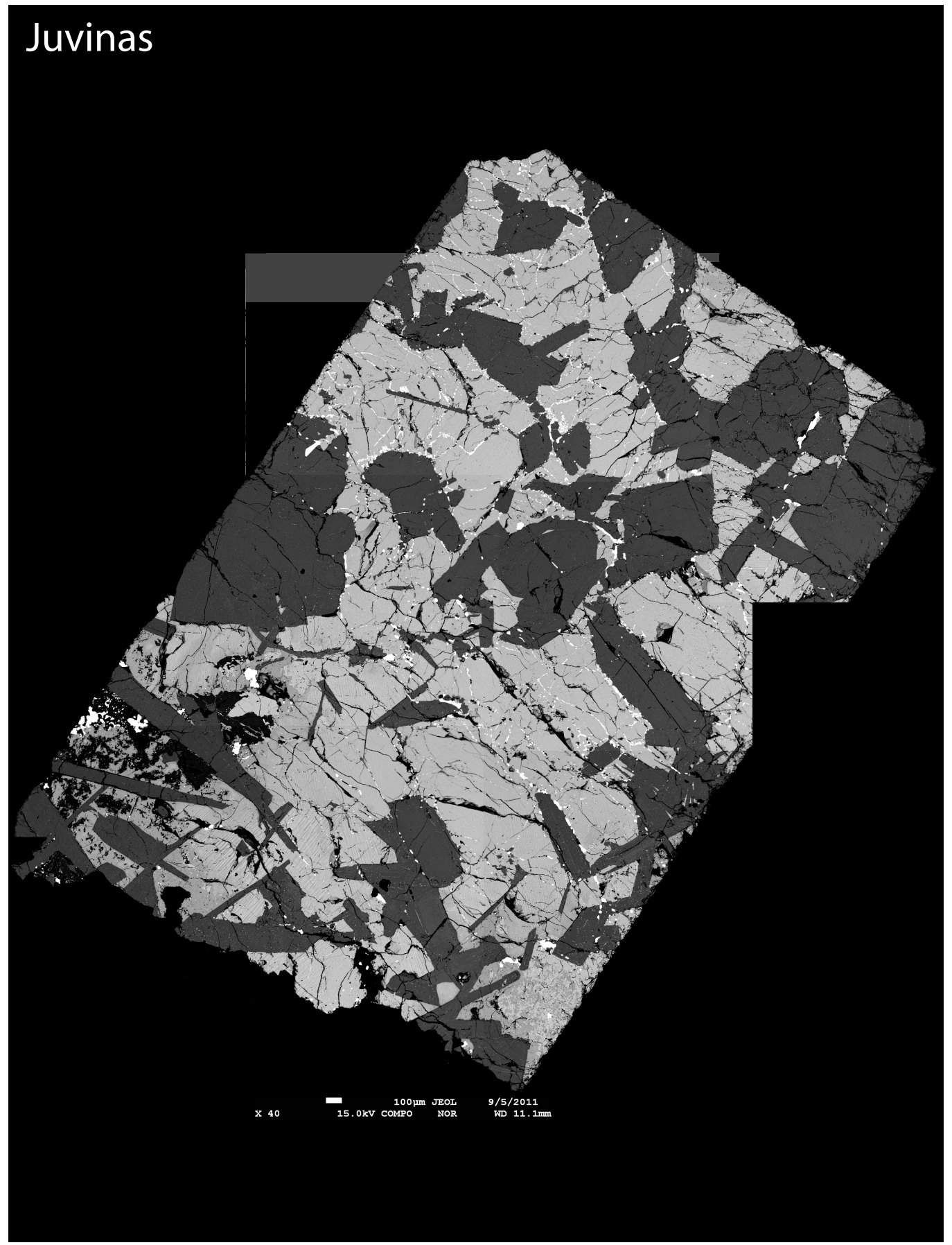

Figure C21: Juvinas 


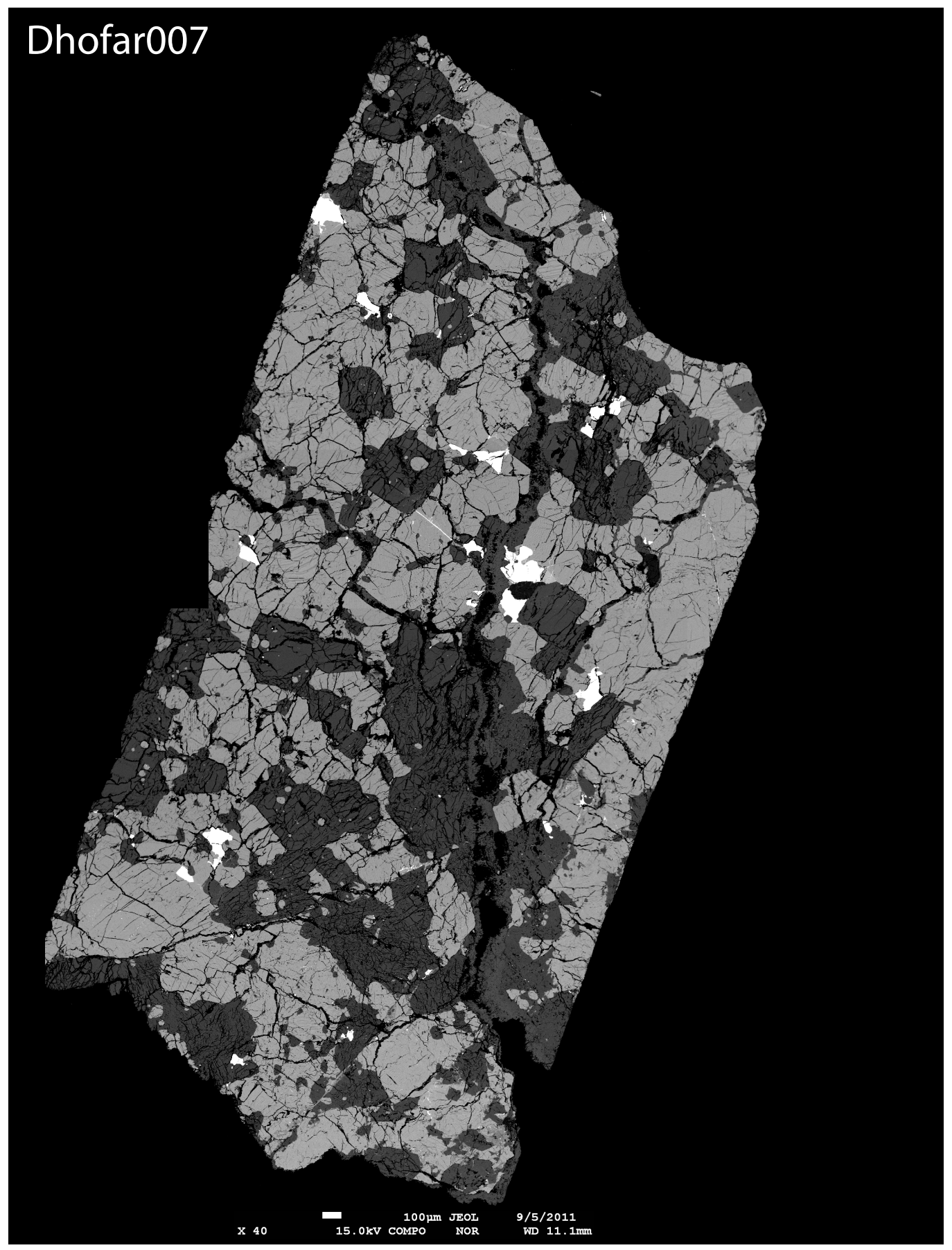

Figure C22: Dhofar007 


\section{Camel Donga}
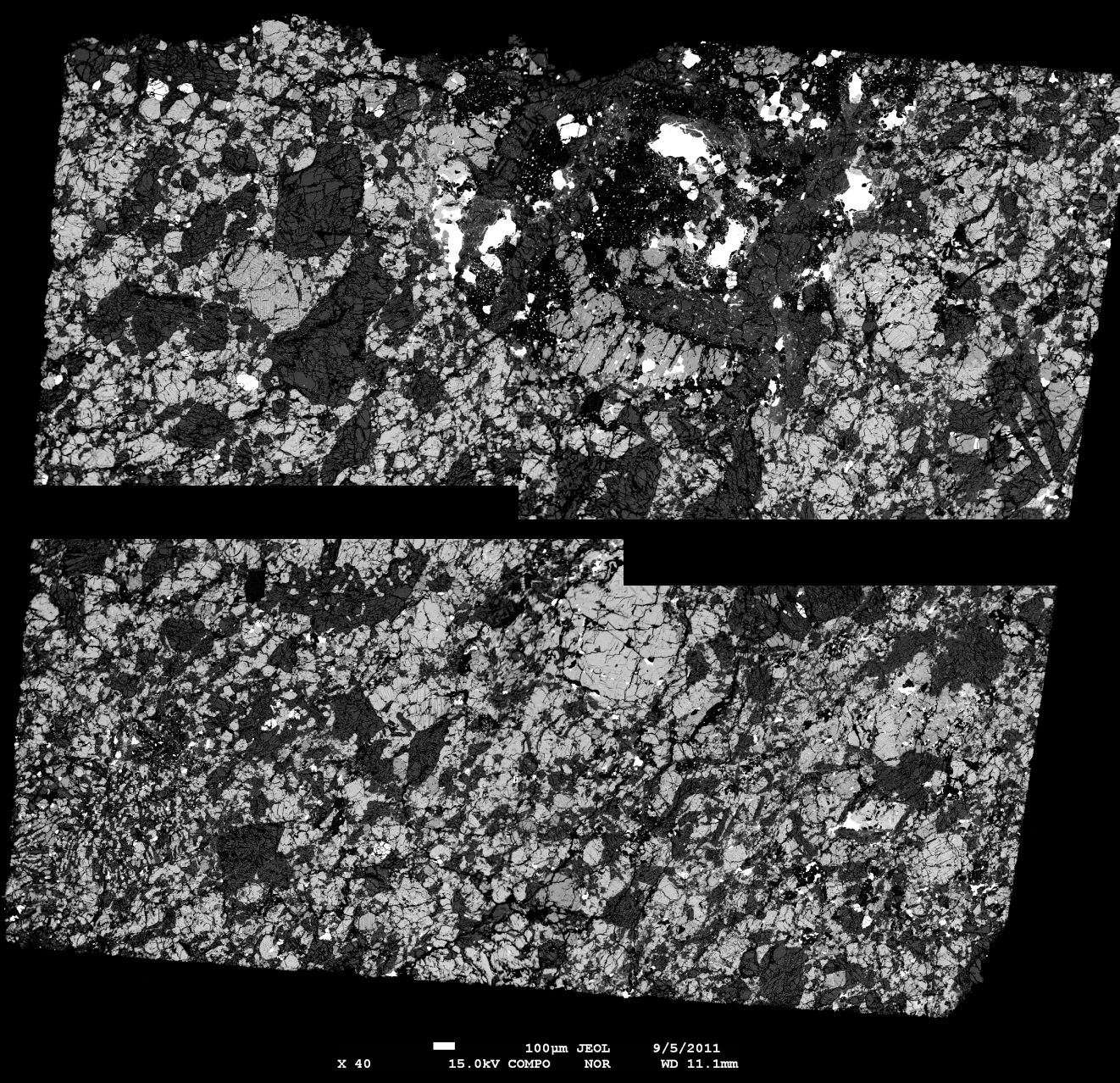

Figure C23: Camel Donga 